\section{Alll02 bI64}

\section{NATL INST OF STANDARDS \& TECH R.I.C.}

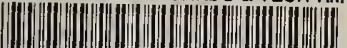

A11102616433

\section{4}

Smith, L. E/Prediction of the long term

QC100.U56 NO.86-3474 1986 C.2 NBS-PUB-C

\title{
Prediction of the Long Term Stability of Polyester-Based Recording Media
}

\author{
L. E. Smit? \\ D. W. Brown \\ R. E. Lowry
}

U.S DEPARTMENT CF COMMERCE

National Bureau of Standards

institute for Materiais Science and Engineering

Polymers Division

Gaithersburg, MD 20899

Progress Report to

June 1986

$-A C \quad$ for
$100 \quad$ II Archives
$.1156 \quad$ gton, DC 20403
$\# 86-3474$
1986
C. 2





\title{
PREDICTION OF THE LONG TERM \\ STABILITY OF POLYESTER-BASED \\ RECORDING MEDIA
}

\author{
L. E. Smith \\ D. W. Brown \\ R. E. Lowry
}

U.S. DEPARTMENT OF COMMERCE

National Bureau of Standards

Institute for Materials Science and Engineering

Polymers Division

Gaithersburg, MD 20899

Progress Report to

June 1986

Prepared for

National Archives

Washington, DC 20408

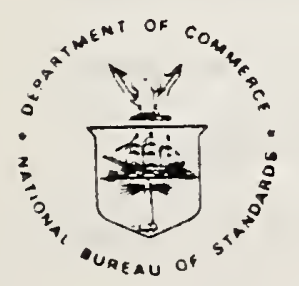

U.S. DEPARTMENT OF COMMERCE, Malcolm Baldrige, Secretary NATIONAL BUREAU OF STANDARDS, Ernest Ambler, Director 

Prediction of the Long Term Stability of Polyester-

Based Recording Media

by

Leslie E. Smith, Daniel W. Brown, and Robert E. Lowry

National Bureau of Standards

Gaithersburg, MD 20899

\section{Abstract}

Magnetic data tapes have been aged at several temperatures and relative humidities. Data previously recorded on the tapes was read back after aging and the inability to read such data was used to make a preliminary estimate of tape lifetime. Based on this criterion we estimate a useful tape lifetime of 20 years at ambient conditions. This involves a long extrapolation, however, because there have been few failures at humidities lower than $100 \%$ and temperatures below $85^{\circ} \mathrm{C}$, and only one failure at all below $60^{\circ} \mathrm{C}$. The tape lifetime estimate should be considerably more certain by the time of the final report in this series which will be issued in November 1987 . There are documented reports of tape failure after ten years of storage under normal room temperature and humidity and we have seen cases of failure after only a few years so the lifetimes can vary considerably.

Reading failures with rapidly-aged tapes appear to be caused primarily by exudation of material from the binder layer. This accumulates on the reading heads or makes the tape stick to the tape transport. In order to test the condition of tapes before failure, three tests were devised that measure adhesion or extensibility of the binder layer. Water content and weight changes on aging were also measured. None of these five measures correlated 
quantitatively with the ability of a tape transport to read data previously written on the tapes, but some of them are useful indicators of risk.

\subsection{Introduction}

Information storage on microfilm and magnetic tape offers higher storage density and more rapid access than corresponding paper records. They constitute a large fraction of current data and have become important parts of many libraries and archives. The expected useful lifetime of these materials at ambient conditions is long but not known. Since October 1980, the National Archives and Records Administration has sponsored research at the National Bureau of Standards aimed at defining the effects of storage environment, developing tests of the condition of the materials, and predicting the lifetime of film and tape. This is the fourth progress report on this research, others being NBSIR 82-2530, 83-2750, and 84-2988 [1,2,3]. Magnetic tapes have been the subject of almost all the work in this reporting period.

Photographic film and magnetic tape consist of different active coatings on a film of poly (ethylene terephthalate) (PET). The stability of PET film was previously investigated in this program and it was concluded that it should retain useful properties for over 500 years at $20^{\circ} \mathrm{C}$ and $50 \%$ relative humidity (RH) [2] .

The ferromagnetic material of the magnetic tapes in this study. small particles of gamma ferric oxide, is suspended in crosslinked polyester polyurethane which also serves to bind the magnetic particles to the supporting film. Other materials such as lubricants, adhesives, or stabilizers are frequentlyn added to this layer and in at least one formulation a second coating without ferromagnetic particles is applied to the other side of the 
supporting film. Polyester polyurethane is subject to auto cataiytic hydrolysis [4], which was expected to limit the lifetime of the tape. Some types of magnetic tapes contain chromium oxide particles which do affect the chemical degradation mechanisms. This has recently been reported by researchers at IBM [10].

Hydrolysis of the binder breaks fragments off the crosslinked network which can be extracted by organic solvents. Cuddihy[5] extracted material from aged tapes and concluded that tape aged at $100 \%$ and $30 \%$ RH contained increased soluble material, as expected, but tapes aged at $11 \%$ and $0 \%$ RH contained less soluble material than unaged tapes. We qualitatively confirmed these observations on several brands of tape[2]. Indeed, most tapes appeared to contain slightly less soluble material after aging even at relative humidities as high as $30 \%$.

Cuddihy[5] attributed this behavior to an esterification reaction between acid and alcohol groups in the binder, essentially the reverse of hydrolysis. However, we had found that uncrosslinked polyester polyurethanes slowly hydrolyzed at 25\% RH[4]. Thus there is an apparent inconsistency between the results with magnetic tape and simpler polyester polyurethanes. Model binders of crosslinked polyester polyurethanes without oxide particles were prepared and aged. They also degraded with aging at $25 \%$ RH. We have also seen coior changes and increased nitrogen contents in binders aged at low humidities [3]. Neither of these observations is consistent with simple esterification so we conclude that more complex crosslinking reactions are taking place that counteract the effects of continuing hydrolysis. Such reactions would also explain the differences in behavior between tape binders and uncrosslinked model polymers. 
Tape lifetime can be limited by detachment of binder from the supporting film. The binder may become weaker due to degradation and fail cohesively or the bond between the binder layer and the support may decrease and cause adhesive failure. Either would be revealed by measuring the force required to peel binder from the support. A preliminary test procedure was developed and measurements made that revealed large decreases in peel force due to aging under some conditions [3].

Digital data were written on and read from aged and unaged tapes using a tape transport under computer control. Problems were encountered in reading some aged tapes after several reading cycles[3].

Our approach to estimating tape lifetime is to write data on tapes, age them at known temperatures and relative humidities, read the data on the tape after aging, and alternate agings and reading attempts until the tape becomes unreadable. Lifetimes will then be known which can be extrapolated to estimate a value under typical storage conditions. Note that the total number of times a tape has been read increases linearly with the number of aging periods.

An easy way of monitoring tape condition during storage is highly desireable because of anticipated uncertainty in the estimate of tape lifetime. other tests were developed with this consideration in mind. The quantities measured were: (1) the force required to peel the binder from the support; (2) the elongation of the tape at which the binder separates from the support: (3) the number of rolling translations of a crease required to separate the binder from the support; (4) the water content of the tape at 45 r relative humidity; and (5) the change in weight of the tape during aging. It will be seen that these five quantities change during aging. The peel force, rolls to detach 
binder, and elongation for binder separation vary greatly, but the changes do not consistently correlate with tape lifetime.

\subsection{Experimental Procedures}

Data was encoded in $1 / 2$ inch-wide tapes at a density of 1600 bpi using a 9-track tape drive of the tension-arm type. The drive is capable of speeds up to 75 ips. A reflecting marker signaling logical BOT was placed about 5 meters from the free end of the tape, the tape advanced to the load point, and a standard label as required by the operating system was written on the tape. The number 1023456789 was then written, initially 100,000 times, but later 48,000 times when the supply of original tape became depleted. We used the system default setting of 2048 bytes for the block size. The number was made negative every $, 10,000$ or 12,000 numbers. Another reflecting marker was attached and the tape was rewound and read on the same drive. The negative numbers were printed to show that reading had been successful. A section of tape containing the numbers was cut from the reel about 5 meters beyond the second reflecting marker. Pieces of tape were from 15 to 25 meters long, depending on how many numbers had been written.

The pieces of tape were formed into loose coils, about three inches in diameter, and weighed after equilibration in a room maintained at $45 \%$ relative humidity and $22^{\circ} \mathrm{C}$. They were then placed in jars containing small bottles of water or aqueous salt solutions, chosen to give relative humidities of 100,75 , 50, or 25\%. Salts used were potassium chloride, sodium chloride, sodium dichromate, and calcium chloride giving relative humidities of $85,75,54$, and 30\%, respectively $[6,7]$. Aging took place in the jars in ovens thermostatted at 85,60 , and $35^{\circ} \mathrm{C}$. 


\subsection{Reading Data from Aged Tapes}

Aged tapes were equilibrated as above, weighed, and the differences between initial and final weights were recorded. Tapes were then read 10 times if possible. Several tapes aged at $85^{\circ} \mathrm{C}$ did not have a readable label block after the first short aging period. These were rewritten, aged again, and almost always successfully read. We suspect the initial problem was caused by a dimensional change but have no proof of this. Such behavior was not counted as tape failure because of the subsequent successful write and reads. The final number and the time consumed in reading were printed out after each read. Tapes that gave difficulty were tried a second time after cleaning the heads of the tape transport.

Unreadable tapes showed one of several behavior patterns. Sometimes the label block was unreadable, as above, but the tape could not be rewritten. More frequently, tapes could be read one or more times with failure to read occurring at a non-integral number of reads. The reading program printed the approximate location of the difficulty in such failures. Another mode of failure was for the tape to stick in the tape transport. Such tapes sometimes developed a puckered edge because of the stress. Occasionally, tapes would become sticky, and crease and wind on the driving capstan of the transport. This pulled tape off the take-up reel as well as off the supply reel and damaged the tape transport because the tension arms were suddenly released when the tape came off the takeup reel.

A small amount of material was transferred from many aged tapes to the tape transport, even from tapes that were read successfully. These deposits were most conspicuous on the read and write heads but also were found at other 
places along the tape path, particularly on the urethane rubber-coated capstan. A swab soaked in ethanol was used to clean the read and write heads after each piece of tape was tested and the whole tape path was cleaned after about ten tapes had been tested.

Subsequent to the reading test, pieces were cut from an end of the tape for measurement of peel force and rolls and elongation for separation. Tapes that had been read successfully were reequilibrated as above, reweighed, and aged for another period.

\subsection{Peel Force Measurements}

The adhesion of the binder layer to the PET support was measured by a somewhat different method than described in the previous report. The current test is similar to that used in ANSI $\mathrm{X} 3.40-1983$ but modified to make it more reproducible for the very small force measurements required with aged tape. Results reported here were obtained by applying a 20 to $25 \mathrm{~cm}$ long piece of 1/2-wide tape, sticky on both sides, to an aluminum or plastic bar. One cm of the sticky tape on what would become the upper end of the bar was masked so as to provide a non-sticky surface. A somewhat longer piece of the tape to be tested was applied to the bar, magnetic side to sticky tape, which was then suspended from a load cell. A piece of sticky tape with an attached string was then applied to the non-magnetic side of the top end of the tape to be tested. The other end of the string went around a 1/4-inch diameter shaft mounted in a high-torque, variable-speed, electrically-driven laboratory stirrer. This stirrer was directly below the load cell. The string had some slack to permit the stirrer to get up to speed quickly. Turning on the stirrer pulled the magnetic tape from the bar, almost always with transfer of binder to the sticky 
tape. The combined length of sticky tape and magnetic tape was frequently pulled from the bar unless the uppermost portion of sticky tape was masked as described. The output voltage of the load cell was recorded. A visual average of this was used to calculate the peel force. The length of chart between initial deflection and final decrease of the deflection was used to calculate the draw rate, although we found peel force was not very dependent on draw rate over a wide range.

The principal advantage of the current test is that it strips binder from all tapes. The test described in the last report was done at much slower draw rates, which resulted in several unaged tapes retaining their binder. The modifications also hold the angle of the peel constant whereas the angle of unsupported tapes will vary somewhat with the stiffness of the tapes.

\subsection{Binder Separation by Elongation}

Upon aging the binder layer becomes stiff rather than elastic. If the tape is stretched, the PET elongates but the binder layer cannot follow so it cracks and separates from the support. The elongation at which this occurs is an indication of the brittleness of the binder.

The elongation for binder separation was measured by mounting the tape to be tested in a tensile tester with an initial jaw separation of four inches and then stretching the tape at a draw rate of one inch per minute while gently touching the binder side of the lengthening tape. Generally, the binder became rough at some fairly specific elongation and came off the tape. This elongation we call the elongation for binder separation. Some unaged and mildly aged tapes broke, usually at more than 100 s elongation, beiore the binder separated. Some severely aged tapes also broke before the binder 
separated, usually at about 18 elongation, even though they were still generally readable in this condition.

\subsection{Rolls for Binder Separation}

A very simple qualitative test for binder separation was done by creasing the tape, across the long direction, so that the binder side was on the outside of the crease. This crease was translated back and forth along the tape by rolling it between thumb and forefinger. No unaged tape lost binder in many such translations. Aged tapes often lost binder, sometimes when creased and sometimes after several passes between the fingers. The number of passes was arbitrarily limited to a maximum of ten. Thus a value less than ten indicates degradation in this test.

\subsection{Water Content}

Water contents were measured at various humidities by placing 10 to 20 grams of loosely coiled tape in a low flask with a $71 / 15$ standard taper joint. The flask and its separated top were placed in a large desiccator above a saturated salt solution or if the dry weight was desired calcium sulfate dessicant. Two days later the desiccator was opened and the top put in the flask, which was weighed promptly. Equilibrium was approached from both directions, except at dryness. Water content was calculated as the difference in the weights of the tape when dry and at other relative humidities.

\subsection{Precision and Accuracy}

Peel force, elongation for separation, and the number of rolls for separation are approximate measurements and subjective to some degree. Values 
reported are reproducible to about $25 \%$ when the same operator does the tests. Some of the imprecision may be due to environmental factors in the test area, since there were days when many results were higher than had been found after the previous aging period. A second worker, trained by the first and then working independently, obtained values for the elongation for separation that differed by as much as two times from those obtained by the first worker.

The mass of tape samples were determined on an analytical balance to about $0.5 \mathrm{mg}$ accuracy. However, tapes of mass $10 \mathrm{~g}$ sorb about $0.5 \mathrm{mg}, 0.005 \%$, of water for each percent relative humidity. Thus humidity control really limits the accuracy of the result. Day to day changes in the mass of samples measured in the room nominally at 45\% RH suggest the imprecision in the mass is about 2 mg or 0.028 . Many of the mass changes during aging were not much more than this. Percentages based on samples equilibrated in desiccators and weighed in closed flasks ought to be precise to about .01\%. Both of these estimates assume the tape is at equilibrium.

\subsection{Results}

\subsection{Tape designations}

Table 1 codes the tapes used in this study. The first column lists the numbers used in the last report and the second lists new numbers used to simplify the coding. More tape has been obtained as needed. Three of the manufacturers had changed the name of the tape during the time of this work and reported to be making it by an improved process. Their tapes with the original names were no longer available. The reorder number then designates the code of these new tapes. All tapes except 6, 51, and 52 were premium tapes from øajor manufacturers. Tapes 6,51 , and 52 are tapes sold but not manufactured by 
other suppliers which designated tape as their premium grade. Tapes 51 and 52 are called their standard grade, nominally the same tape, but with a large difference in initial peel force[3]. Tape 72, which had not been obtained at the time of the last report, was available only for a short while and only a little work was done with it.

\subsection{Organization of results}

The six dependent variables for each tape tested makes analysis of the results rather difficult. The most direct way is to plot each quantity measured for each tape aged at each condition versus aging time. This has been done and all of the plots are included in this report, most of the them in the Appendix. Our principal concern in this report is tape lifetime as a function of aging condition. The other measurements of physical condition, while very useful as indicators of tape condition, did not quantitatively correlate with results of the read test. Therefore, values of peel force, elongation for binder separation, rolls for binder separation, water content, and weight gain on aging will be discussed only briefly.

\subsection{Reading tests}

Some of our preliminary experiments were surveys in which six brands of tape were in one jar during aging at 100,50 , or $25 \%$ relative humidity. These experiments will be called survey experiments in this report. Failed tapes were not aged additionally so the environment of the unfailed tapes changed with time. Some of the results are in Fig. 1-4, plotted as successful reads versus aging time. Ten successful reads are plotted as some value between 8 and 10 to avoid superimposing data from different tapes. Included in Fig. 1. 
which contains all our data from aging at $85^{\circ} \mathrm{C}$ and $100 \%$ relative humidity, are results from two pieces of tape 6 , aged in their own jar. Figures $1-3$ show that decreasing relative bumidity greatly increases the time to failure at $85^{\circ} \mathrm{C}$. Figures 1 and 4 show that a lower aging temperature at $100 \%$ relative humidity increases the time to failure.

\subsubsection{Description of Failures}

The supporting film of tape 51 broke as the tape was being loaded on a reel after 203 days aging at $85 \mathrm{C}$ and $50 \% \mathrm{RH}$. This demonstrates that binder degradation is not the only limit to tape lifetime even though it is the most common.

To date, the only other tape in the survey experiments that can not be read ten times is tape 1 which was aged at $60^{\circ} \mathrm{C}$ and $50 \%$ relative humidity, for 329 days. Other tapes have been read through 410 days aging under these and milder conditions.

Most data comes from experiments using pieces of tape from a single supplier in separate containers. Results of the read test from some of these are in Fig. 5-8. Prefixes to the tape identifying numbers in the figure legends equal the number of pieces aged. Pieces with the same aging history which were read ten times or were read the same number of times give superimposed lines on these plots. Occasionally different pieces of tape have very different times to failure, tape 41 at $85^{\circ} \mathrm{C}$ and $75 \%$ relative humidity for example. Usually tapes fail in the same or adjacent aging periods, showing that behavior is reasonably reproducible. Tapes 21 and 41 lasted longer at $85^{\circ} \mathrm{C}$ and $50 \%$ relative humidity when aged individually than when aged with other brands, suggesting that volatiles from one tape may affect another tape. The line for tape 72 in Fig. 7 shows that failed tape does not necessarly fall 
absolutely. In this case a few reads were possible even at times equal to twice that of the initial failure and similar behavior has been seen with other brands of tape.

Tapes 41 and 42 aged at $85^{\circ} \mathrm{C}$ and $75 \%$ RH for 86 days, Fig 5, actually broke in the tape transport. The other tapes that are were read 10 times after this much aging were capable of much less elongation than originally. Thus lifetimes of several tapes may be limited by the degradation of the support film.

Four pieces of tape 1 were read without difficulty after 242 days aging at $60^{\circ} \mathrm{C}$ and $50 \% \mathrm{RH}$, suggesting that the failure of this tape in the survey experiment under the same conditions was related to the presence of other brands of tape or was not at the low end of the 225-329 day range.

Aging under milder conditions bas resulted in only two failures. Both involved tapes that were initially aged without data and then were first written after about 500 days aging. Tape 41, written after 534 days at $60^{\circ} \mathrm{C}$ and $25 \%$ RH, could be read only twice. Another piece of tape 41, written after 537 days at $35^{\circ} \mathrm{C}$ and $100 \% \mathrm{RH}$, could not be read at all at 722 days. Tapes preaged at $35^{\circ} \mathrm{C}$ and $25 \% \mathrm{RH}$ have been read after 1100 days total aging.

The binder layer of most of the failed tapes was scratched, even when no deposit was obvious on the reading head. Usually any deposit on the heads was white, suggesting that it contained little or no iron oxide. Scratched areas are not transparent, indicating that the binder layer has not been completely removed. Many aged but unfailed tapes also have scratches.

Tape 1 has always failed by sticking to the tape transport, generally by wrapping around the capstan. It is the only tape tested that has a coating on both sides of the supporting film with the back side non-magnetic. The capstan 
bears against the non-magnetic side of the tape, so tackiness of the back coating is disastrous. Such tackiness was noticed when the tapes were loaded onto reels before the reading test because adjacent layers of the tape did not slide over one another. Other tapes have behaved somewhat similarly on a few occasions but they only followed the capstan part way around and then peeled off with an abrupt snap. Degradation products may have moved from the magnetic side to the back side of the adjacent layer making such tapes marginally tacky.

\subsubsection{Attempts to Rejuvenate Tape}

One tape that failed after slight progress into the data block was completely read ten times after it had been hand wound so all of the data area had passed over the read and write heads, which were then cleaned. A substantial deposit had accumulated on the read and write heads. Niplng another failed tape with an alcohol soaked swab did not make it readable. Presumably the swab should also have removed deposits from the tape.

About ten attempts were made to rejuvenate failed tapes by aging them at 85 and $60^{\circ} \mathrm{C}$ over a desiccant. Only one such tape became readable.

\subsubsection{Lifetime Estimates}

Tape lifetime, defined as the aging time associated with failure to be readable for 10 passes, lies in the interval between the end of the aging period at which a piece of tape was read ten times and the end of the subsequent aging period after which it could not be read ten times. Figure 918 show these intervals for aging at 85 and $60^{\circ} \mathrm{C}$ as horizontal bars, the ends of which show the interval described above. Symbols showing the maximum times at which ten reads have been made are used if failure has not yet cccurred. Replicates are shown by plotting additional lines and symbols displaced by 2-5t from the actual relative humidities. Examination of these figures shows that 
failures have generally been at $85^{\circ} \mathrm{C}$ at several humidities or at $60^{\circ} \mathrm{C}$ and $100 \%$ RH.

A simple way to approach lifetime estimation at ambient conditions is to treat lifetime, (LT), as the reciprocal of a rate and use an Arrhenius equation. Thus $L T^{-1}=A \exp (-E / R T)$ so $L T=[\exp (E / R T)] / A$. Here $E, R, T$, and $A$ are the activation energy, gas constant, absolute temperature, and preexponential factor, respectively. Consequently, plots of log LT versus 1000/T were made, Fig. 19-23. Data are too few to do more than demonstrate general trends so an average lifetime is plotted for each tape aged at any condition at which any sample of that tape had failed. Each average is the arithmetic mean of the sum of the times at the midpoint of the appropriate bars in Fig. 9 - 18 and the maximum number of days unfailed samples had been aged at the same condition. Storage conditions are assumed to be about $20^{\circ} \mathrm{C},(1000 / \mathrm{T})$ $=3.41$, at $50 \% \mathrm{RH}$.

Linear extrapolation of the plotted lines is valid if the Arrhenius equation is applicable. Lifetimes at ambient conditions estimated by this procedure are approximately 20 years. However, the single failure that has occurred to date at $35^{\circ} \mathrm{C}$, with tape 41 , has occurred earlier than predicted by this linear extrapolation. Obviously, more data are required before any firm conclusion can be drawn.

\subsection{Results with other measured quantities}

Table 2 contains the values of peel force, elongation for binder separation, rolls to detach binder, and water content at $45 \%$ relative humidity found for unaged tapes. More than 10 rolls were required to detach the binder but the value listed is ten for all tapes. The quantities above provide an 
indication of changes in properties of the tape although they do not correlate in a definite way with ability to read the tape.

\subsubsection{Peel force}

The unit used for peel force is the number of grams required to separate half inch wide tape from the binder layer. In the previous report, we normalized the data to the width of the tape and reported the results in units of Newtons/m. However, some of the tapes peel in patches and we are now skeptical of the validity of dividing by the width.

Peel force of unaged tape is plotted versus peel rate in Fig. 24. Values of force generally decrease with peel rate but we have ignored this effect in working with the aged tapes because of the approximate nature of the measurements. Peel rates are about ten times greater than used for the data in the previous report: All tapes lost binder but some required quite high peel rates before separation occurred. The force recorded is higher, about $1000 \mathrm{~g}$. if the binder is retained on the magnetic tape. Aged tapes generally peeled easily so a peel rate of about $5 \mathrm{~cm} / \mathrm{s}$ was used unless the binder would not come off.

Fig. A1- A28 of the appendix show how peel force varies with aging time. Each plot shows all results for one tape aged at one temperature. Rapid and very great decreases to an approximately constant value occur at high temperature and all relative humidities. Tape 1 retains a higher peel force than other tapes. Aging at $35^{\circ} \mathrm{C}$ causes a substantial decrease in peel force at 100\% relative humidity but results in a smaller change at $25 \%$ relative humidity. All tapes behave in a qualitatively similar manner but the percentage change in peel force is less for tapes with low initial peel force. 
The lowest peel force found was $1 \mathrm{~g}$. This value is probably relatively uncertain but indicates an enormous change from any initial peel force. However, several such tapes were read ten times without any difficulty. Some tapes with higher peel forces could not be read ten times. Thus, a low peel force does not guarantee a failure to read a tape but it does indicate a tape in poor condition and a high probability of failure.

\subsubsection{Elongation for binder separation}

Fig. A29 - A55 show how the elongation for binder separation is affected by aging. Aging at high temperature causes large, rapid decreases in elongation for binder separation, except for tape 1 . Aging at $35^{\circ} \mathrm{C}$ results in lower elongations at $100 \%$ relative humidity but not at $25 \%$ relative humidity. Tapes can remain readable long after the elongation values have become low but some tapes could not be read 10 times when the elongation for binder separation was $40 \%$.

\subsubsection{Rolls to detach binder}

Fig. A56 - A76 show how the number of rolls less than 10 required to detach binder from the tapes is affected by aging. Aging decreased the number of rolls to very low values in some cases. Tape 6 seems particularly labile since it was the only tape aged at $35^{\circ} \mathrm{C}$ for which rolls decreased. Tapes 1, 21 , and 22 are particularly resistant to binder detachment. Some tapes could be read ten times even when the rolls required had decreased to zero (binder had flaked off when the tape was creased). In some cases tape 21 was unreadable when binder did not come off in ten rolls.

\subsubsection{Water content of tapes}

Fig. A77 - A83 show water content as a function of relative humidity for aged and unaged tapes. The plotted symbols that appear to be error bars are 
percentages obtained when equilibrium was approached from high and low humidity. Symbols are plotted at the midpoint between these values. Aged tapes are more hygroscopic than unaged tapes in all cases. Differences in water content in aged and unaged tapes range from somewhat less than 0.18 to $0.2 \%$ at $50 \% \mathrm{RH}$. Larger differences occur at higher humidities. Usually equilibration was slower with aged tapes and was particularly slow when excess water was desorbing. This is reflected in the longer bars through the symbols, i.e. the tapes were further from equilibrium.

Moving samples from one desiccator to another is a slow process. A room with $45 \%$ RH was therefore used as the equilibration chamber, since it had mechanical air circulation which speeds up the equilibration. Water content measured in the room for a variety of aged tapes is plotted versus aging time in Fig. A84 - A90. Water content is usually increased by aging, the more so the higher the relative humidity. A few tapes, usually those aged at low relative humidity show the same or lower water content as the unaged tape.

\subsubsection{Weight changes of tapes during aging}

The increased water content of tapes aged under certain conditions suggested the possibility of monitoring aging by simply weighing the tape at constant relative humidity. The anticipated storage environment ought to be at approximately constant humidity, at least during certain periods of the year. A 2000-foot long tape on its reel has a mass of about $900 \mathrm{~g}$, of which the tape is $600 \mathrm{~g}$. Differences in water content of $0.1 \mathrm{~s}$ equal $0.6 \mathrm{~g}$. Balances are commercially available that can accommodate the reel of tape and weigh it to 1 $m g$.

However, there was evidence that materials left the tape. White deposits accumulated on the inner wall of the jars used for aging tape. Hater used for 
aging tapes at $100 \%$ relative humidity left a deposit when it was evaporated to dryness. Conceivably, water content might increase but tape mass might decrease due to loss of other materials. Tape mass were measured in the controlled humidity room before and after aging. Fig. A91 - A96 are plots of cumulative weight change versus aging time. Occasionally we did not make a weighing and show this by discontinuing the line and starting it again in the next complete intervai. Usually weight gains were found in samples aged at high humidity and weight losses were found in samples aged at low humidity. There are several instances of initial weight gain at $75 \%$ RH followed by weight loss, e.g., Fig. A92, A93, A94, A95, and A96. This might mean that a severe degradation generates volatile fragments. It appears that weight changes will not serve to monitor tape degradation unless results at $35^{\circ} \mathrm{C}$ show more regular behavior.

\subsection{Naturally aged tapes}

Some measurements have been made on tapes more than 10 years old. Results of these are in Table 3. Tapes 11 and 33 have the same manufacturars as tapes 1 and 31, respectively. However, tape 11 does not have a back coat. Binder layer is actually flaking of the outer layers of tape[8], which was the portion used for the tests. The tapes had been kept in a reasonably clean laboratory environment with little exposure to organic or acid vapors. The years listed are those written on the reel. Initial values of the measured quantities for these tapes are not known but only the current values for tape 8 appear very low. Peel force and elongation for binder separation of tape 33 are significantly lower than initial values for tape 32 , but peel force for tape 33 is about equal to the initial value for tape 31 . 
Some unreadable tapes written as early as 1972 were obtained from the Jet Propulsion Laboratory, with the proviso that they were not to be tested destructively. All of these tapes required more than 10 rolls to detach the binder from the support. No other tests have been made. A worker there commented that many old tapes could be read only once so that a tape testing program involving random sampling might eventually destroy a substantial portion of a tape library without finding bad tapes.

An entire box of cassette data tape was obtained and opened after seven years of storage at laboratory ambient conditions. All of these tapes bind badly in the cassette drive and an oxide colored deposit accumulates on the read and write heads. Under some circumstances tape lifetimes at ambient conditions can be considerably shorter than the 20 years we have suggested from our acceierated tests.

\subsection{Discussion and Future Work}

No attempt will be made to discuss the lifetime measurements because there are too few failures at less than 100\% RH to properly appraise the situation. More data will be obtained before the project is terminated.

Many factors have been measured that characterize general tape condition but they do not correlate well with tape lifetime. That leads us to speculate as to what aspect of accelerated aging does bring about tape failure, if we define failure as inability of the tape transport to read the tape. Failure to read a particular bit has been attributed to a deposit pushing the magnetic particles too far from the reading head to be detected[8]. Our tape transport writes in nine tracks across the tape, eight data bits and a parity bit. Correction for one unread bit in a byte is made from the parity bit. Thus two 
bits in a single byte must be undetected for the tape to be unreadable. It is our tentative conclusion that artificial aging causes materials to exude from the tape binder, giving rise to deposits that cause failure. These may operate by the mechanism above or cause the tape to stick in the tape transport.

Observations suggesting this are: (1) Head deposits were most frequently observed from the more labile tapes, 1, 6, and 31; (2) Head deposits are more often white than oxide colored; (3) Tapes without backcoating left deposits on the capstan, which does not contact the magnetic side of the tape; (4) Tape 1 , the only back-coated tape, has the most pronounced tendency to stick when aged at high humidity; (5) Scrapes and striations on failed tapes do not go through the binder layer; (6) Dry aging of failed tapes does not rejuvenate them.

Bertram et al.[9] made an observation consistent with this conclusion. They aged a tape at $55^{\circ} \mathrm{C}$ and $100 \% \mathrm{RH}$ until it had an immeasurably high bit error rate. The tape was wiped with a commercial wiping tissue and the error rate dropped to $2 \times 10^{-6}$.

It is uncertain whether the exuded material is an additive or a degradation product. The fact that humidity has a strong effect on lifetime seems more consistent with a degradation product than an additive, i.e. there would not be sufficient sorbed water to change the phase diagram or affect the migration of additives.

Tape aging and reading tests will be continued during the next year including measurements on videotape which is now aging. Binder detachment tests will be discontinued for tapes which already have suffered great reductions in these values. An effort will be made to identify the materials that come out of the tapes by use of infrared spectrometry. These materials include jar deposits, materials in the humectant, and head deposits. Samples 
of poly (ethylene terephthalate) and model binders are still being aged. Acid contents of both materials and solubility characteristics of the latter will be determined.

\section{References}

1. D. H. Brown, R. E. Lowry, and L. E. Smith, Prediction of the Long Term Stability of Polyester Recording Media, NBSIR 82-2530, June 1982.

2. Ibid., NBSIR 83-2750, August 1983.

3. Ibid., NBSIR 84-2988, December 1984 .

4. D. W. Brown, R. E. Lowry, and L. E. Smith, Macromolecules 13: 248; 1980.

5. E.F. Cuddihy, IEEE Trans. Magn. 16: 558; 1980.

6. D. S. Carr and B. L. Harris, Ind. Eng. Chem. 41: 203; 1949.

7. C. D. Hodgewan, Handbook of Chemistry and Physics, Cleveland, OH, Chemical Rubber Co.

8. S. B. Geller, NBS Spec. Publ. 500-101, June 1983.

9. N. Bertram, A. Eshal, J.C. Mallinson and M. Wildman, Recording Media Archival Attributes (Magnetic), Ampex Corporation, November 1979, p.93.

10. R. Bradshaw, et al.. IBM Journal of Research and Development 30(2): 203; 1986. 
Table 1. Tape Numbering Scheme

$\frac{\text { old \# }}{1}$
2
3
4
$5 A$
$5 B$
6
None

\begin{tabular}{cc} 
New \# & Reorder \# \\
\hline 1 & 1 \\
21 & 22 \\
31 & 32 \\
41 & 42 \\
51 & No Reorder \\
52 & No Reorder \\
6 & No Reorder
\end{tabular}

Table 2. Initial Tape Characteristics

Tape \# Peel Force, $g$ Elong. for Sep., \& Rolls for Sep., \# $\underline{H}_{2} \underline{O \text { wt. } \%}$

$\begin{array}{rrrrc}1 & 130 & 74 & 10 & 0.31 \\ 6 & 190 & 88 & 10 & 0.30 \\ 21 & 160 & >96 & 10 & 0.25 \\ 22 & 320 & >109 & 10 & -- \\ 31 & 707 & 10 & 0.27 \\ 32 & 740 & 135 & 10 & -- \\ 41 & 440 & 98 & 10 & 0.33 \\ 42 & 460 & 135 & 10 & -- \\ 51 & 400 & 145 & 10 & 0.32 \\ 52 & 20 & 79 & 10 & 0.30 \\ 72 & 320 & >118 & 10 & 0.31\end{array}$

A) symbol means the tape broke at the listed elongation before the binder separated.

Table 3. Characteristics of Tapes stored at Ambient Conditions

$\begin{array}{ccccc}\text { Tape \# } & \text { Year } & \text { Peel Force, g } & \text { Elong. for Sep., } & \text { Rolls for Sep., \# } \\ 8 & 1974 & 3 & 33 & 0 \\ 11 & 1974 & 94 & 72 & 10 \\ 33 & 1975 & 70 & 85 & 10\end{array}$




\section{LIST OF FIGURES}

Figure 1. Successful Reads Versus Time at $85 \mathrm{C}$ and $100 \% \mathrm{RH}$.

Figure 2. Successful Reads Versus Time at $85 \mathrm{C}$ and $50 \% \mathrm{RH}$.

Figure 3. Successful Reads Versus Time at $85 \mathrm{C}$ and $25 \% \mathrm{RH}$.

Figure 4. Successful Reads Versus Time at $60 \mathrm{C}$ and $100 \% \mathrm{RH}$.

Figure 5. Successful Reads Versus Time at $85 \mathrm{C}$ and $75 \% \mathrm{RH}$.

Figure 6. Successful Reads Versus Time at $85 \mathrm{C}$ and $50 \% \mathrm{RH}$.

Figure 7. Successful Reads Versus Time at $60 \mathrm{C}$ and $100 \% \mathrm{RH}$.

Figure 8. Successful Reads Versus Time at $60 \mathrm{C}$ and $75 \%$ RH.

Figure 9. Lifetime of Tape 1 at 85 and $60 \mathrm{C}$.

Eigure 10. Lifetime of Tape 6 at 85 and $60 \mathrm{C}$.

Figure 11. Lifetime of Tape 21 at 85 and $60 \mathrm{C}$.

Figure 12. Lifetime of Tape 22 at 85 and $60 \mathrm{C}$.

Figure 13. Lifetime of Tape 31 at 85 and $60 \mathrm{C}$.

Figure 14. Lifetime of Tape 32 at 85 and $60 \mathrm{C}$.

Figure 15. Lifetime of Tape 41 at 85 and $60 \mathrm{C}$.

Figure 16. Lifetime of Tape 42 at $75 \%$ RH at 85 and $60 \mathrm{C}$.

Figure 17. Lifetime of Tape 51 at 85 and $60 \mathrm{C}$.

Figure 18. Lifetime of Tape 52 at 85 and $60 \mathrm{C}$.

Figure 19. Log Lifetime of Tapes 1 and 6 Versus 1000/T.

Figure 20. Log Lifetime of Tapes 21 and 22 Versus 1000/T.

Figure 21. Log Lifetime of Tapes 31 and 32 Versus 1000/T.

Figure 22. Log Lifetime of Tapes 41 and 42 Versus $1000 / T$.

Figure 23. Log Lifetime of Tape 51 and 52 Versus $1000 / T$.

Figure 24. Peel Force of Tape Binder Versus Peel Rate. 


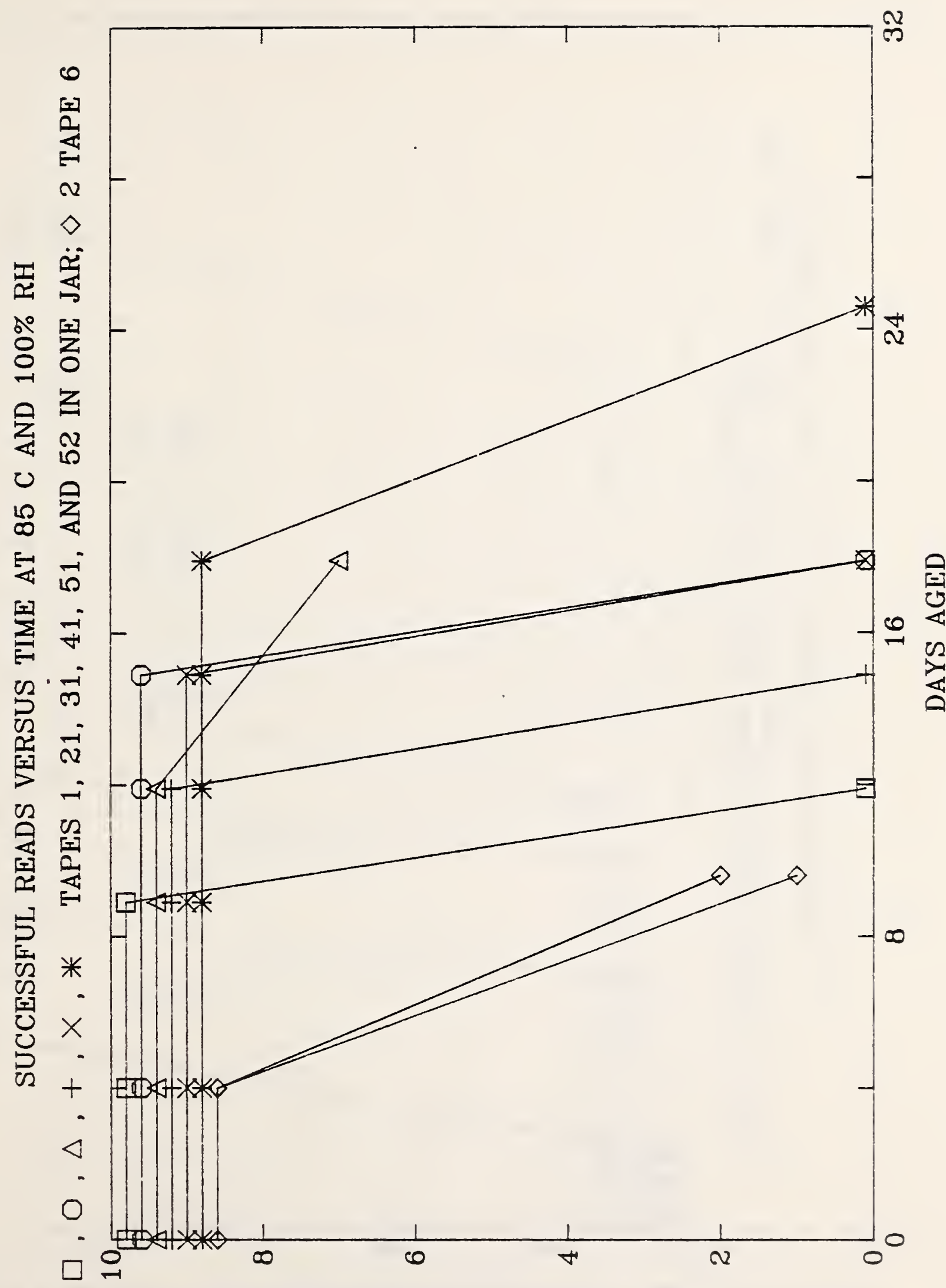

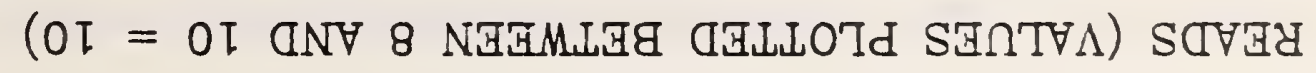




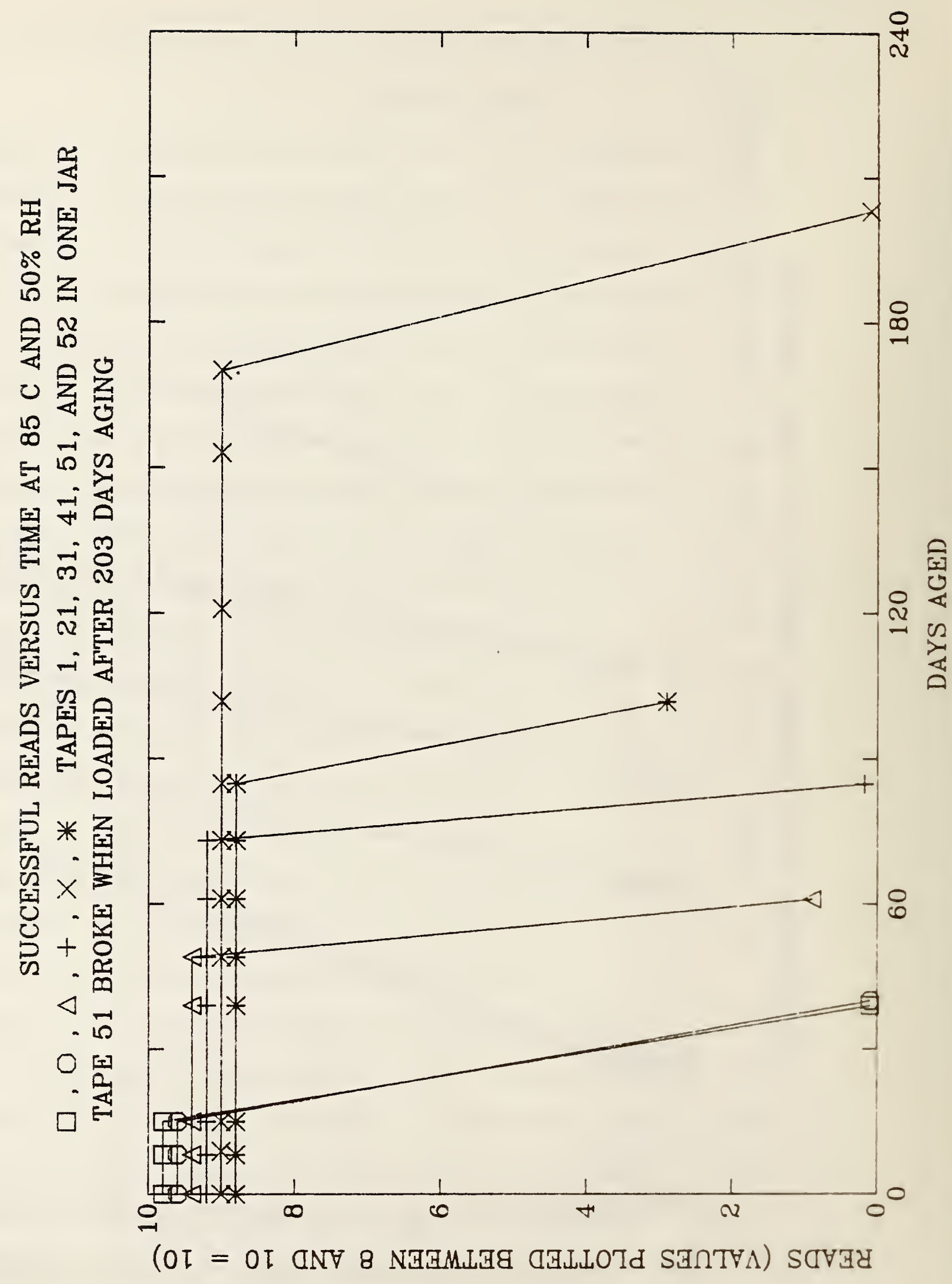




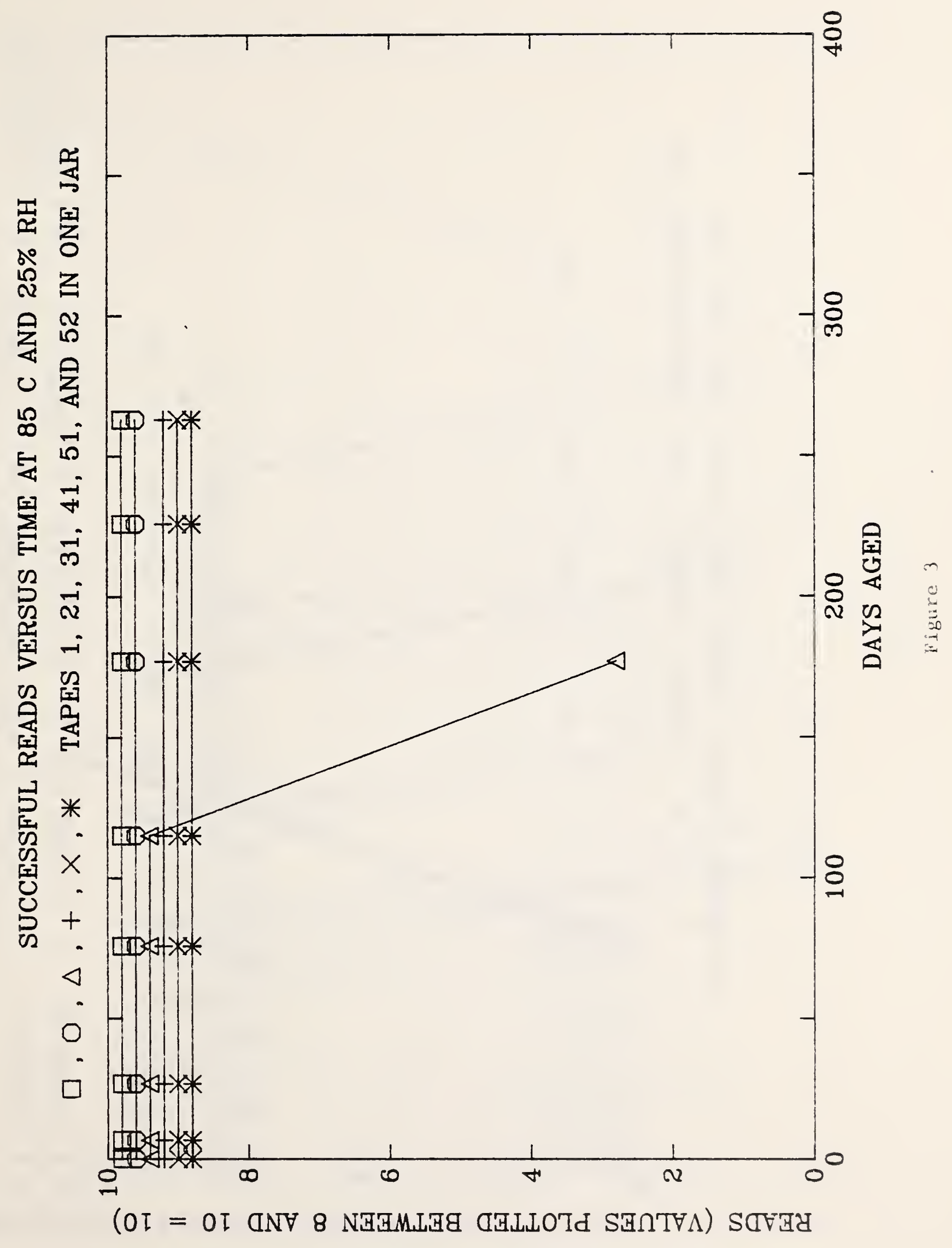




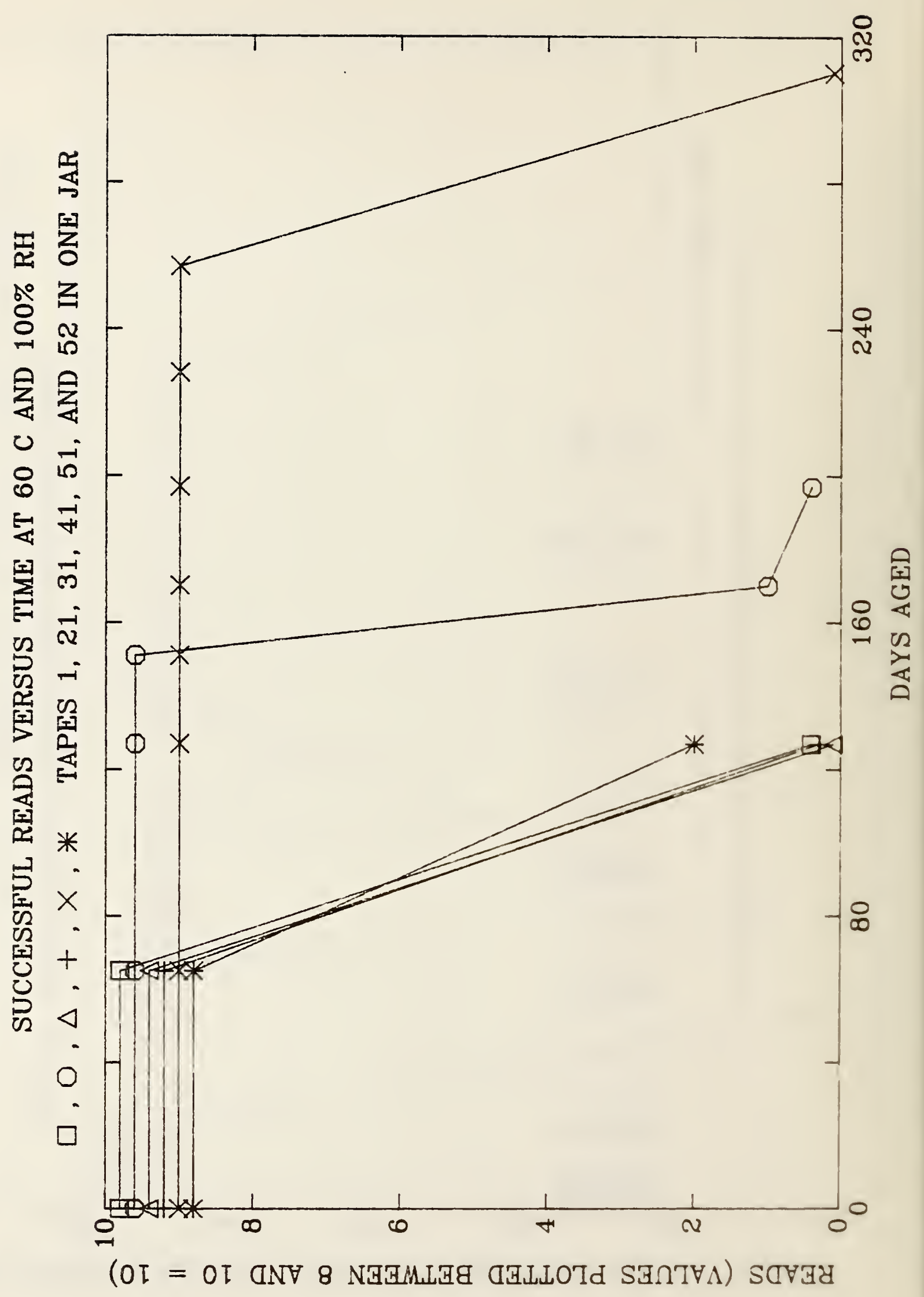




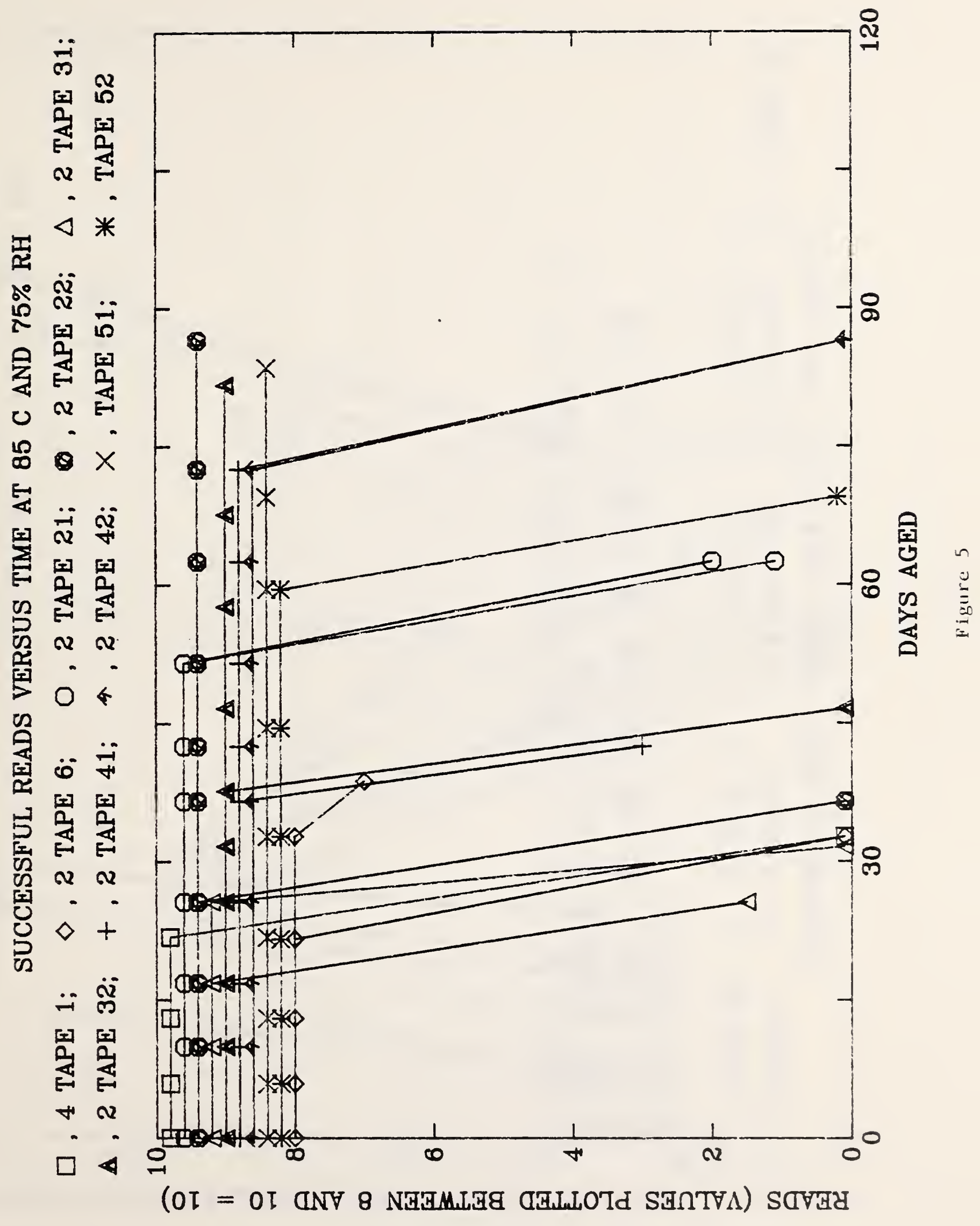




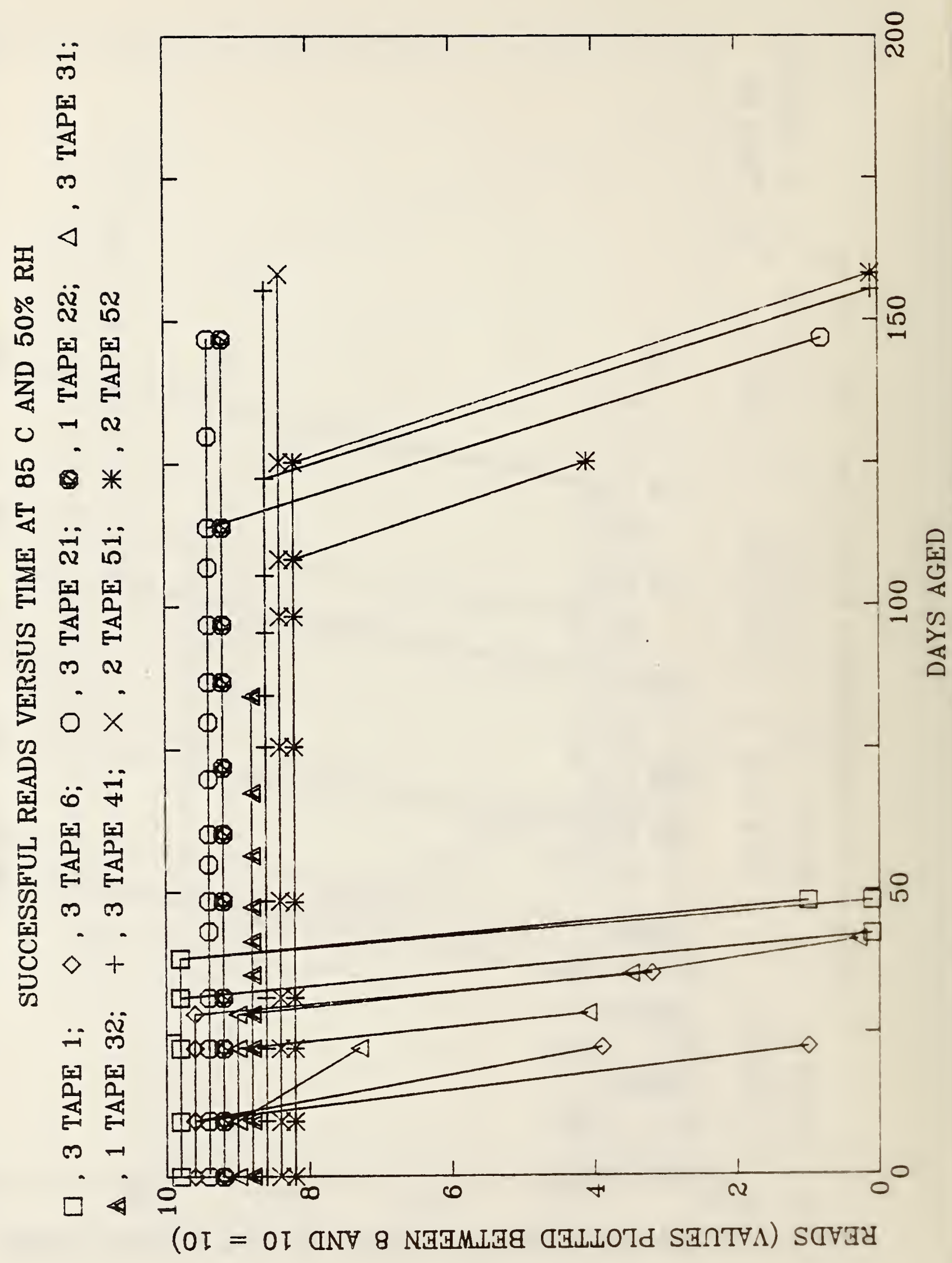




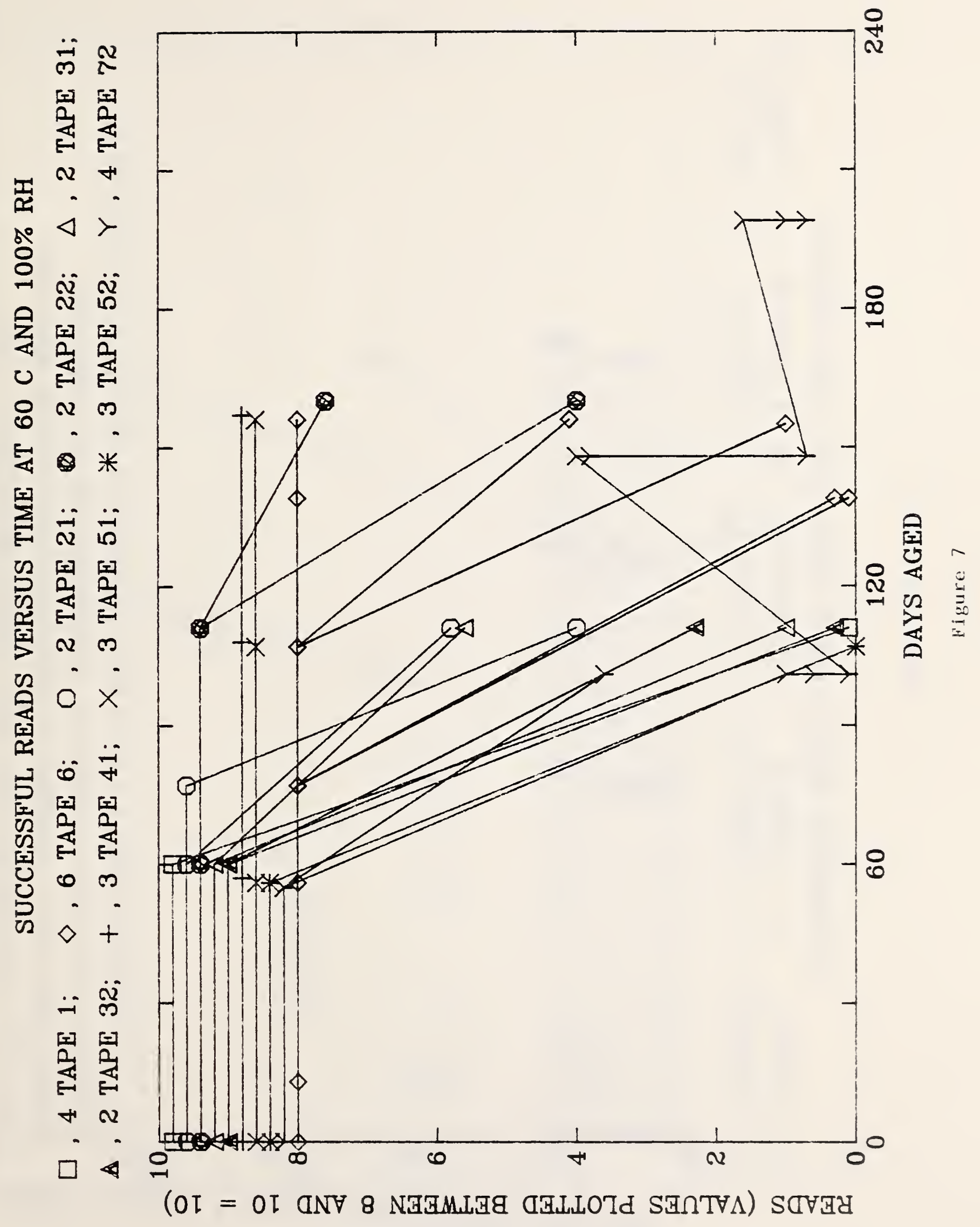




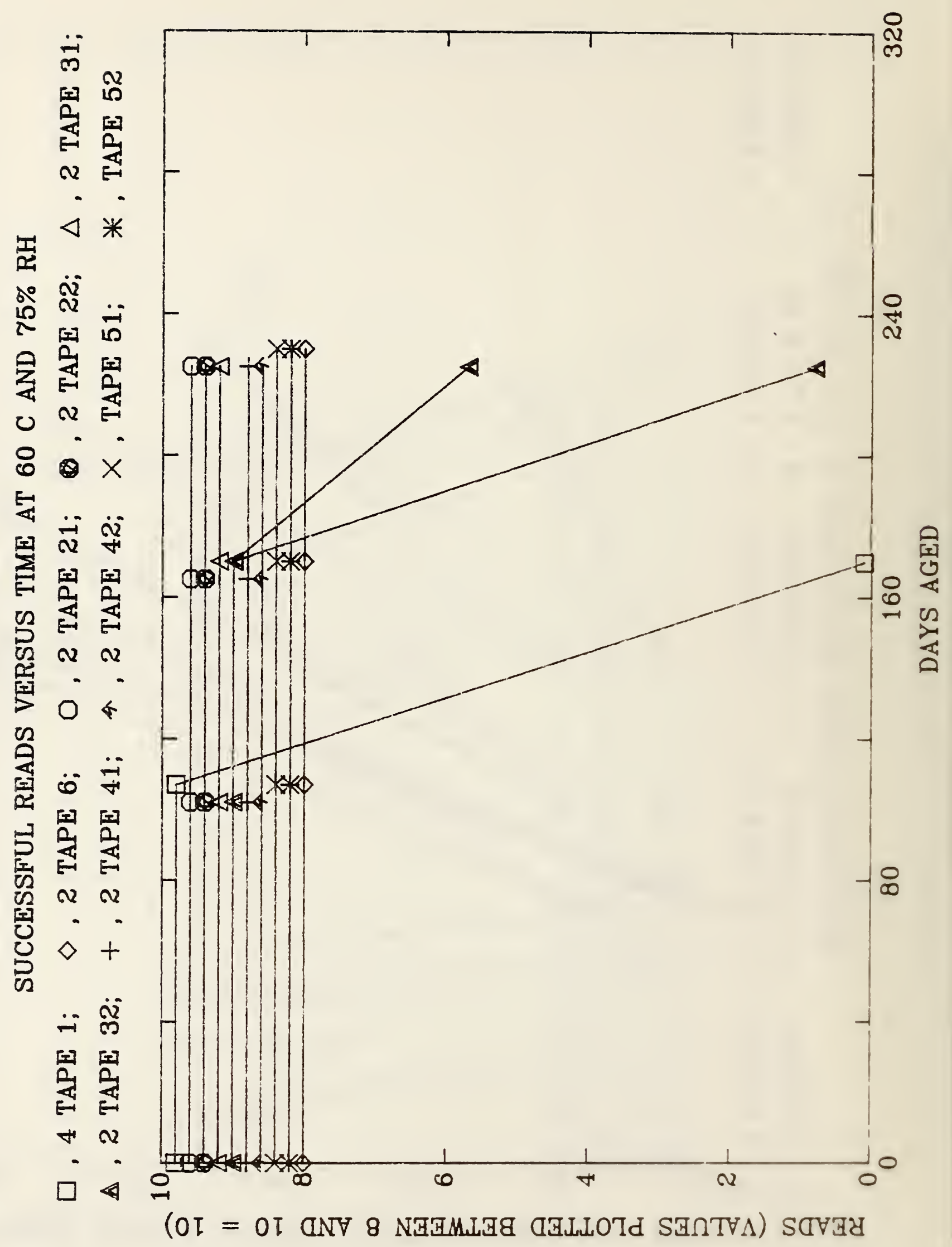




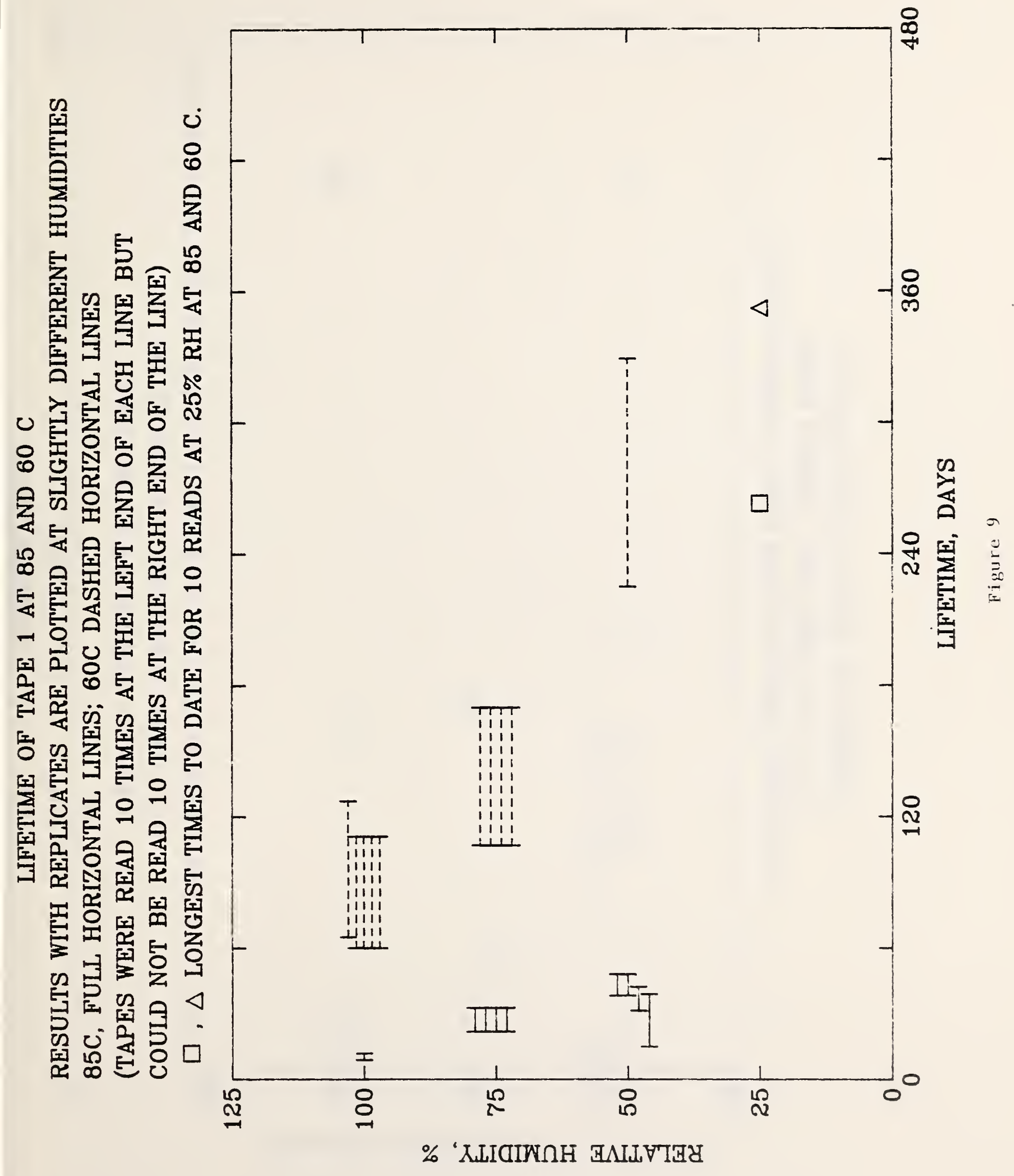




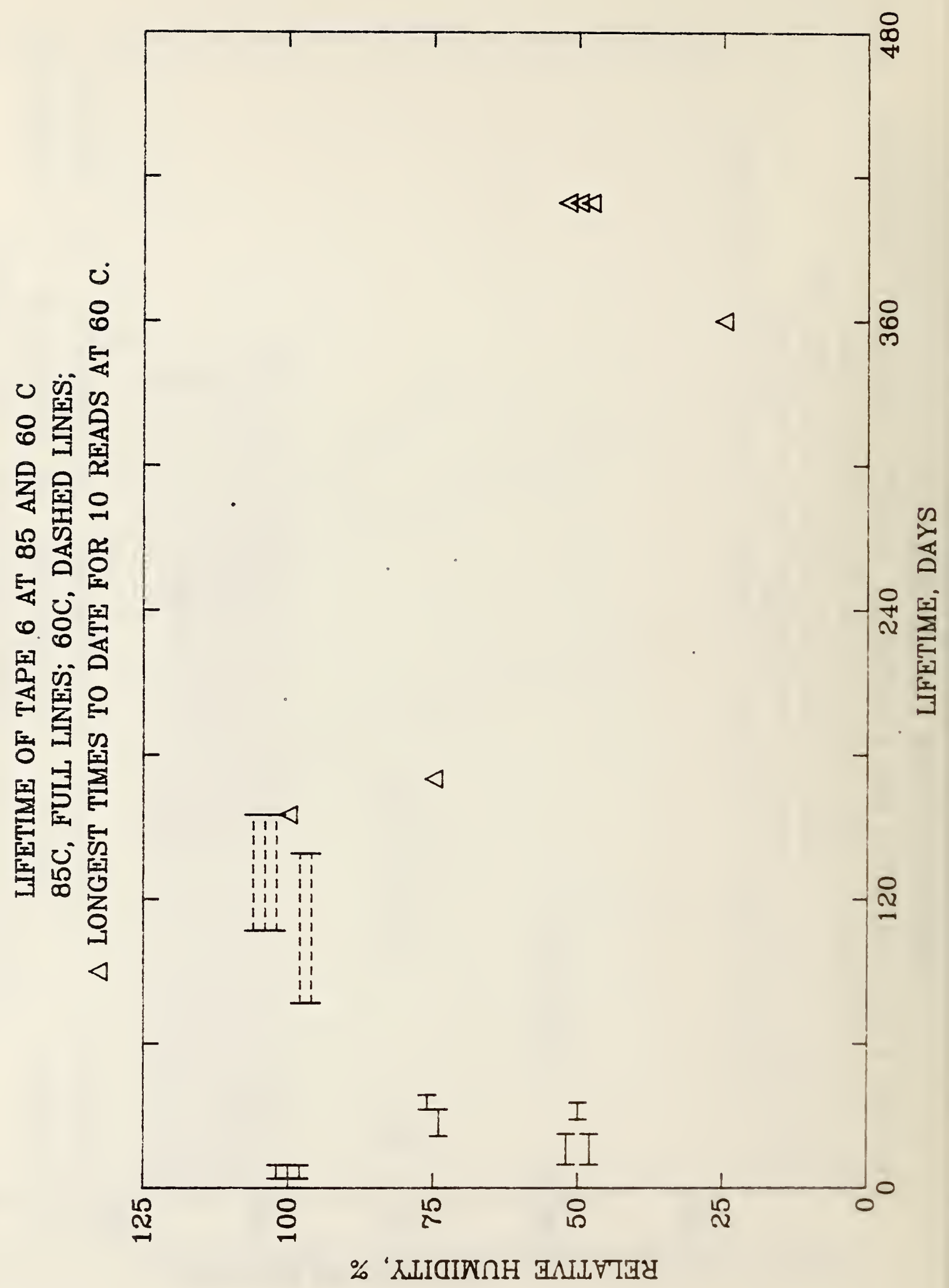




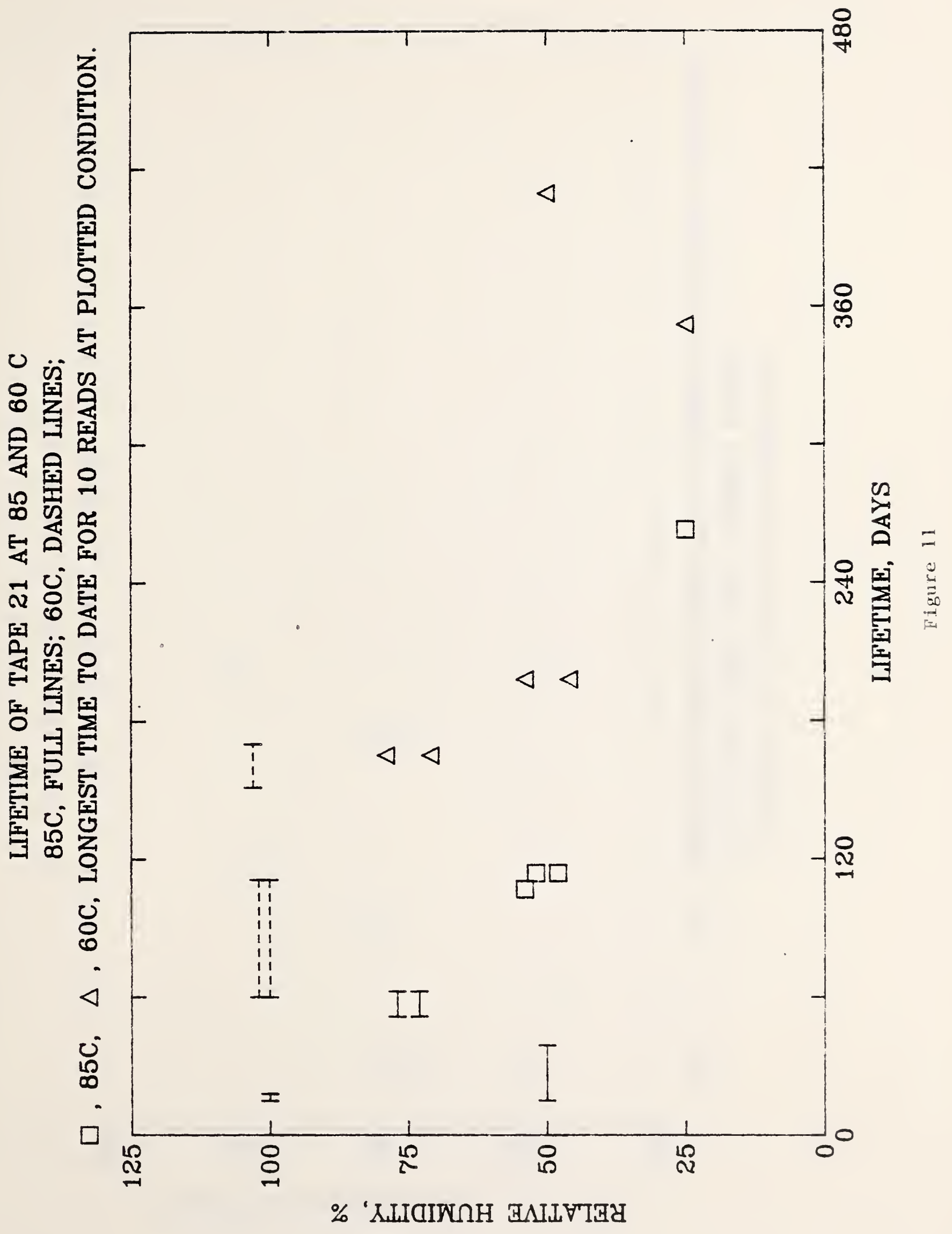




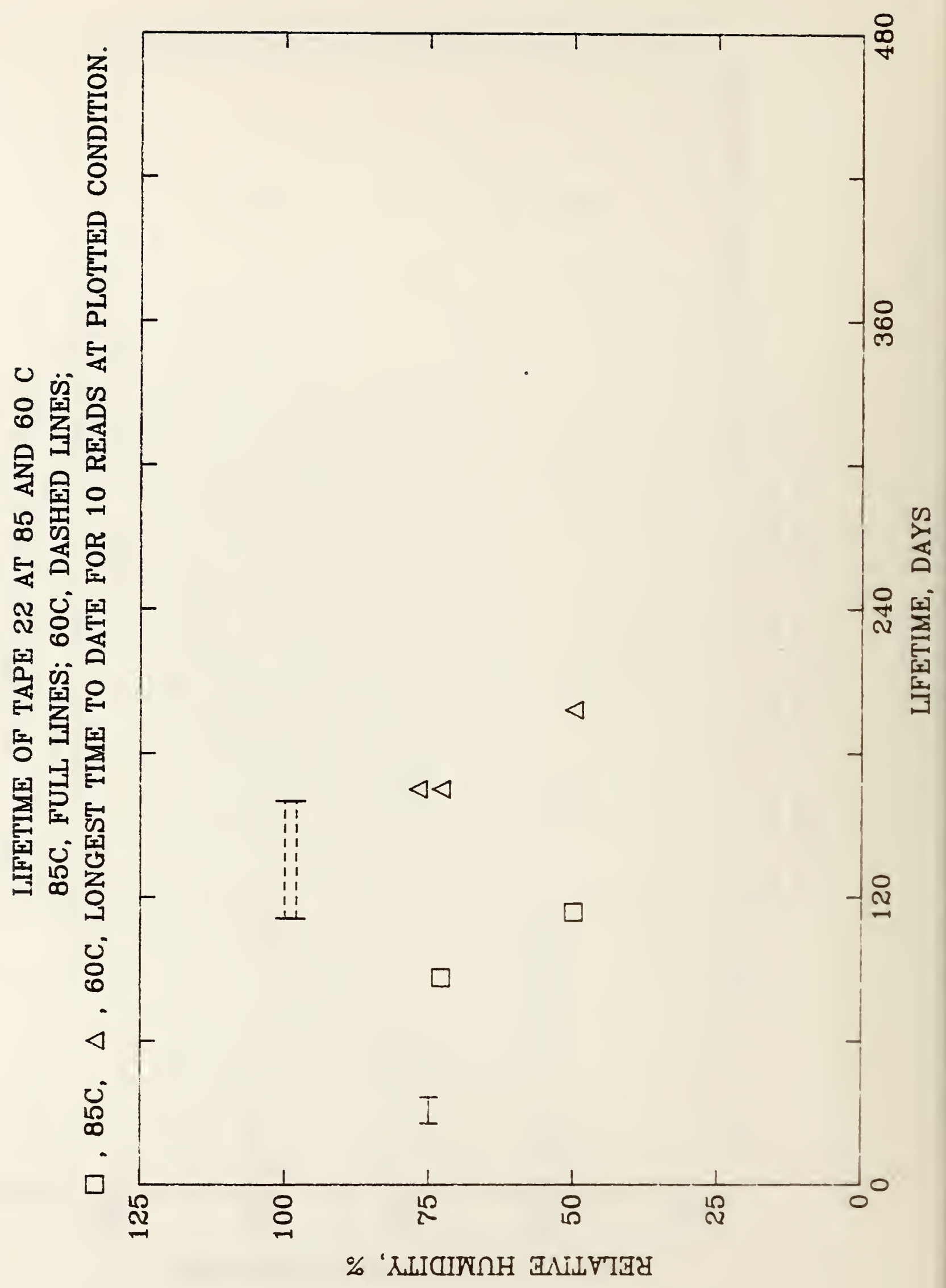




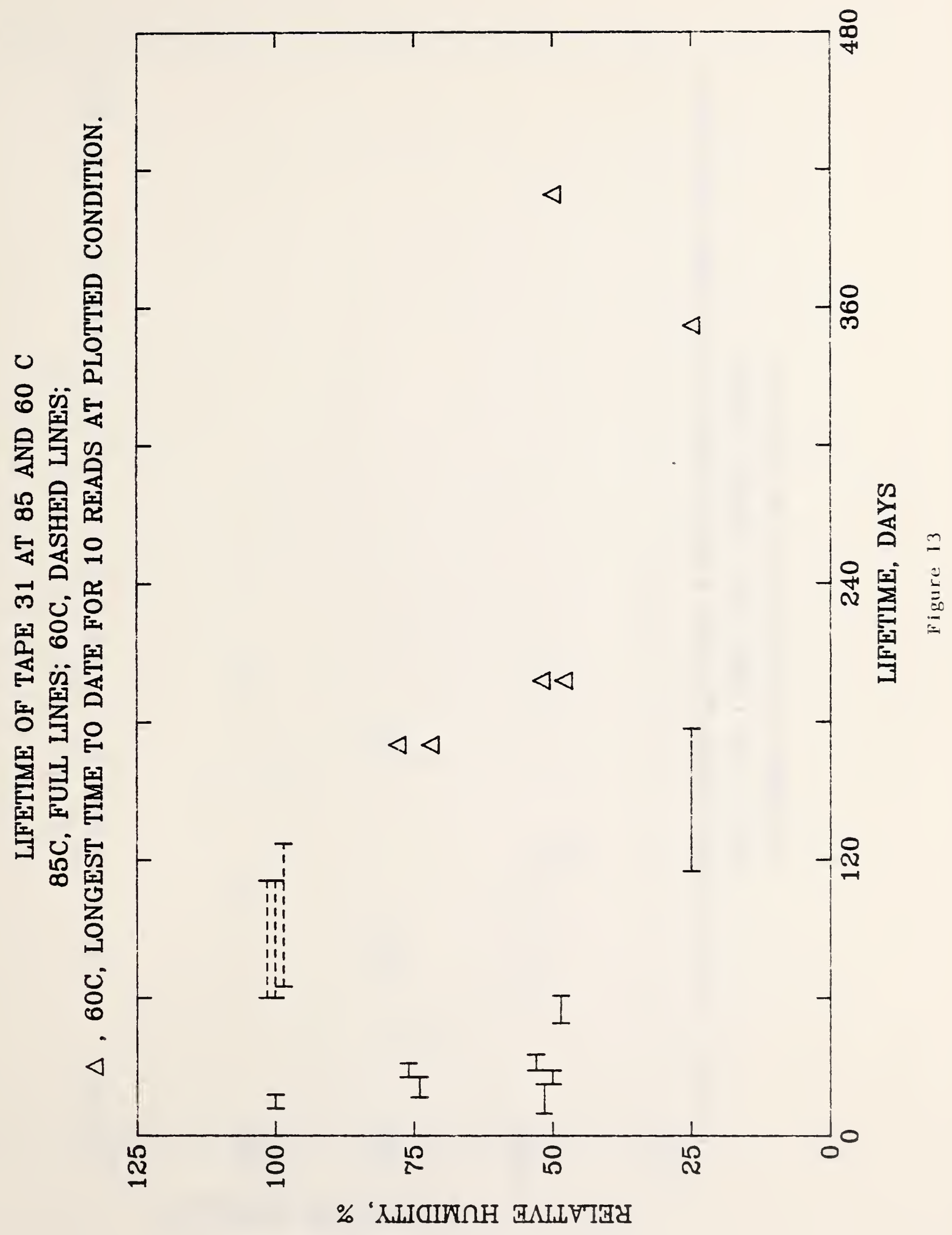




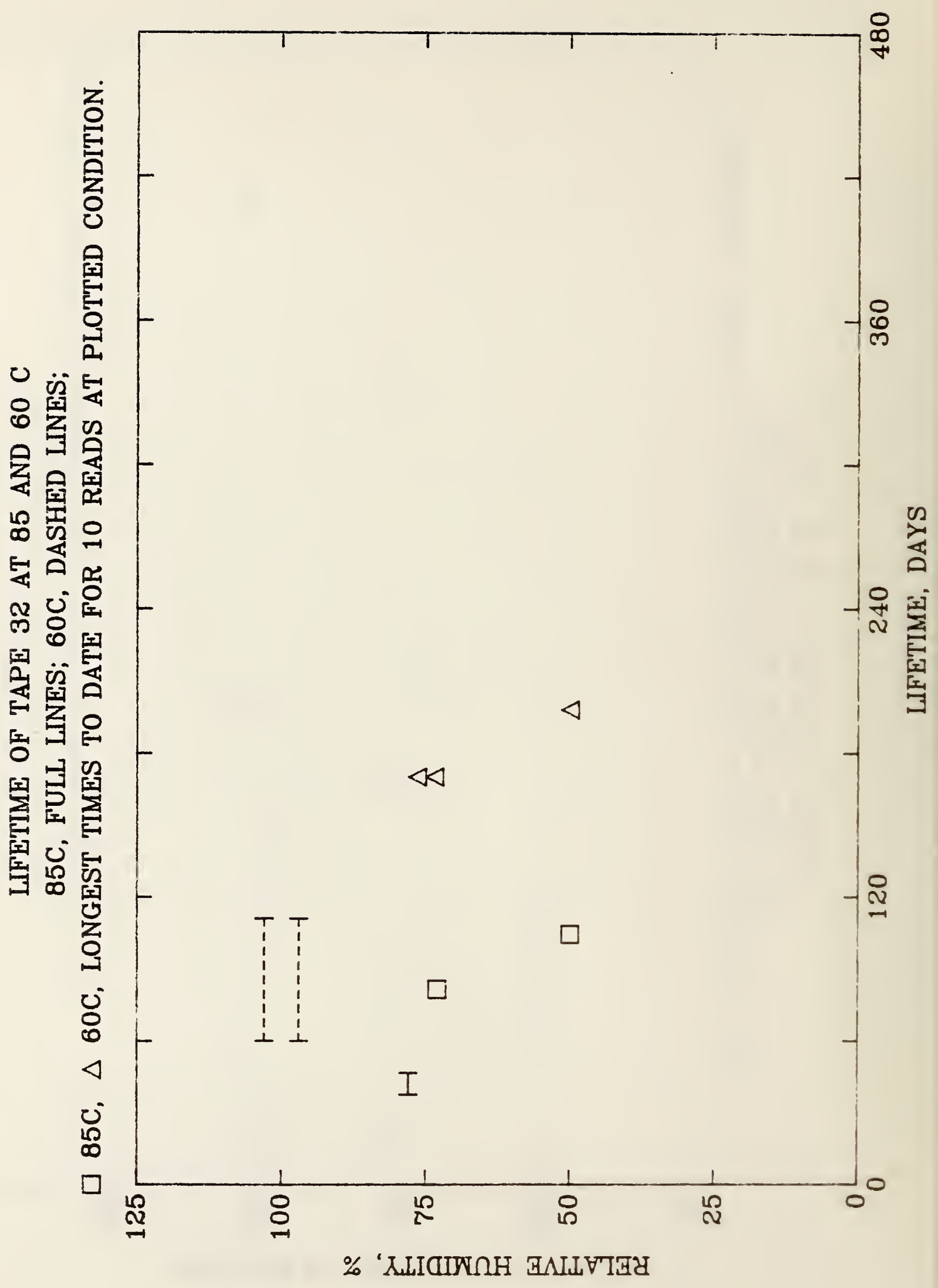




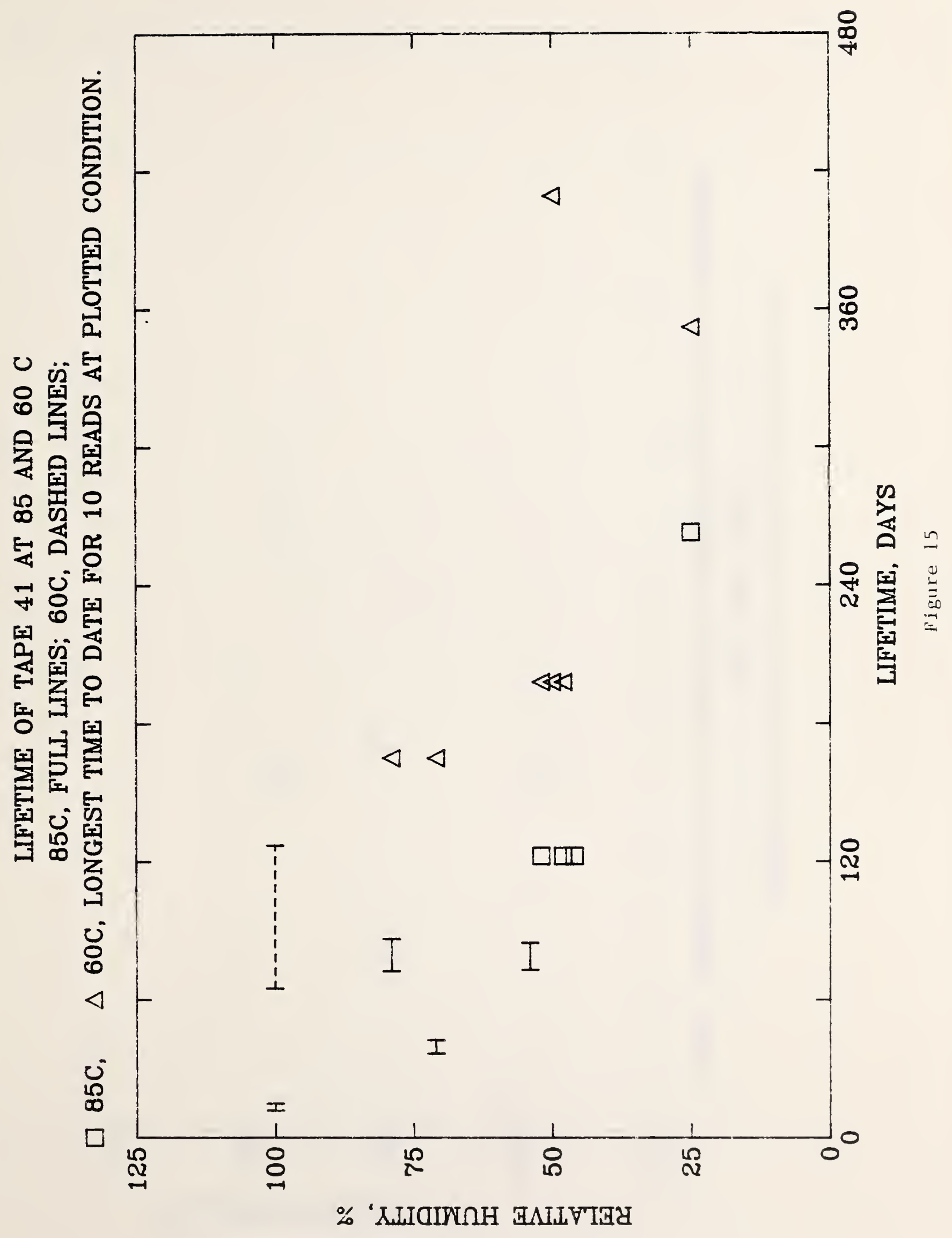




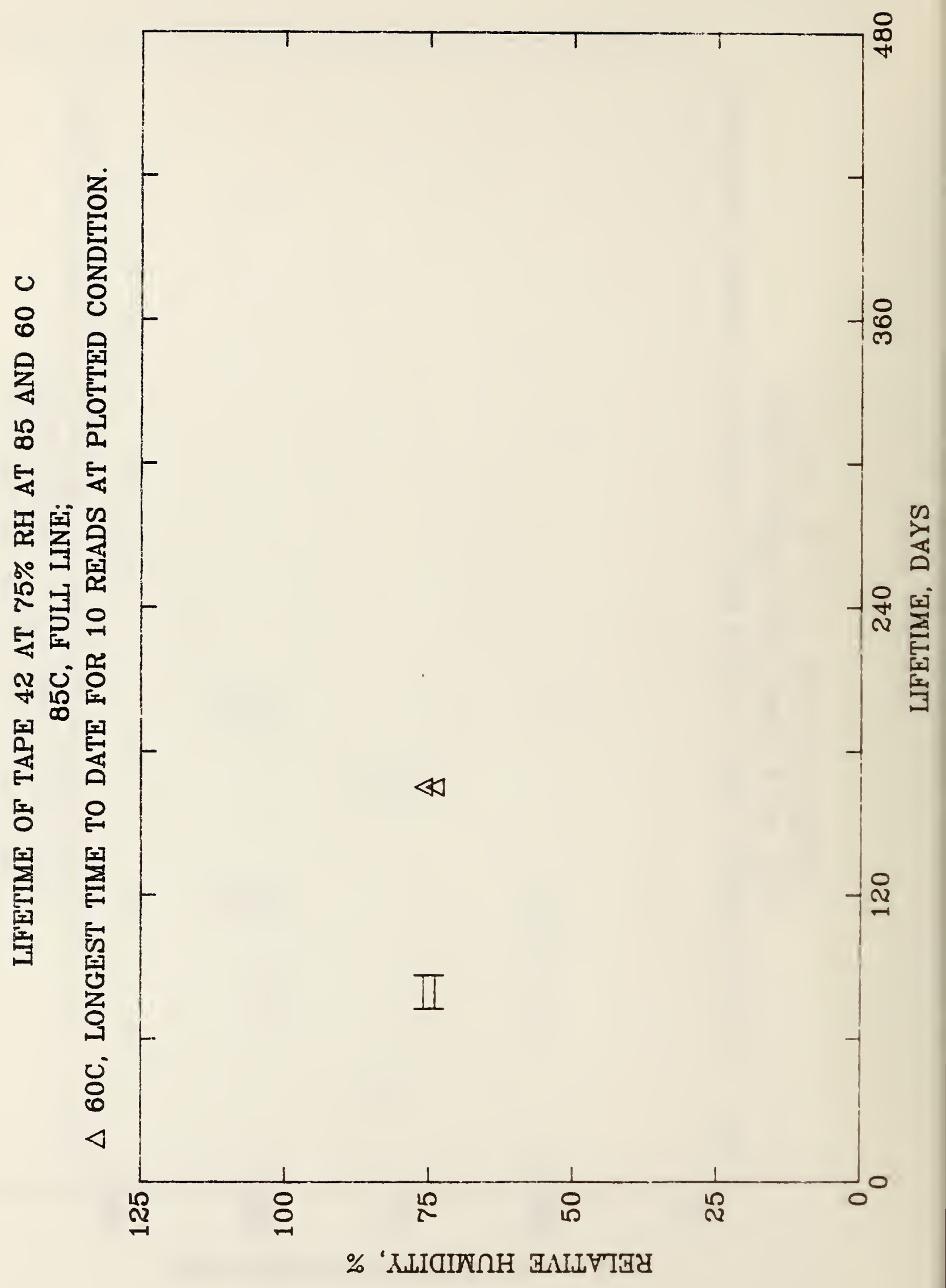




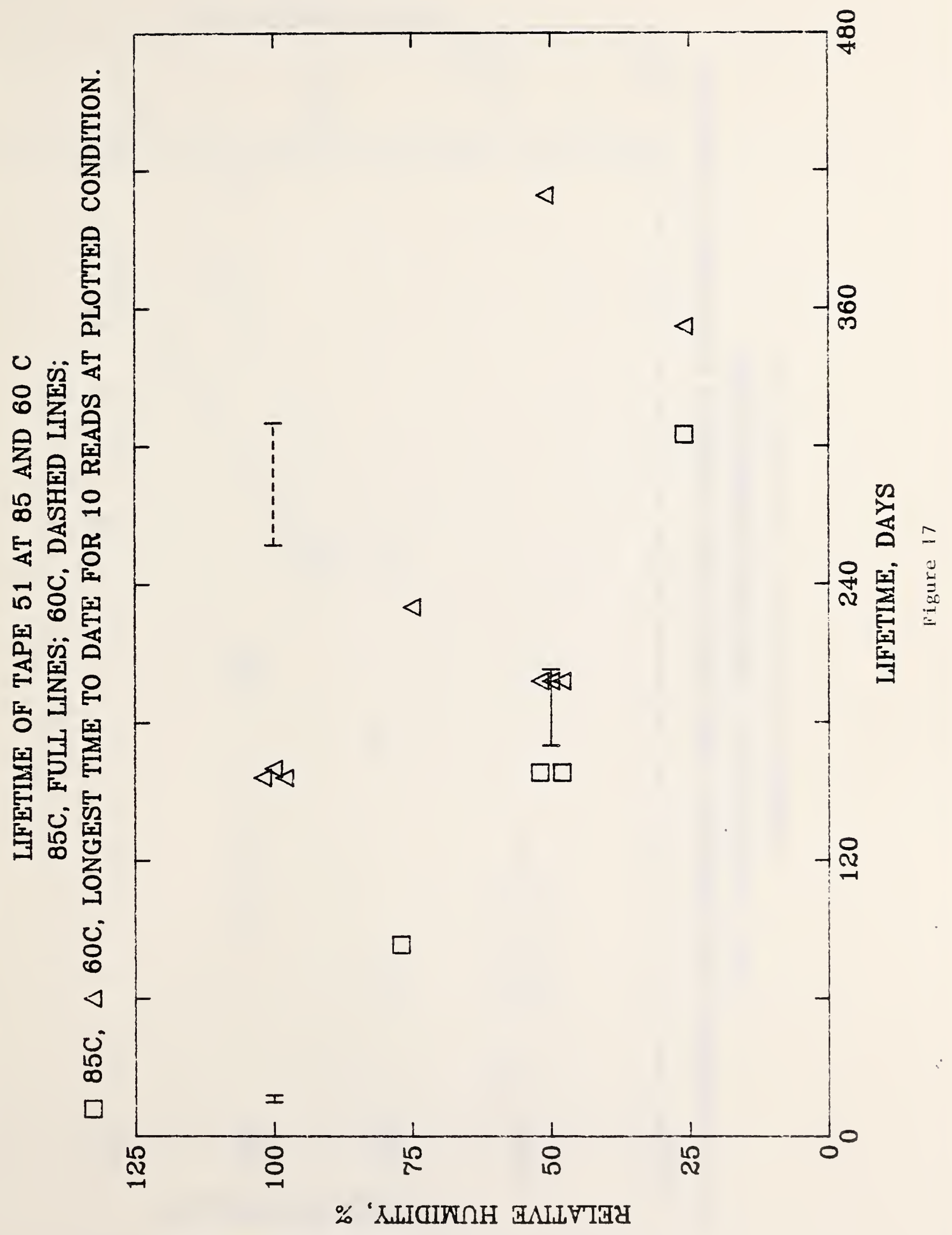




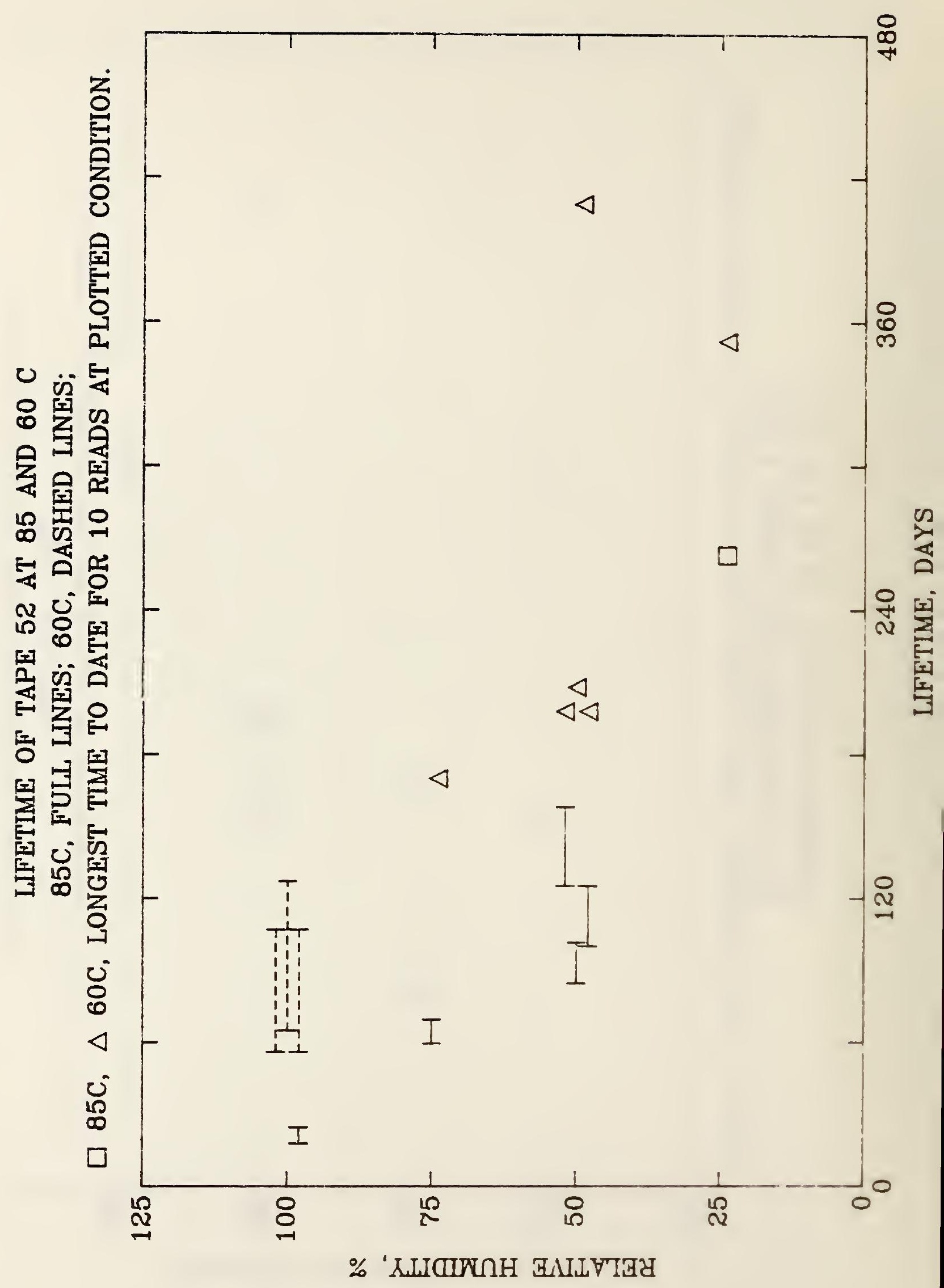


LOG LIFETIME, DAYS

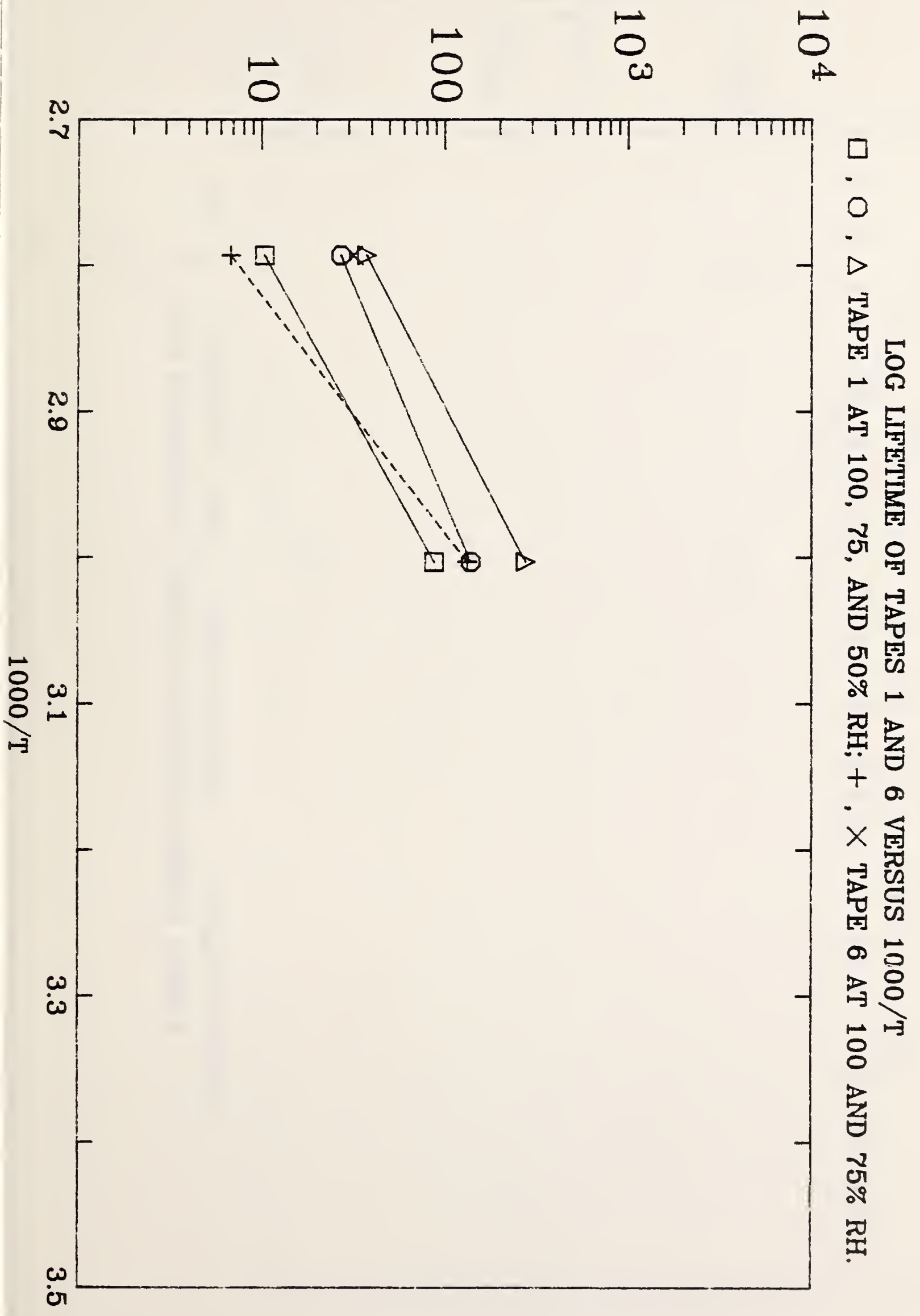




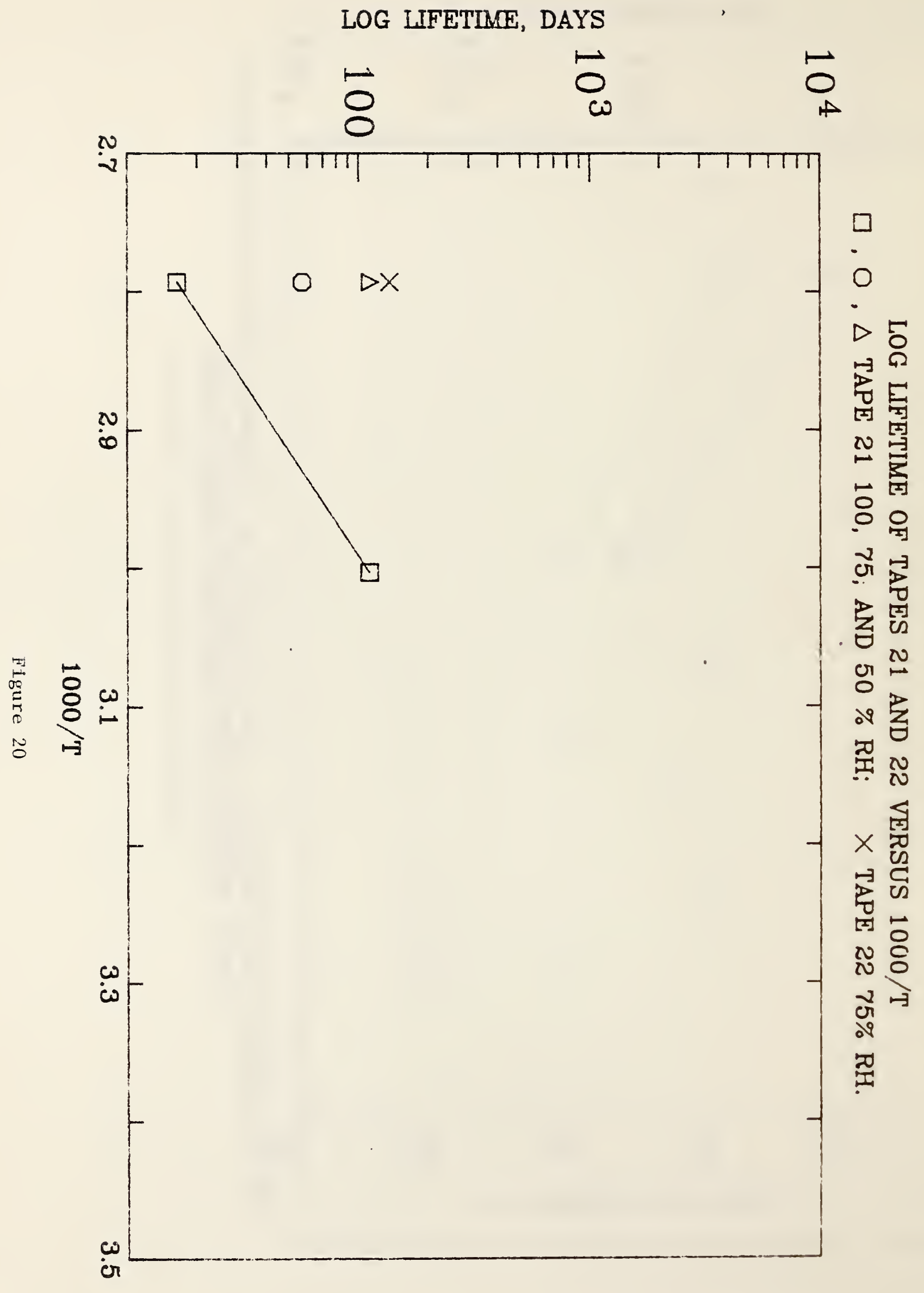


LOG IJFETIME, DAYS

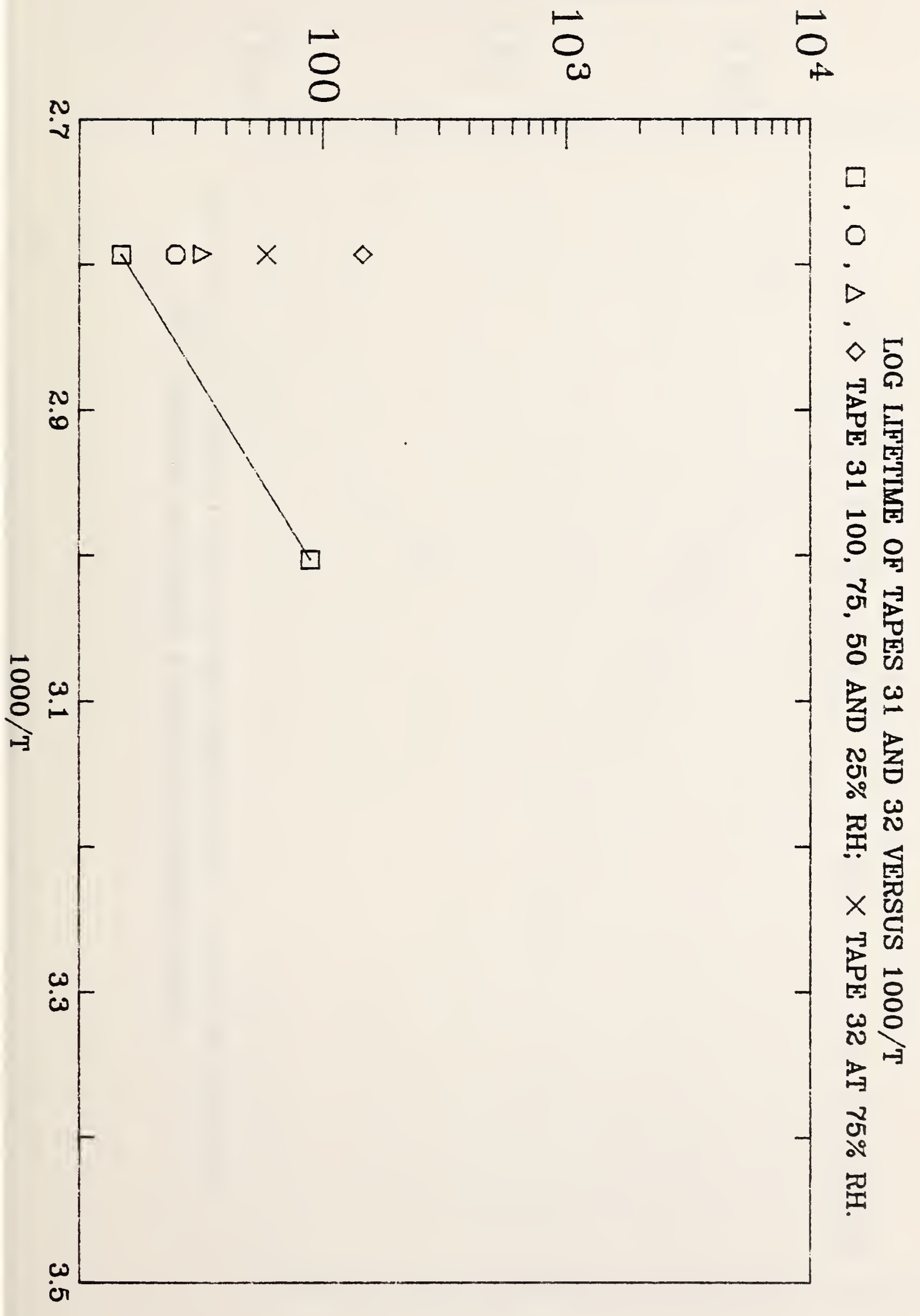


LOG LIFETIME, DAYS

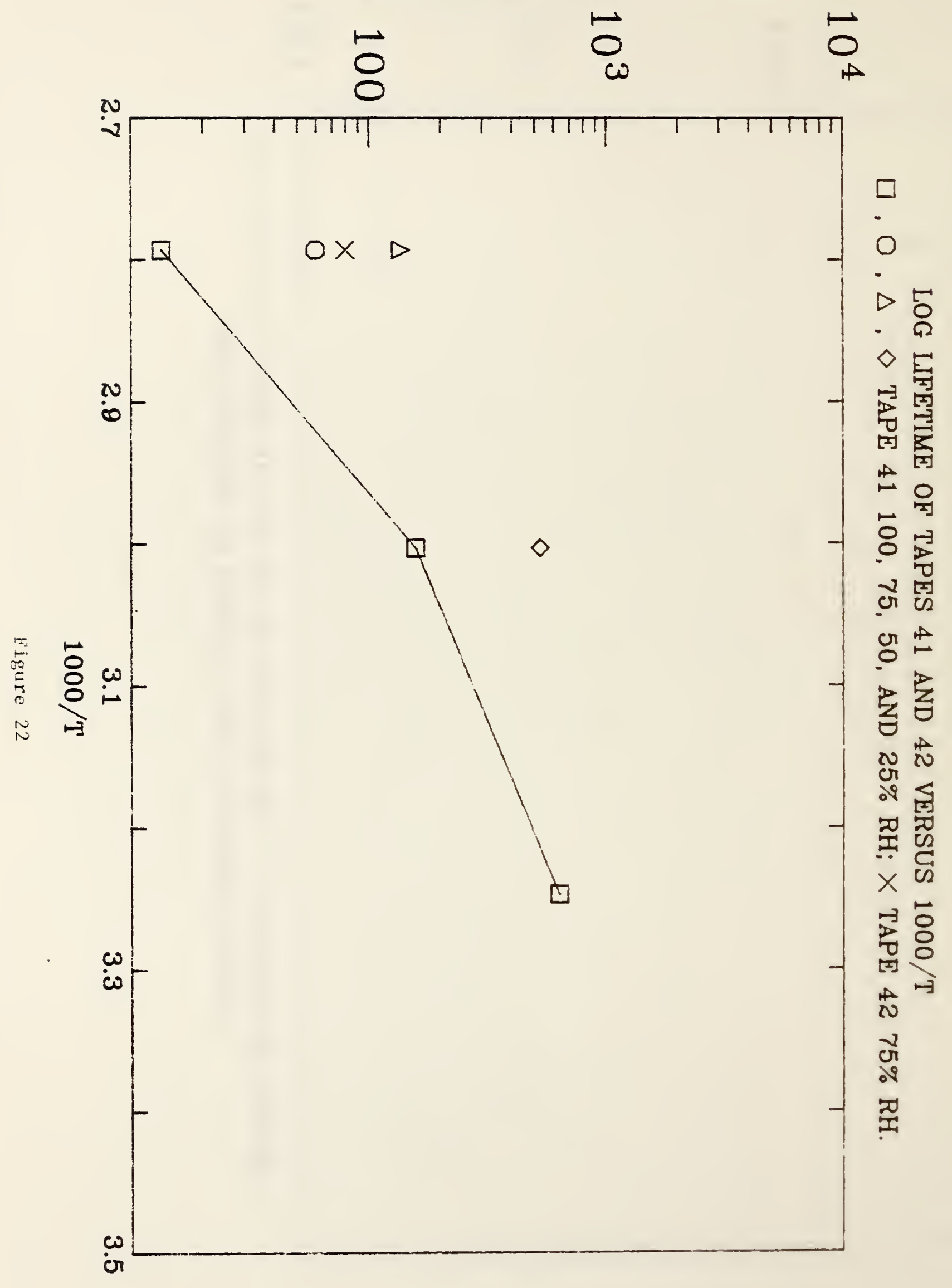


LOG IIFETTME, DAYS

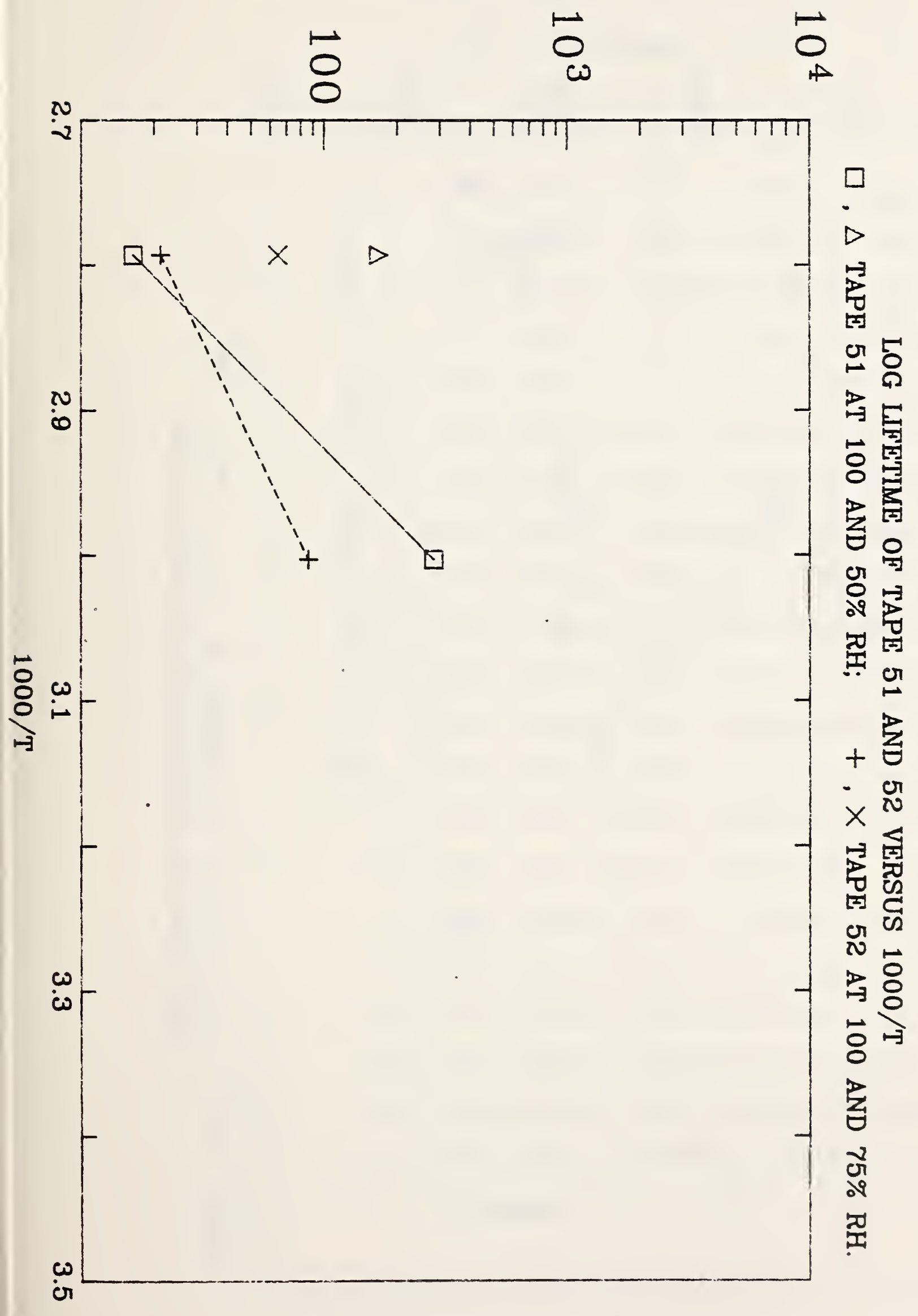




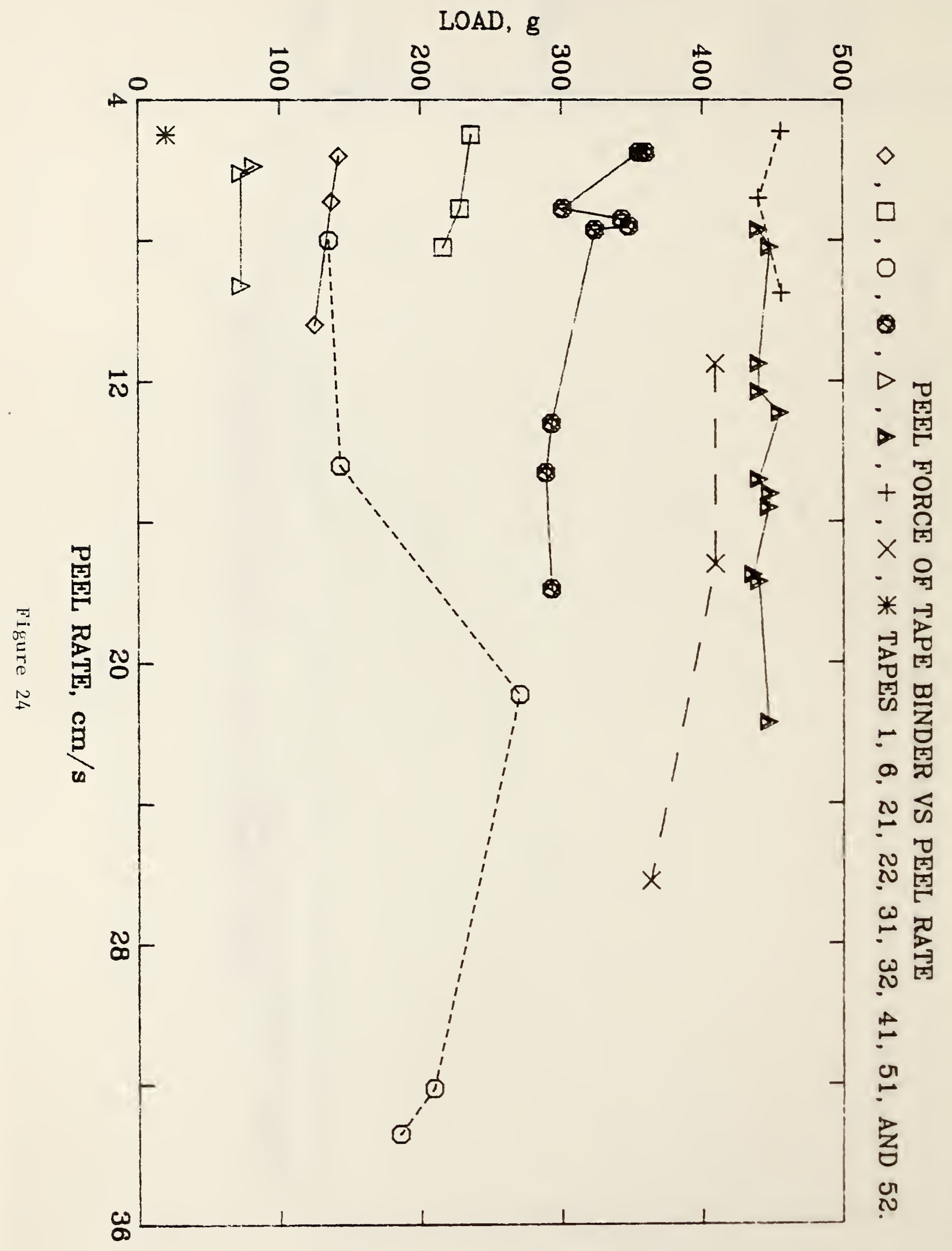




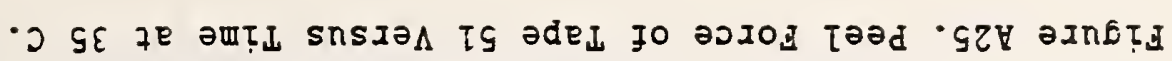

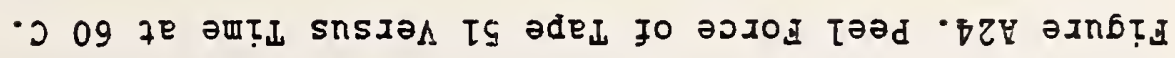

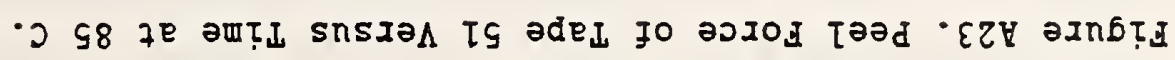

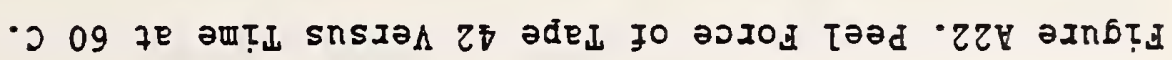

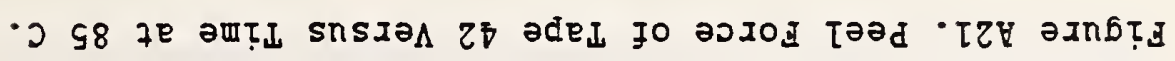

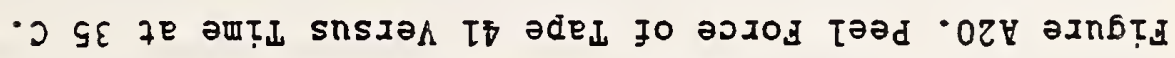

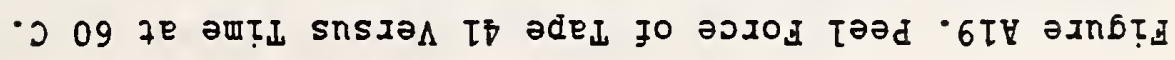

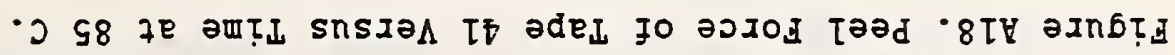

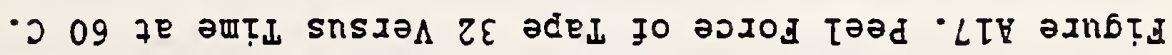

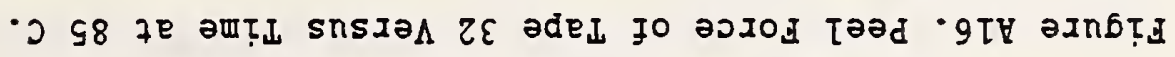

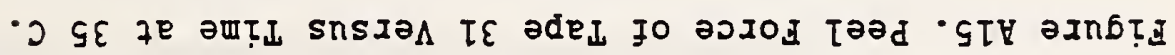

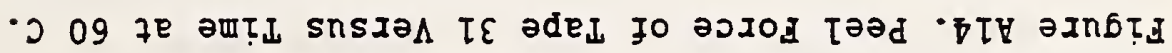

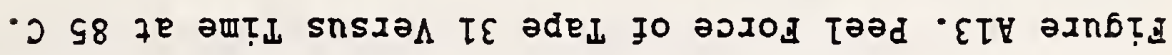

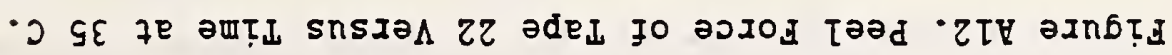

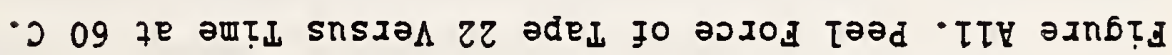

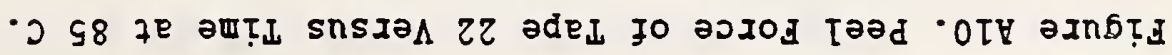

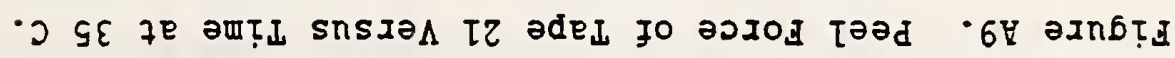

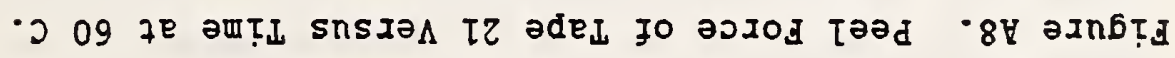

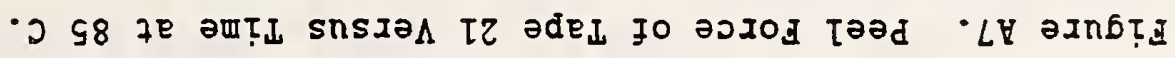

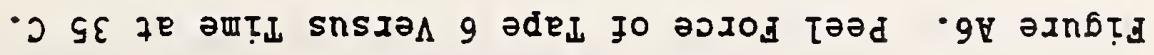

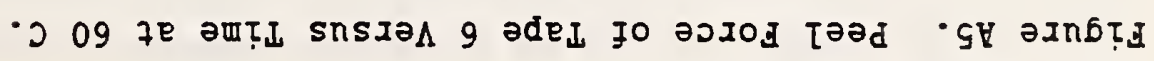

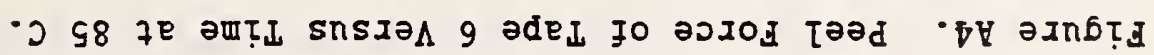

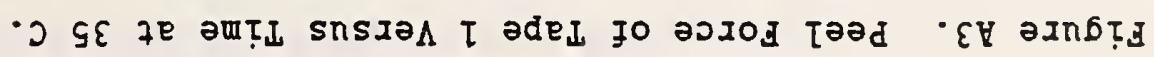

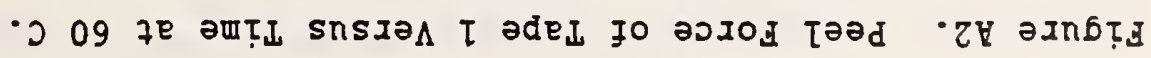

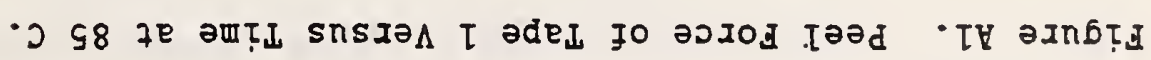

\section{XIaNkddY}




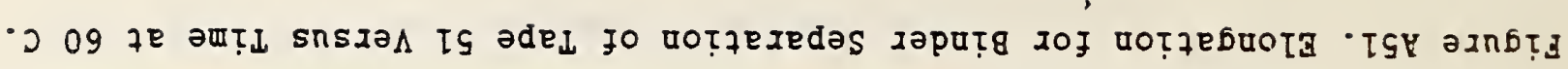

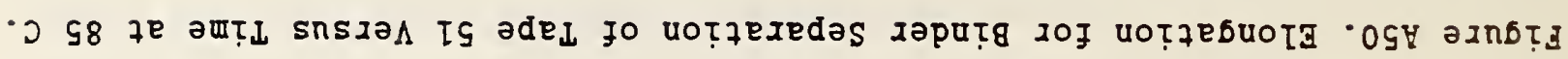

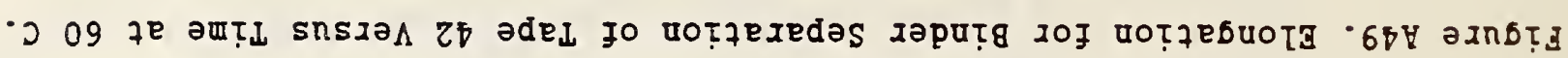

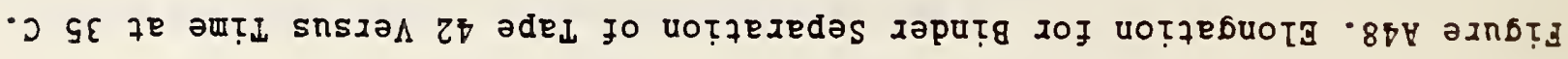

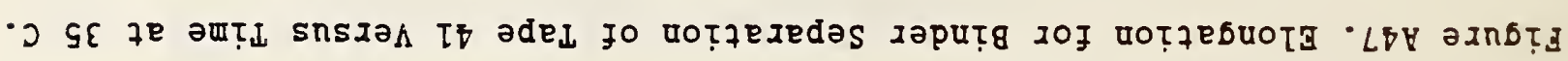

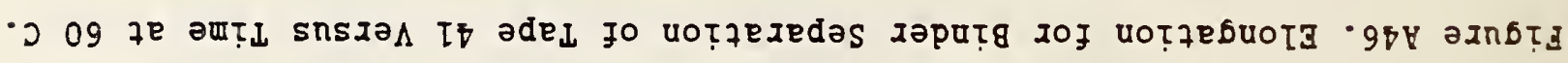

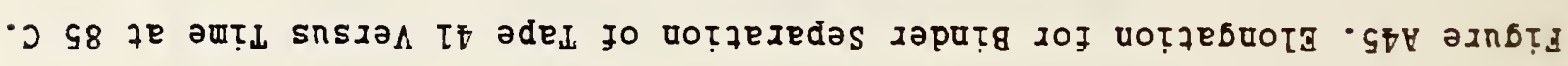

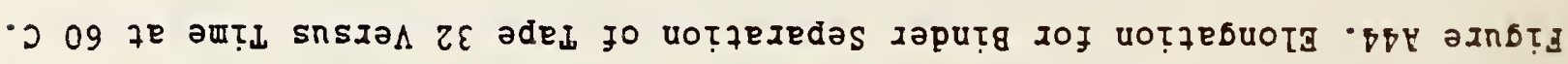

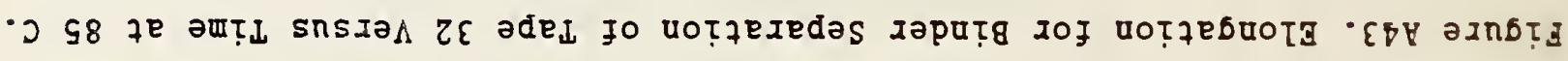

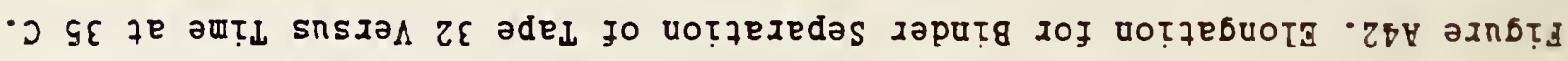

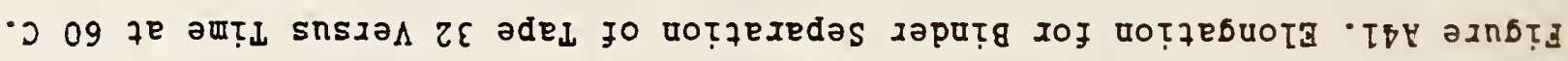

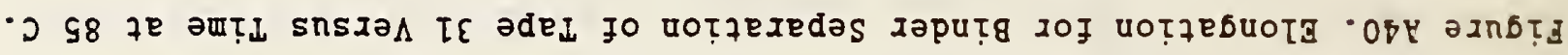

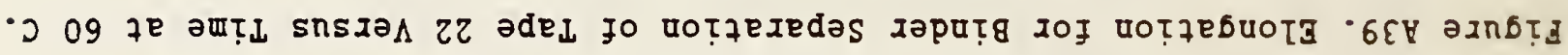

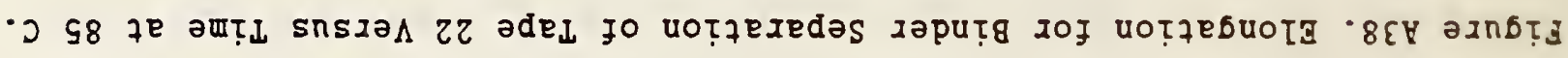

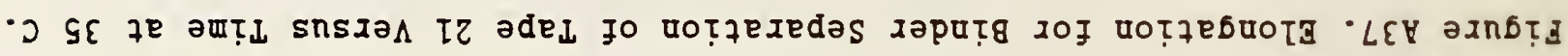

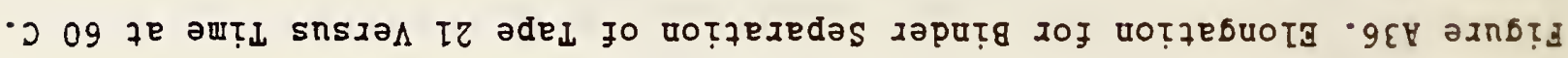

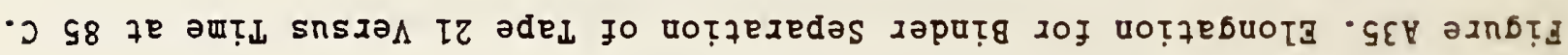

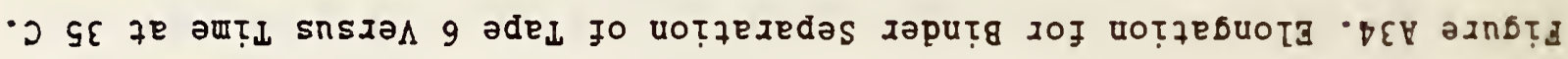

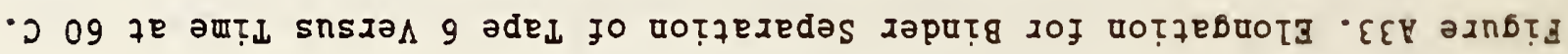

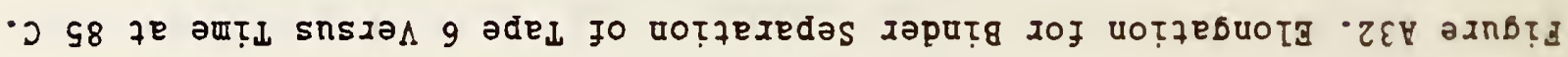

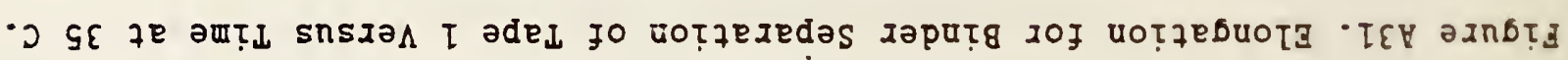

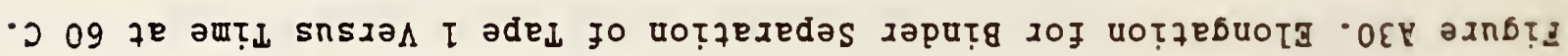

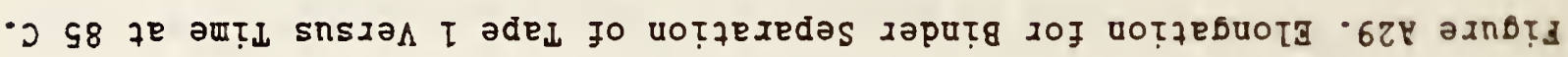

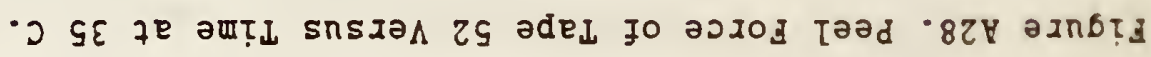

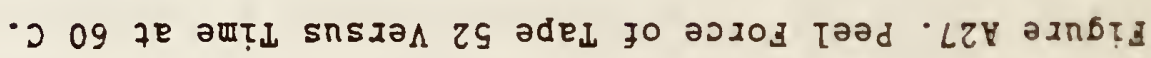

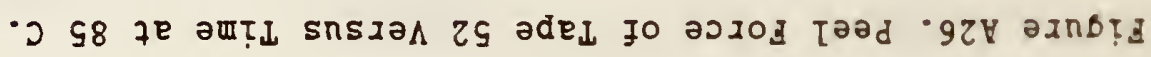


- 5 \$8 7e әயTL snsza八

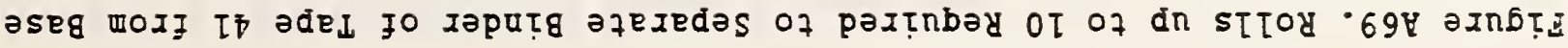

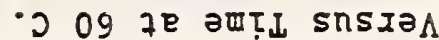

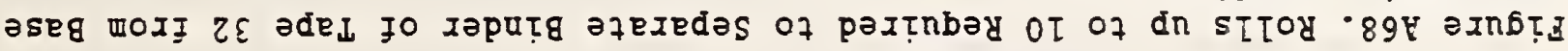

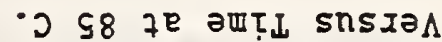

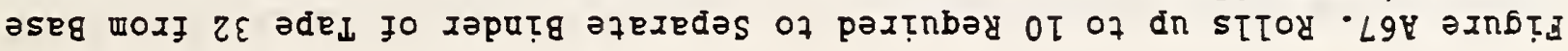

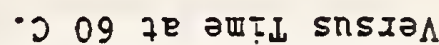

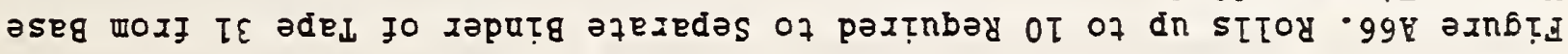

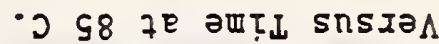

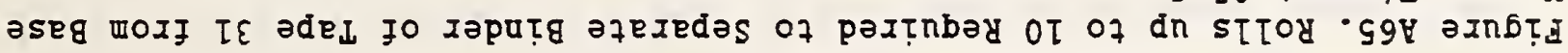

- 09 7e әயTL snszaA

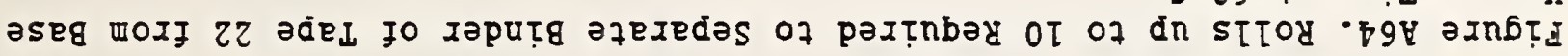

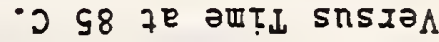

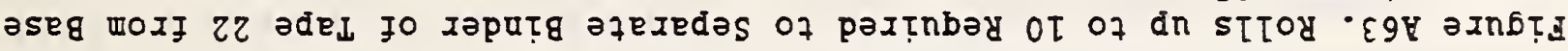

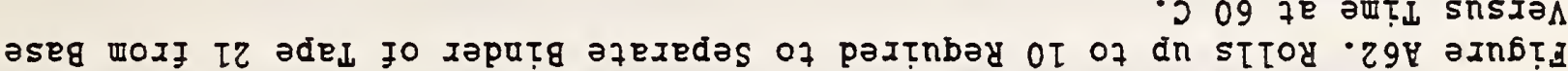

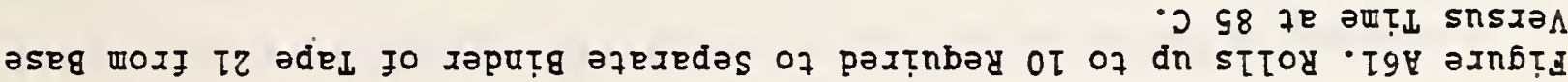

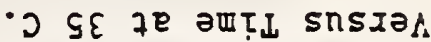

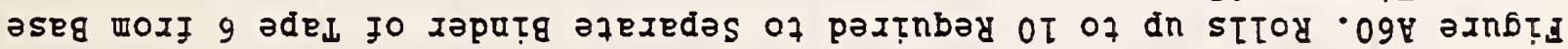

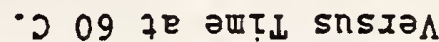

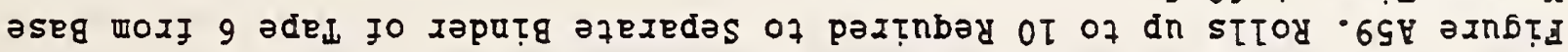

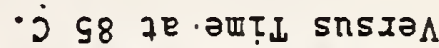

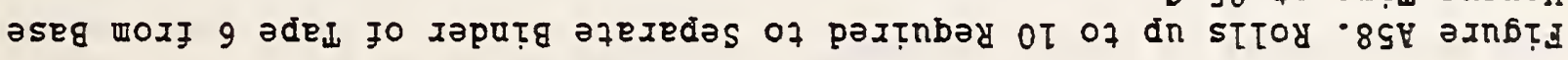

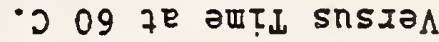

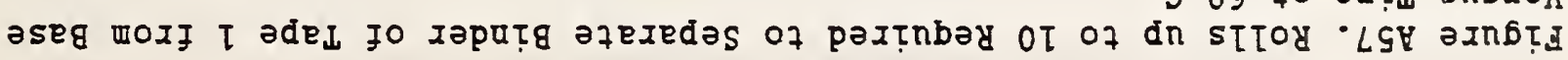

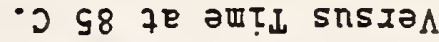

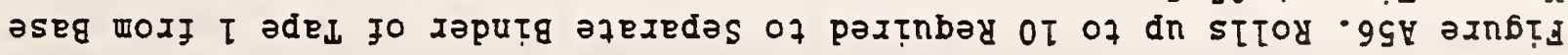

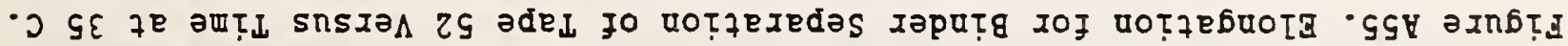

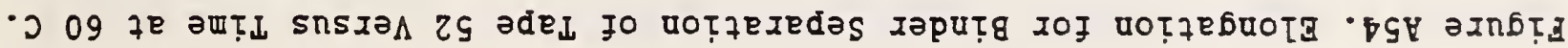

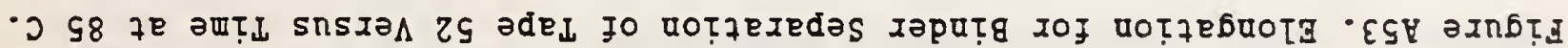

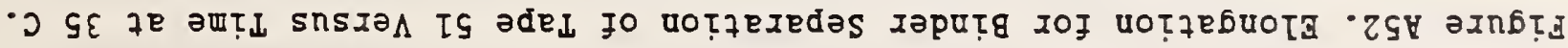




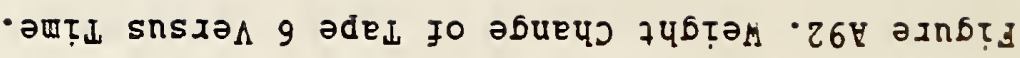

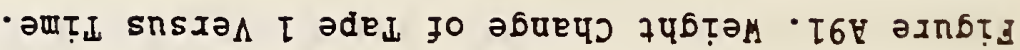

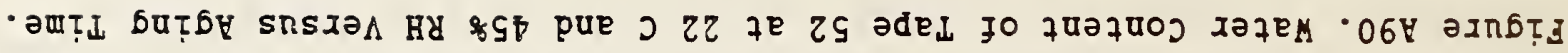

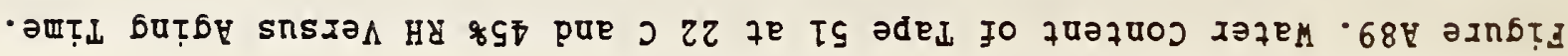

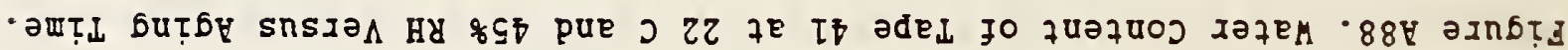

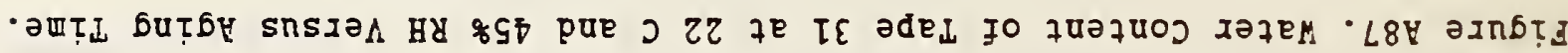

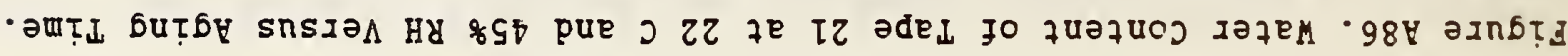

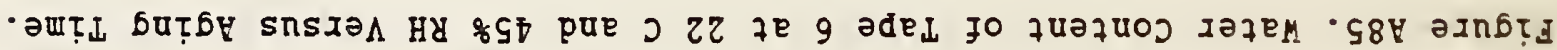

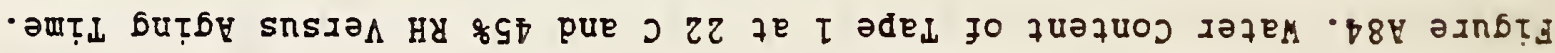

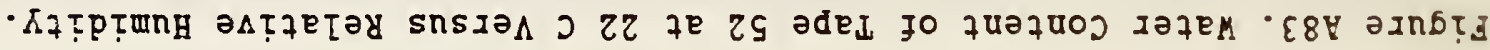

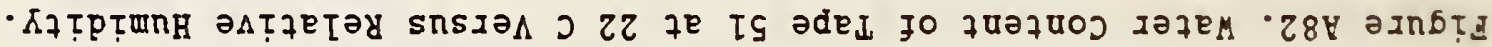

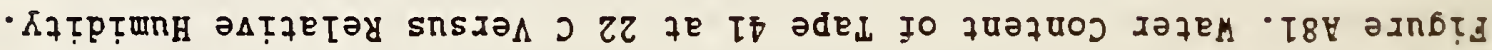

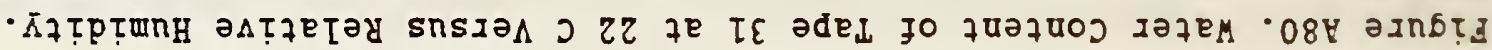

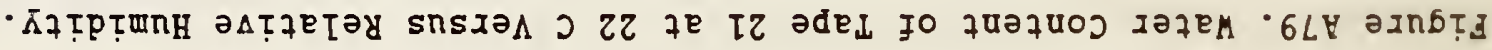

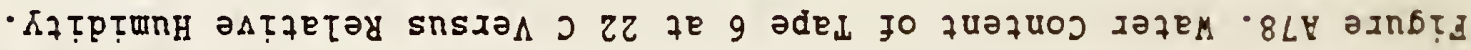

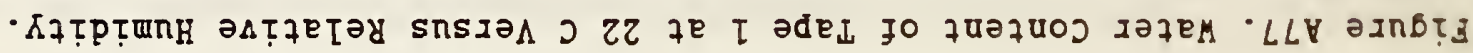
әseg

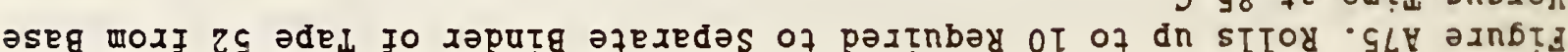

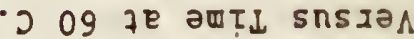

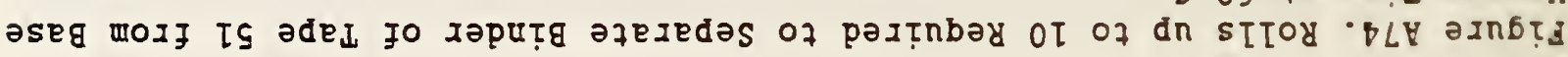

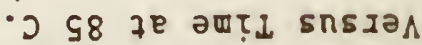

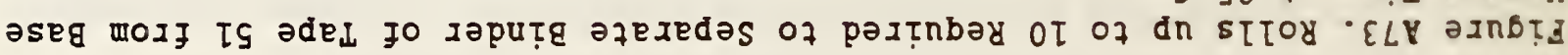
- 09 7e วயTJ snsias

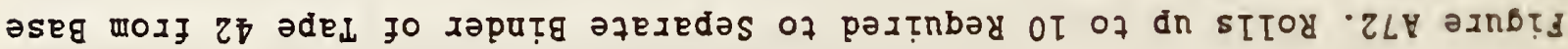

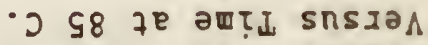

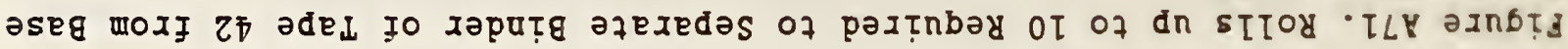

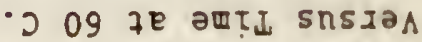

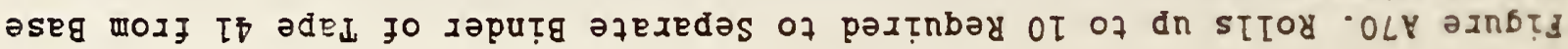




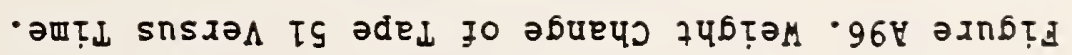

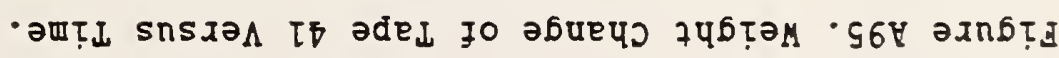

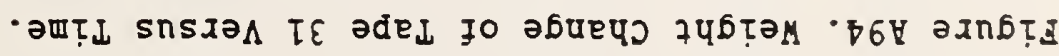

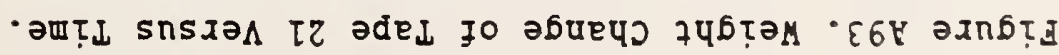



PEEL FORCE, $g$

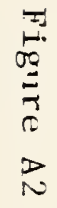

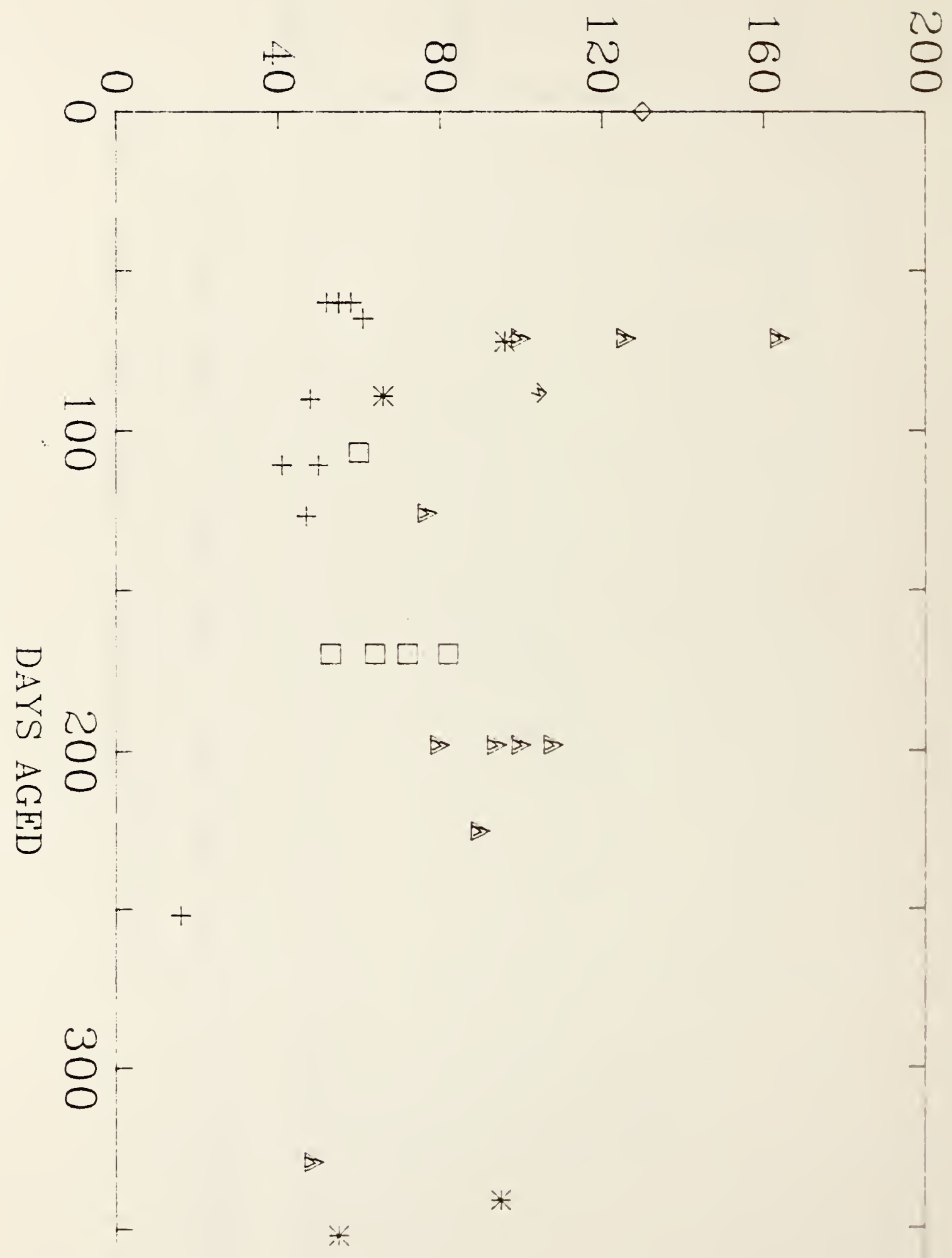

$\begin{array}{ll}\rightarrow & 0 \\ 0 & \&\end{array}$

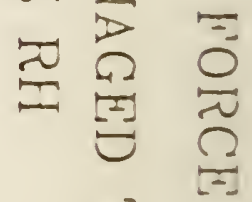

$=0$
$= \pm$
$\therefore \quad=$

$0=$

0

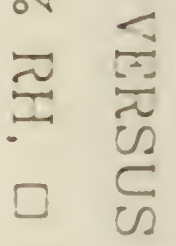

oै $=$
०ै

$=$

or 0

o

正

$\because$

$N$

or

포

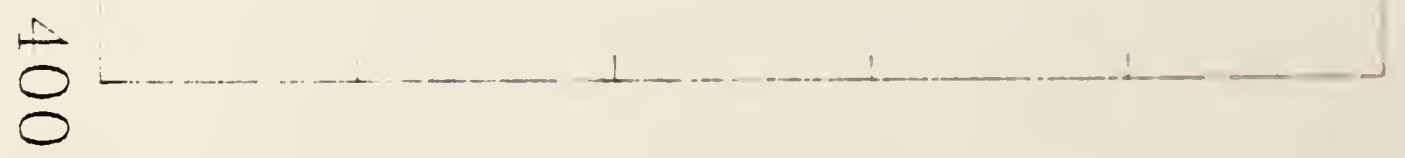


PEEL FORCE, g

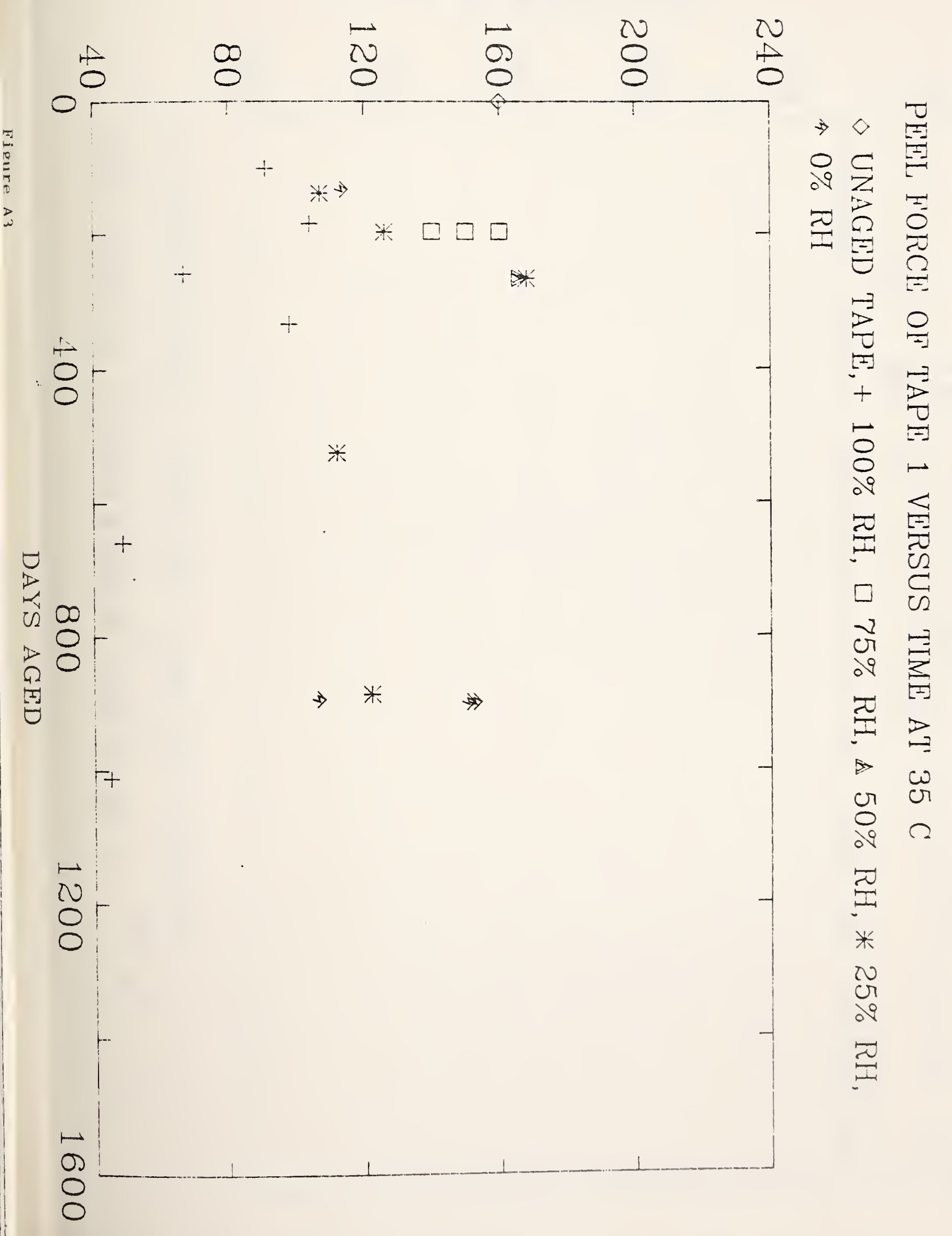


PEEL FORCE, $g$

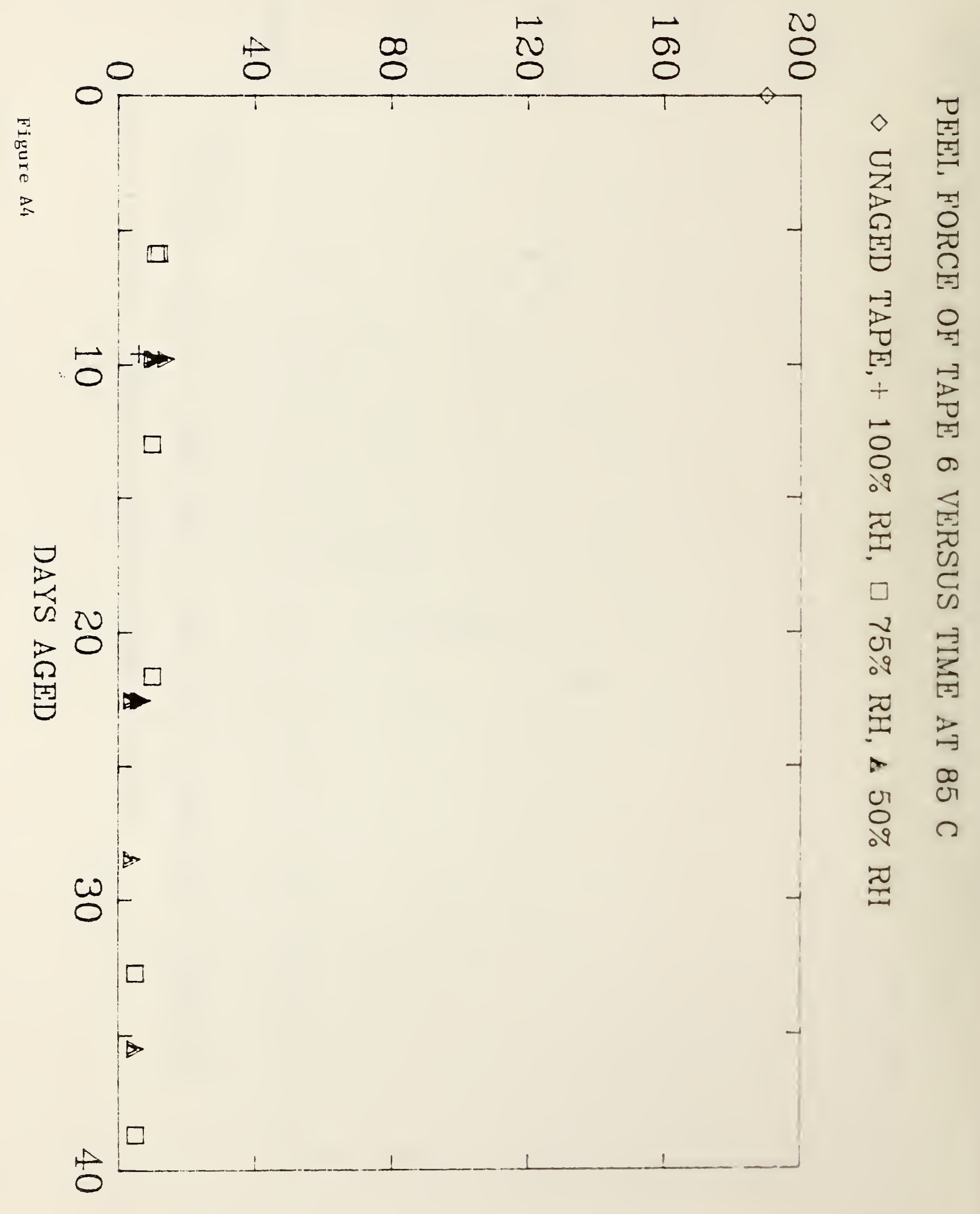




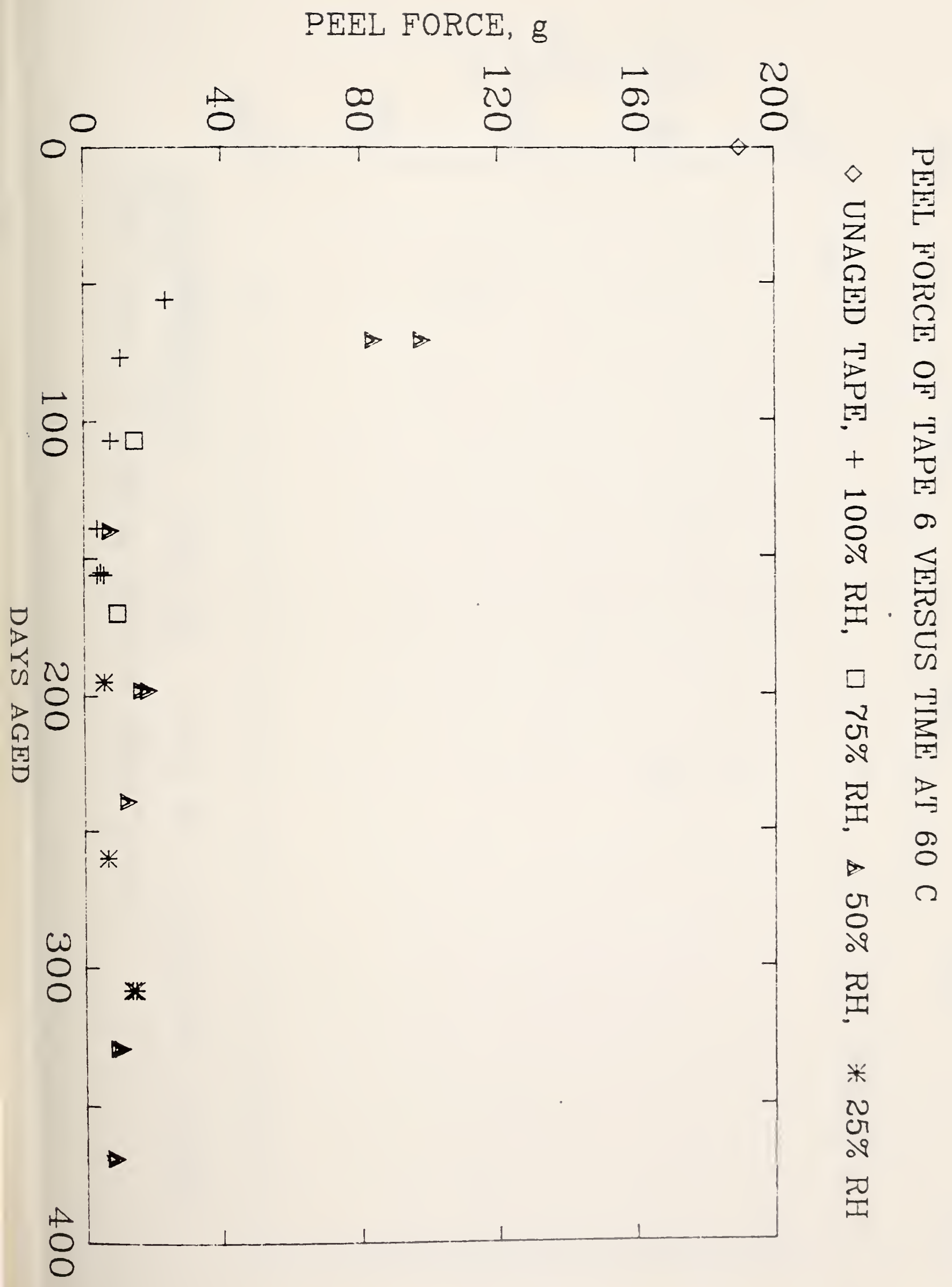




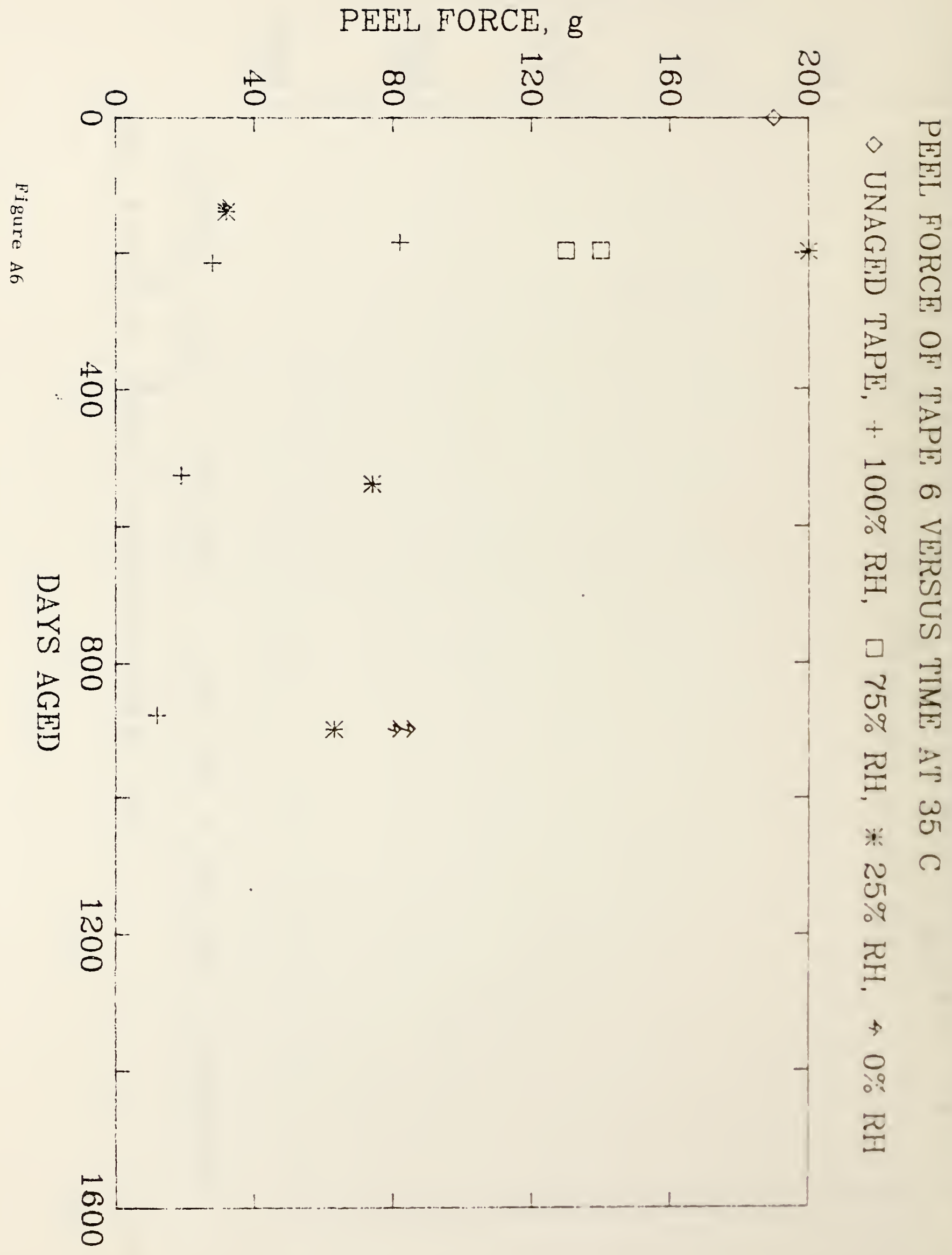


PEEL FORCE, $g$

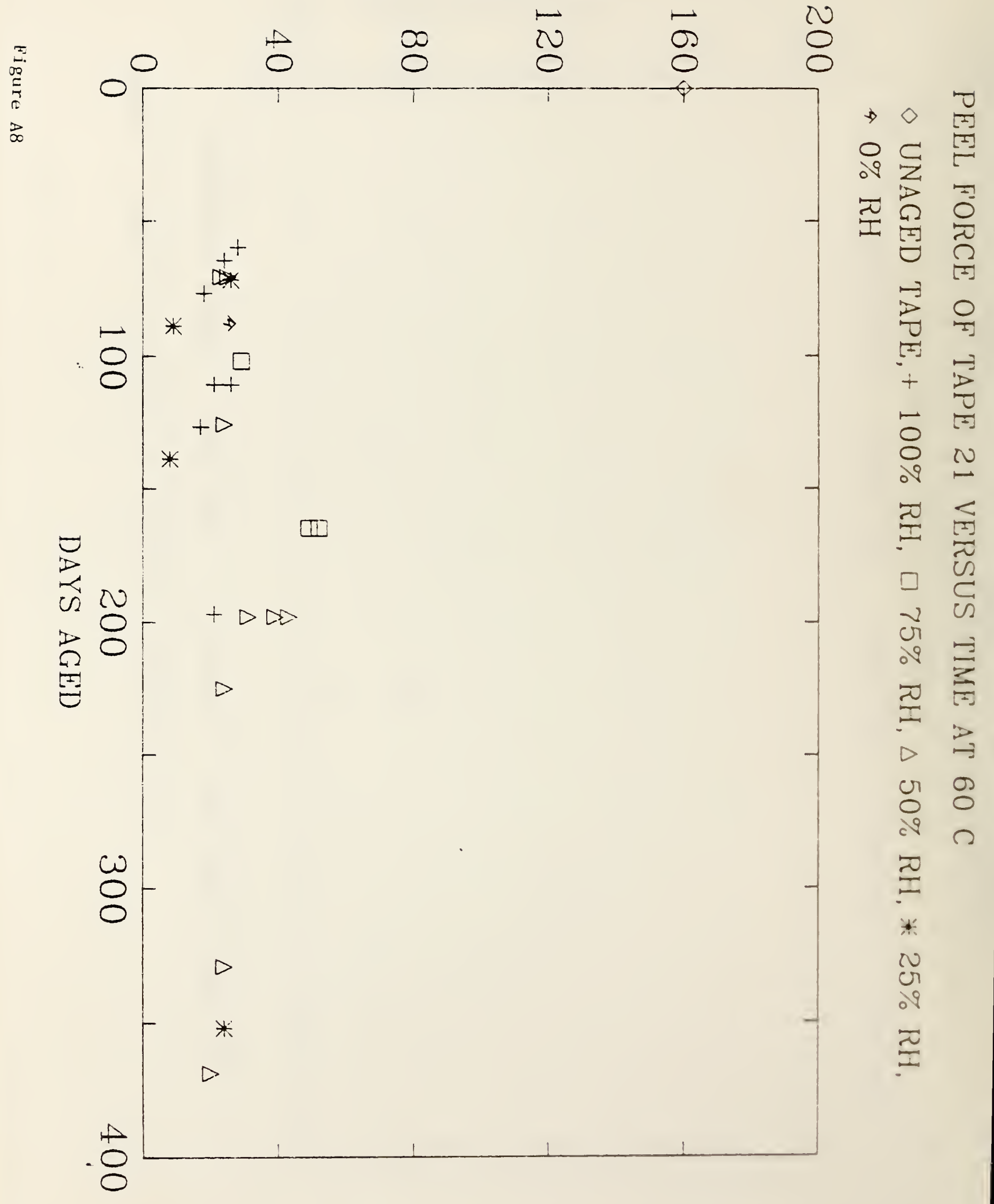


PEEL FORCE, $g$

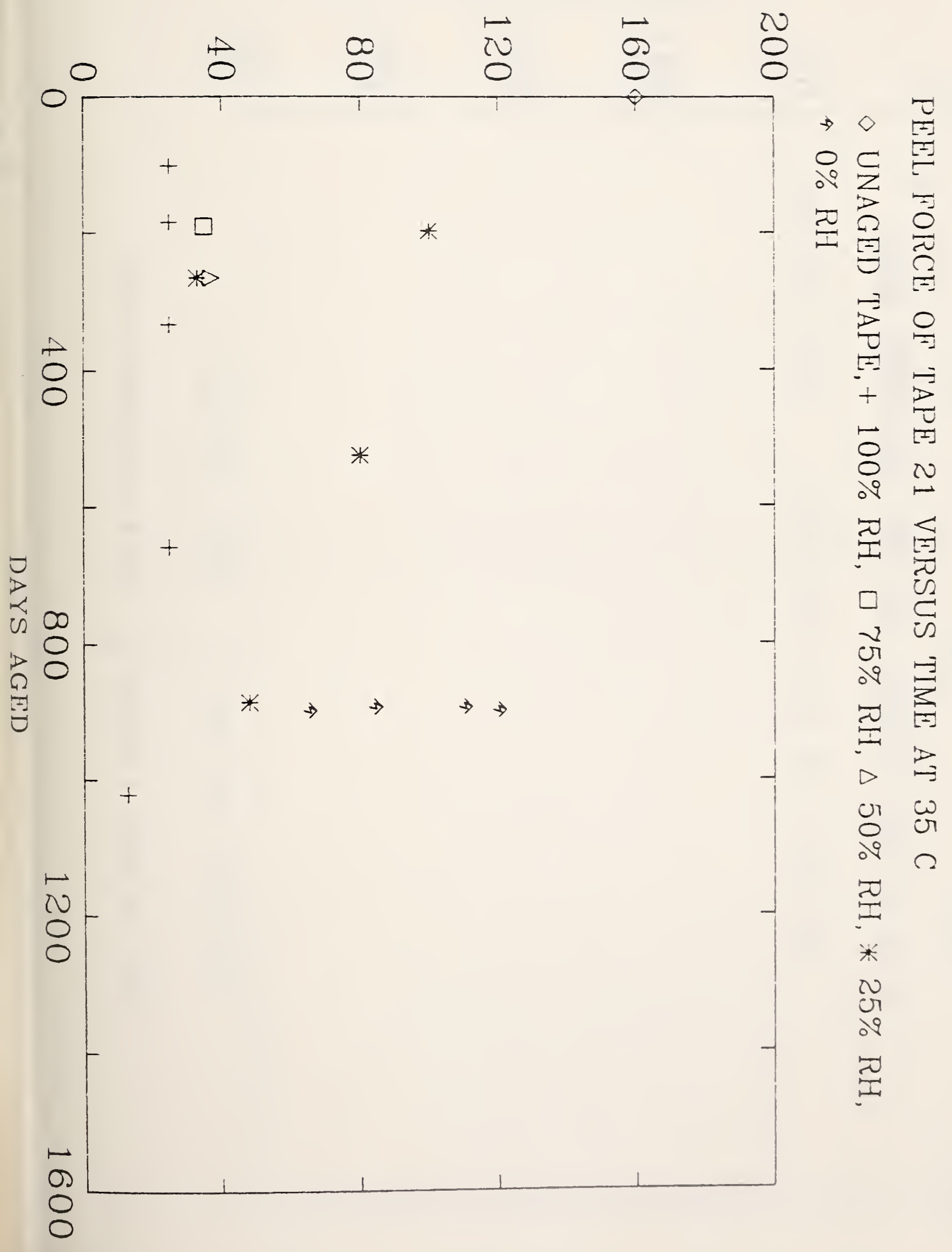


PEEL FORCE, $g$

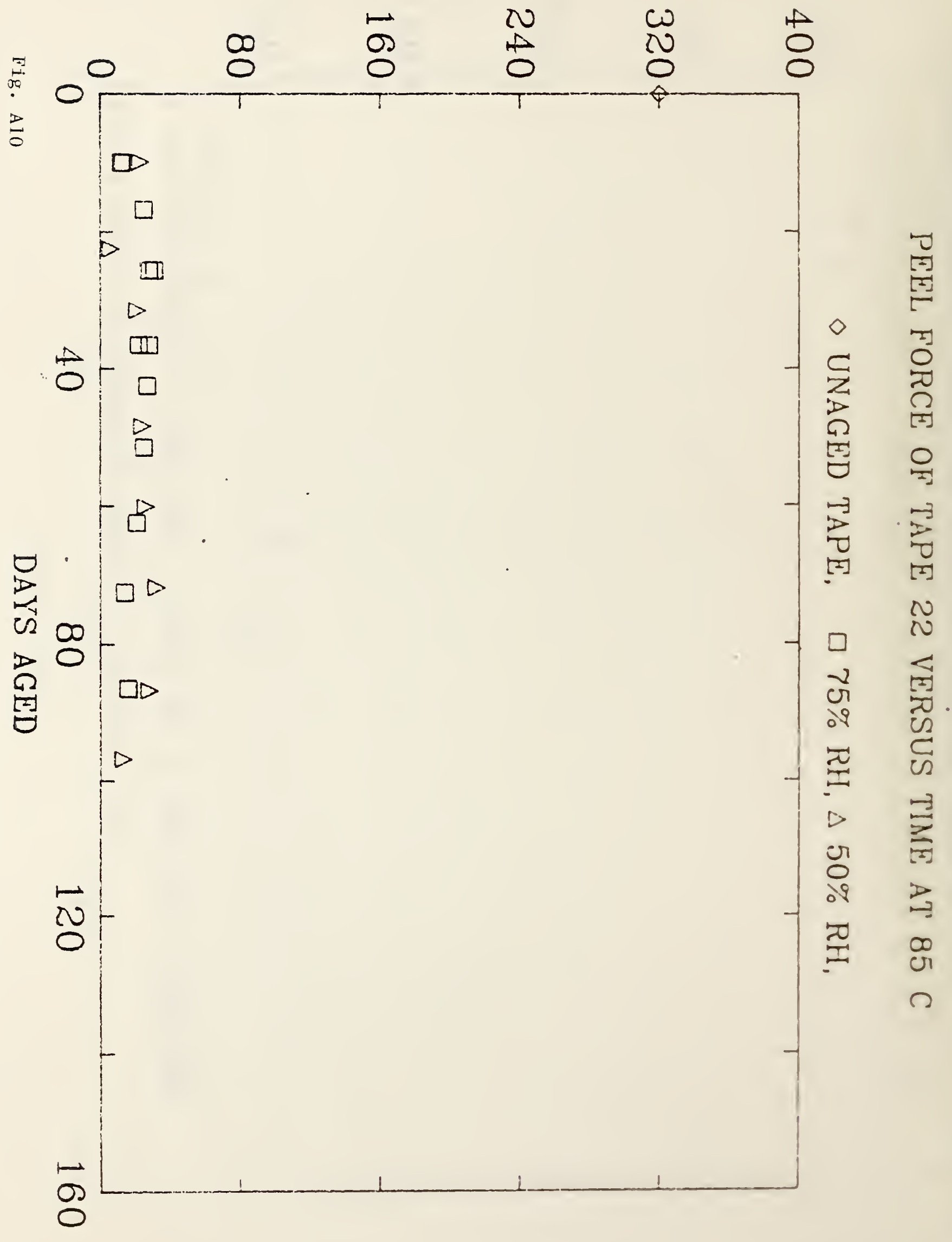


PEEL FORCE, g

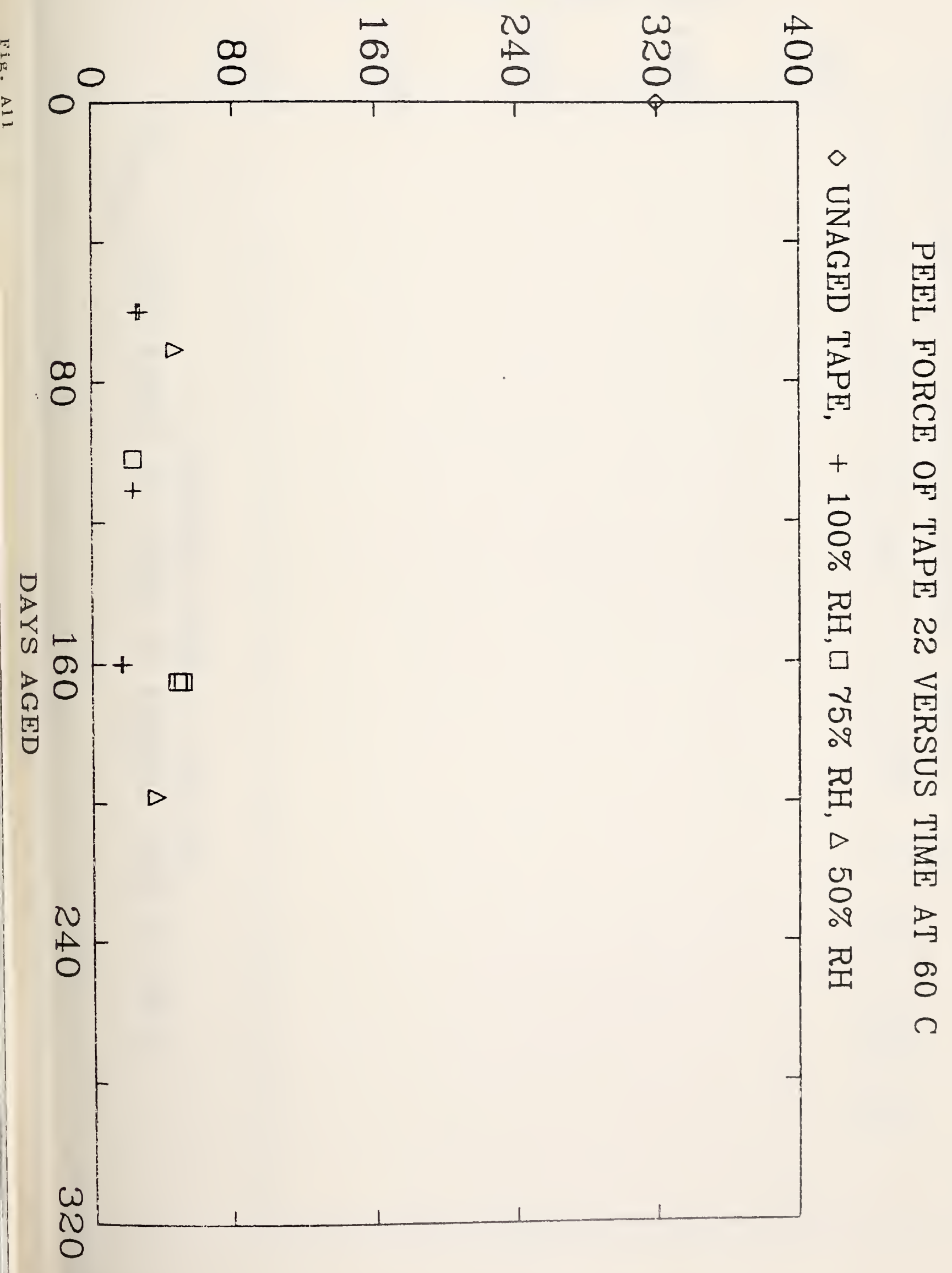


PEEL FORCE, $g$

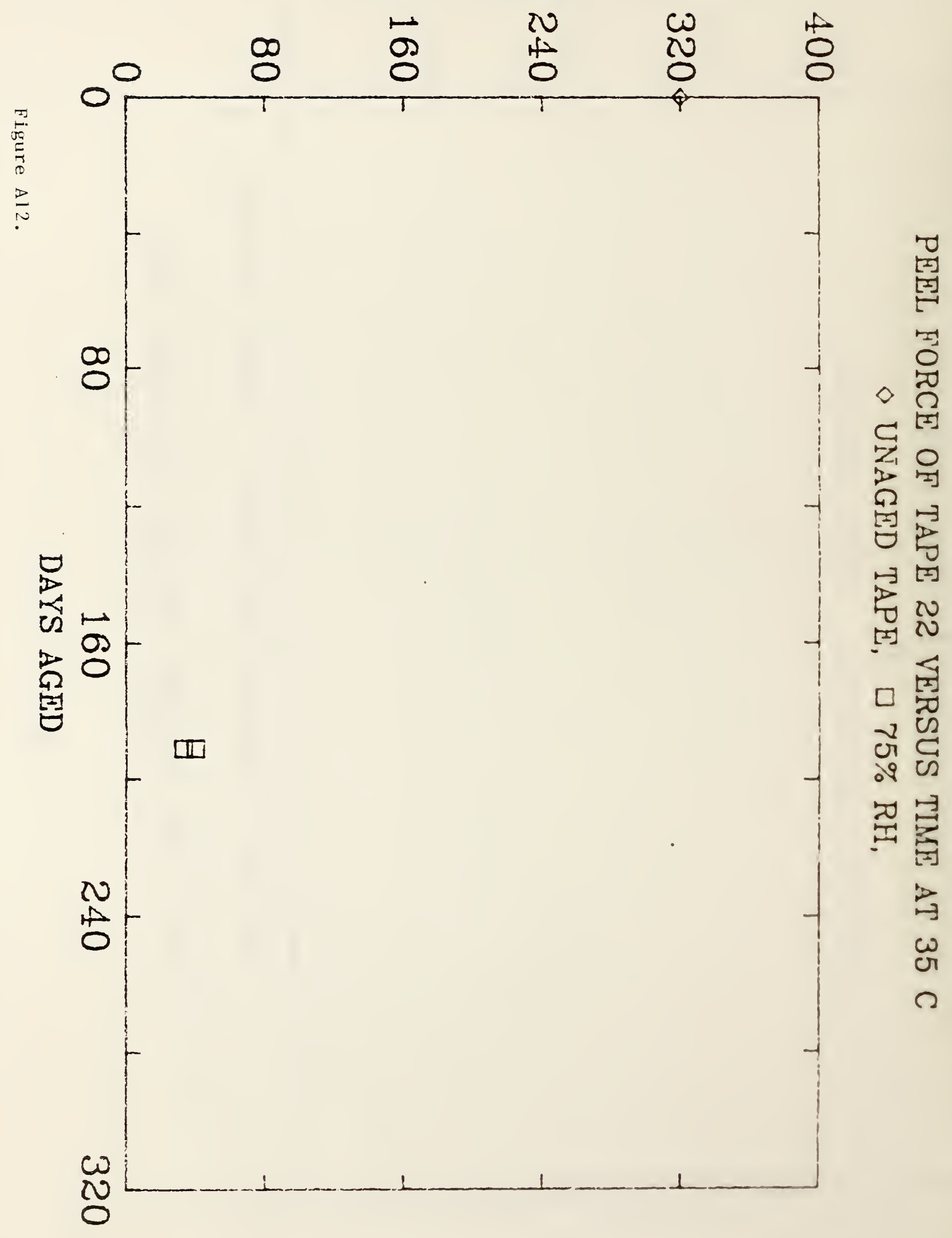


PEEL FORCE, $g$

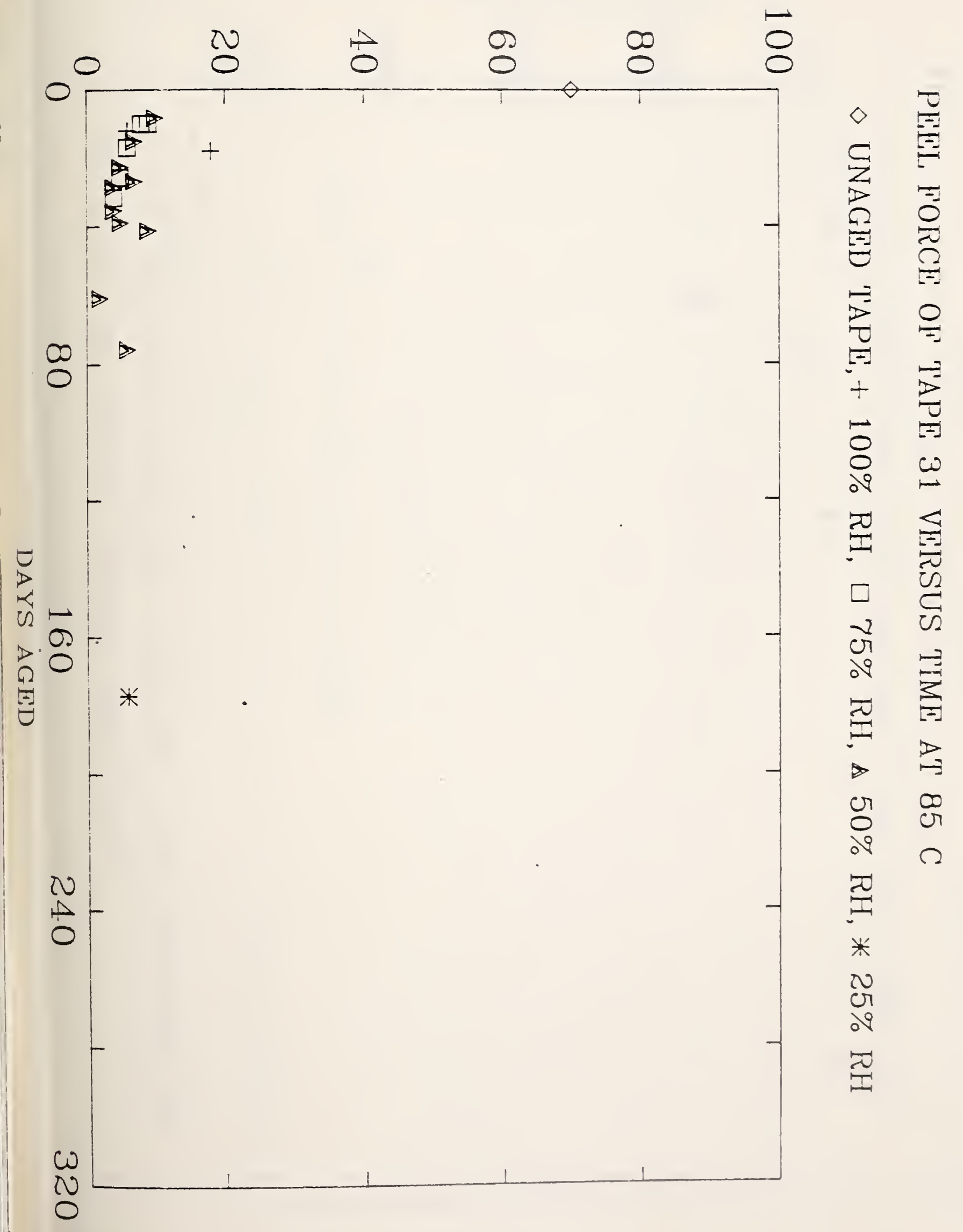


PEEL FORCE, $g$

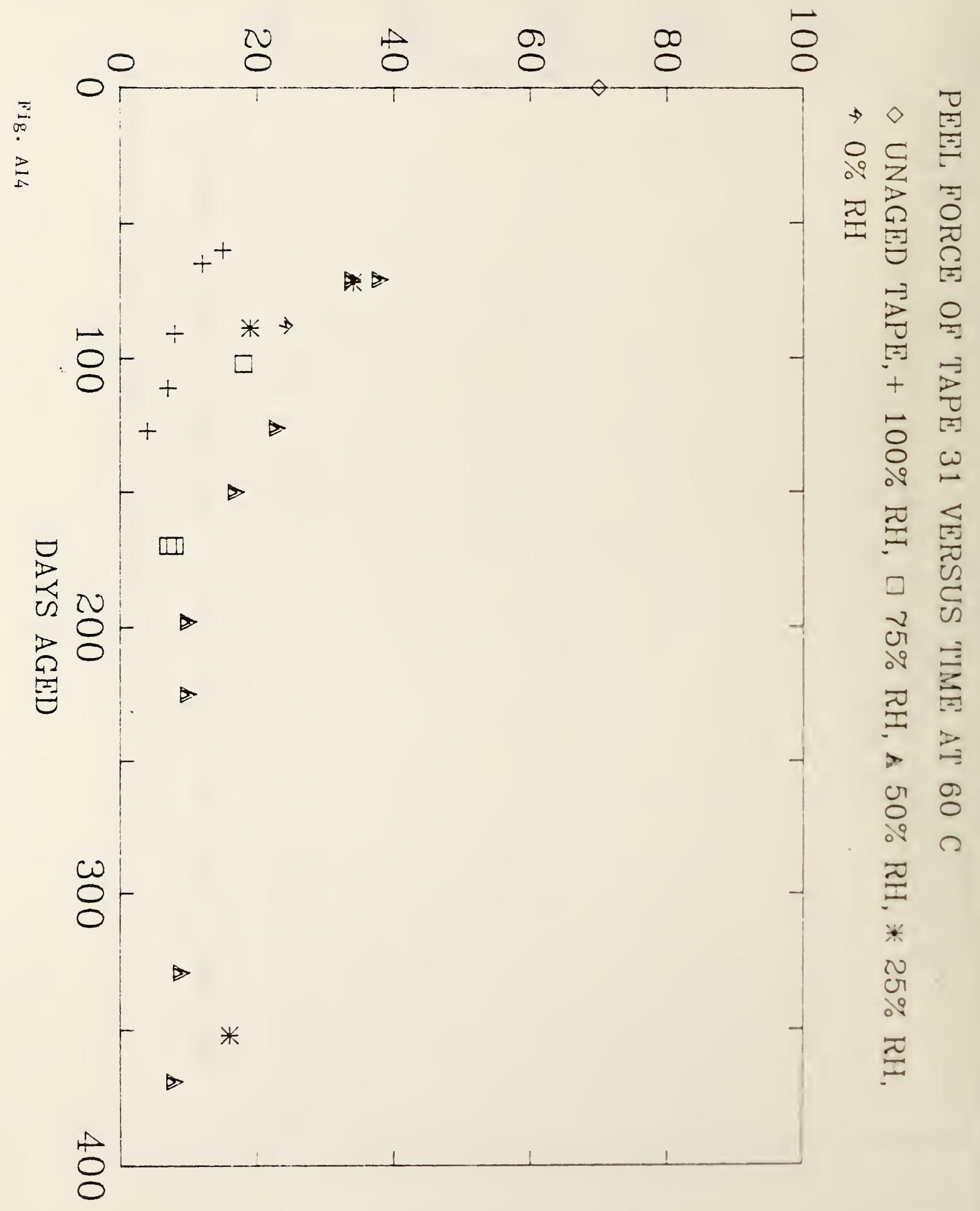




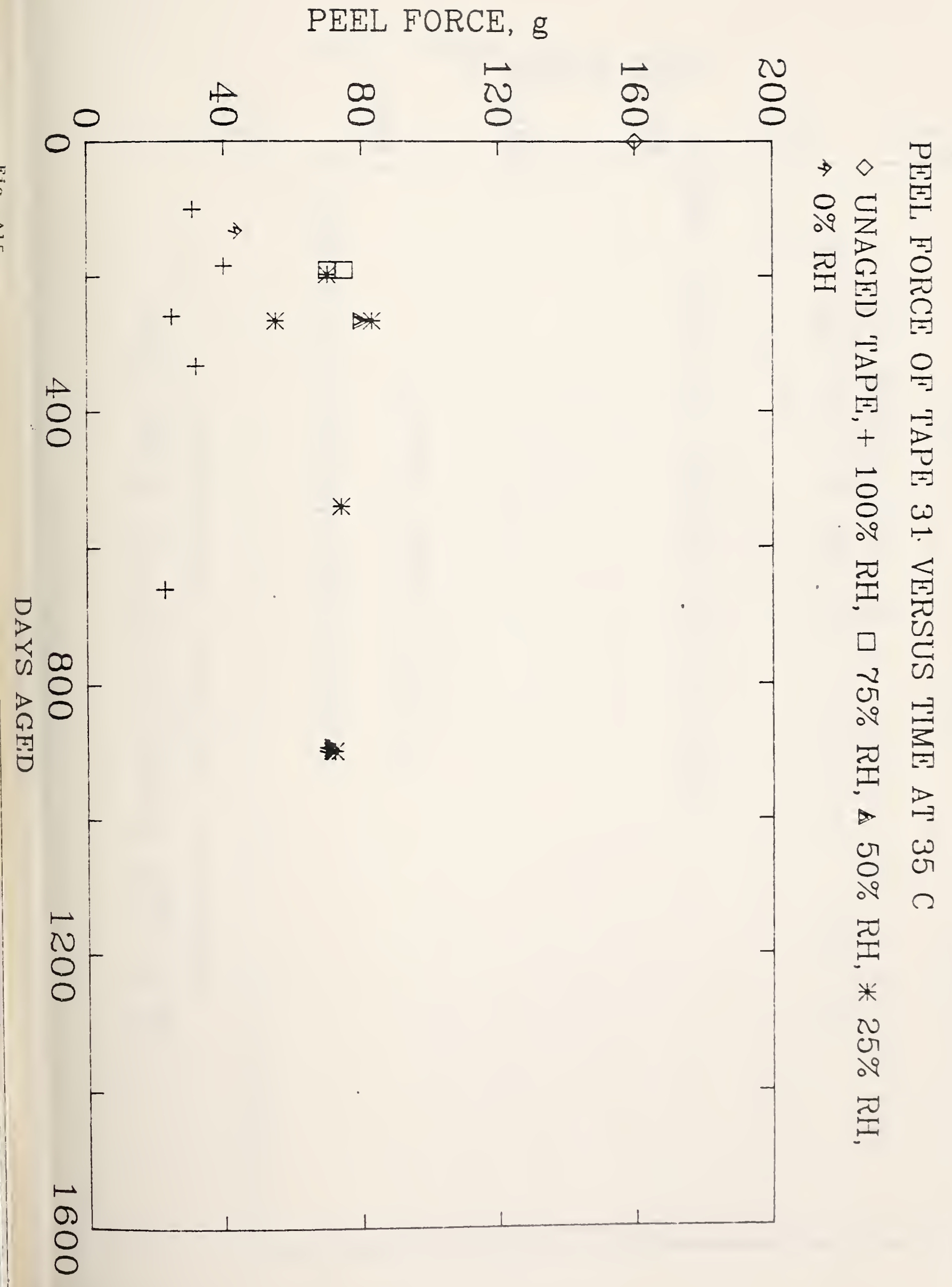


PEEL FORCE, g

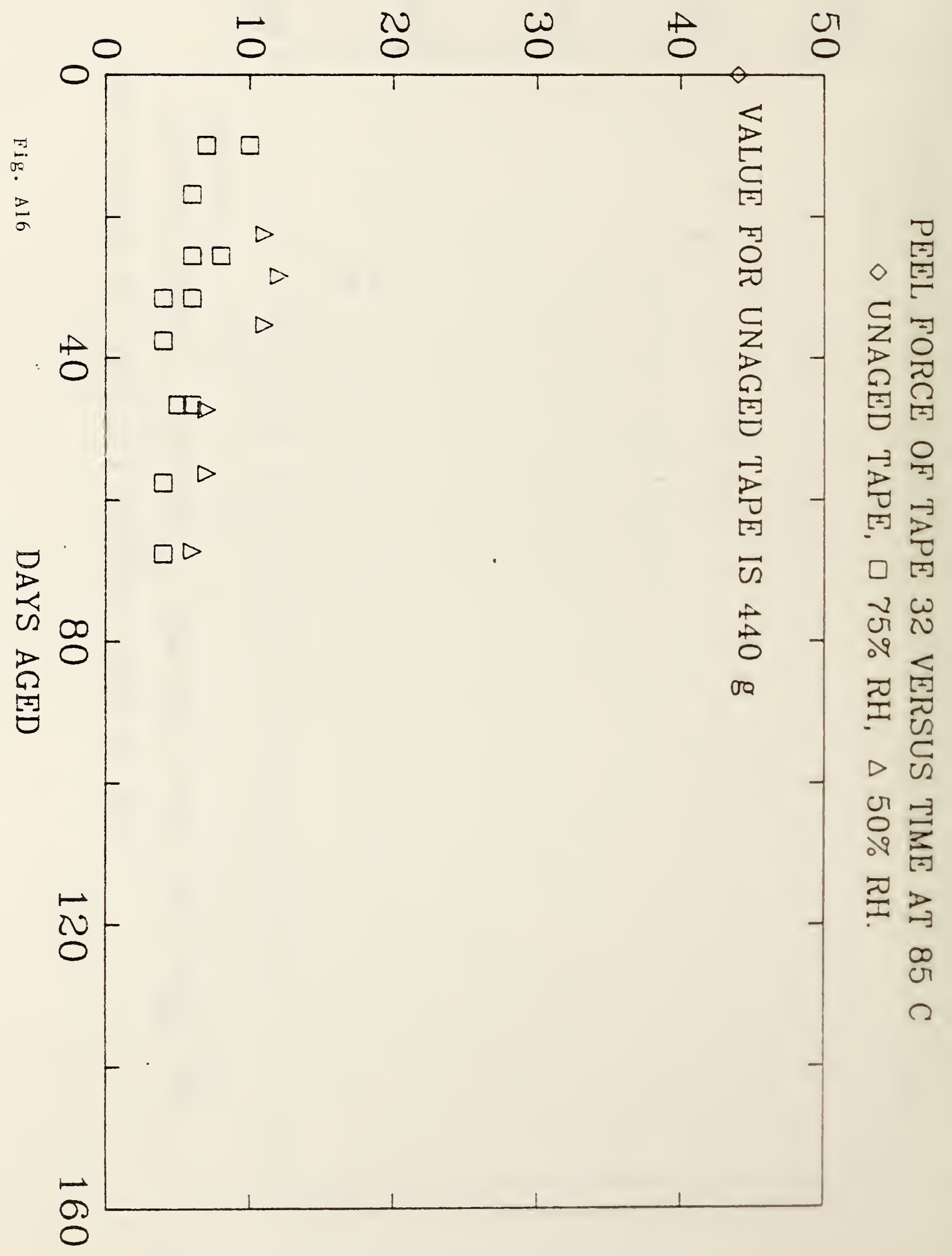




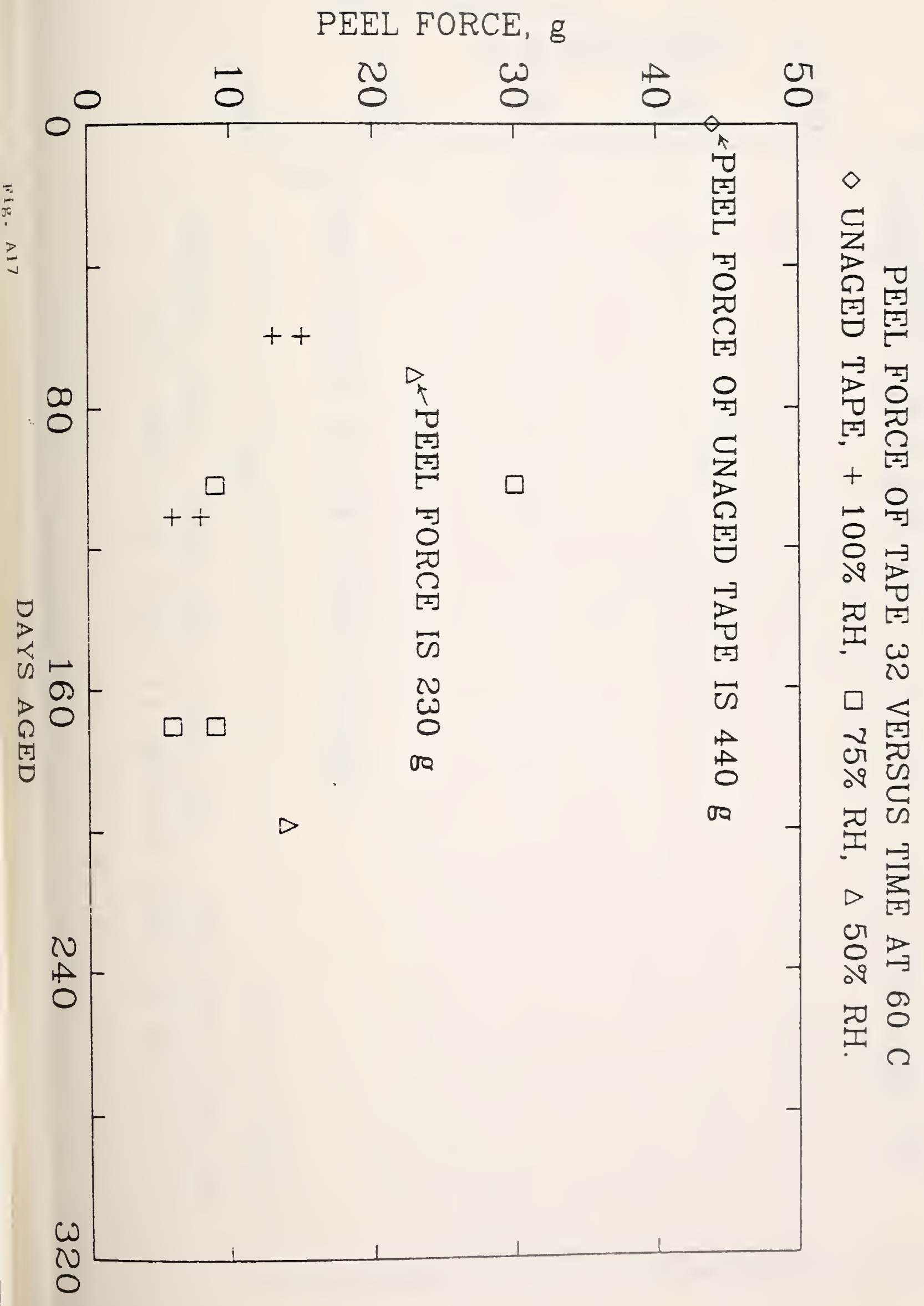


PEEL FORCE, $g$

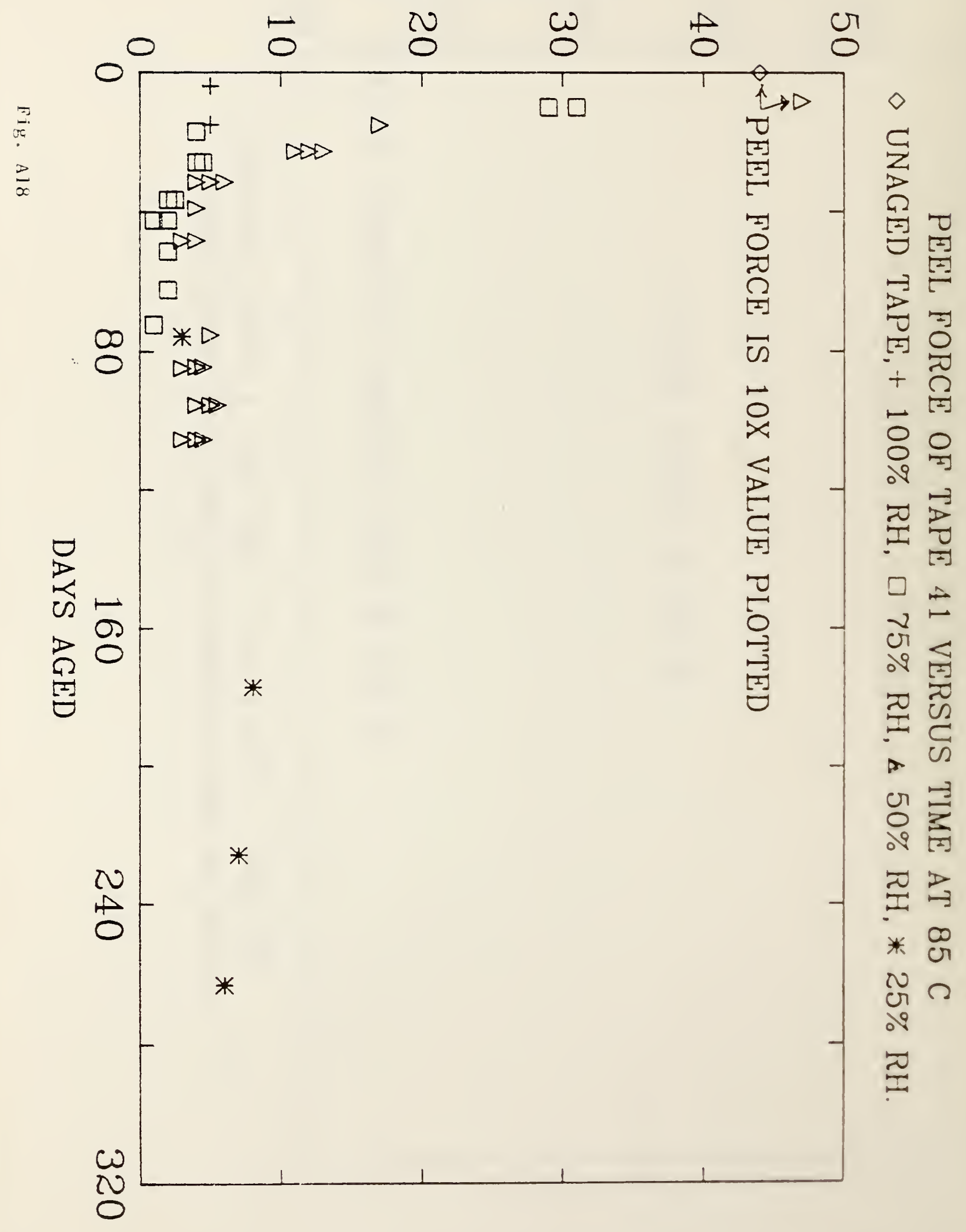




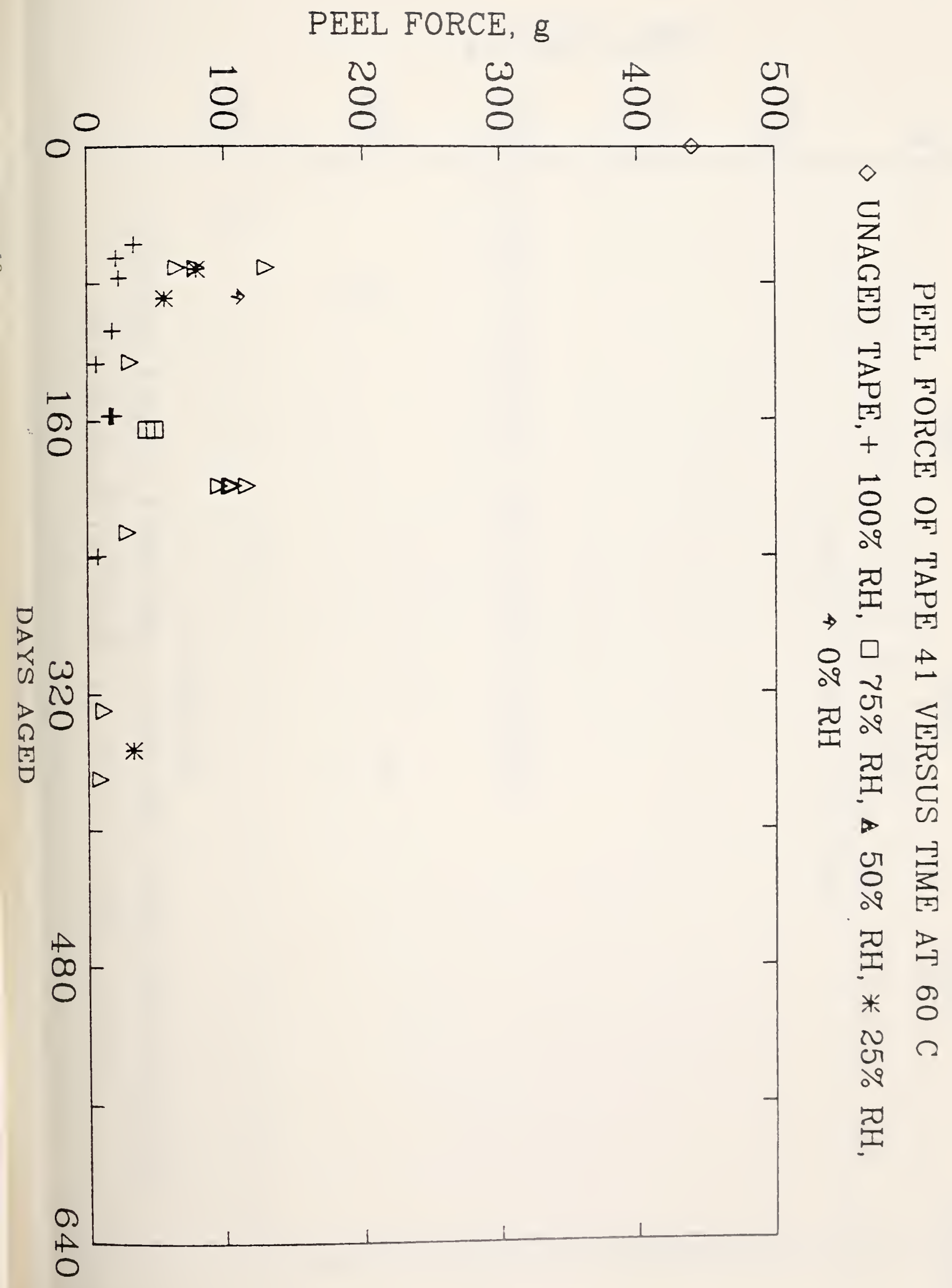


PEEL FORCE, $g$

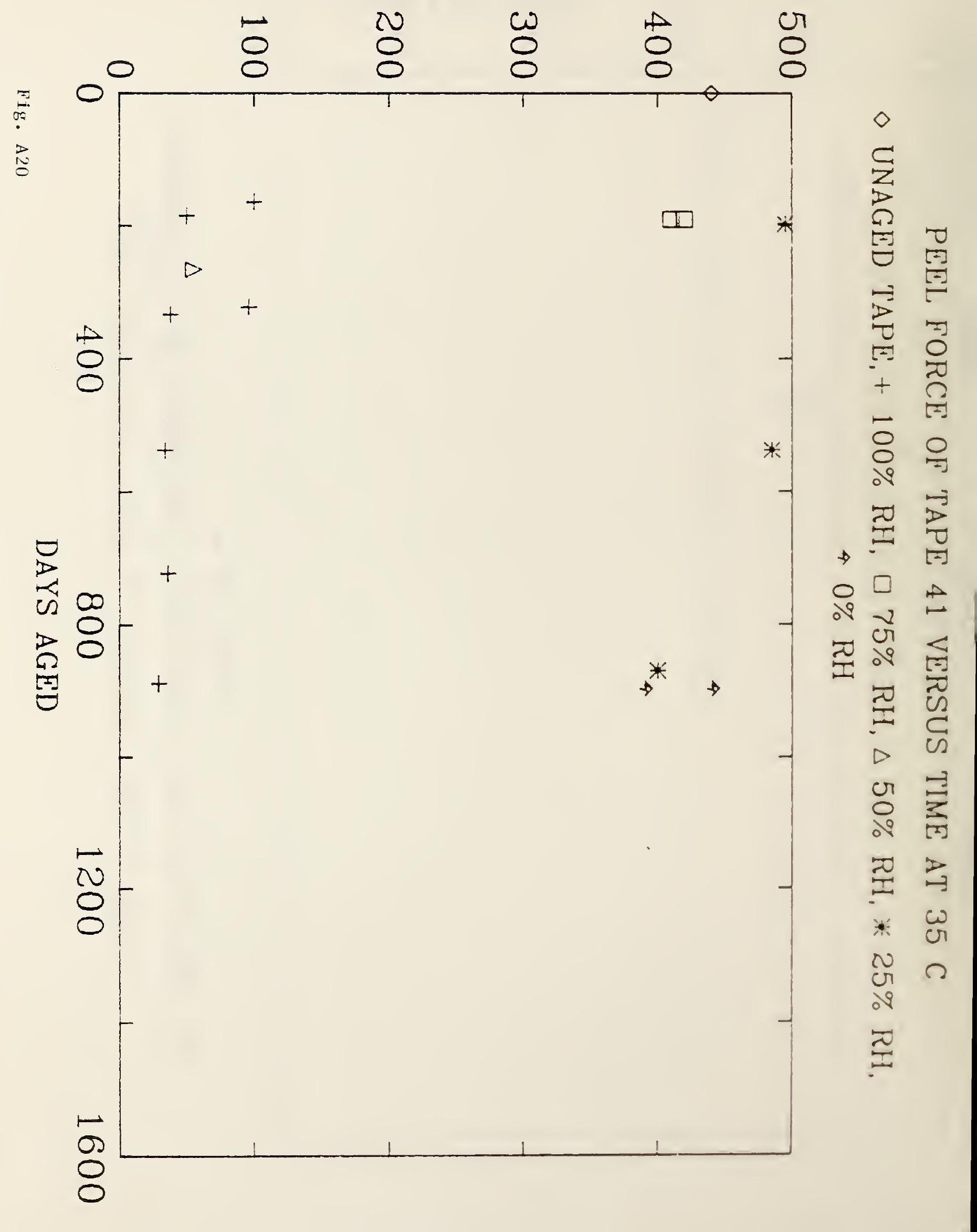


PEEL FORCE, g

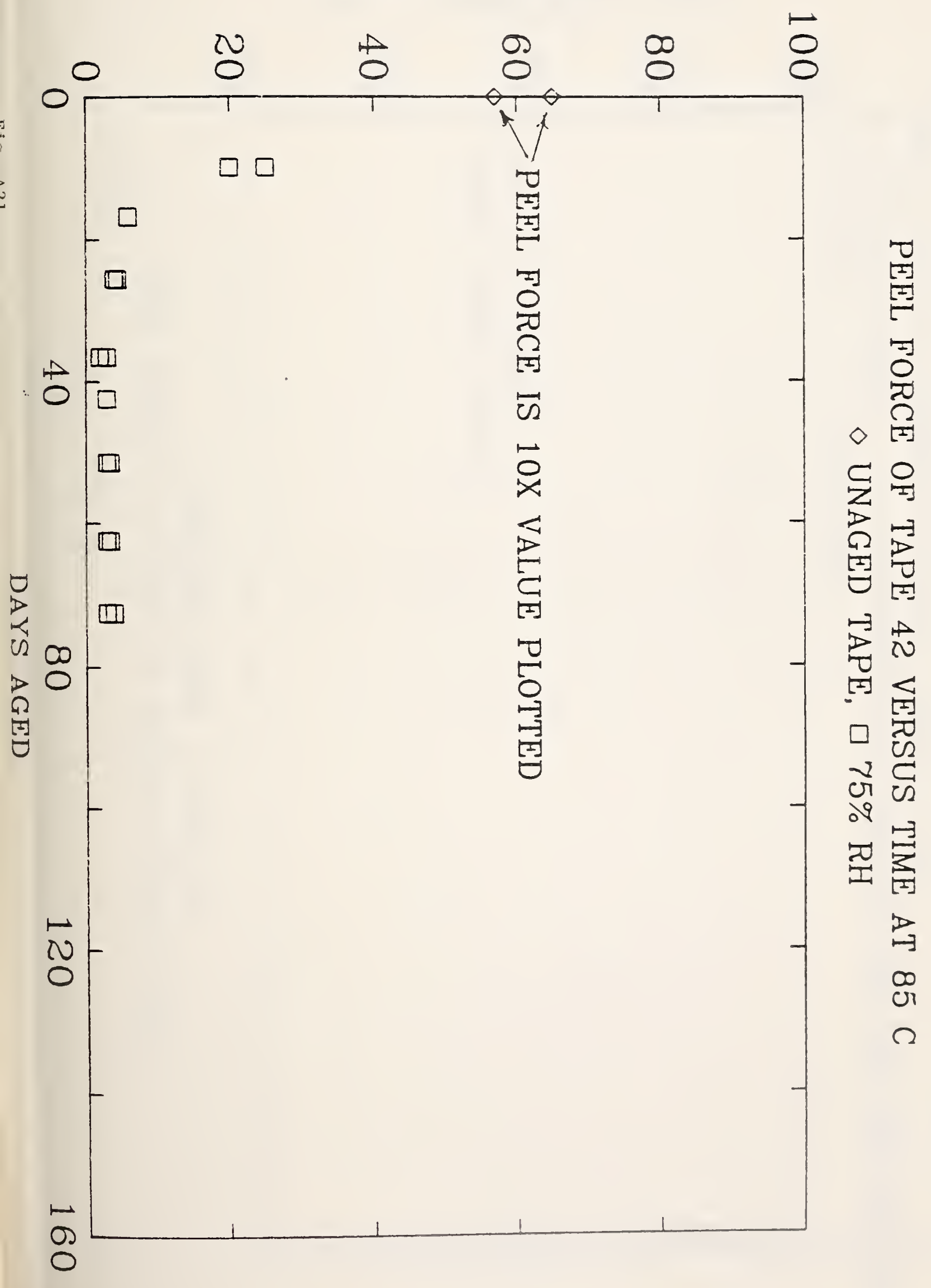


PEEL FORCE, g

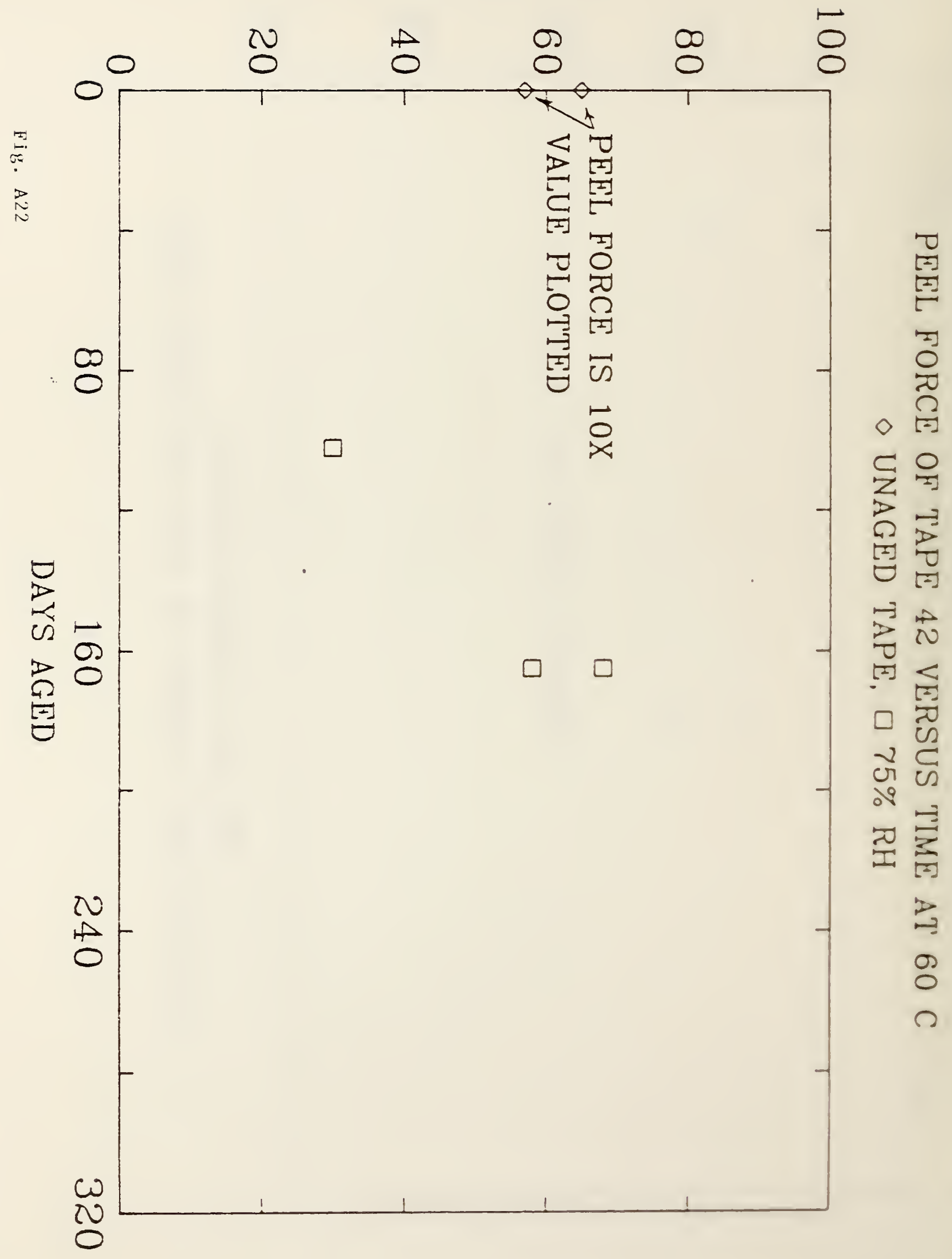


PEEI FORCE, $\mathrm{g}$

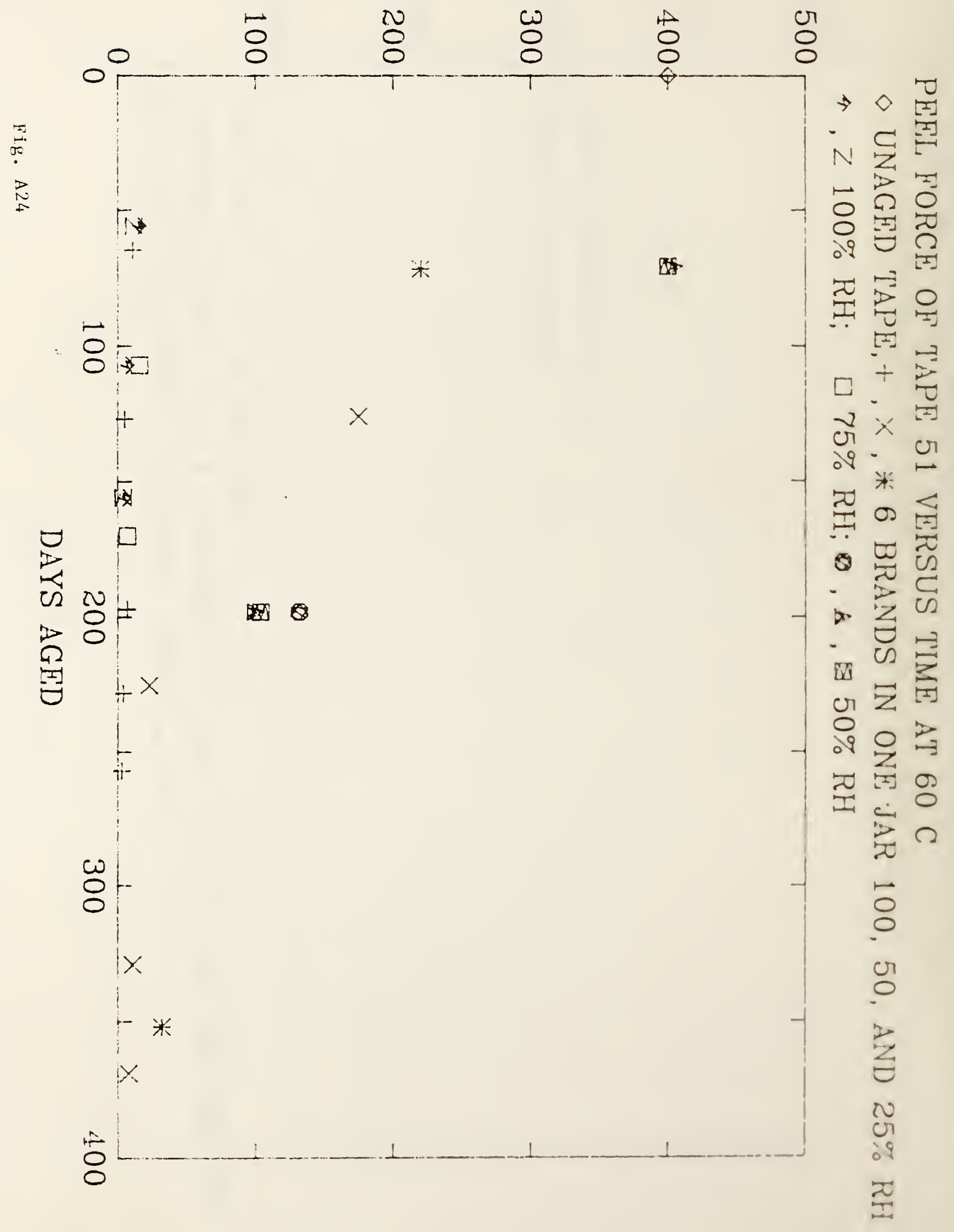




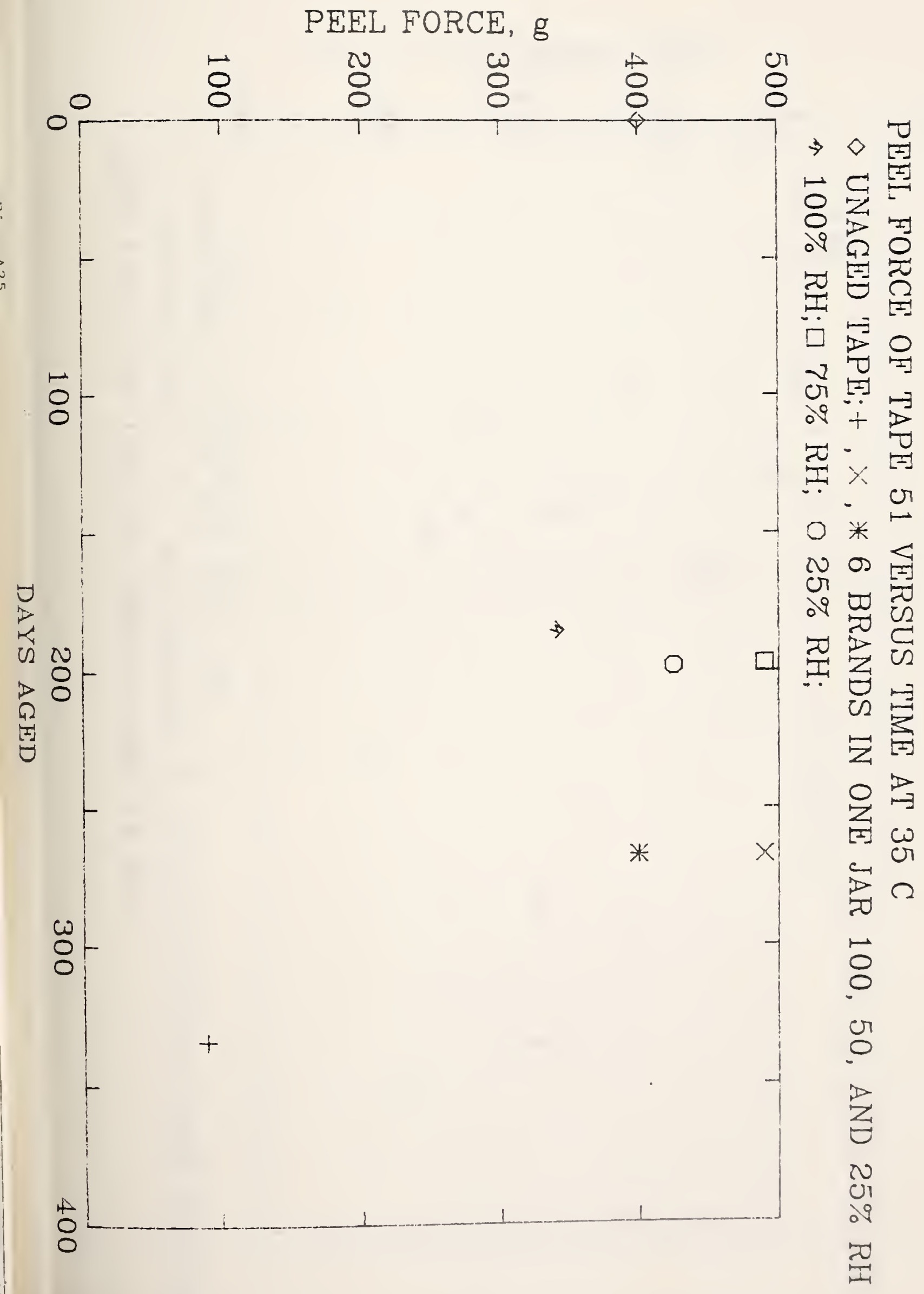


PEEL FORCE, g

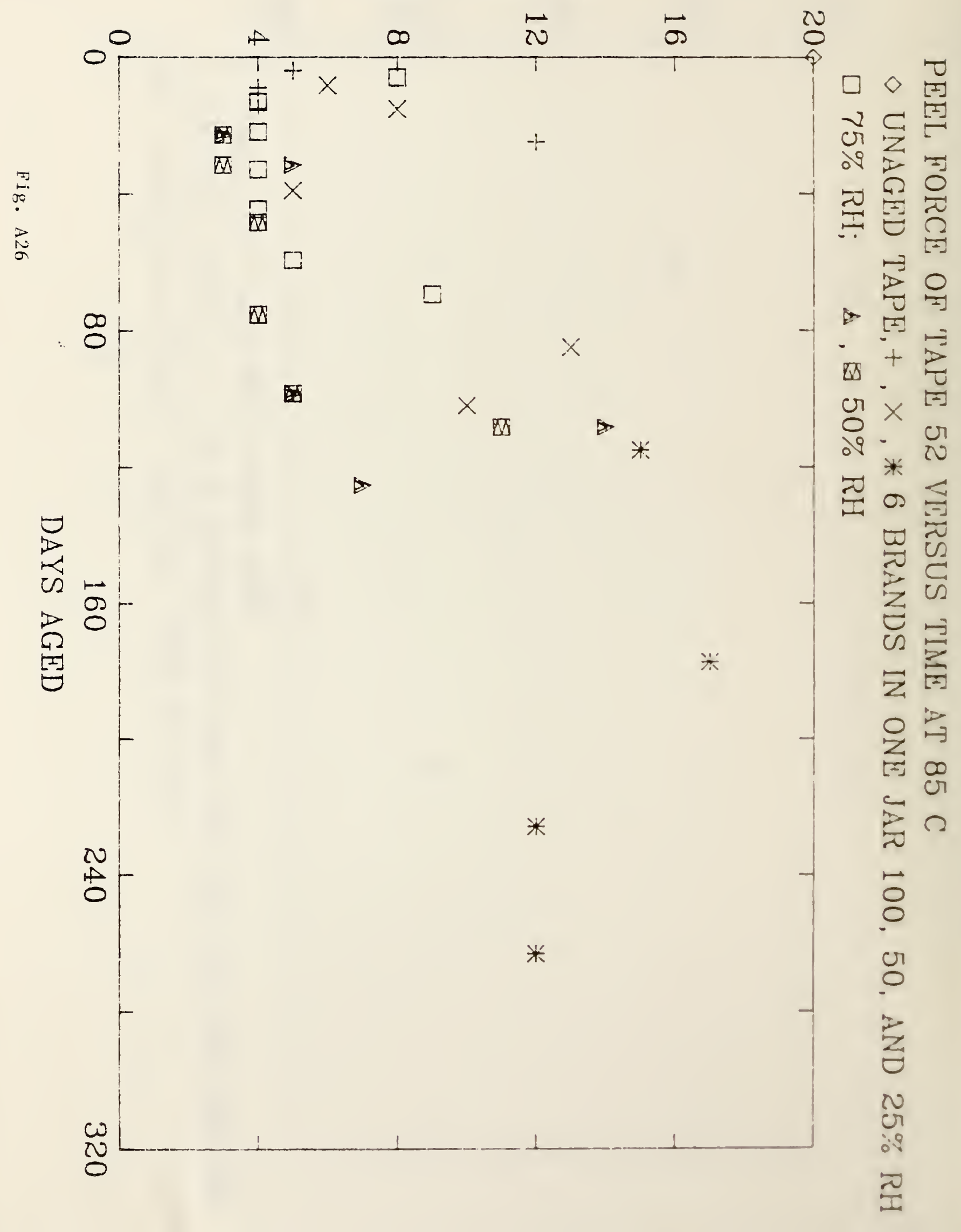




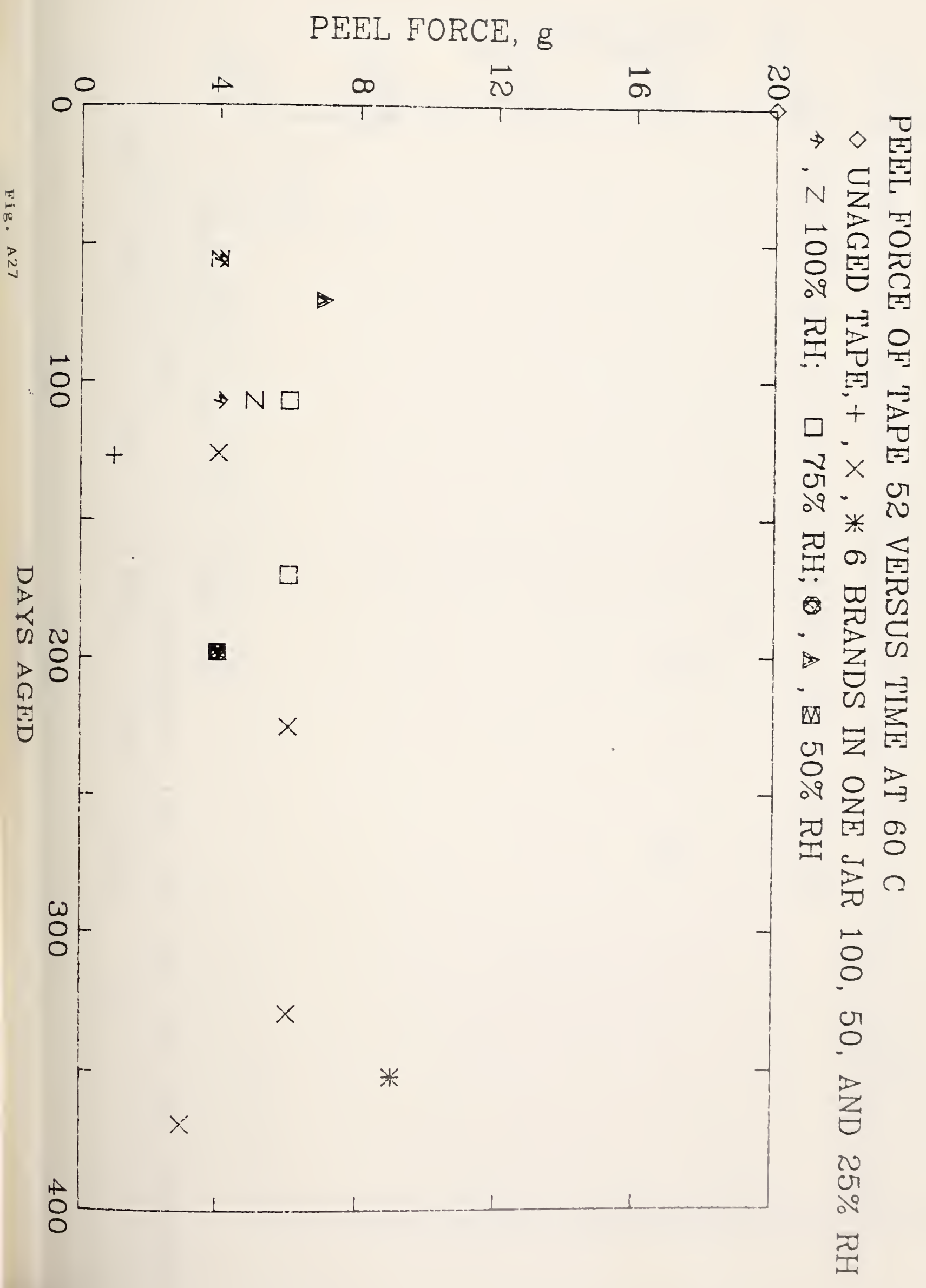


PEEL FORCE, $g$

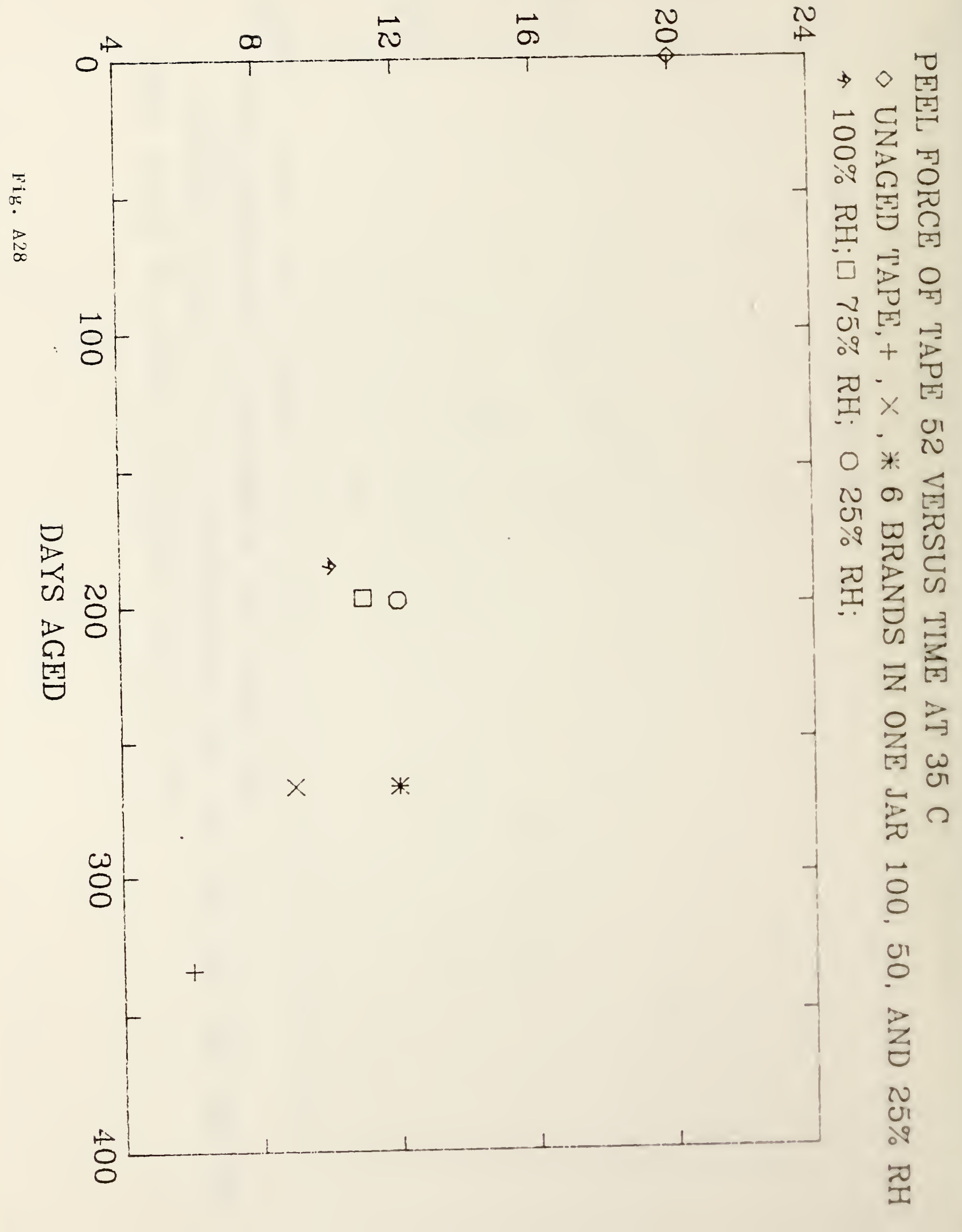




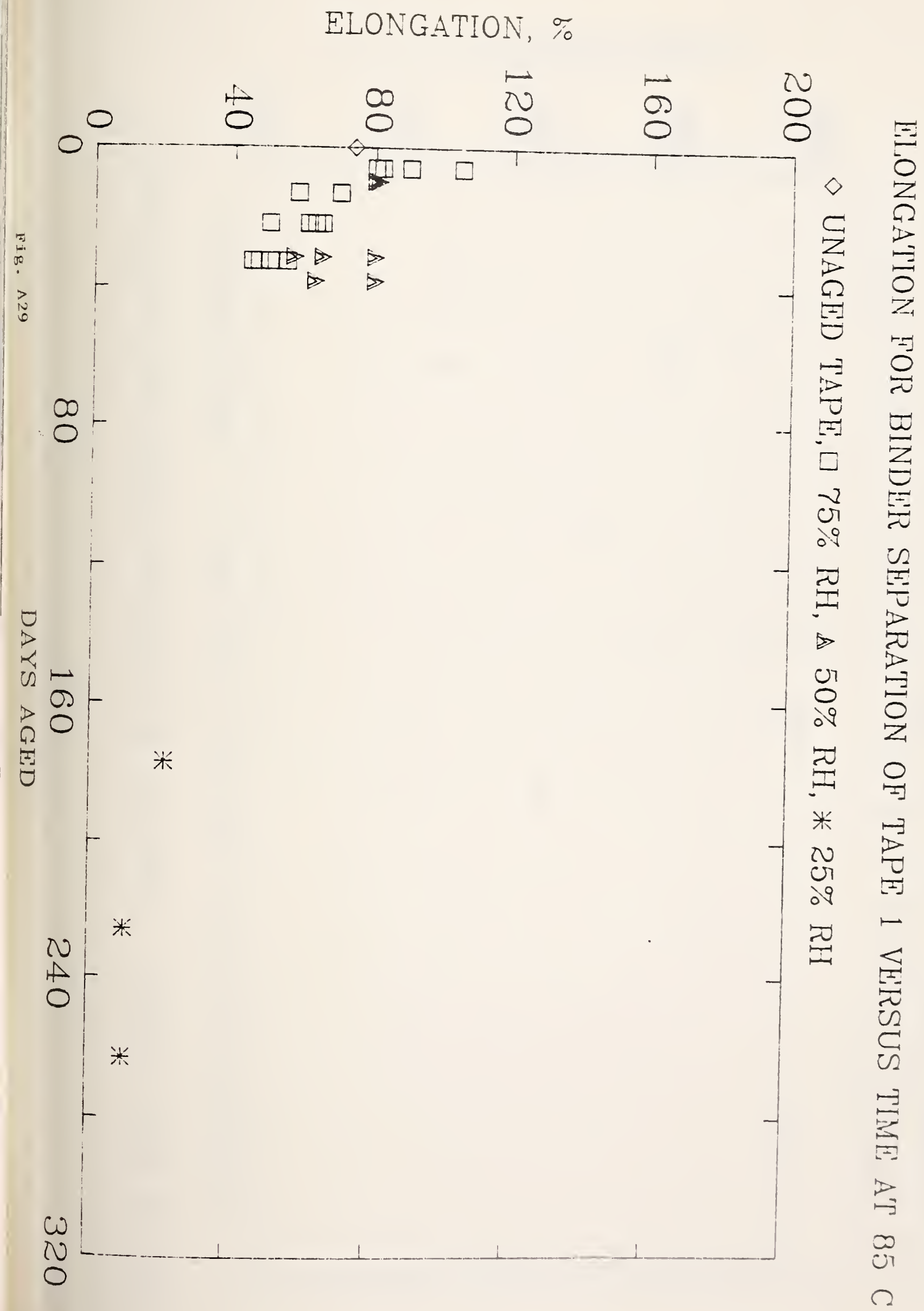


ELONGATION, \%

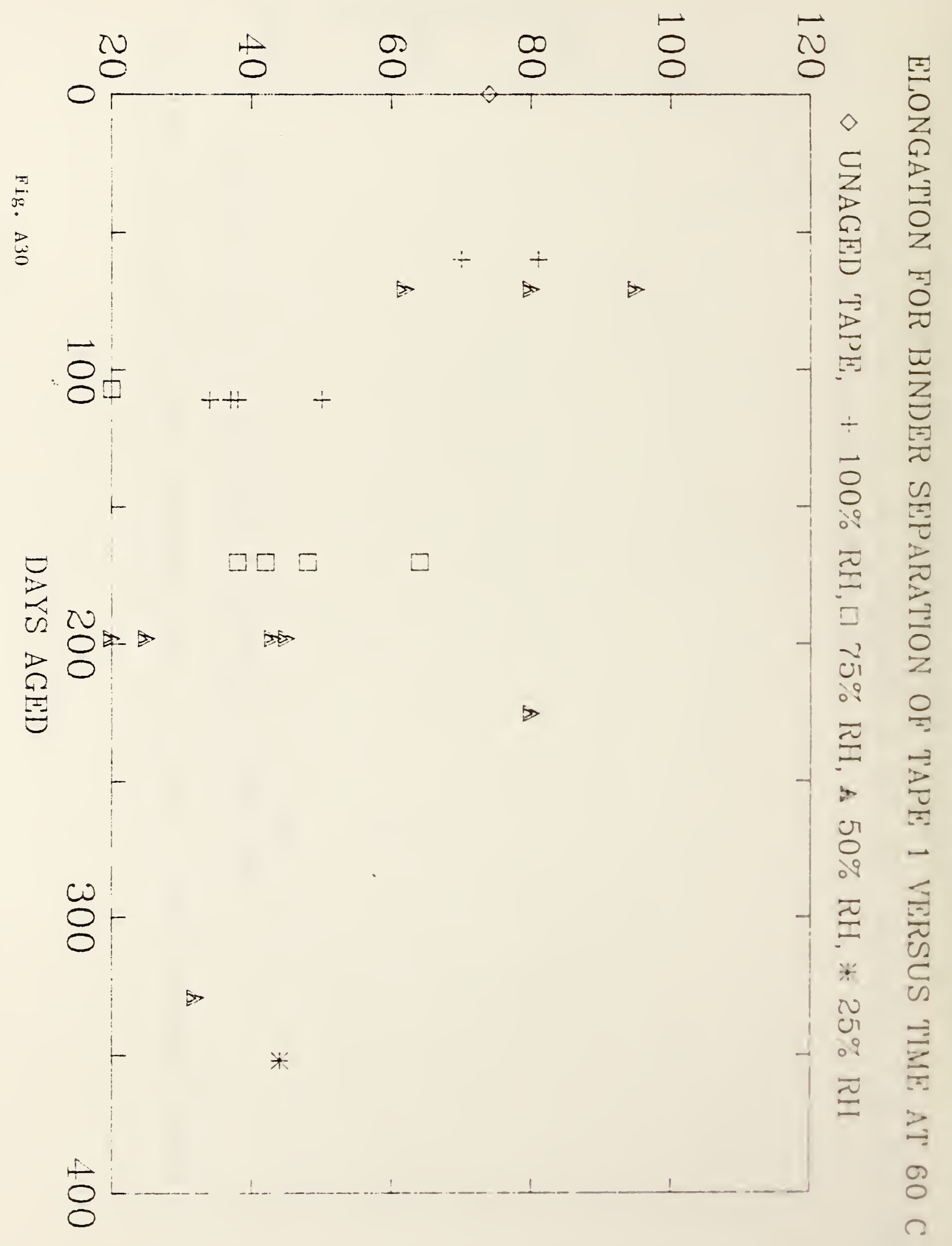




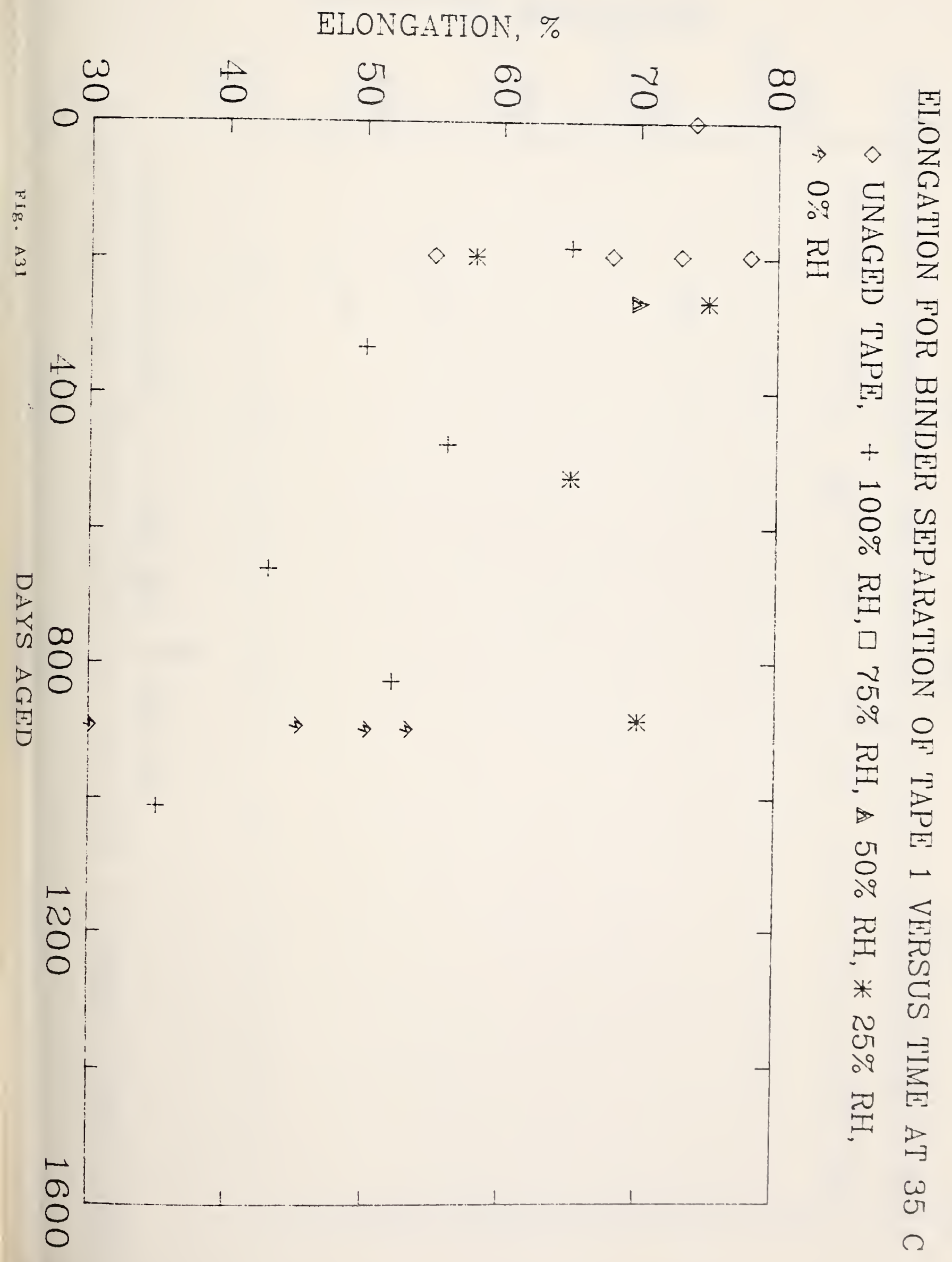


ELONGATION, \%

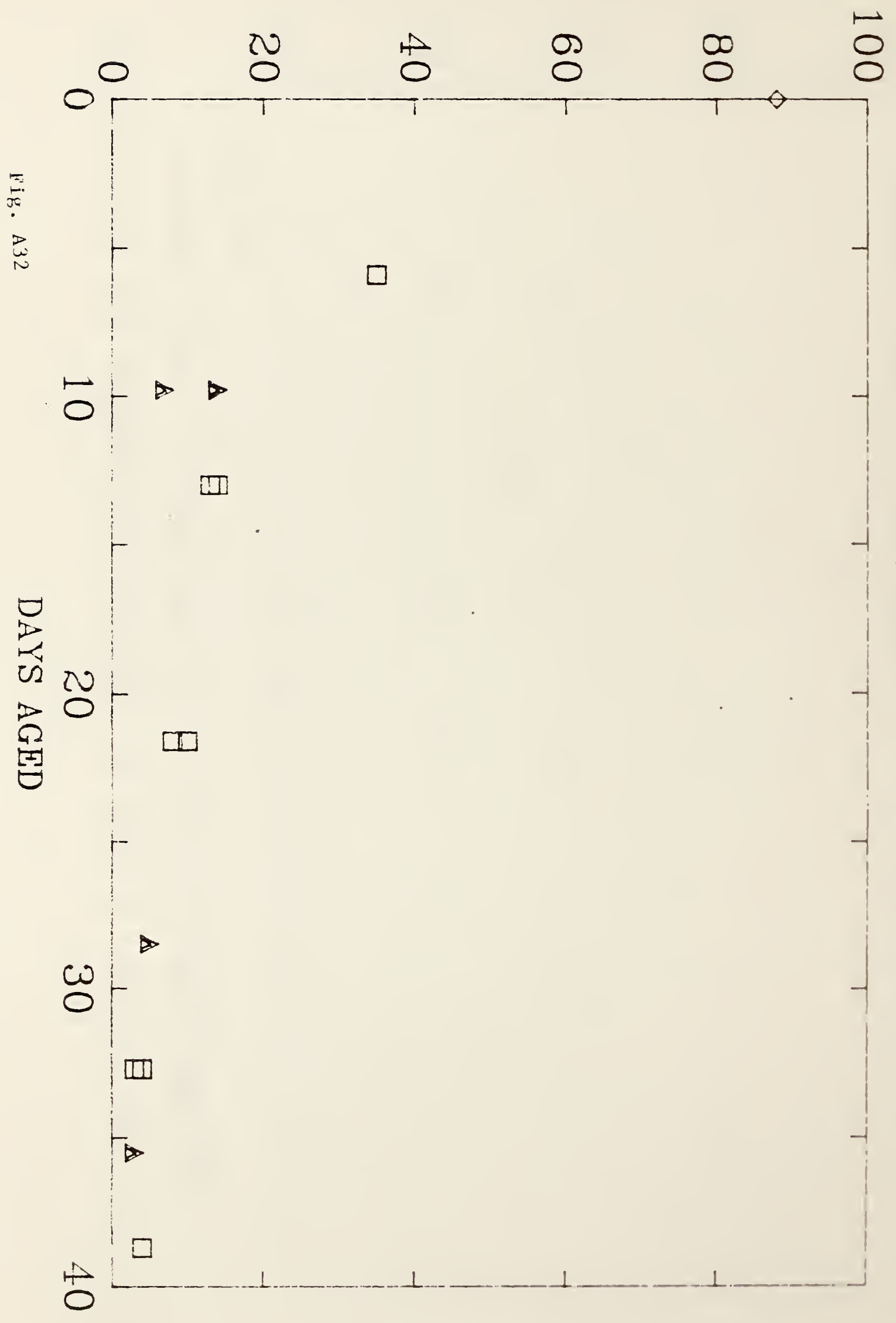




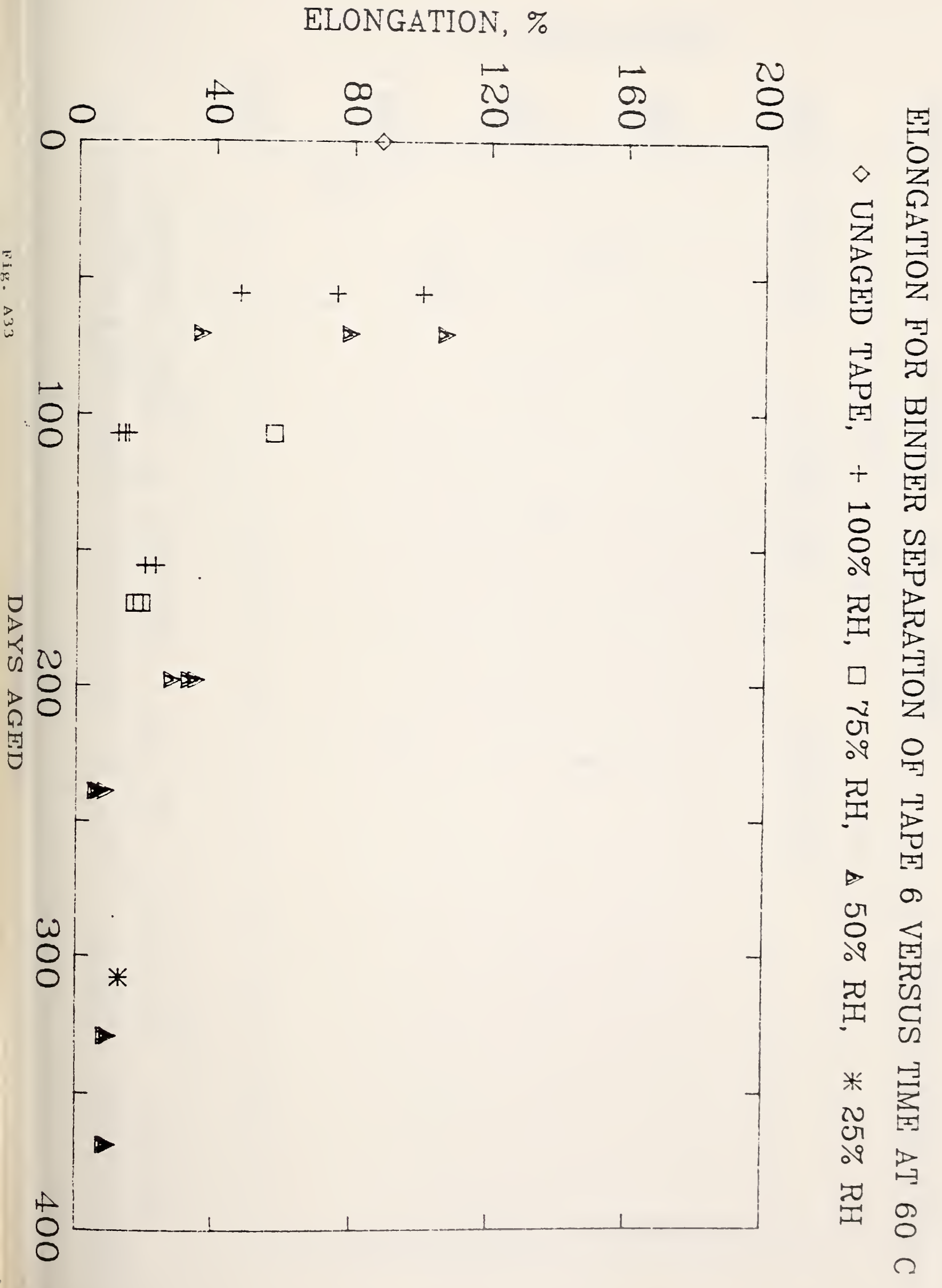


ELONGATION, \%

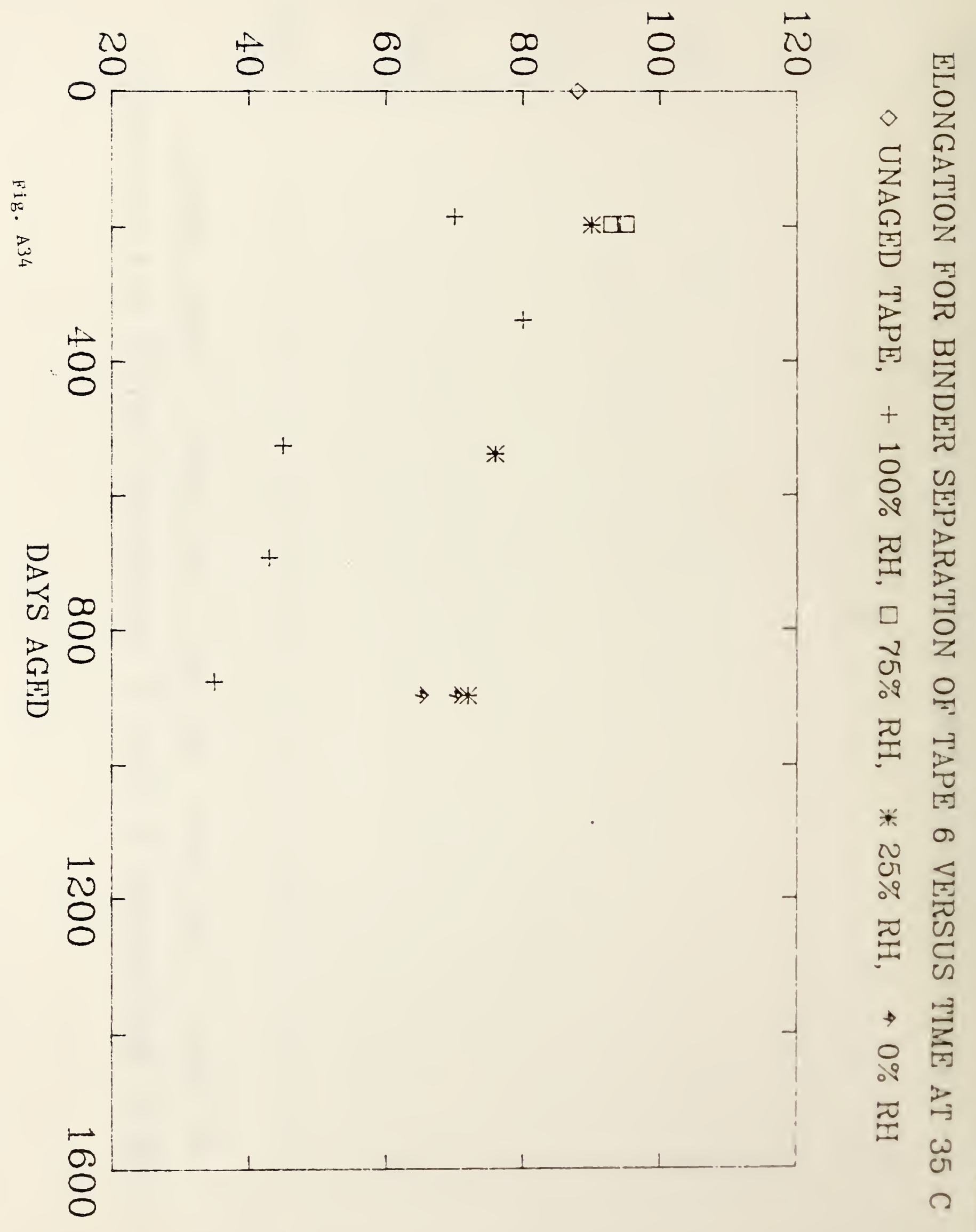


ELONGATION, $\%$

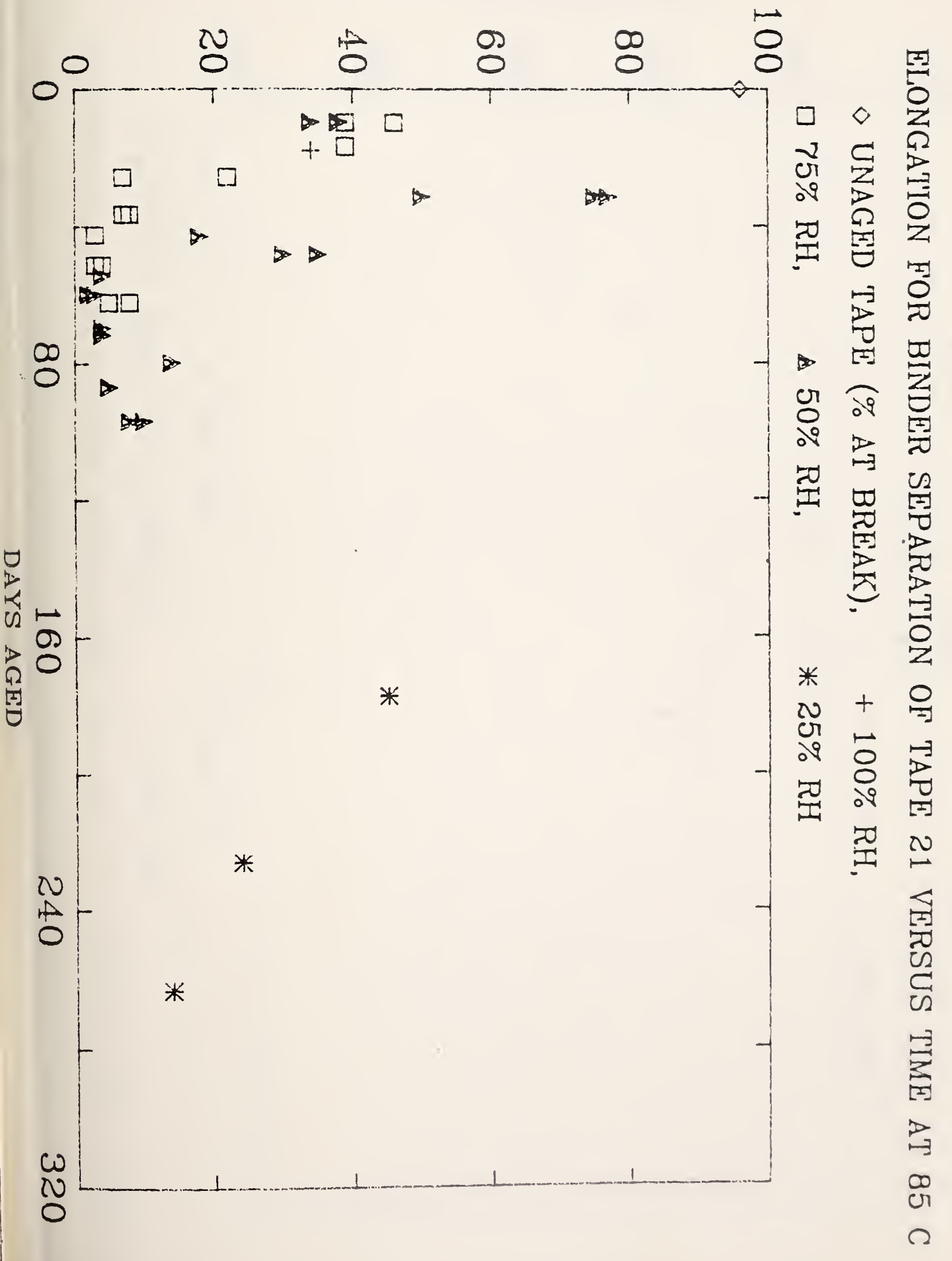




\section{ELONGATION, \%}

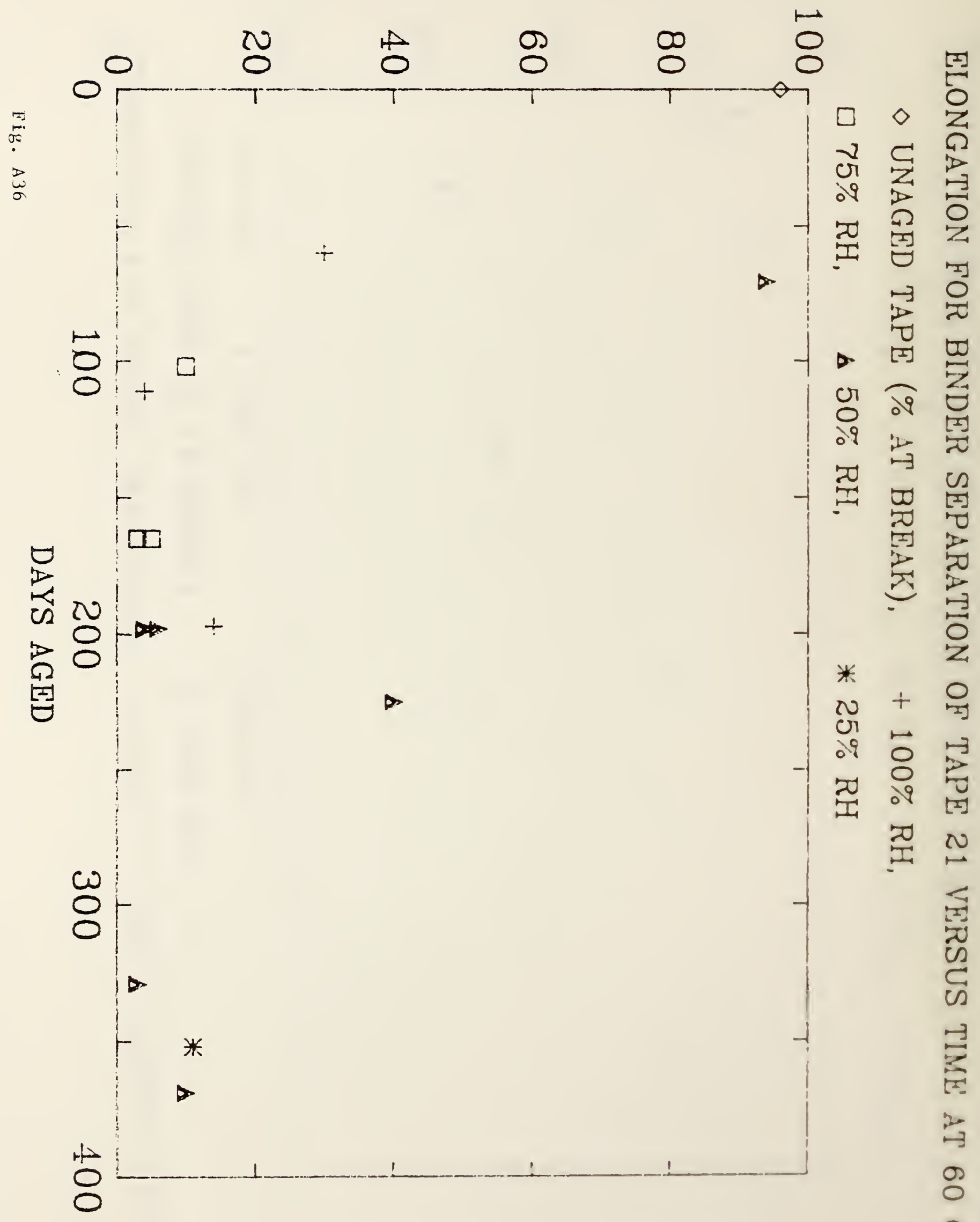




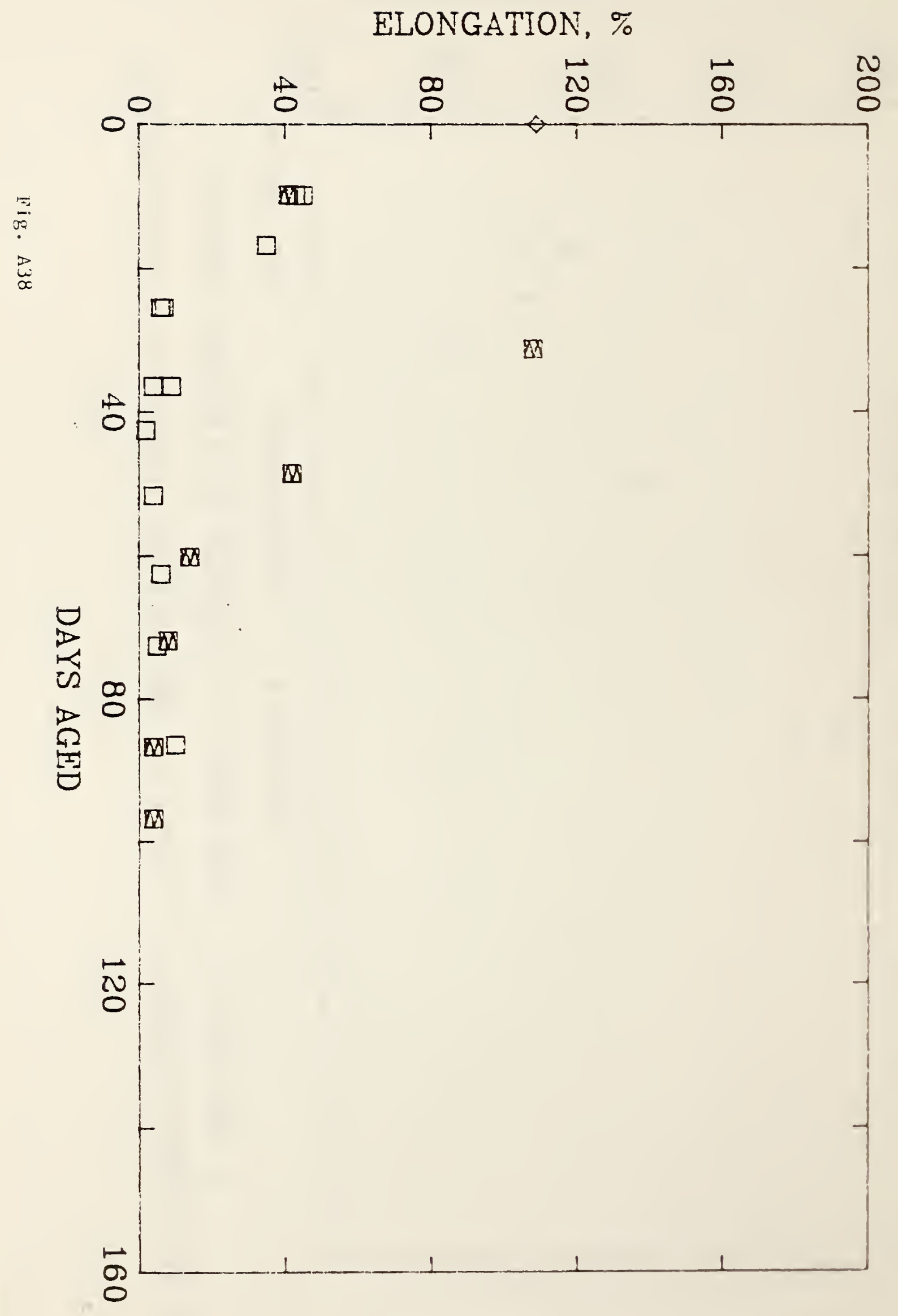

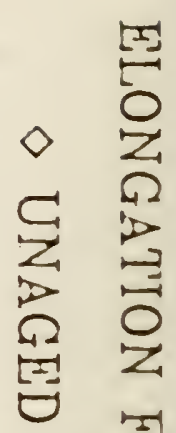

30

[1

ลิ 岂

$\rightarrow$

is

$\varpi$

总总

묵

जै ?्ञ

N

Q

or

으

记

㿿

3

or 


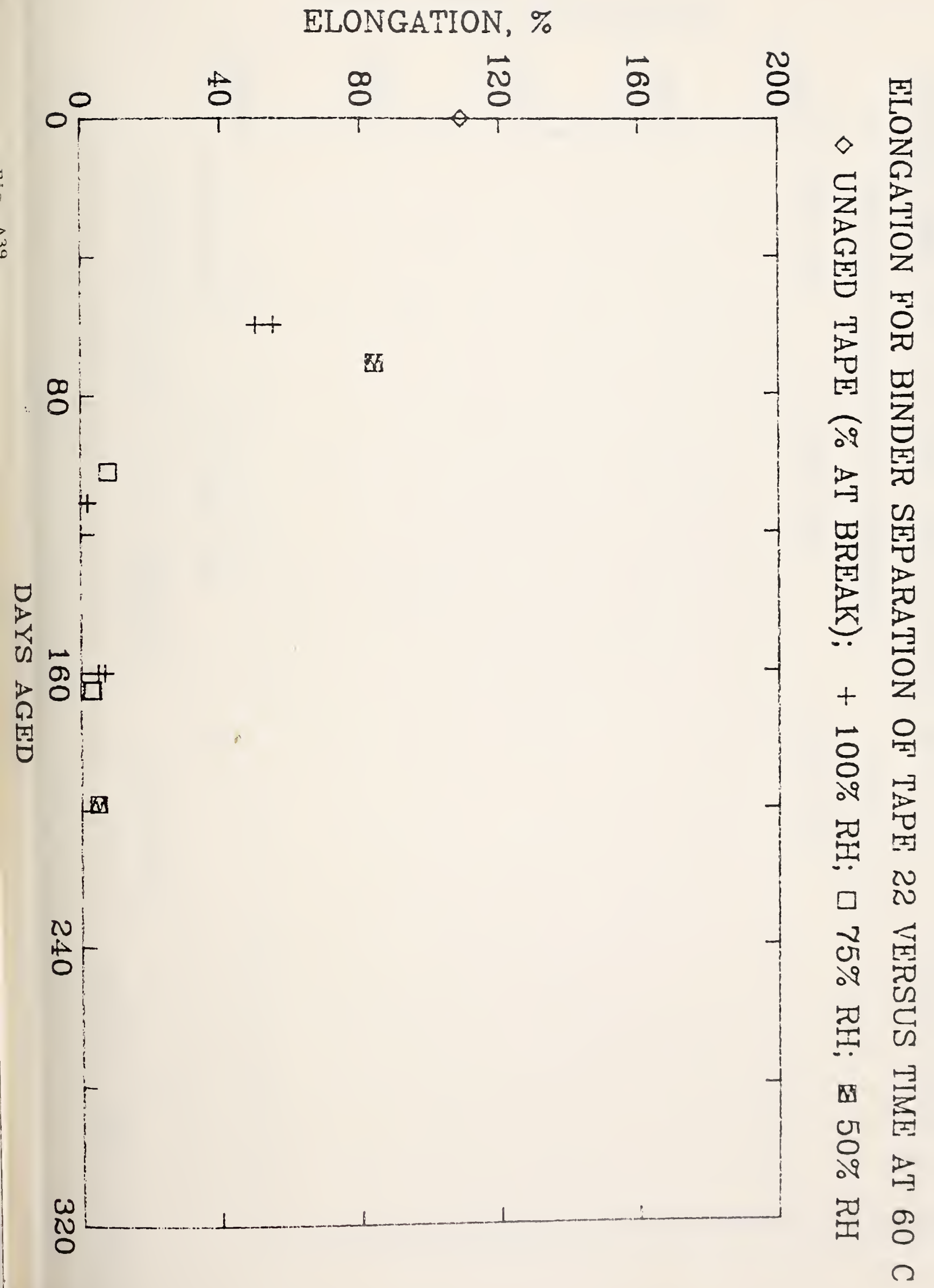


ELONGATION, \%

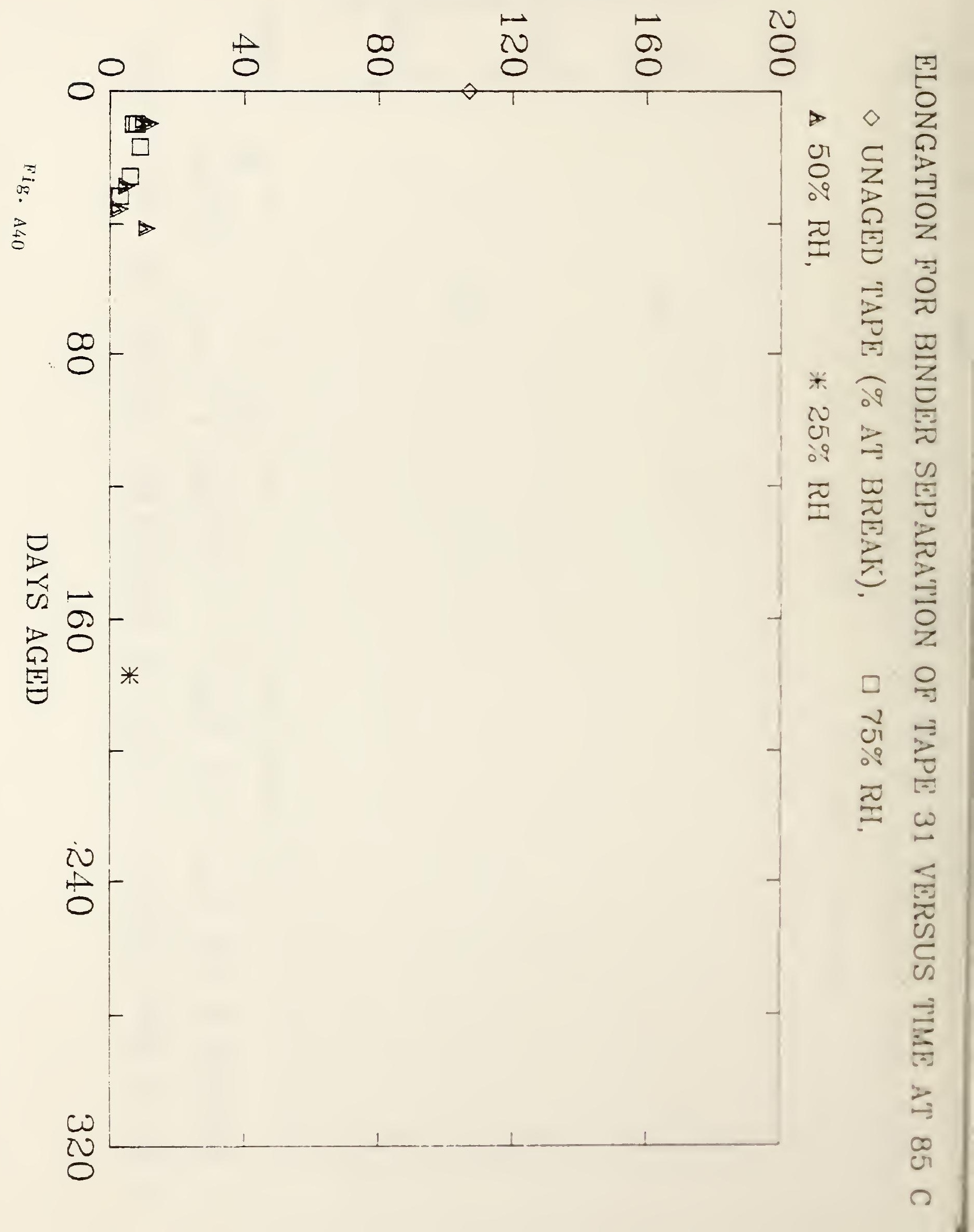




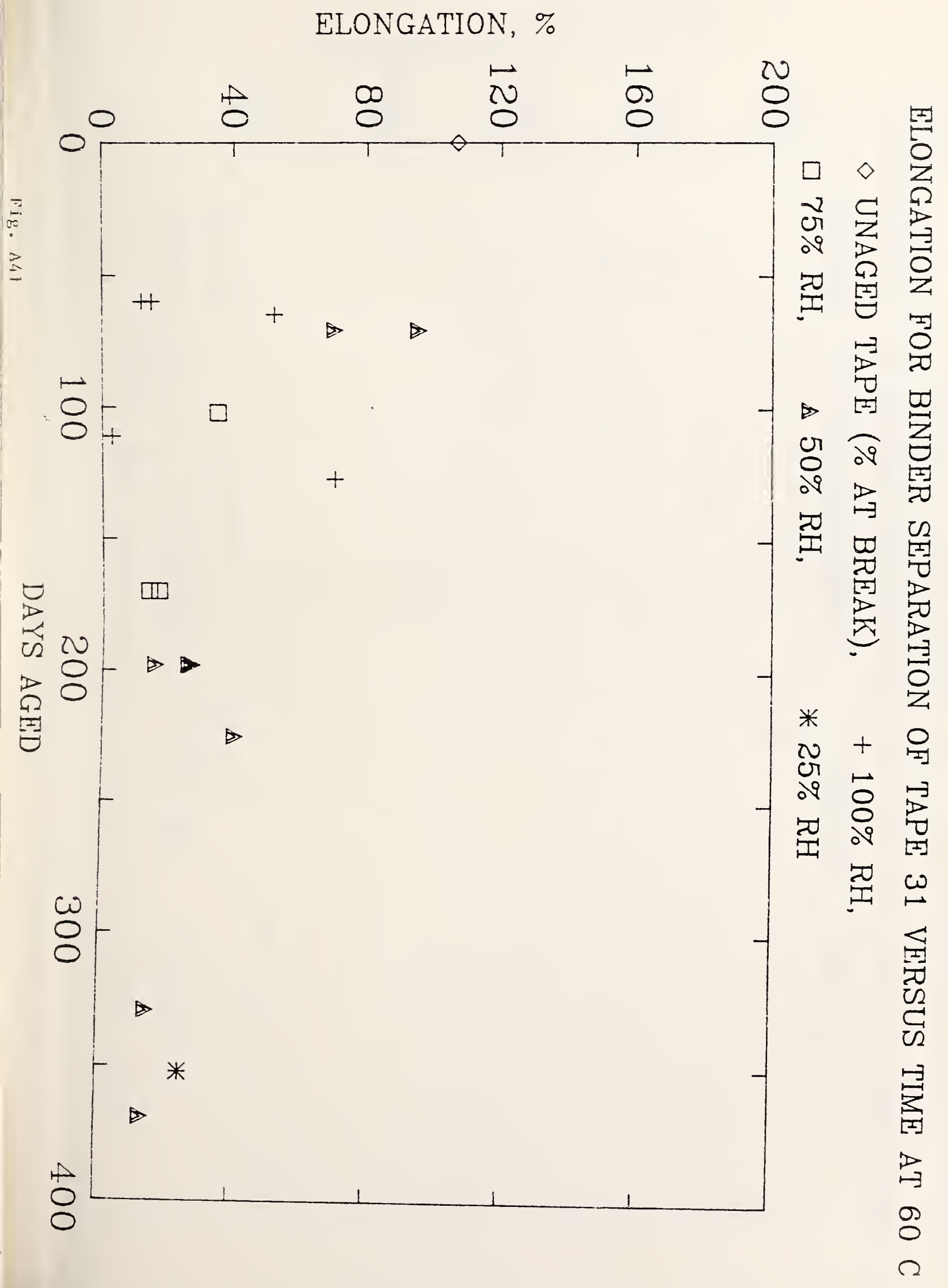


ELONGATION, \%

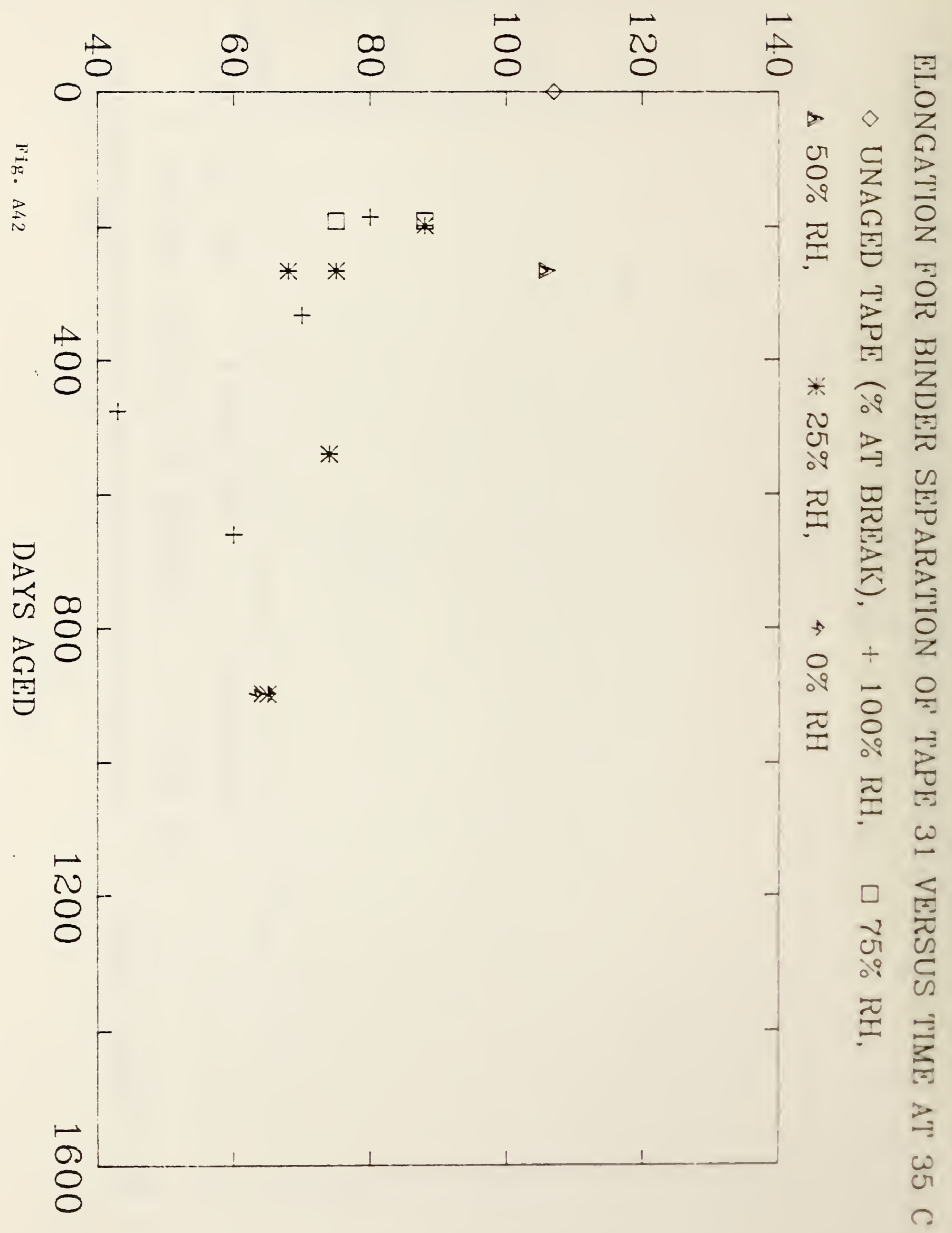


ELONGATION, \%

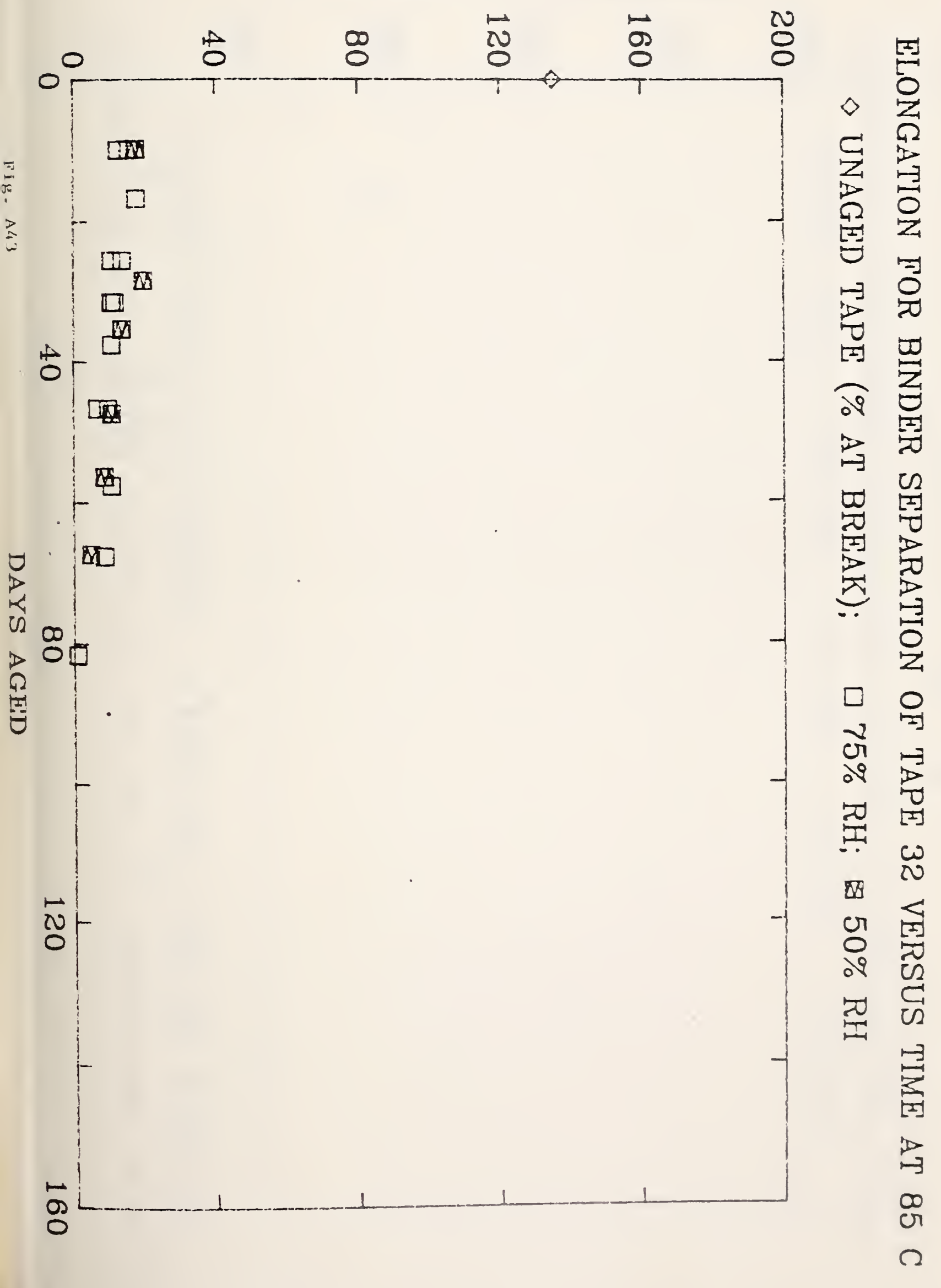



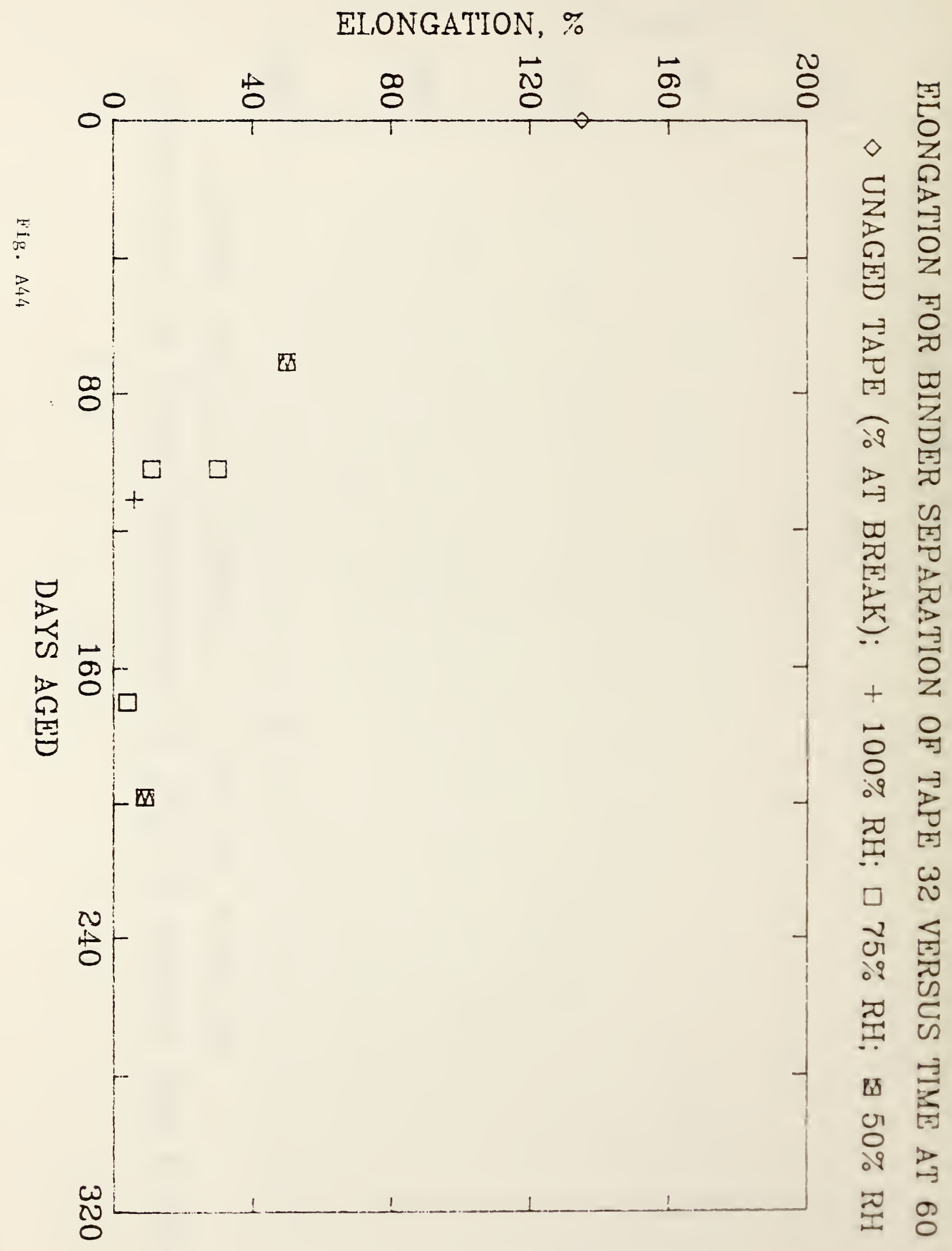
ELONGATION, \%

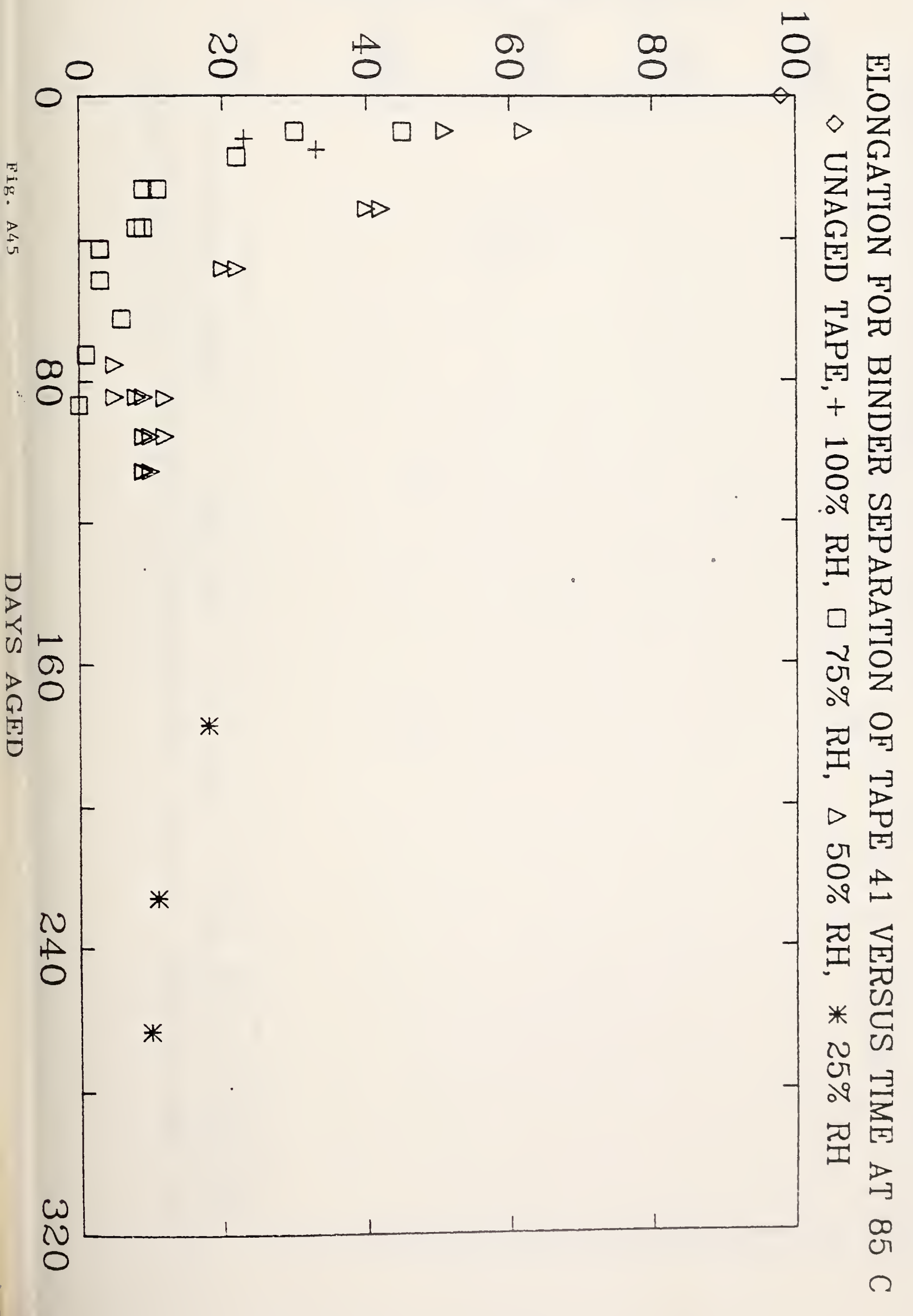


ELONGATION, \%

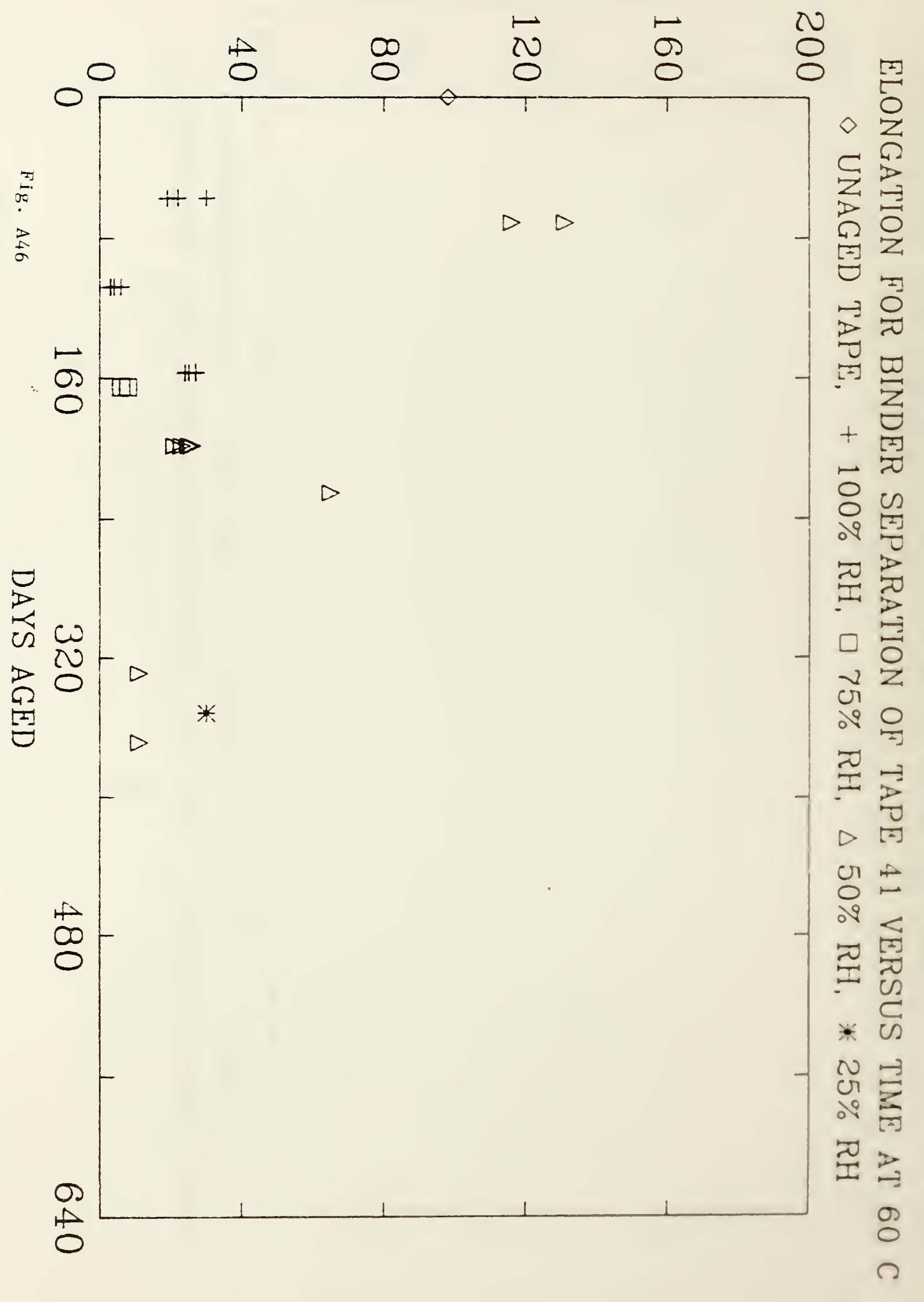




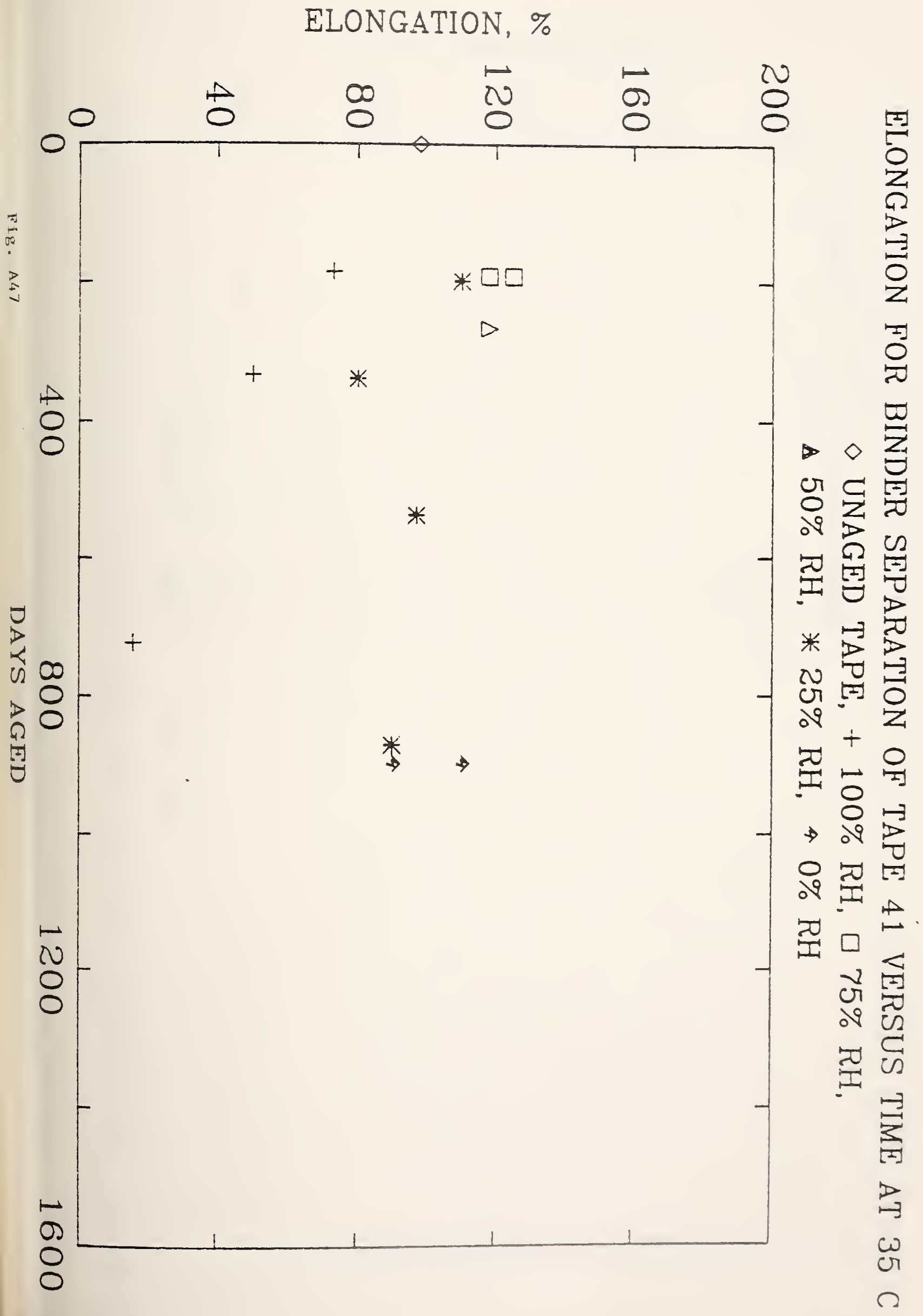




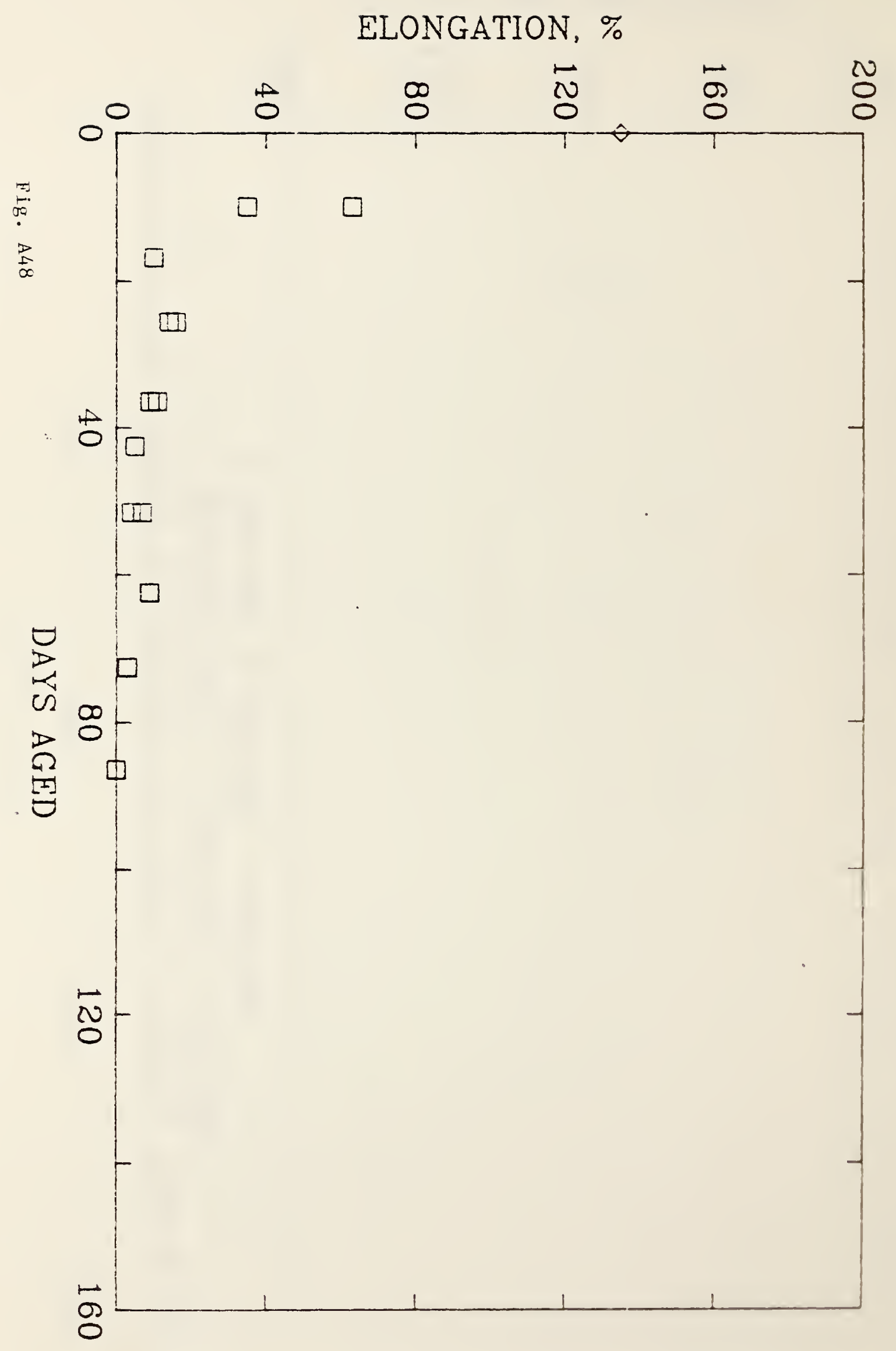

펄
0
0
2
3
3
0
0
0

0

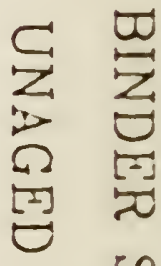

$\mapsto \quad 0$

$\nabla$

피

$\square$

$\checkmark 2$

०ी

푬

i

E

5

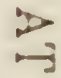

or 


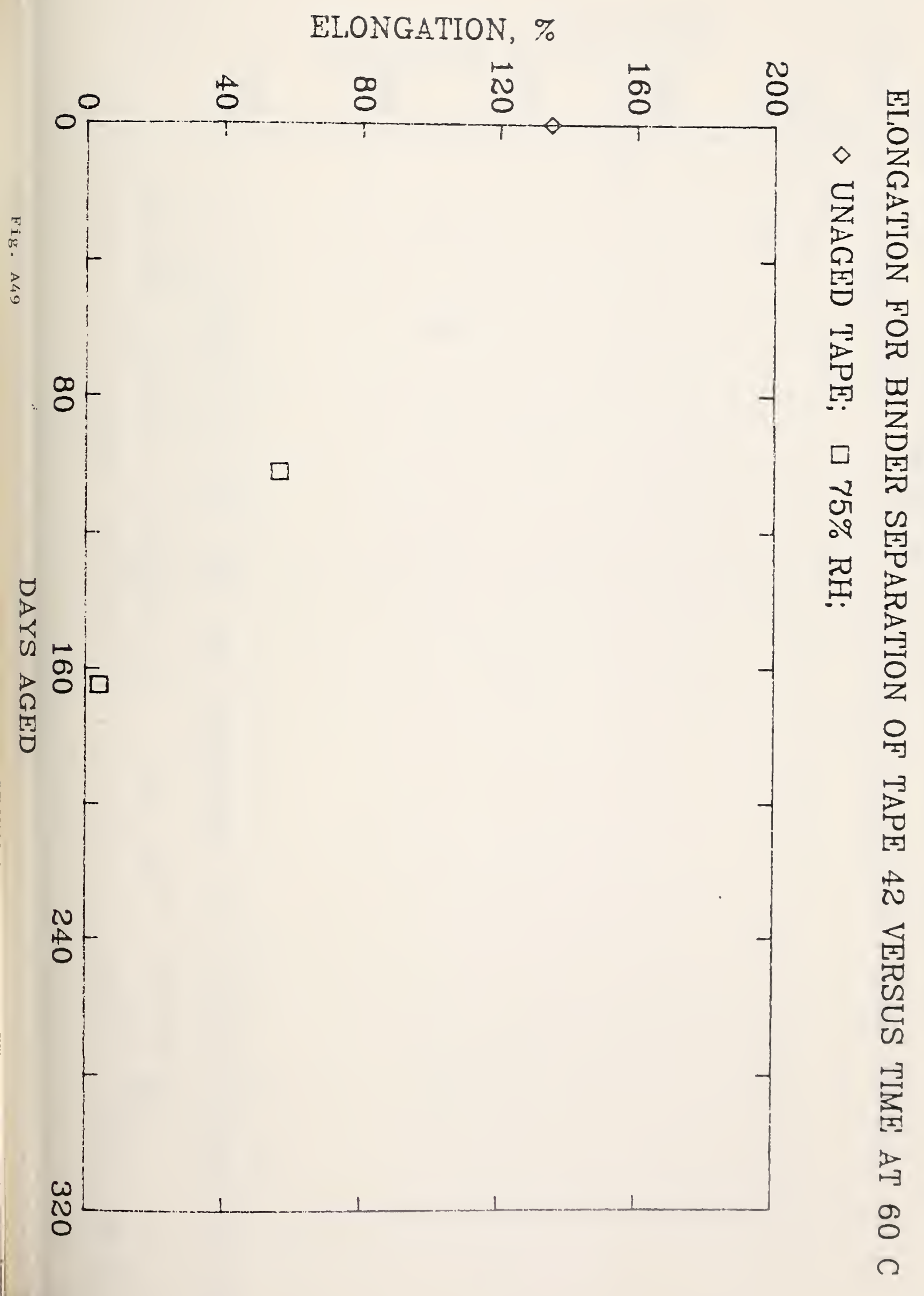




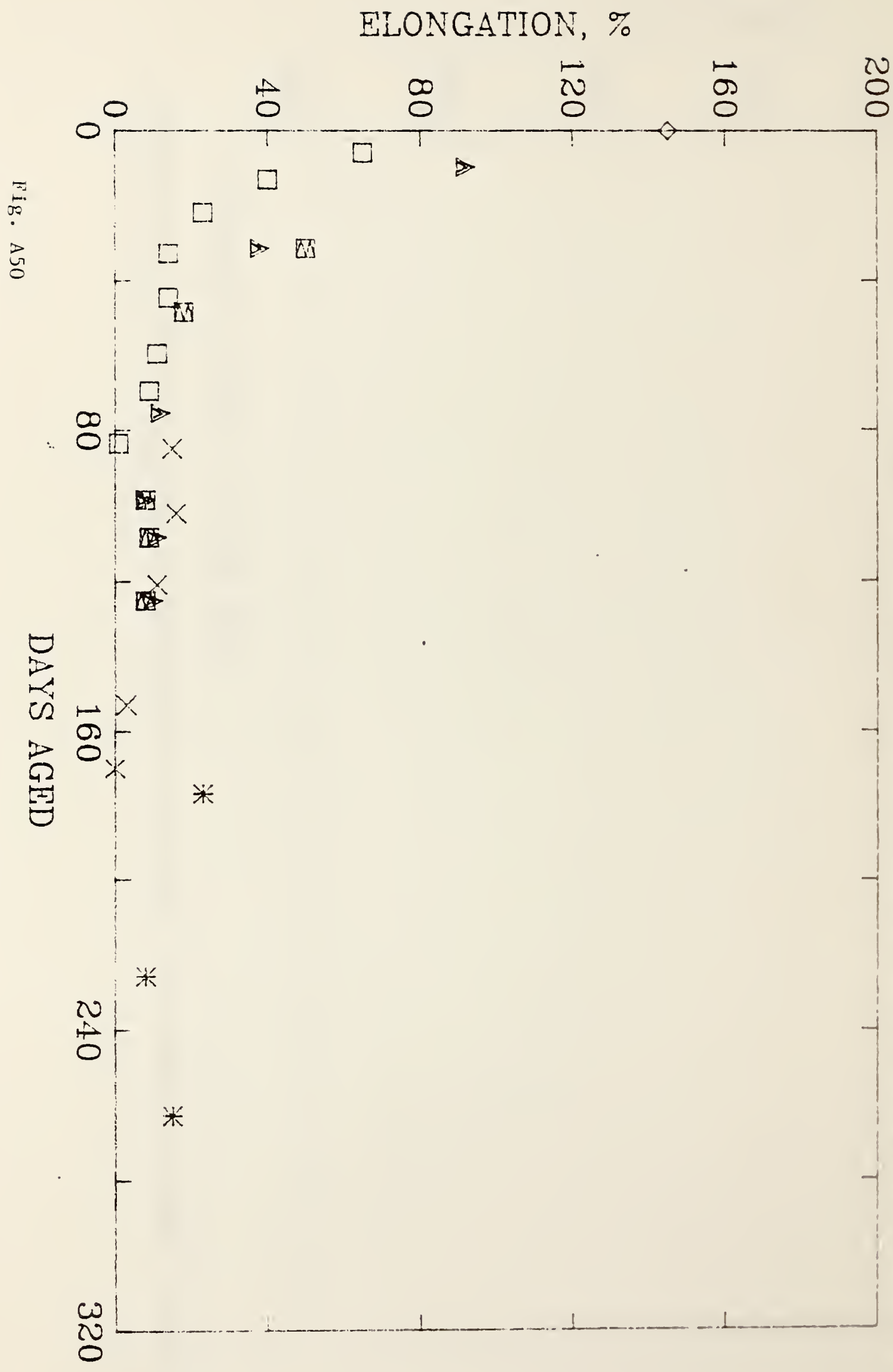

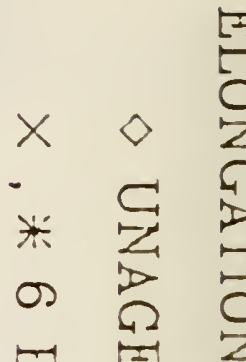

E

点

证

学 $\widehat{\circ}$

只墨

[न Ш U

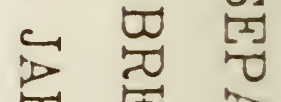

胥

or

:9

z

몁 웅

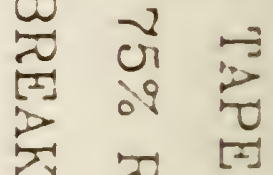

s

目品

盯品

$\forall$ or

of is

us

一觉

!

ż

N

บ? 


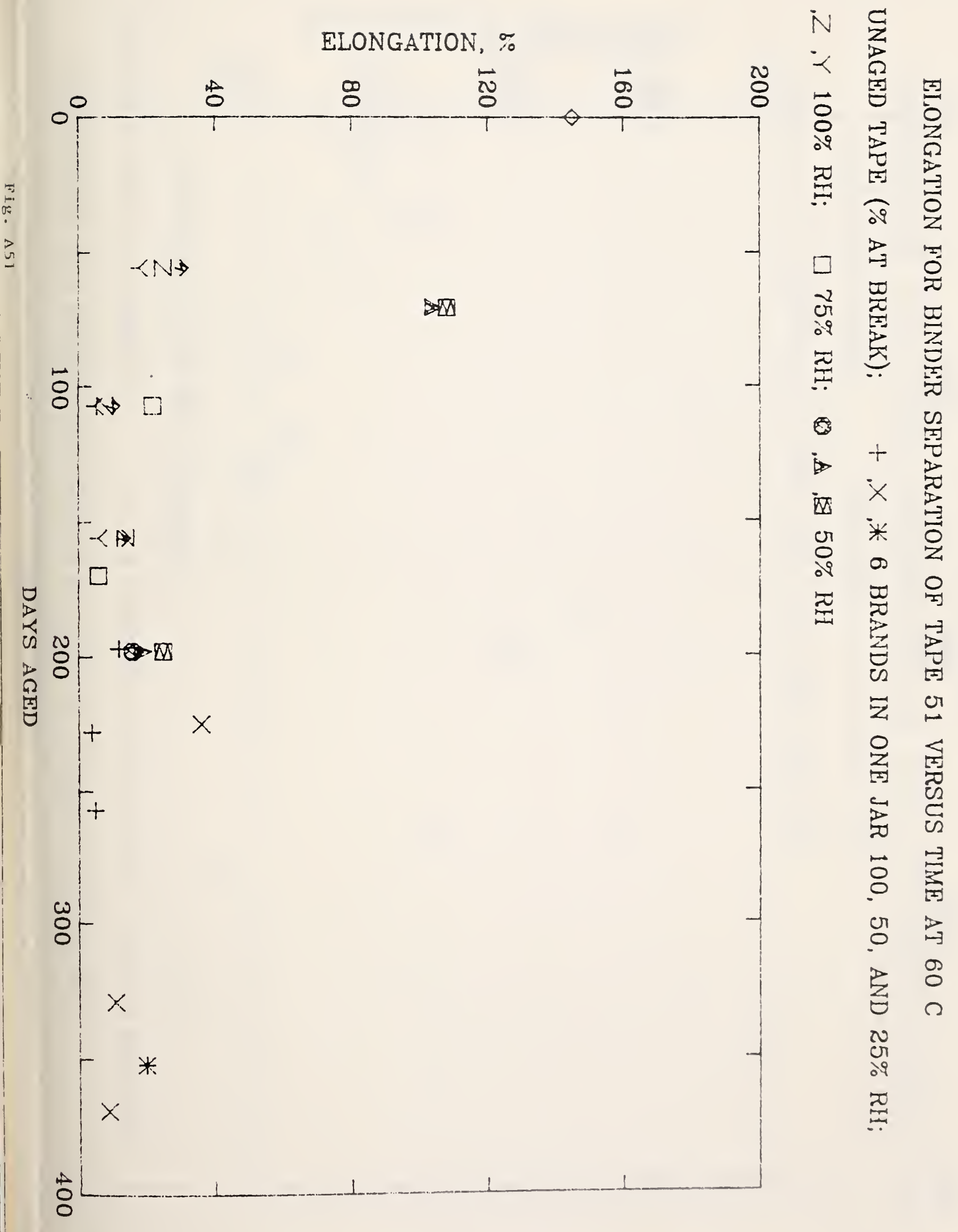




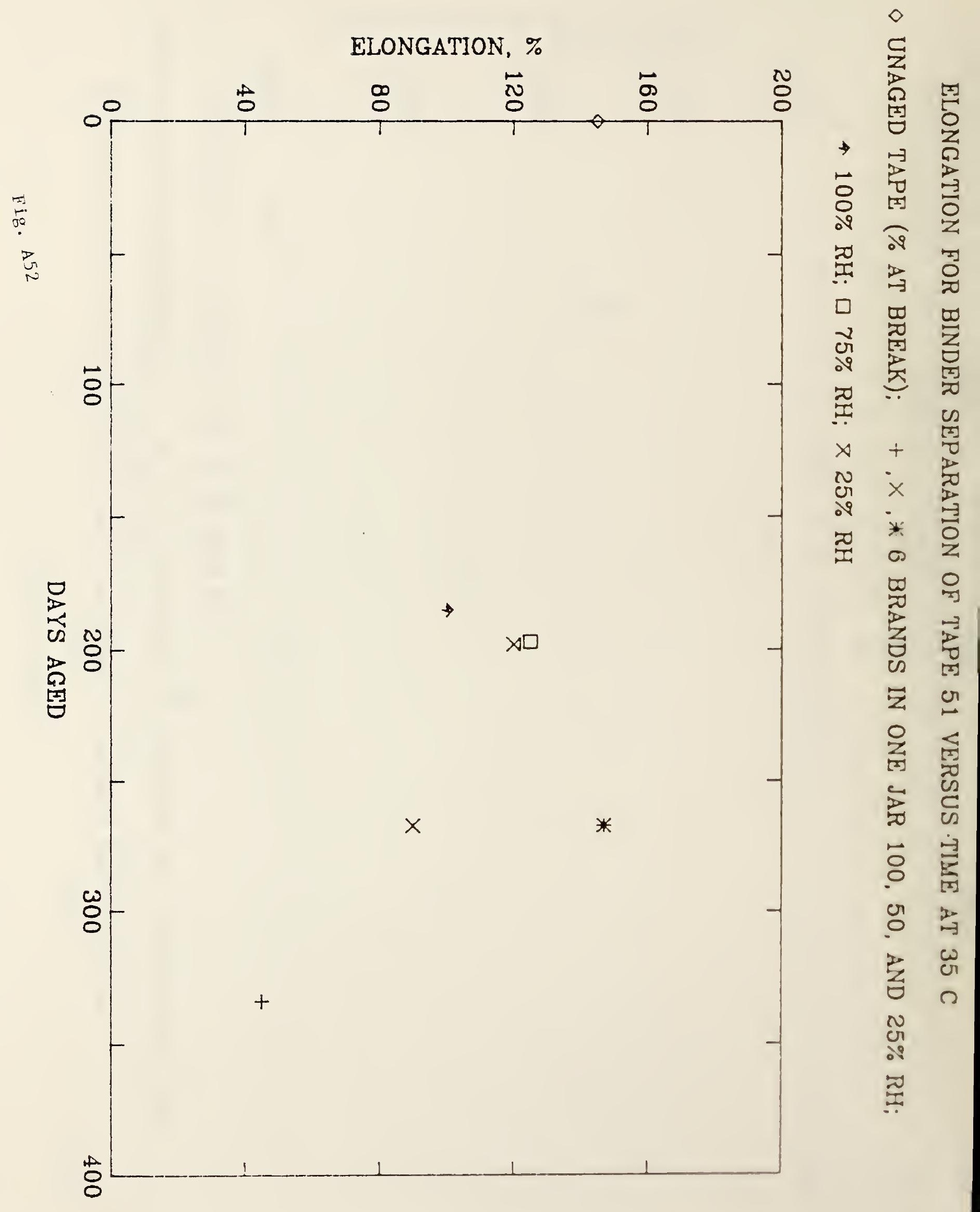


ELONGATION, \%

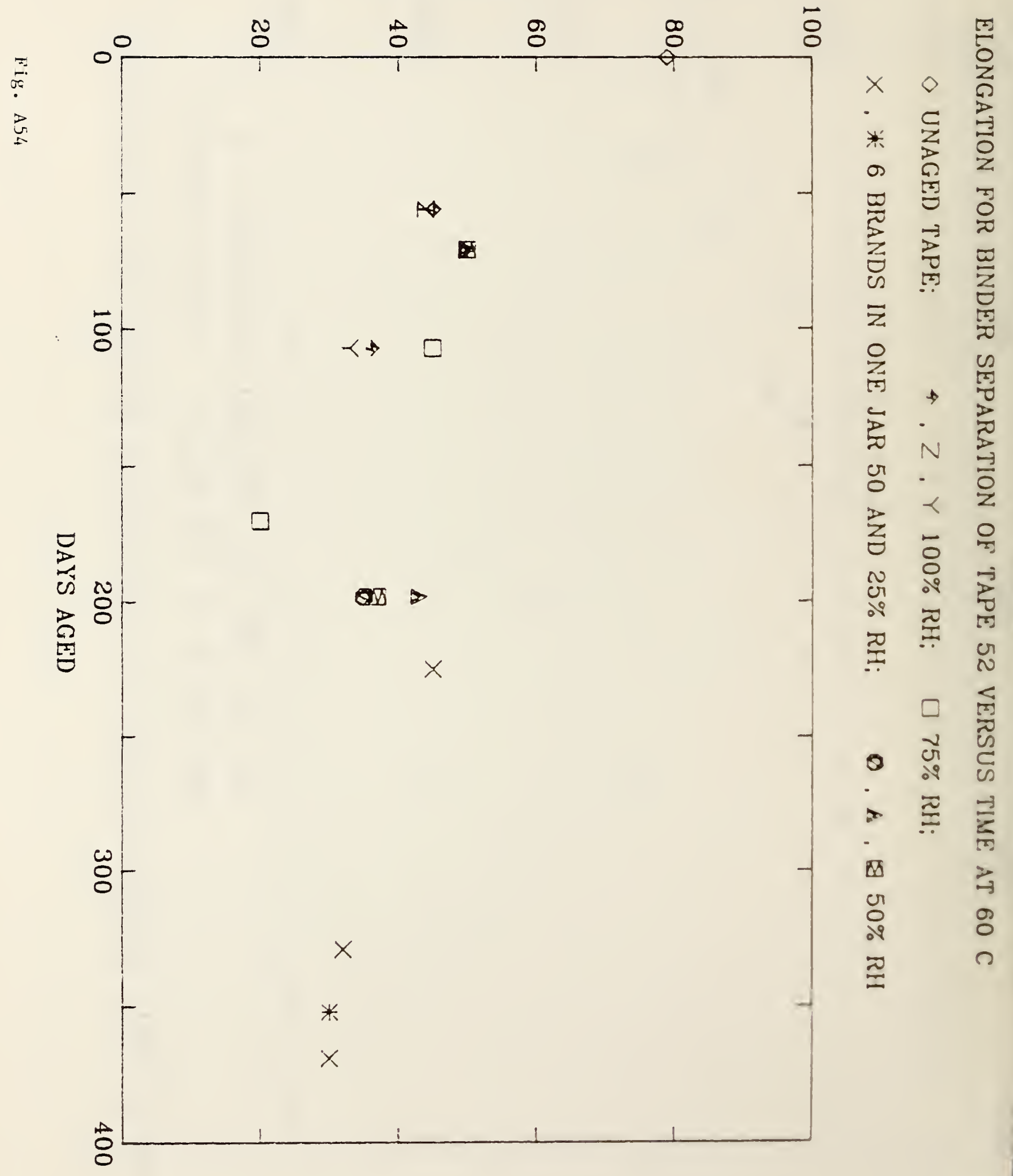




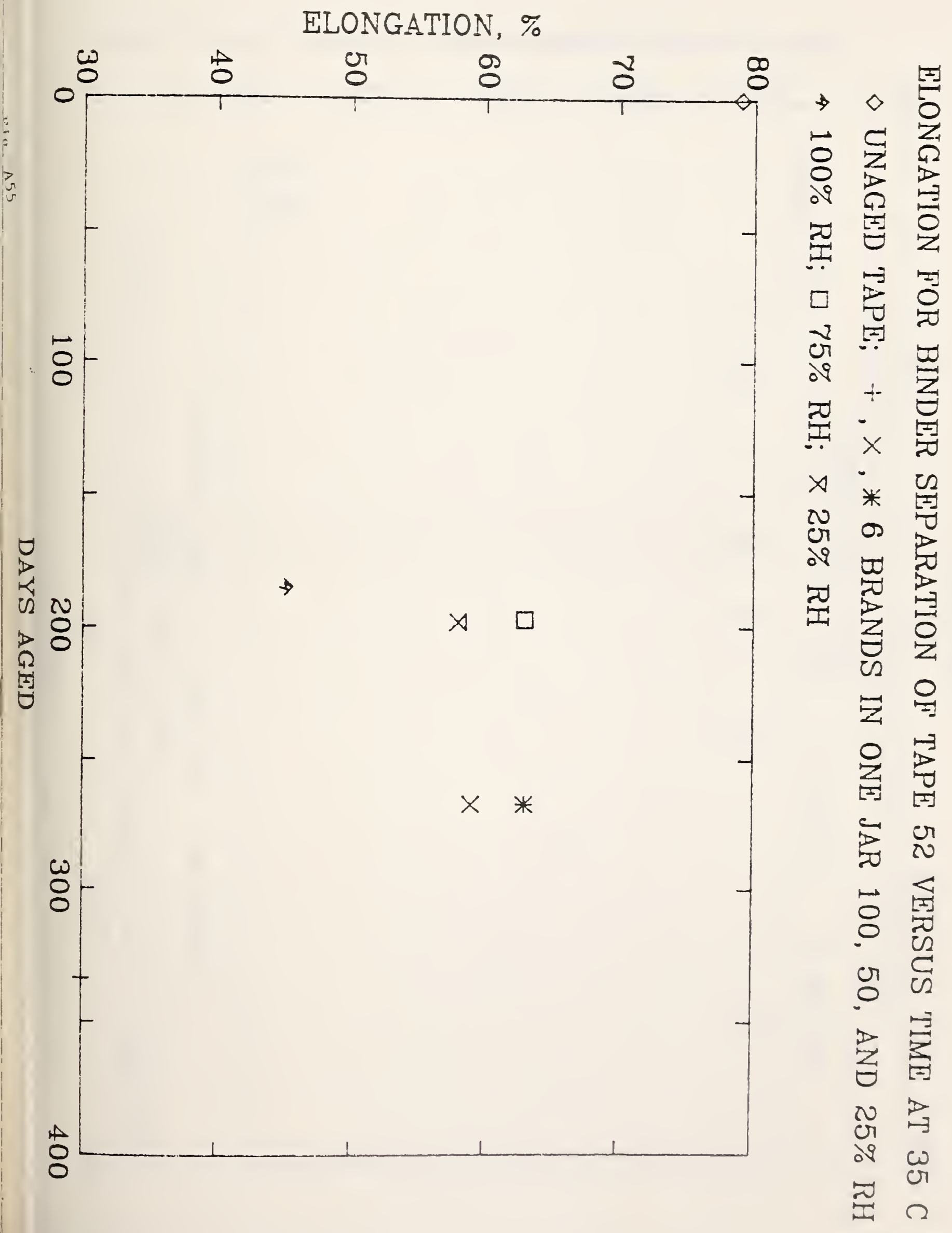


ROLLS (VALUES BETWEEN 9 AND $10=10$ )

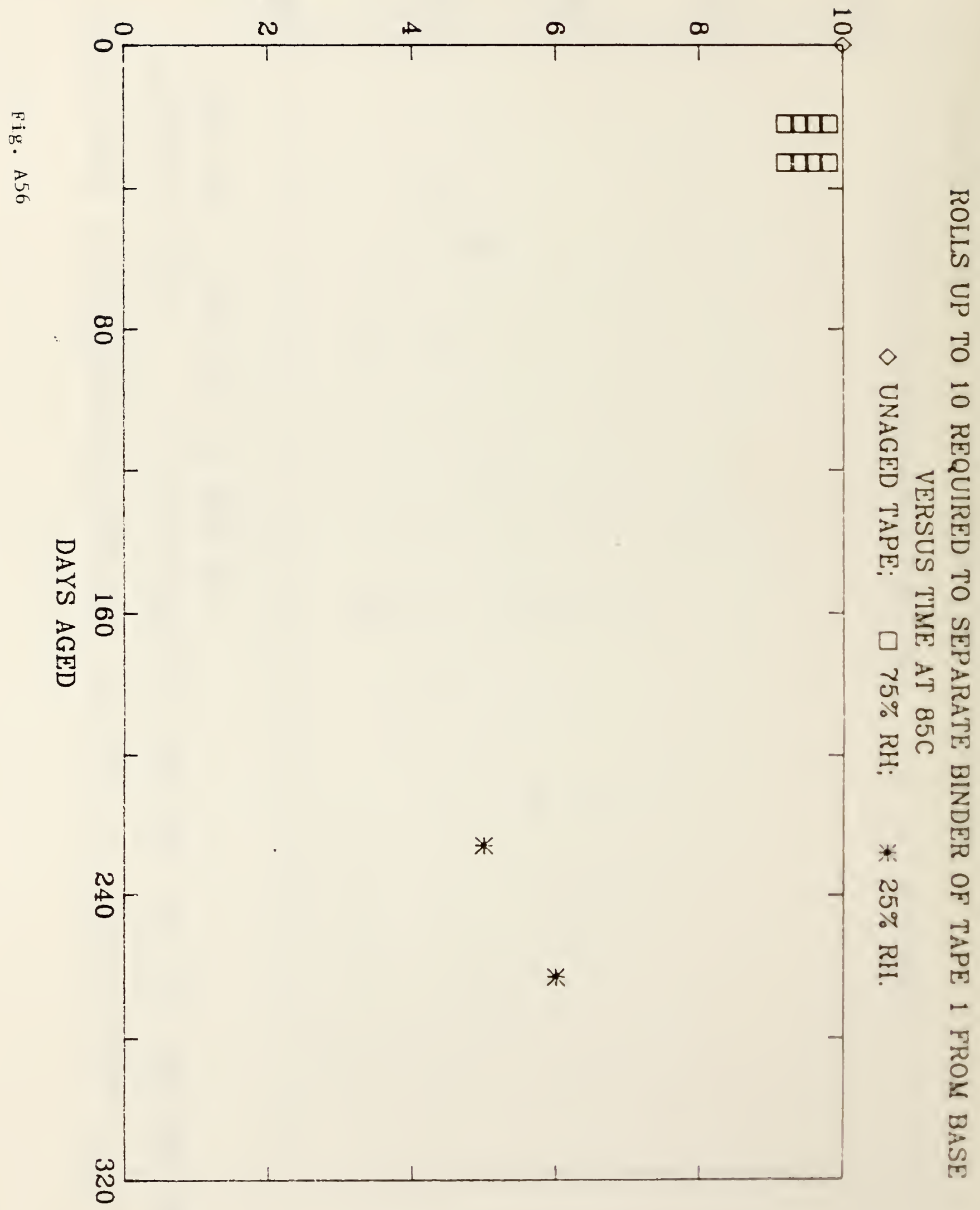


ROLLS (VALUES PLOTTED BETWEEN 9 AND $10=10$ )

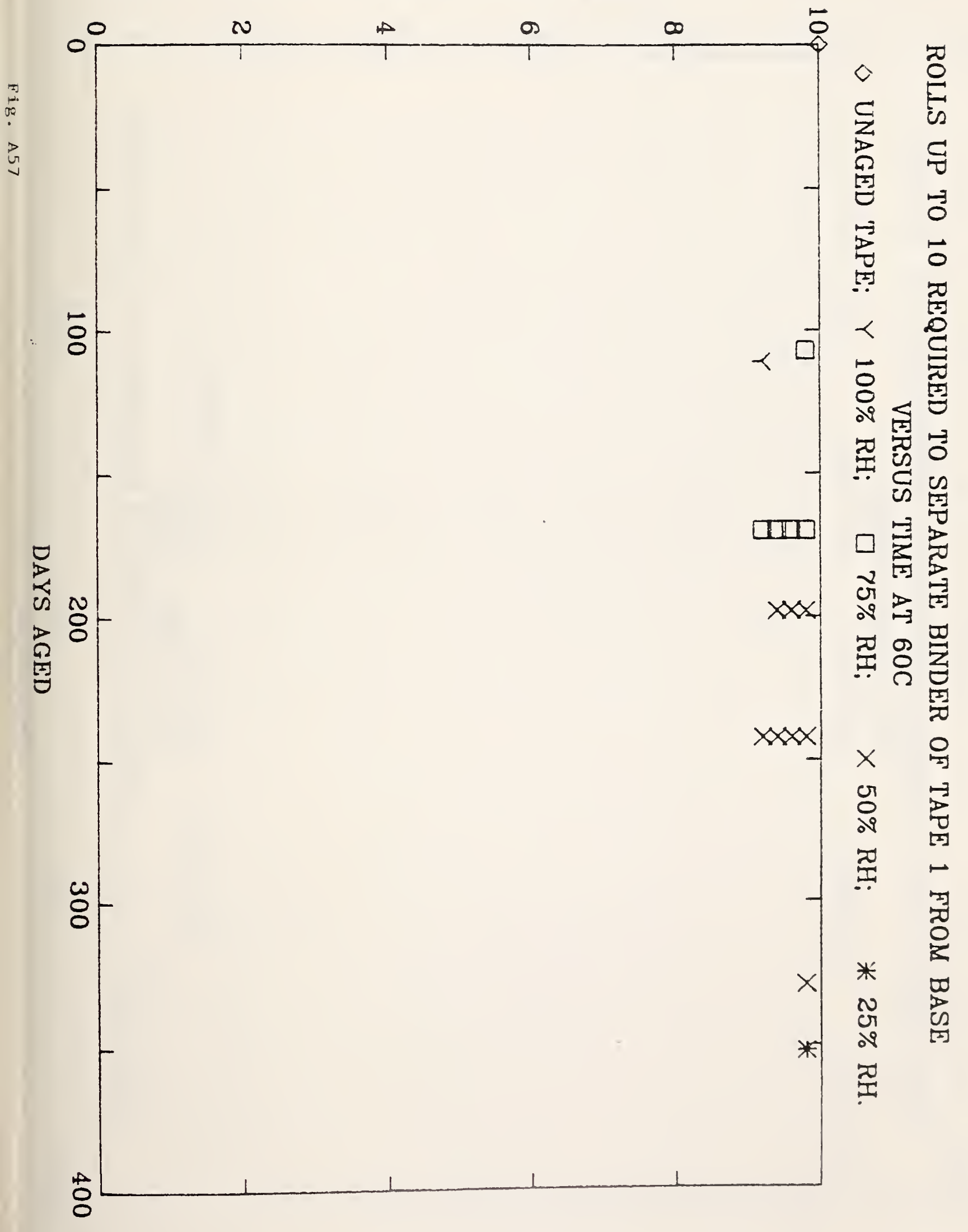


ROLLS

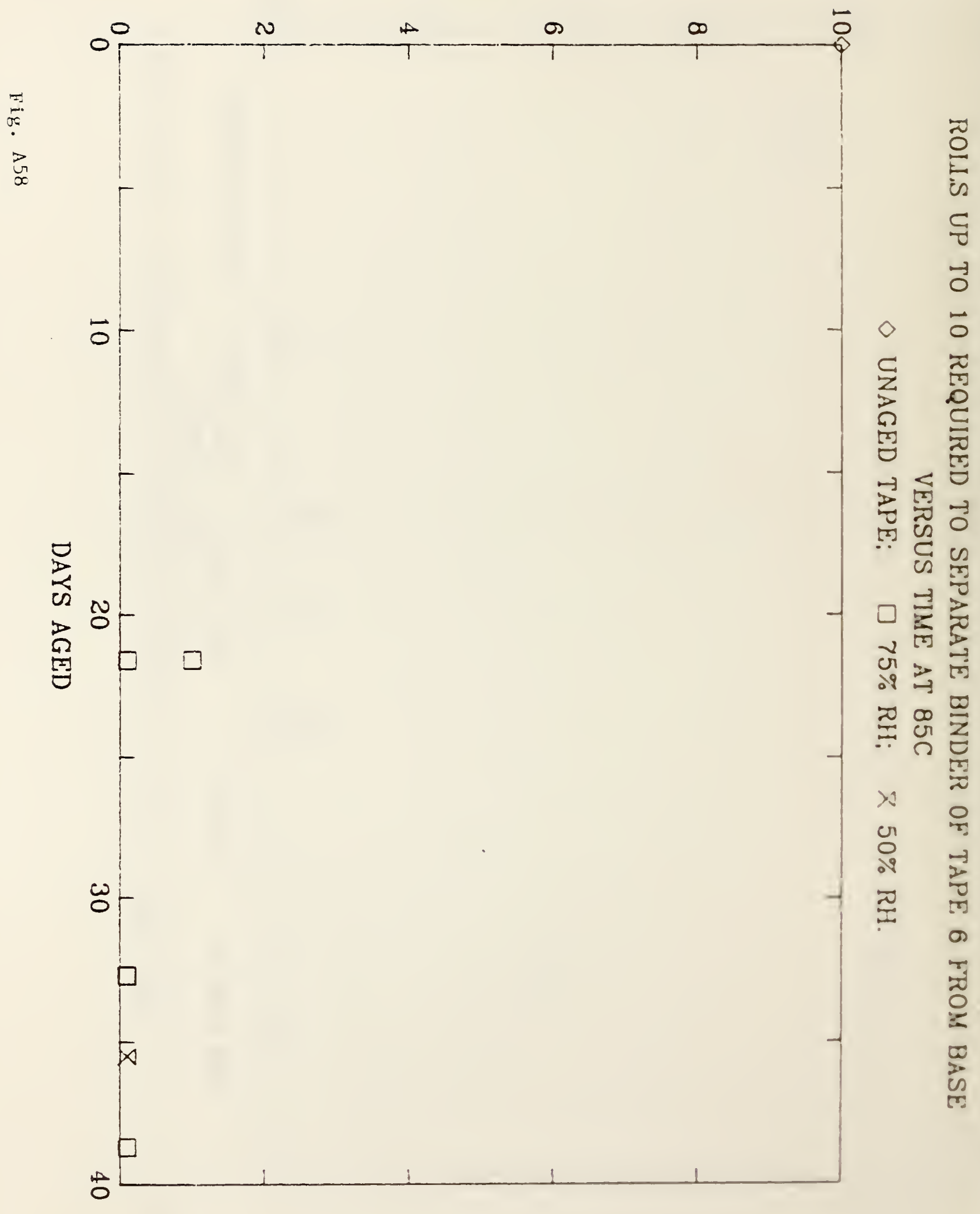


ROLIS

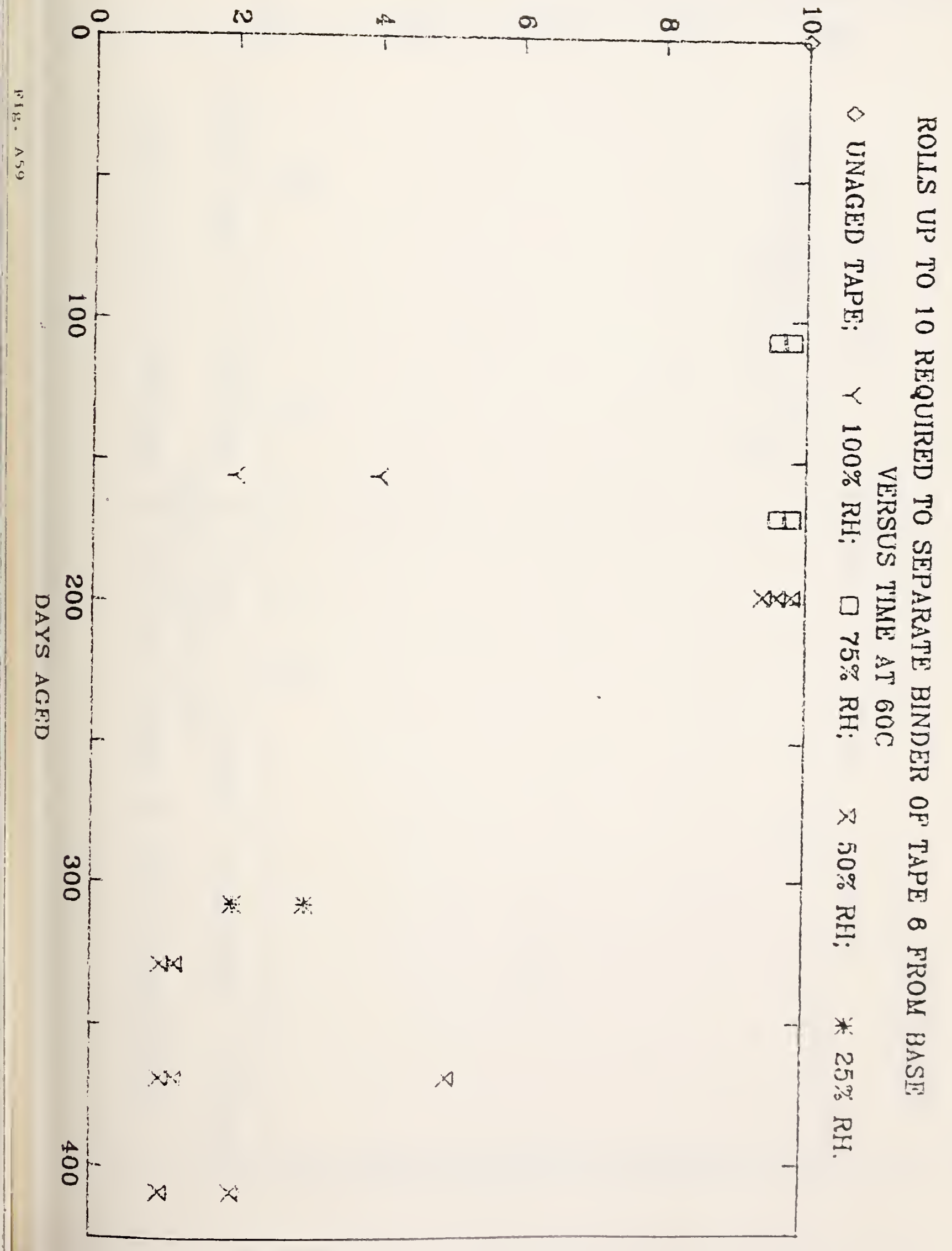




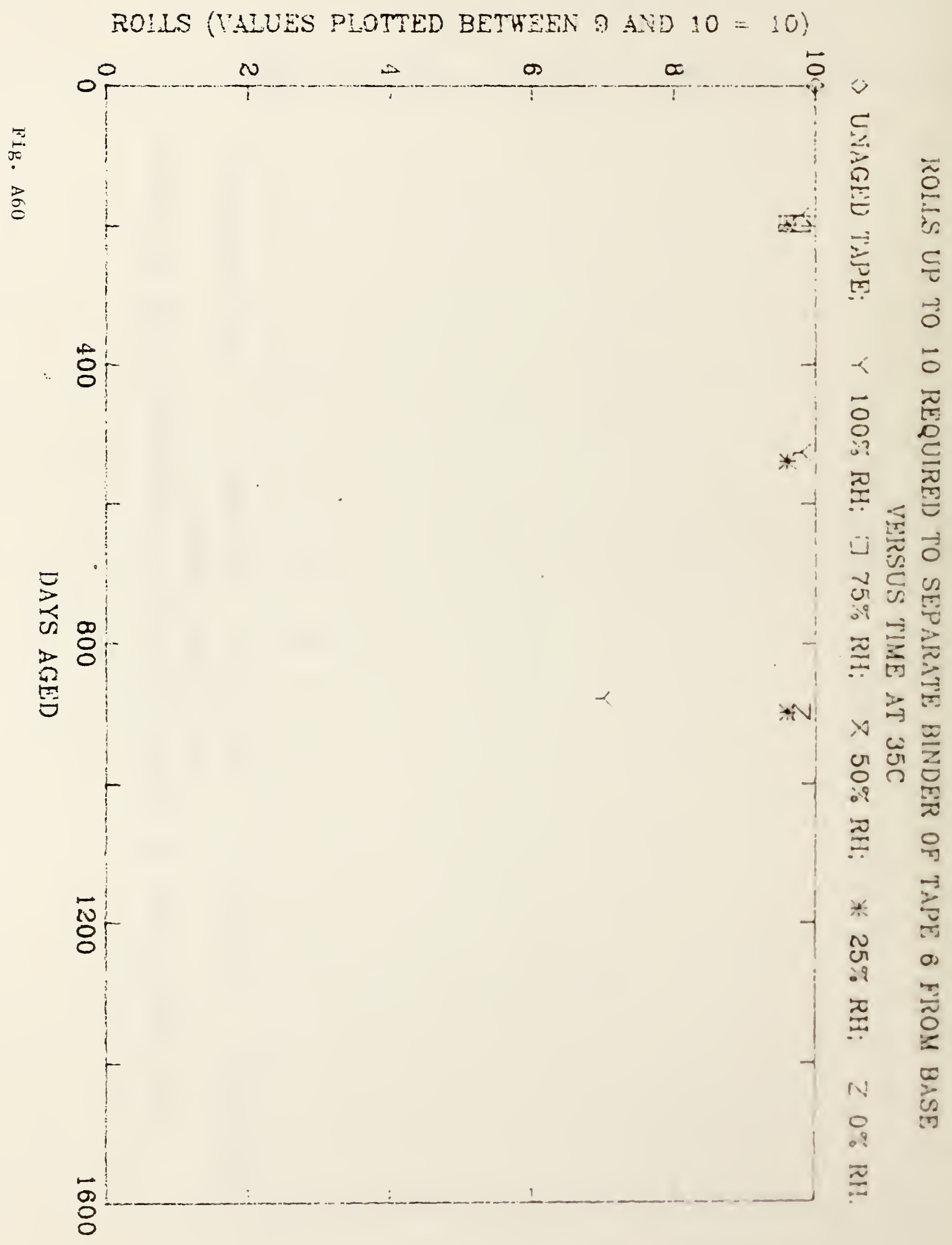




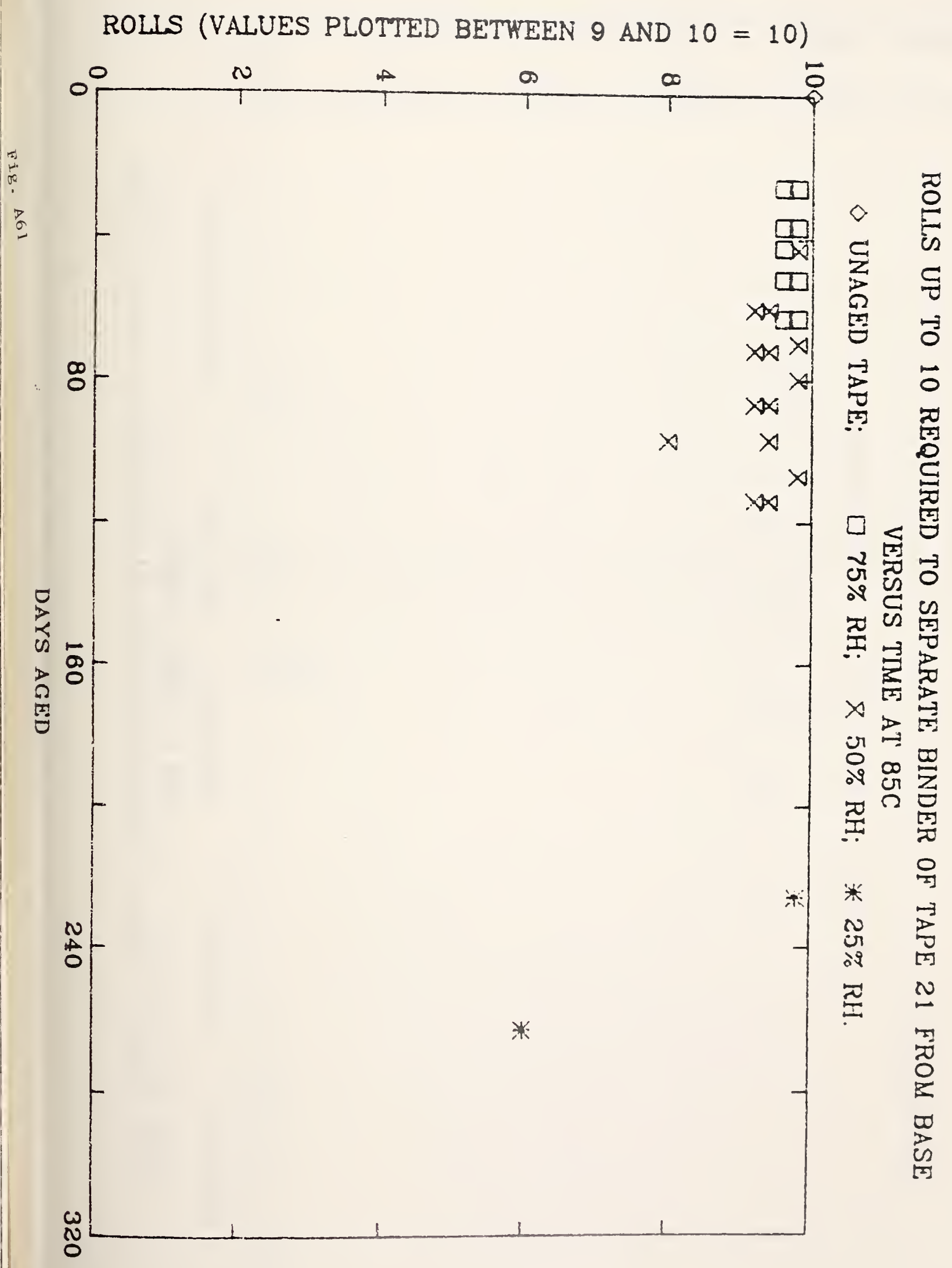




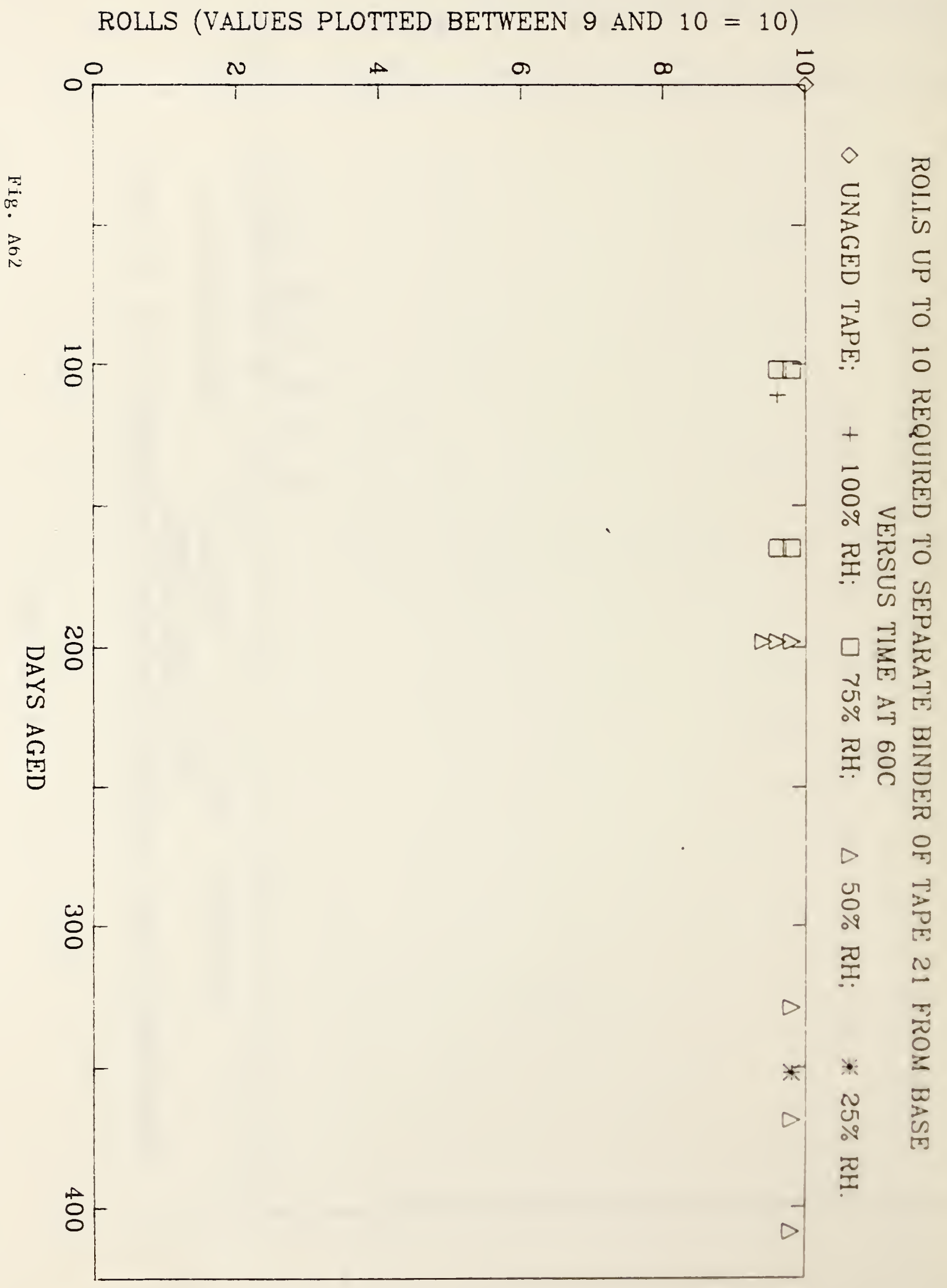


ROLLS (VALUES PLOTTED BETHEEN 9 AND $10=10$ ) $0_{0}^{0} \quad \infty \quad \infty \quad \infty \quad \infty \quad \infty$

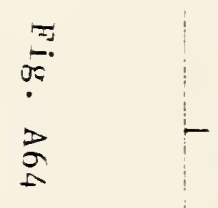

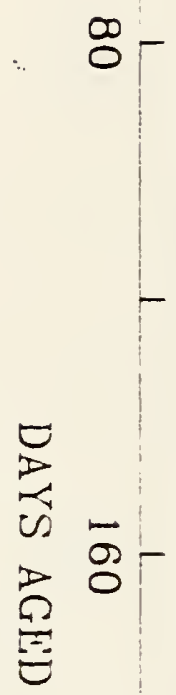

م-

$\stackrel{w}{0}$ 


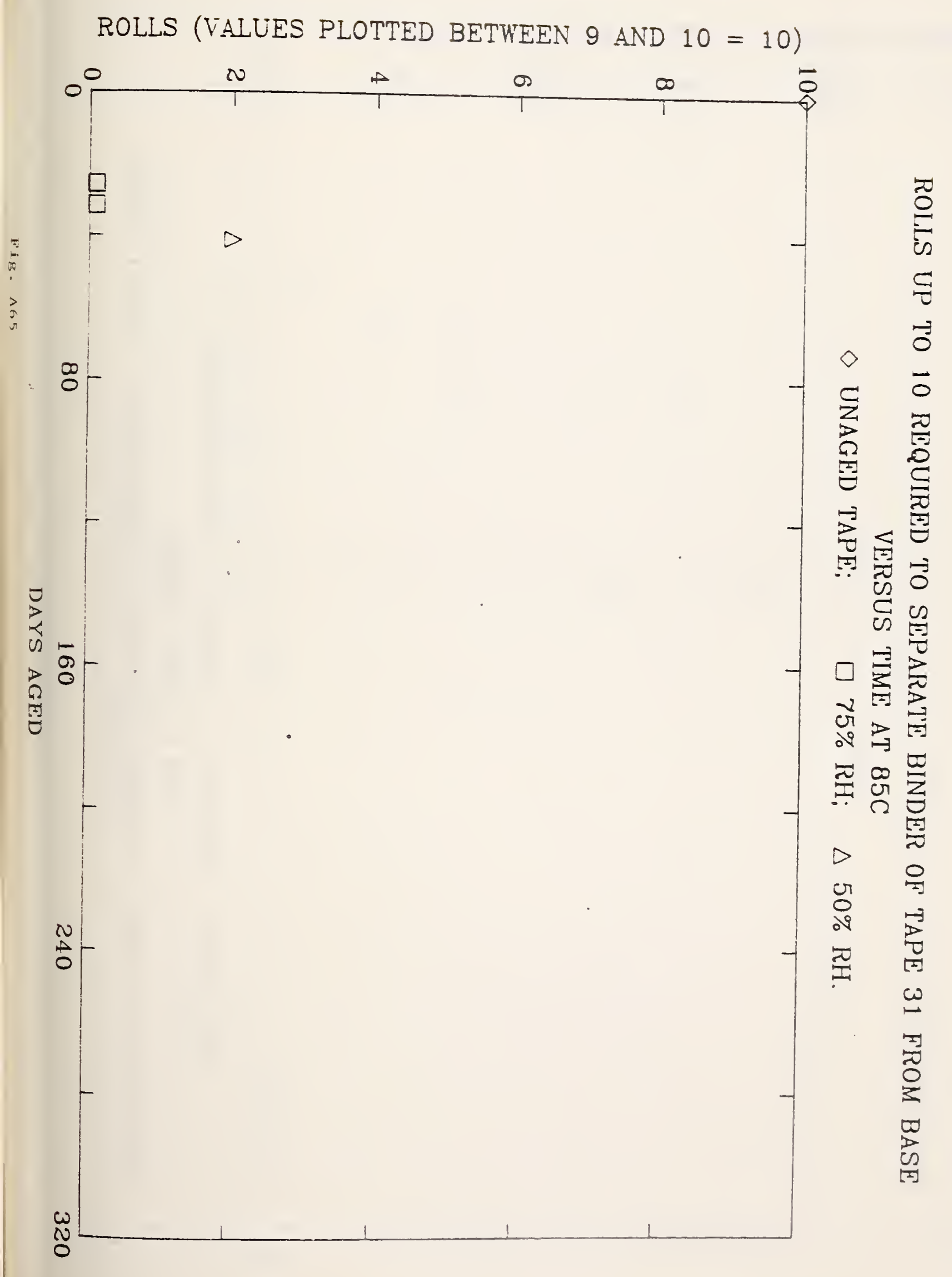




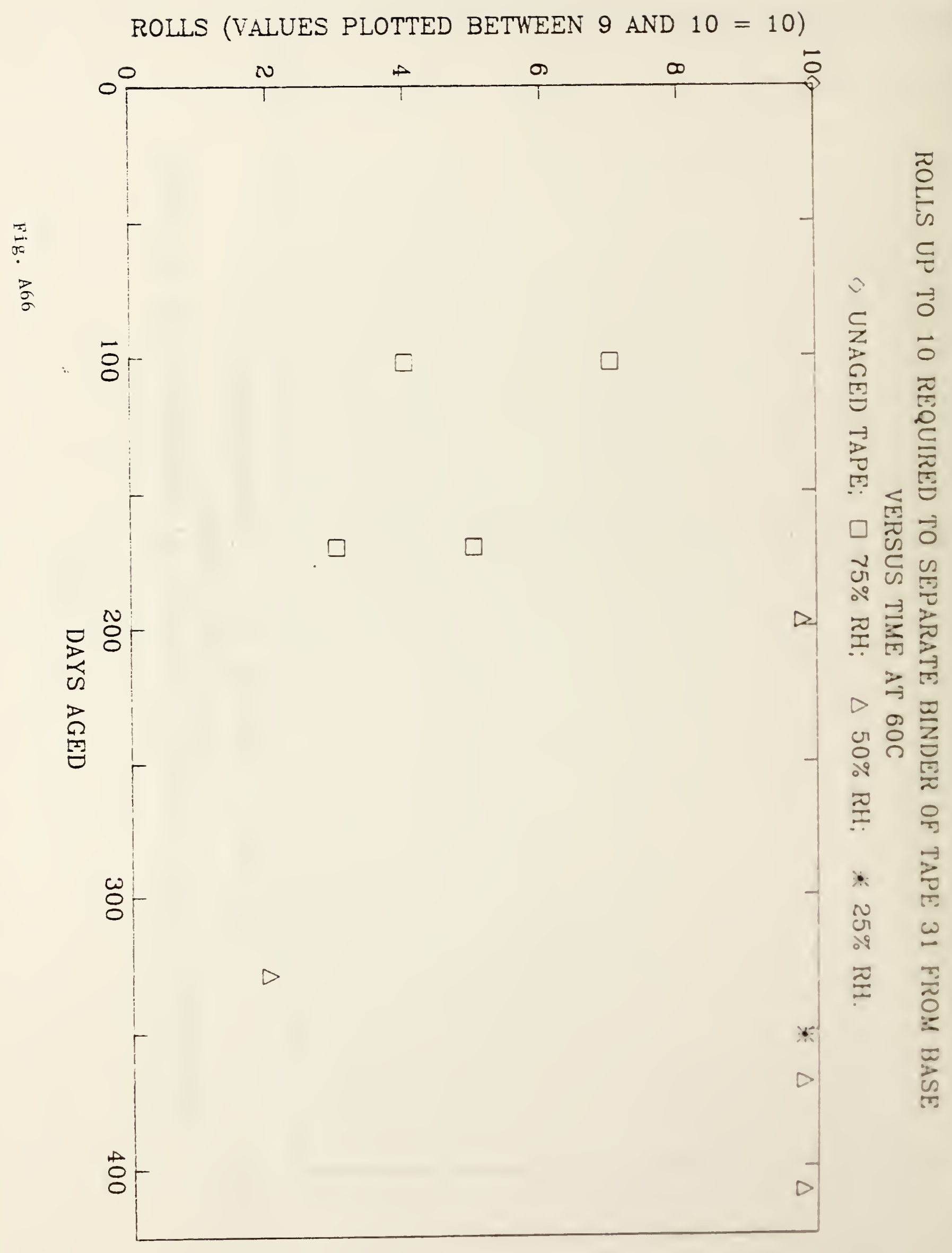


ROLLS (VALUES PLOTTED BETWEEN 9 AND $10=10$ )
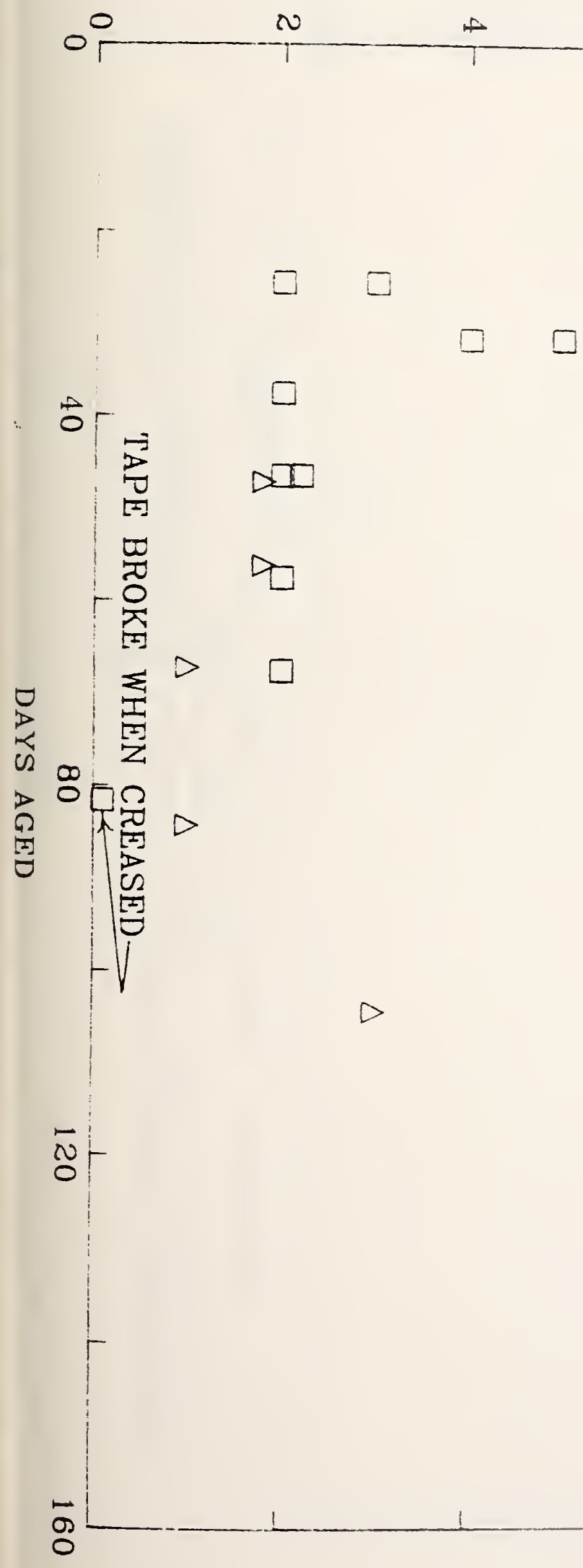

$D$ $\begin{array}{lll}1 & \infty & 0\end{array}$

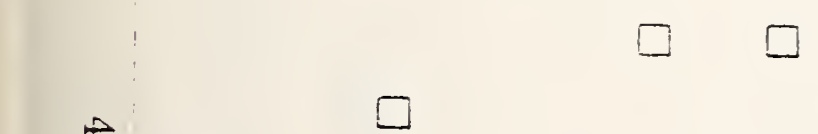


ROLLS (VALUES PLOTTED BETHEEN 9 AND $10=10$ )

$=$
$=$
$\infty$
$\infty$

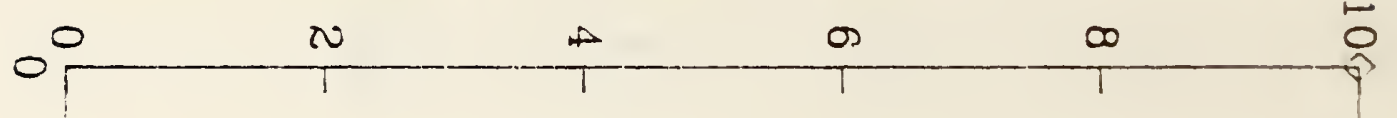

$\stackrel{\infty}{\circ}+$

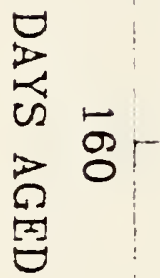
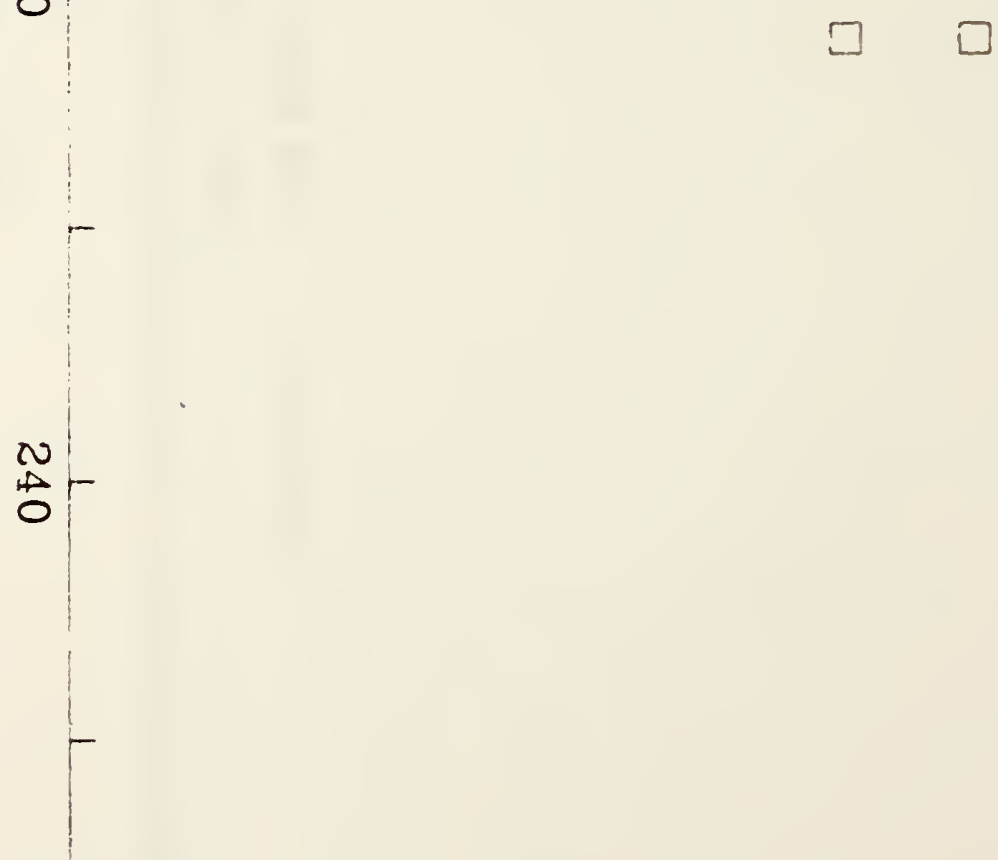

w 


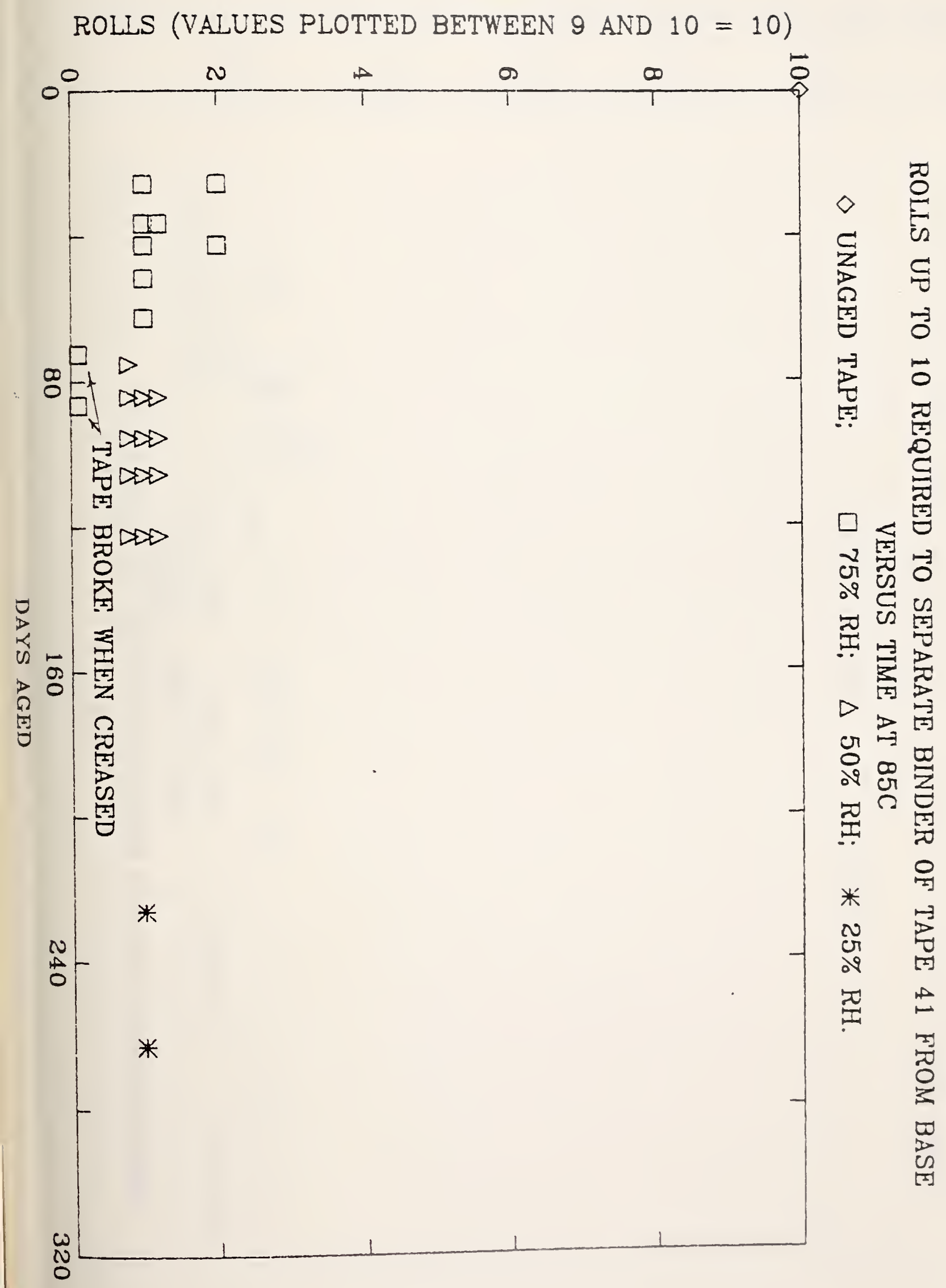


ROLLS (VALUES PLOTTED BETWEEN 9 AND $10=10$ )

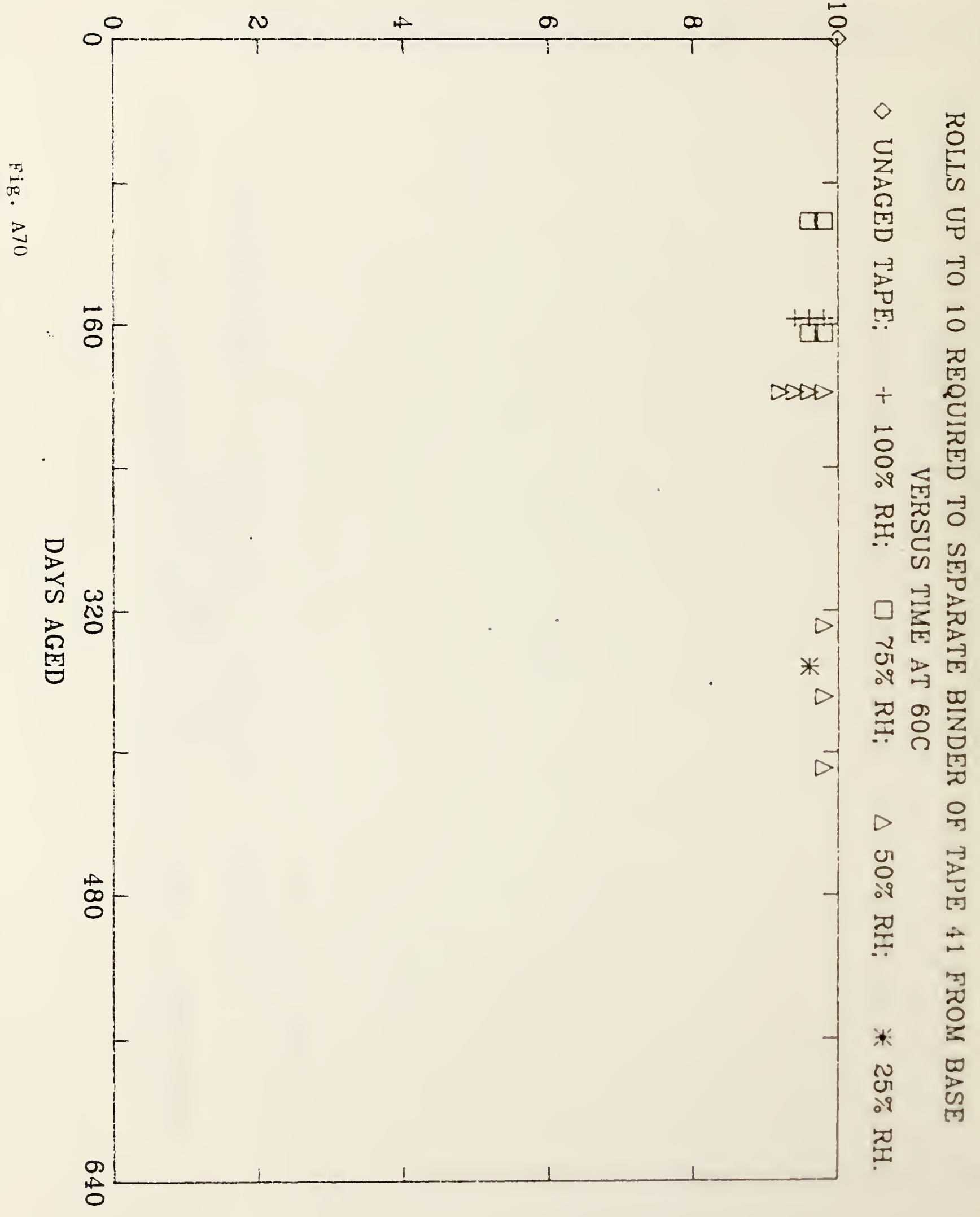




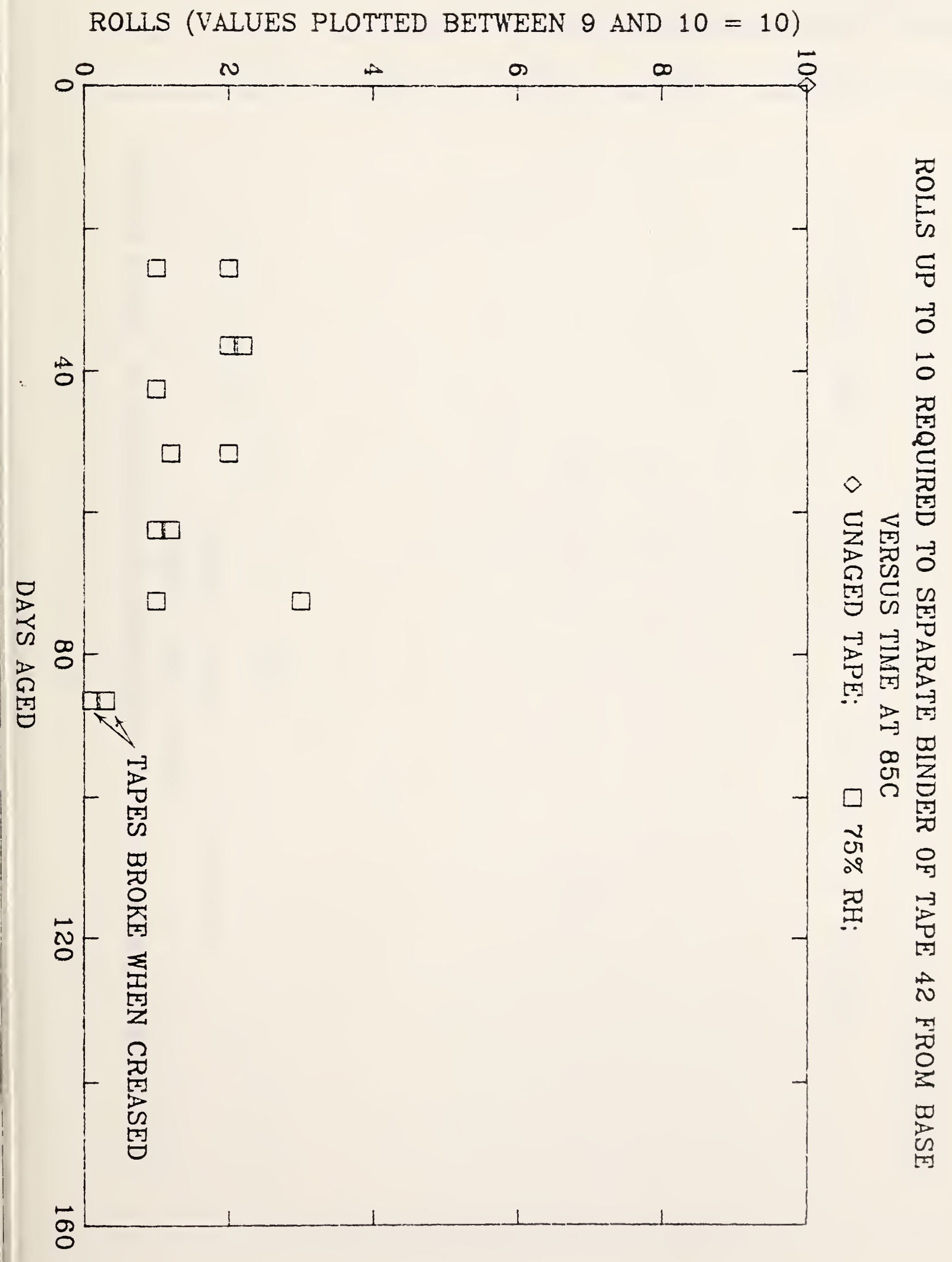


ROLLS (VALUES PLOTTED BETWEEN 9 AND $10=10$ )

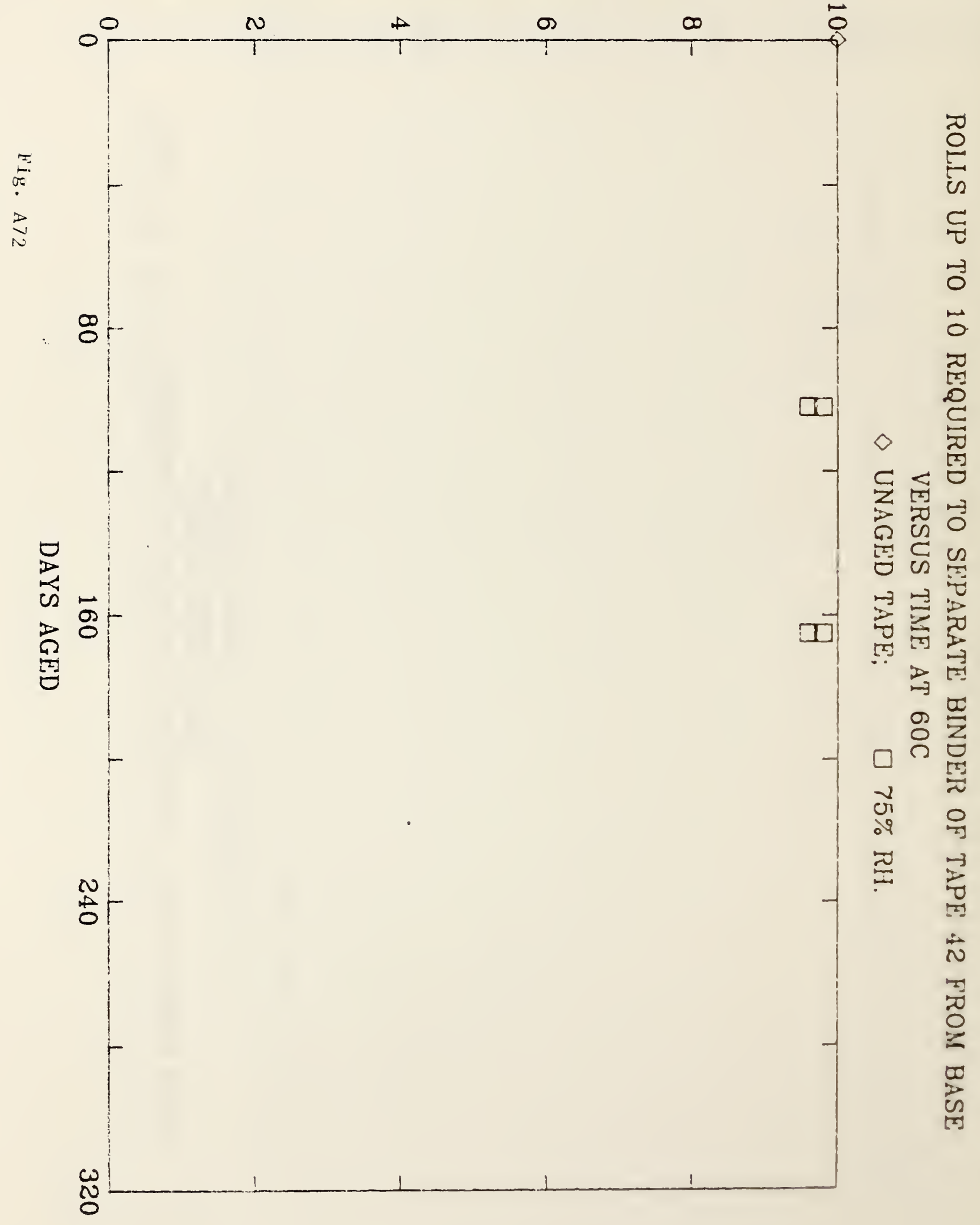




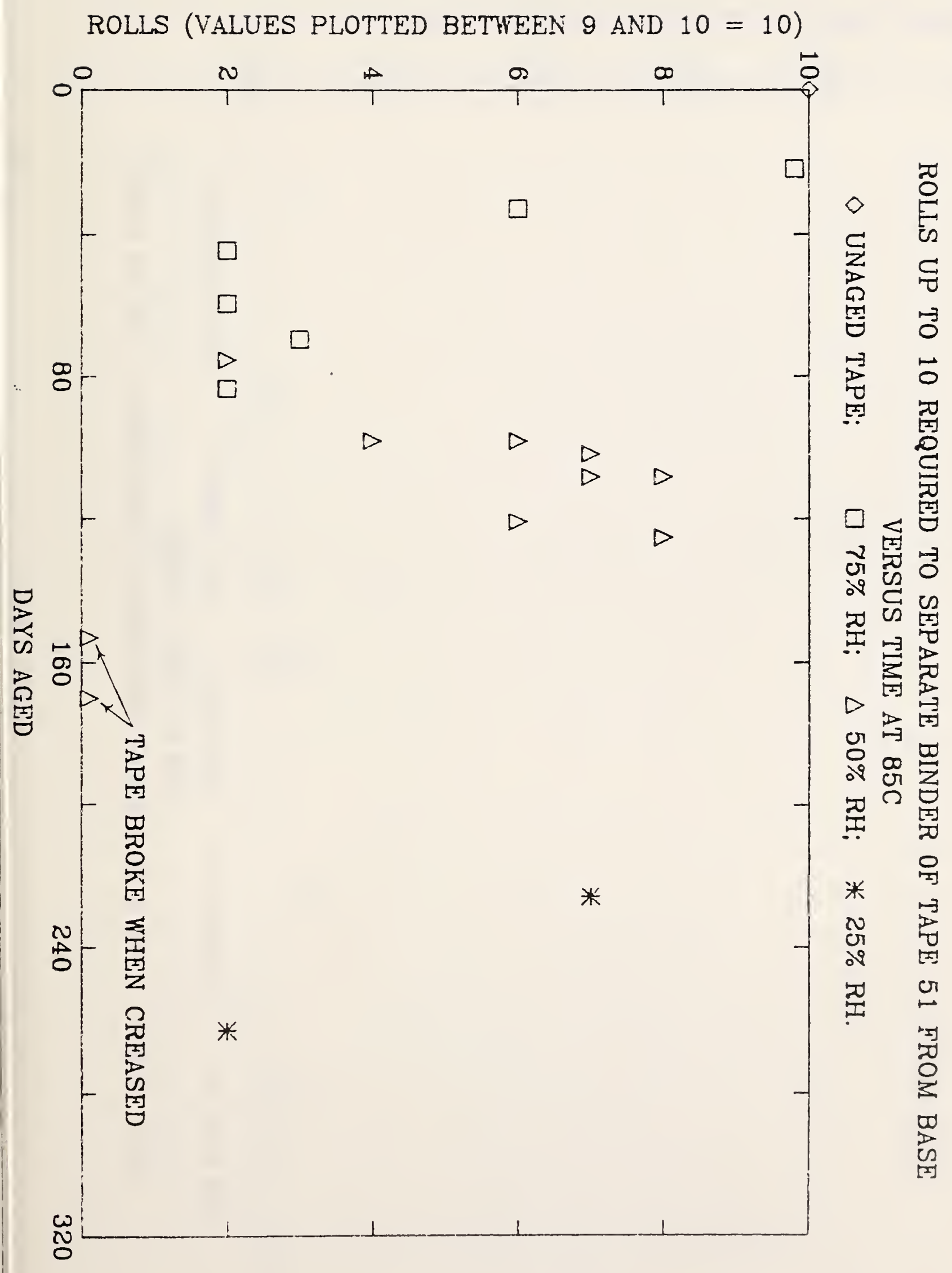


ROLLS (VALUES PLOTTED BETWEEN 9 AND $10=10$ )

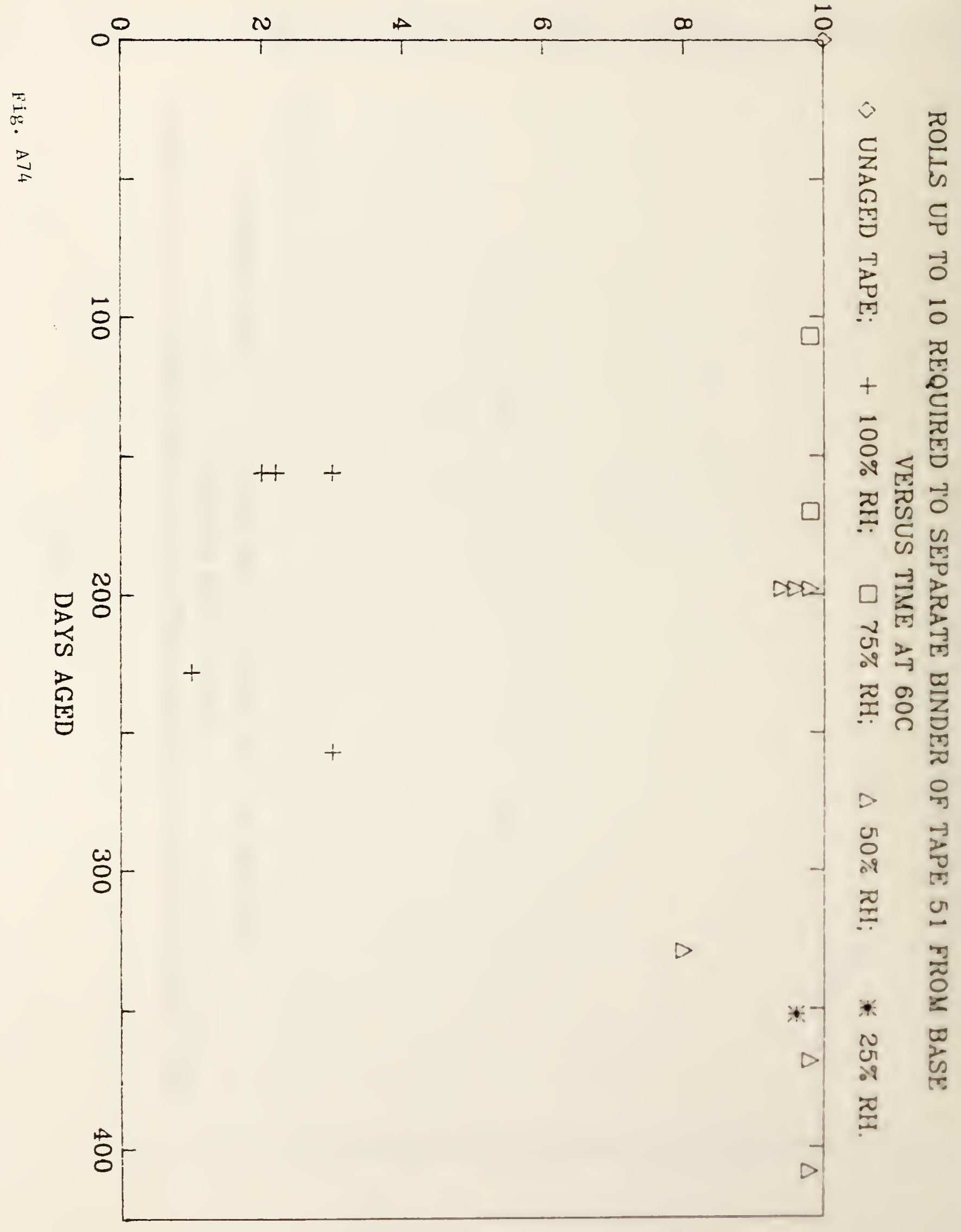




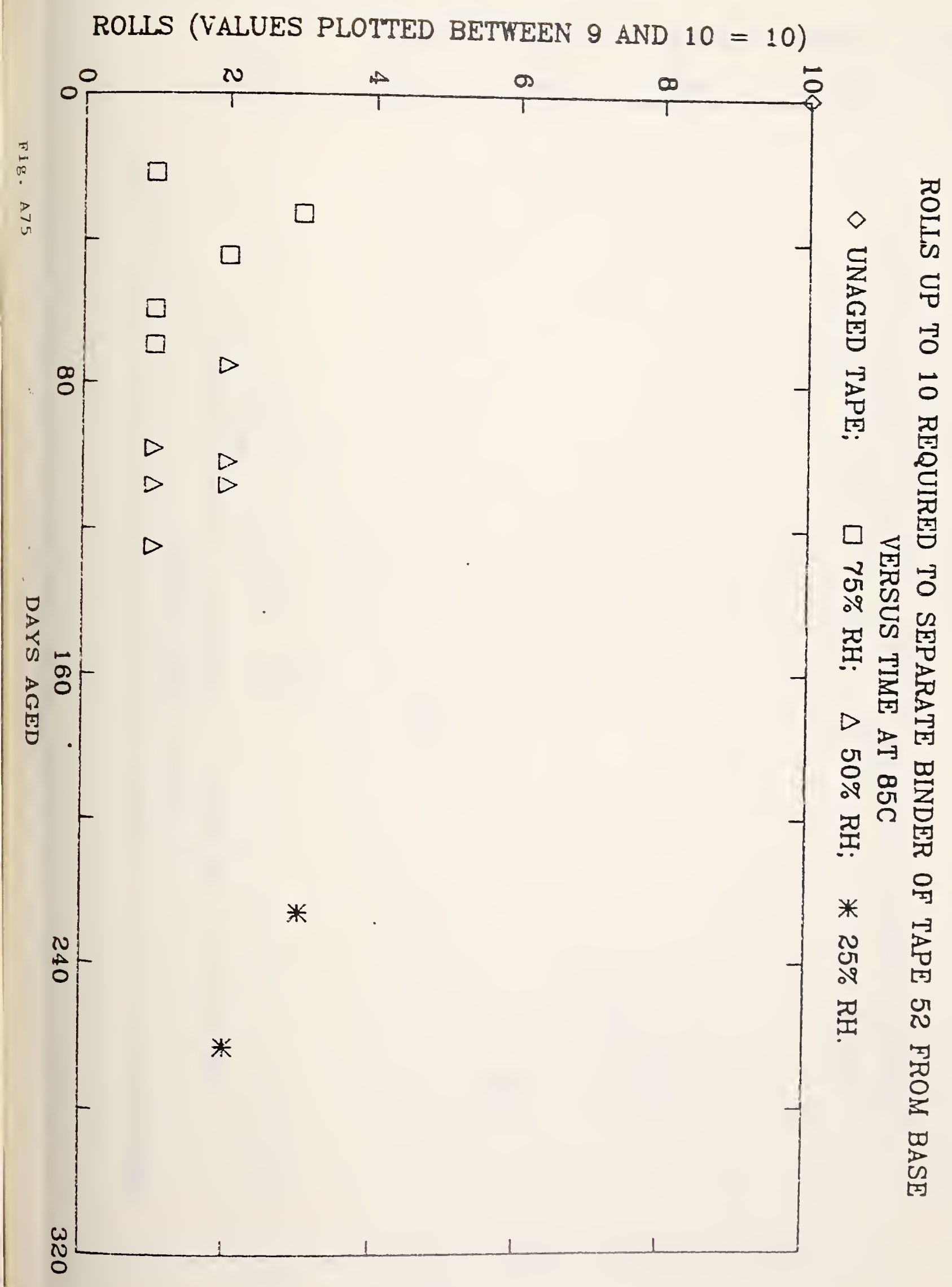


ROLLS (VALUES PLOTTED BETWEEN 9 AND $10=10$ )

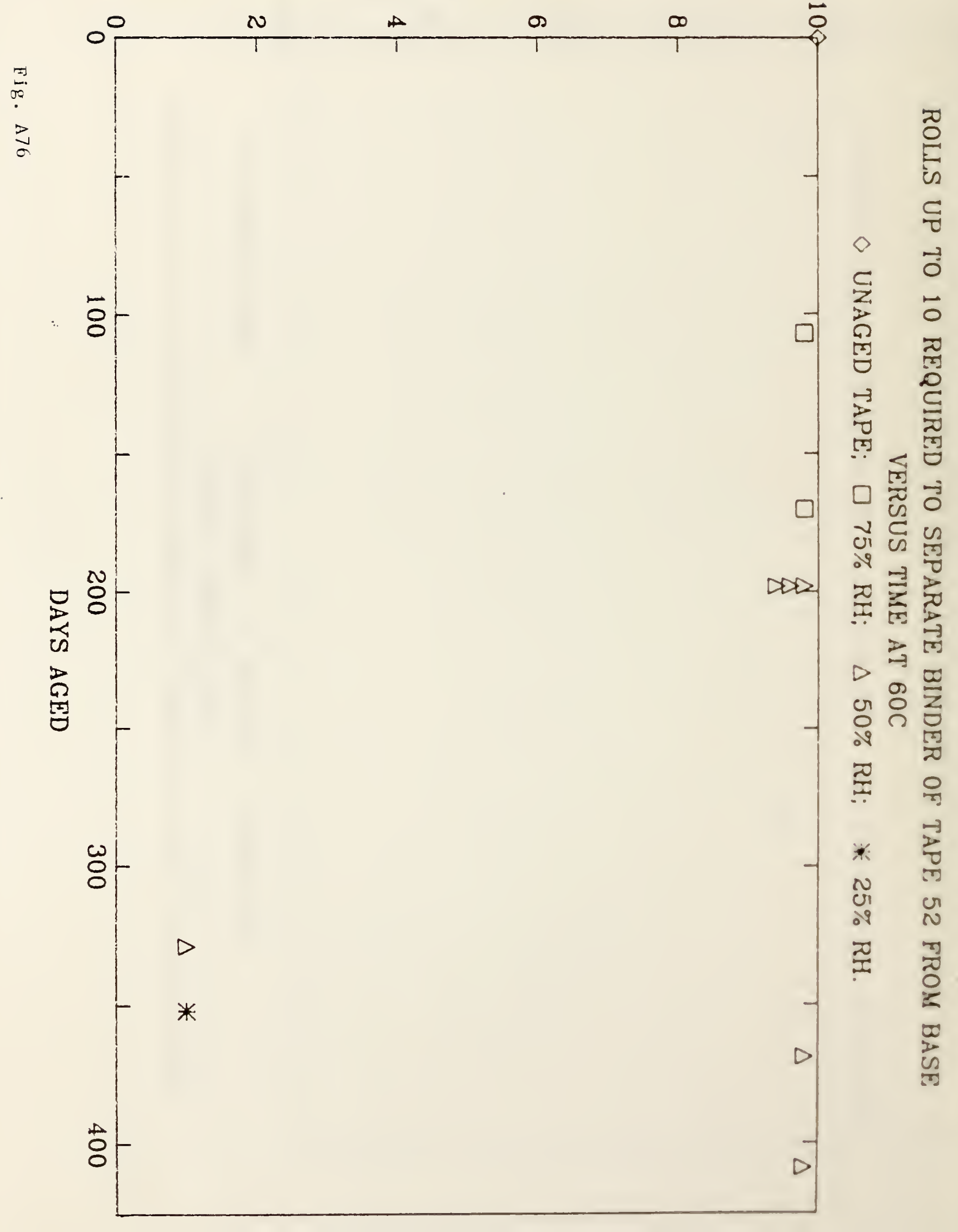




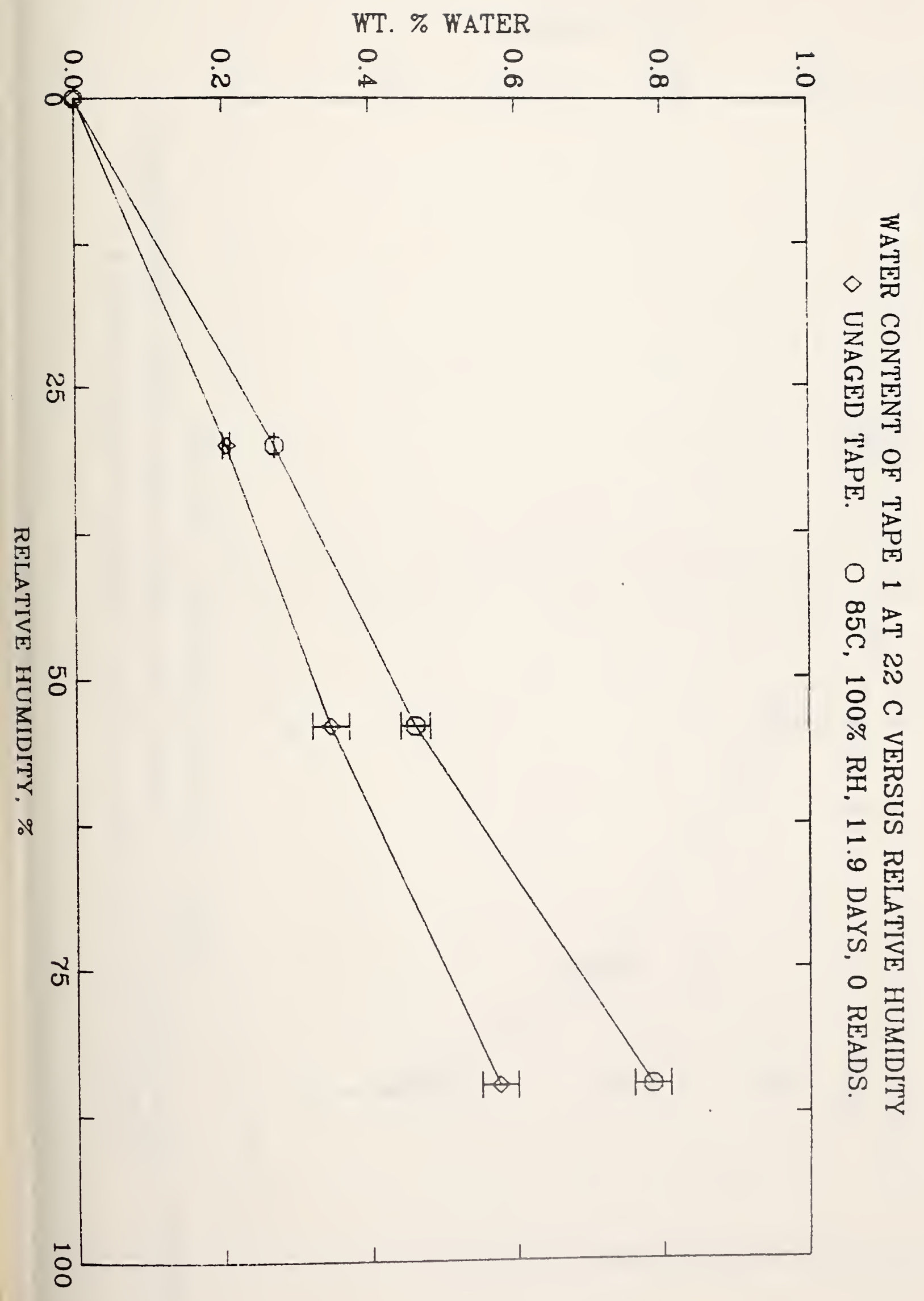




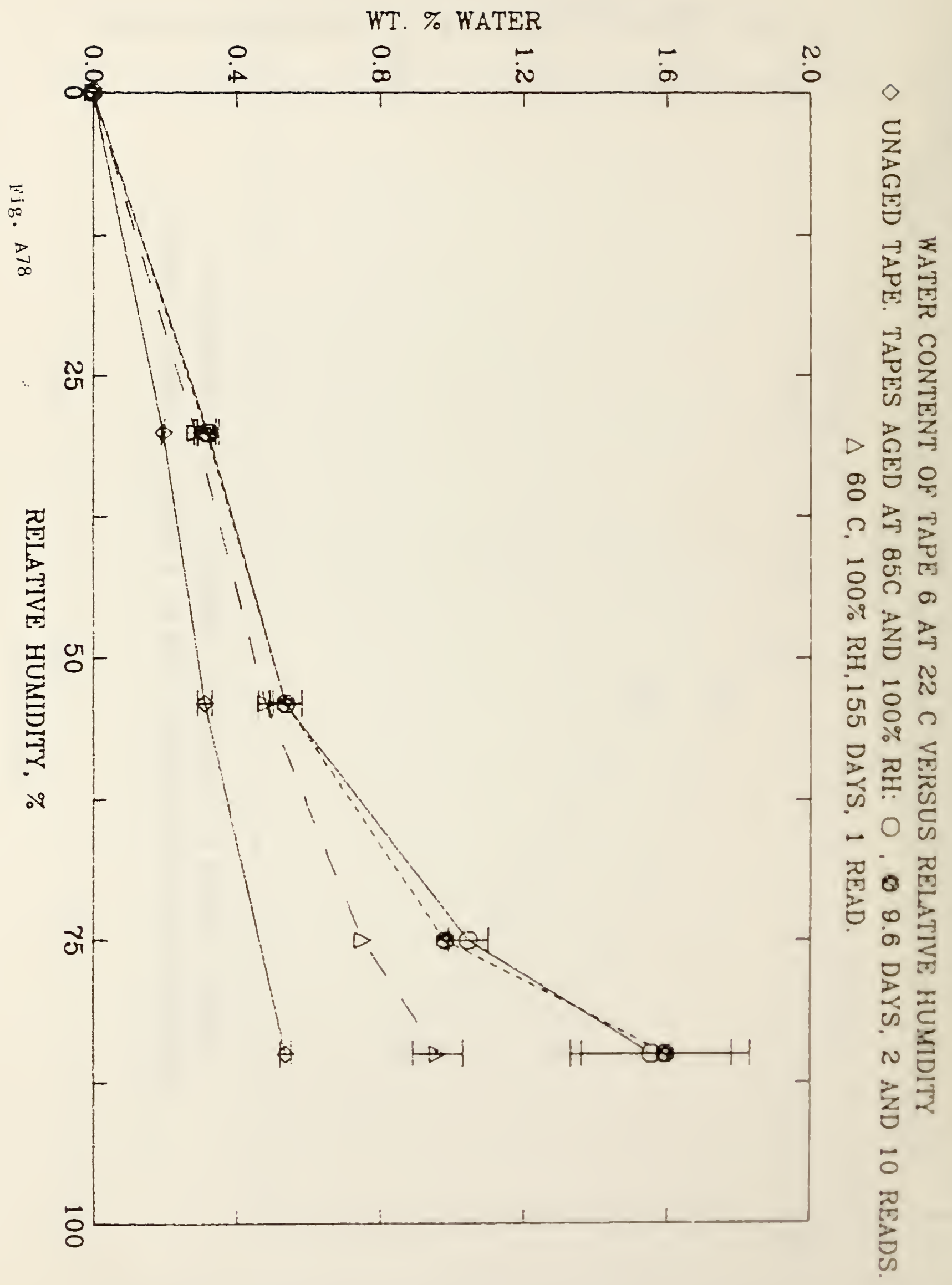




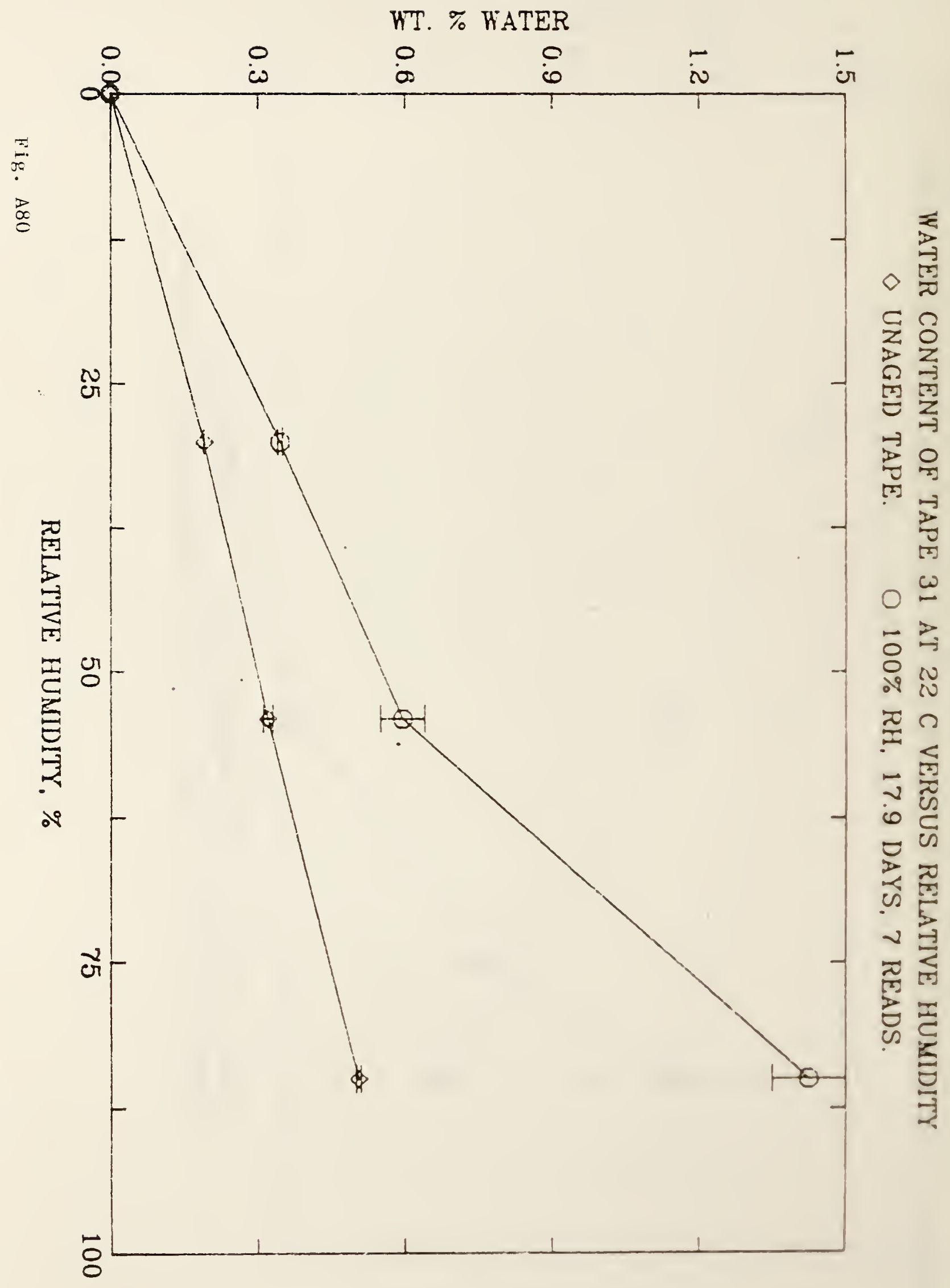




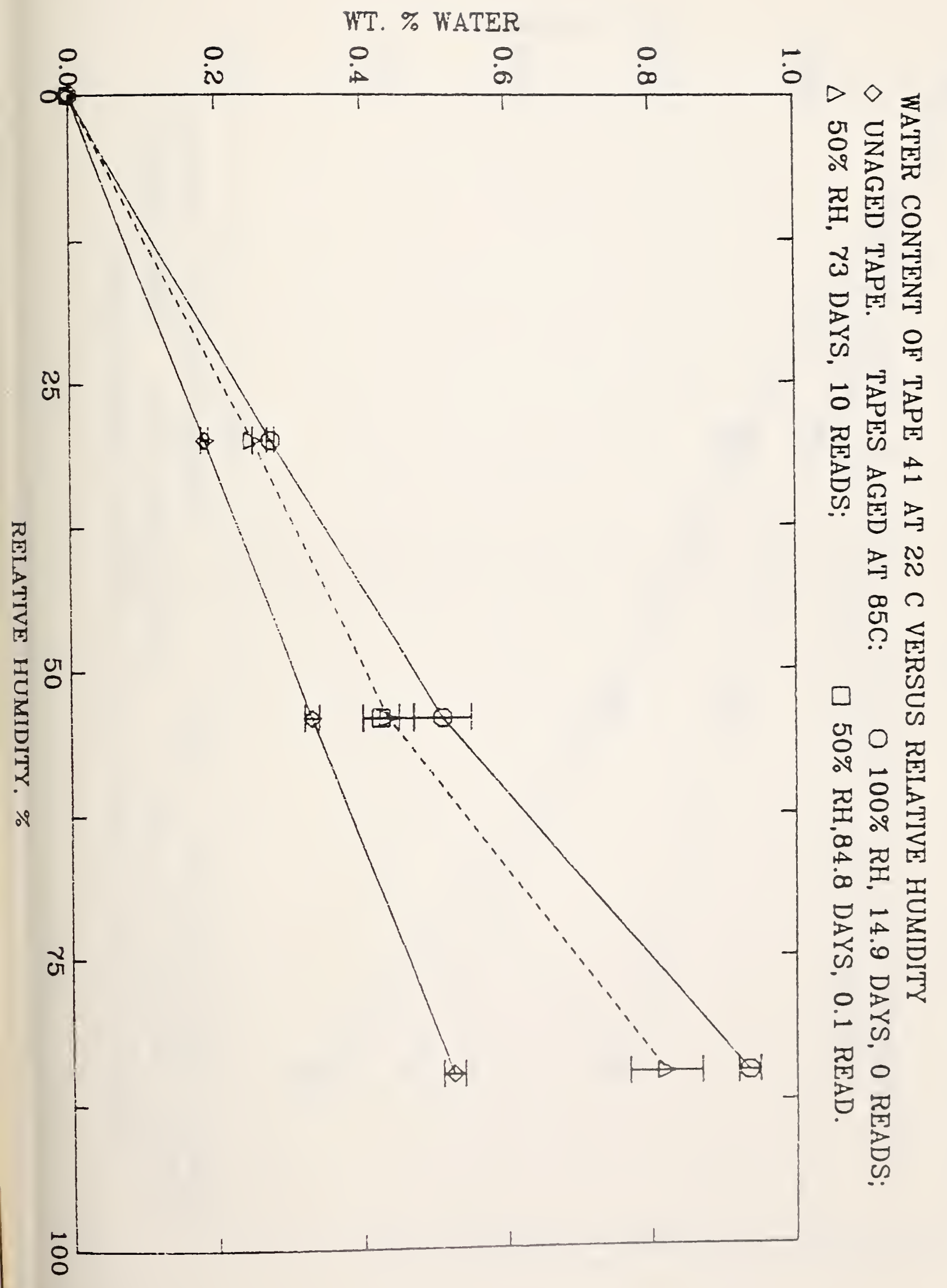




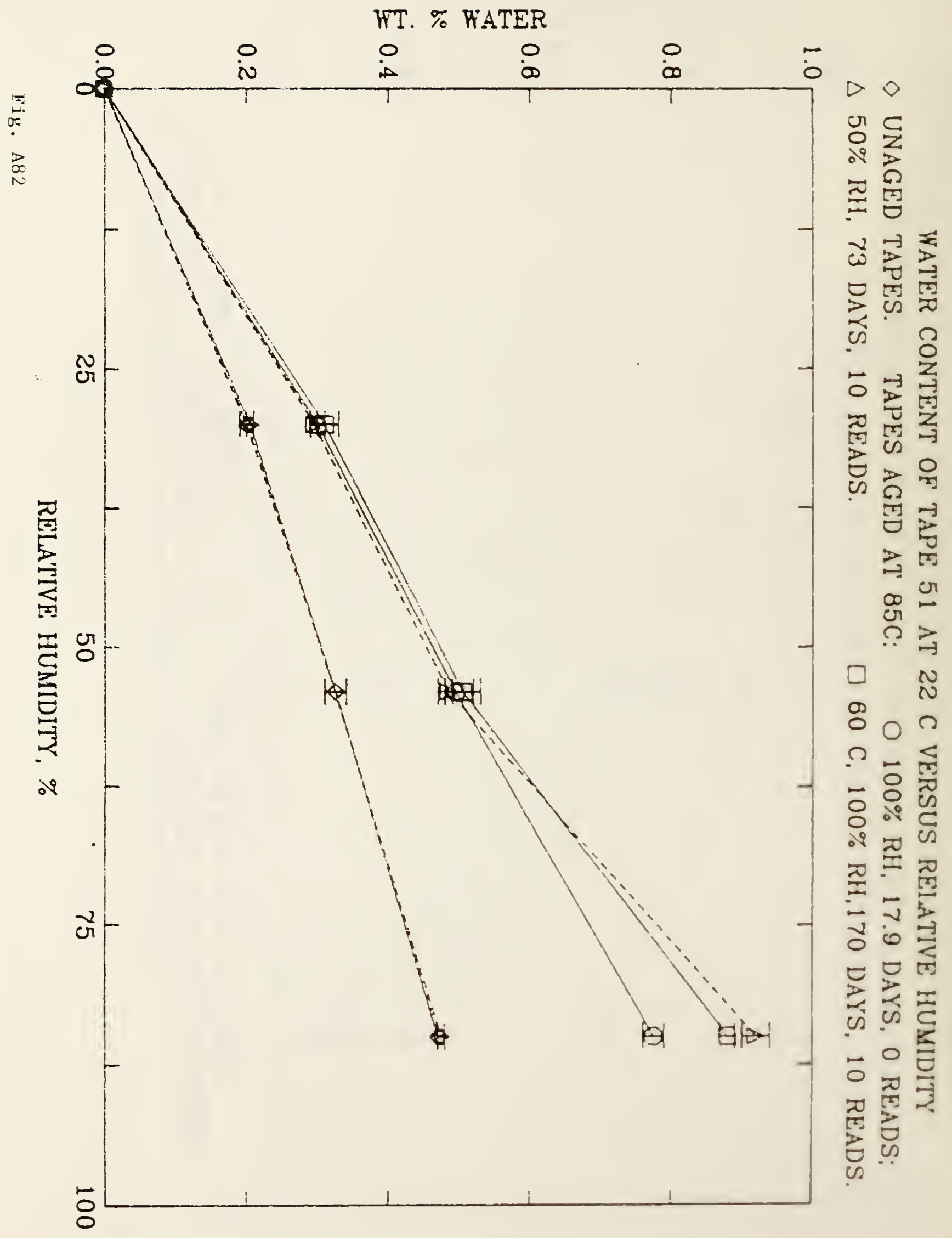




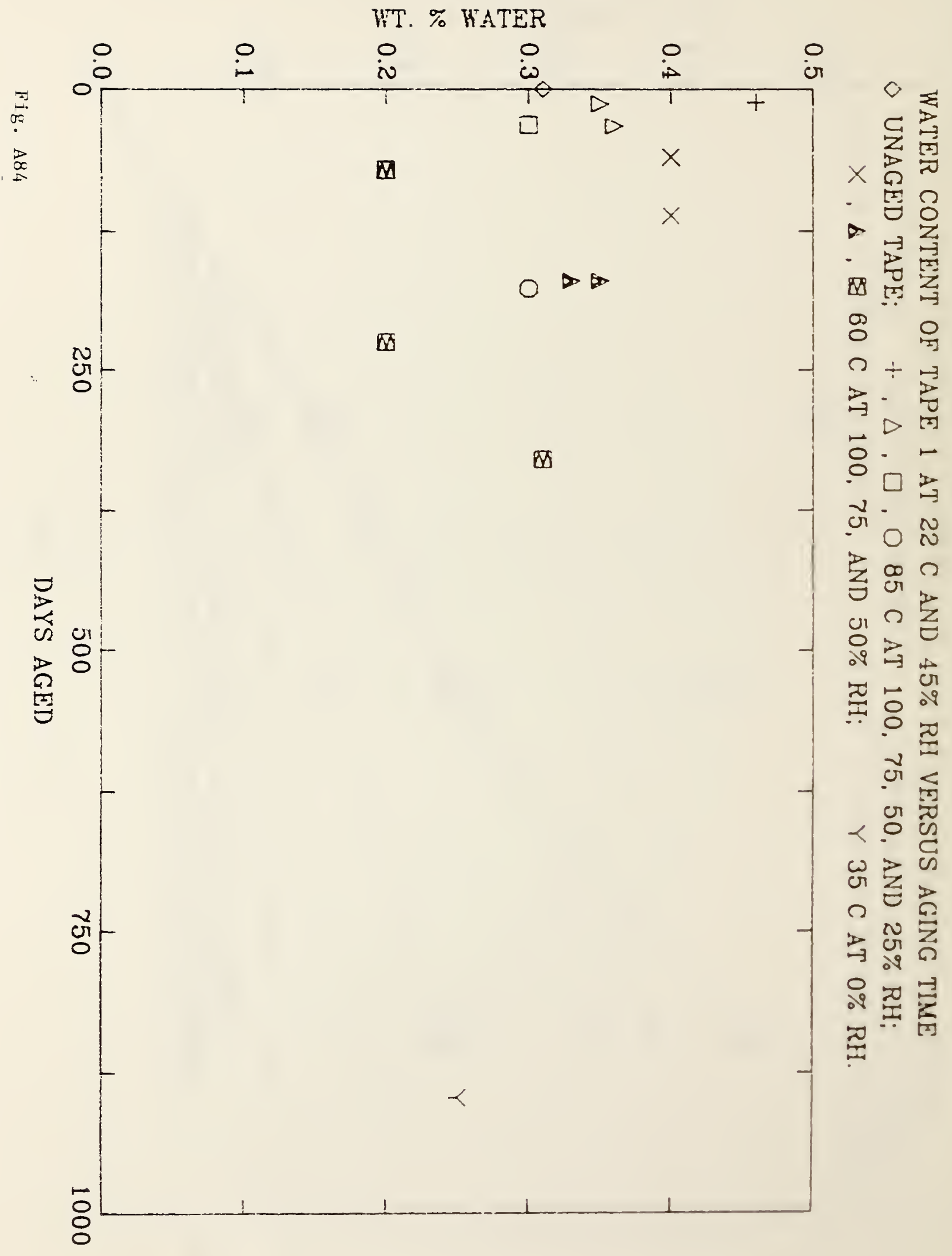




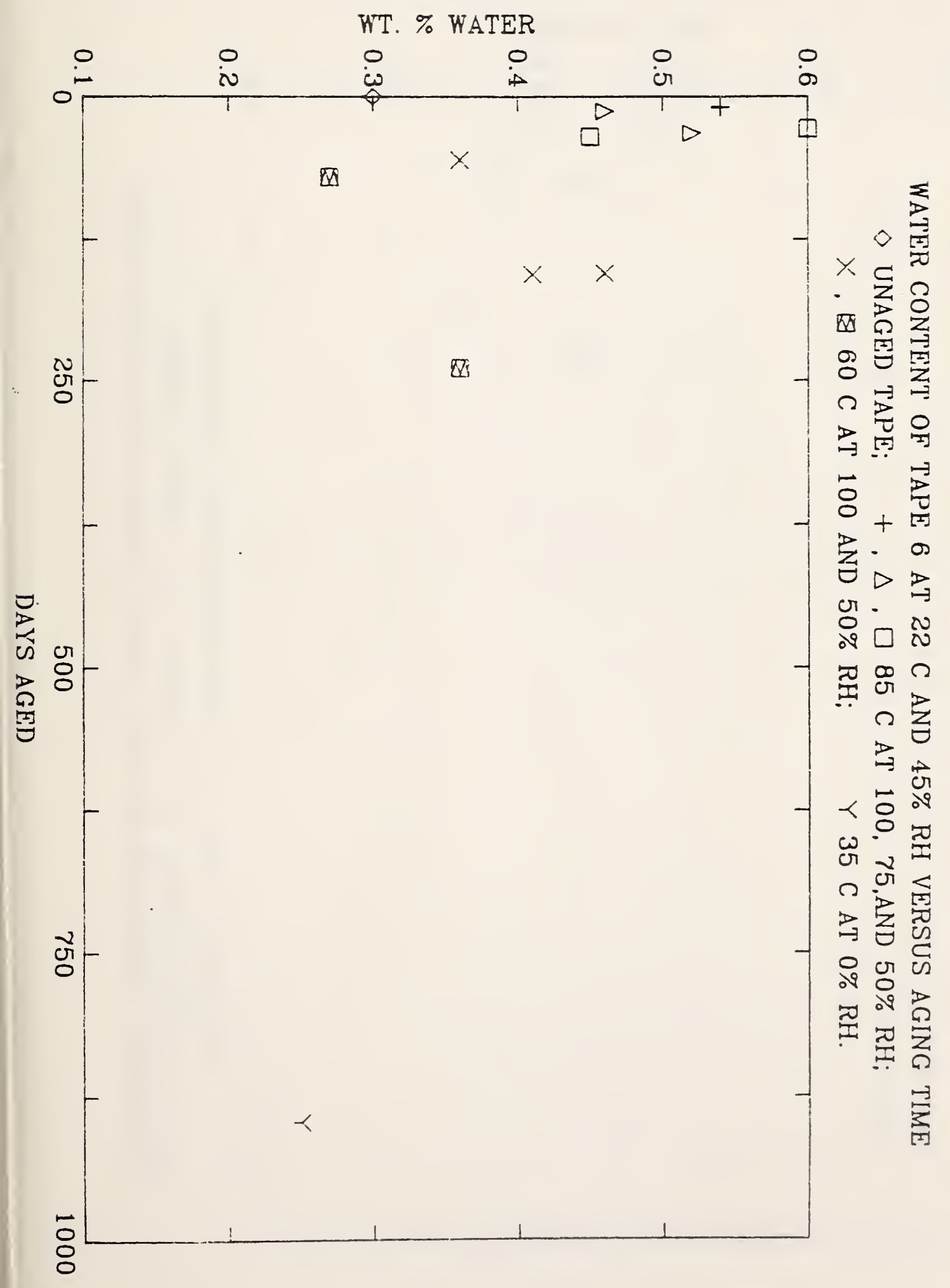




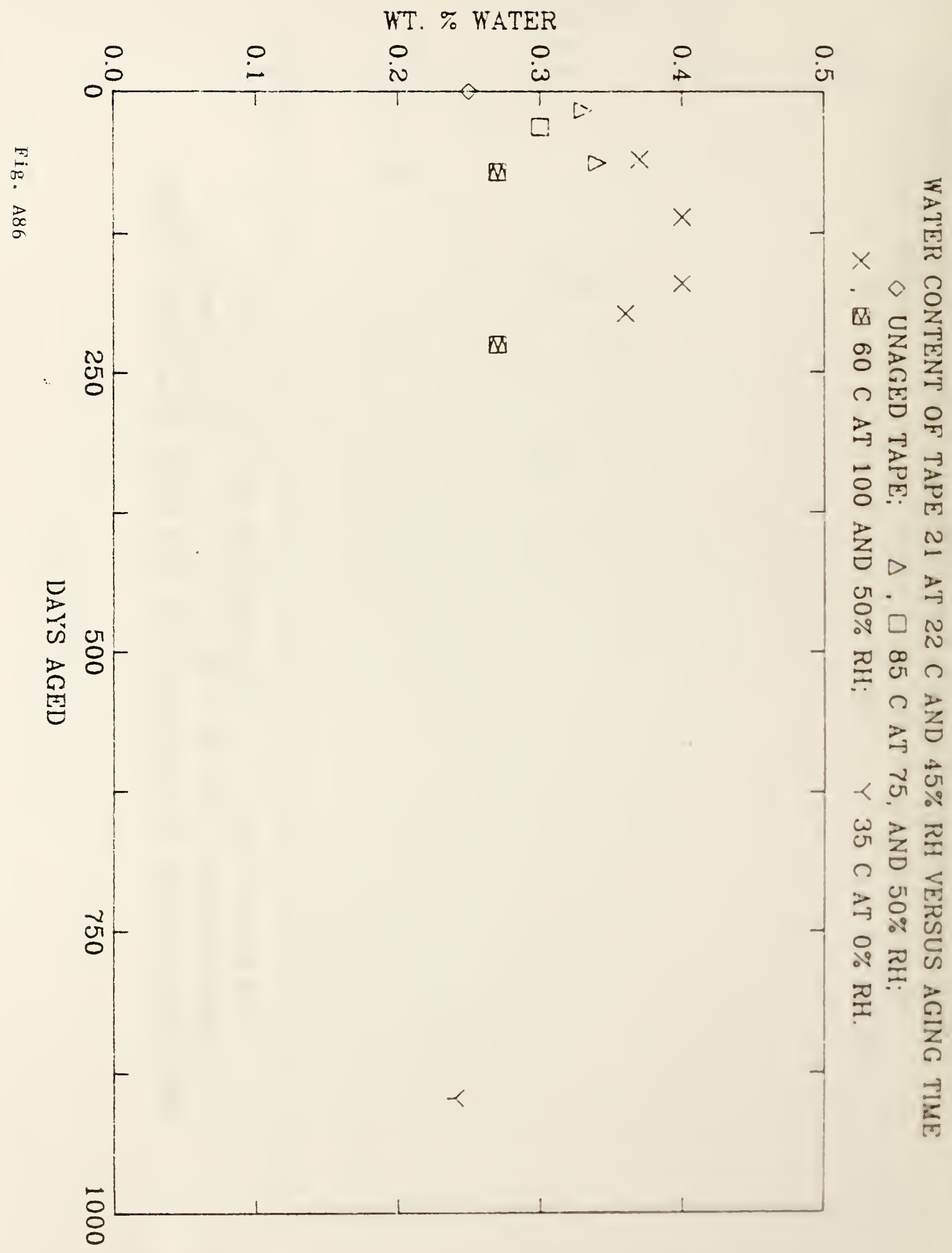




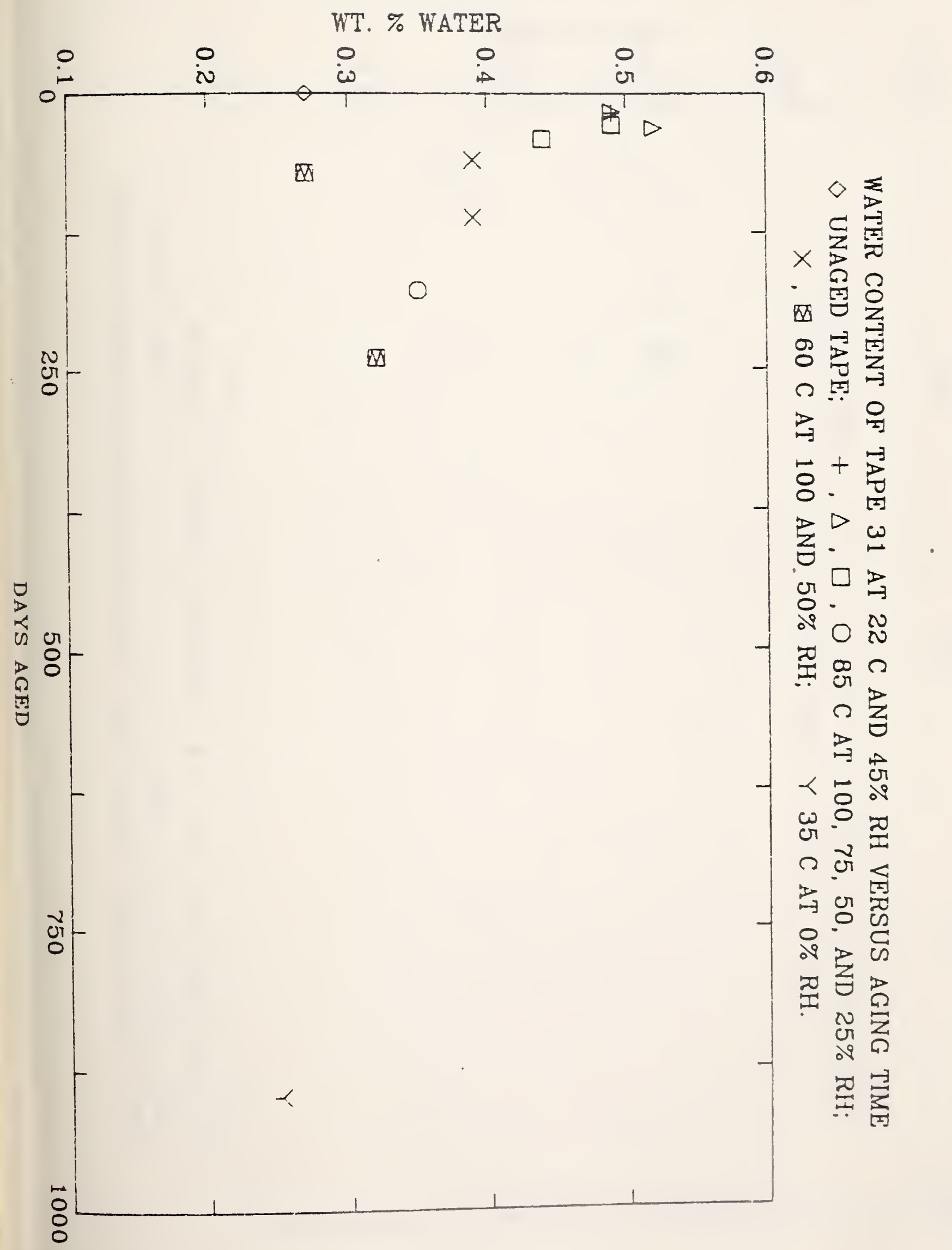




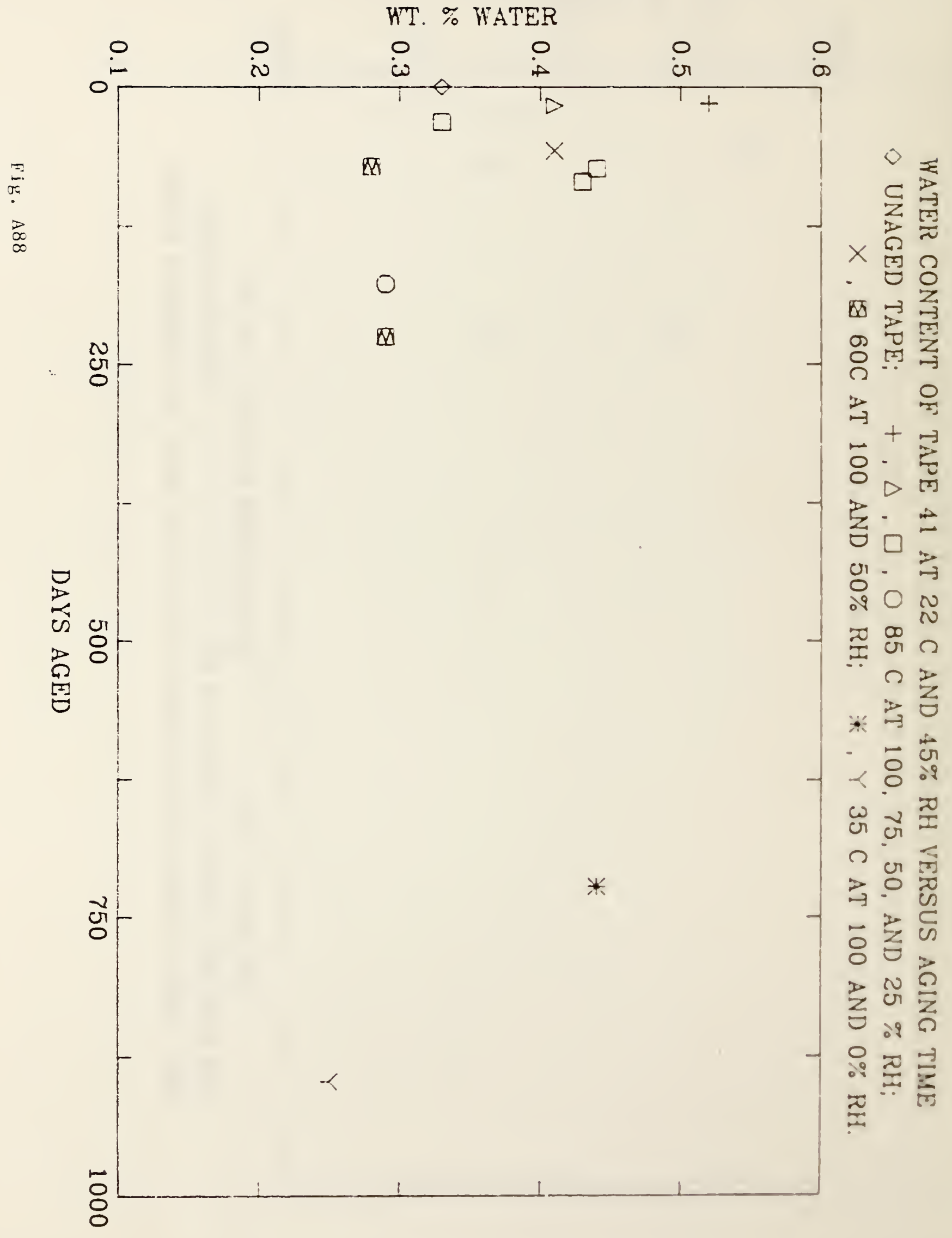




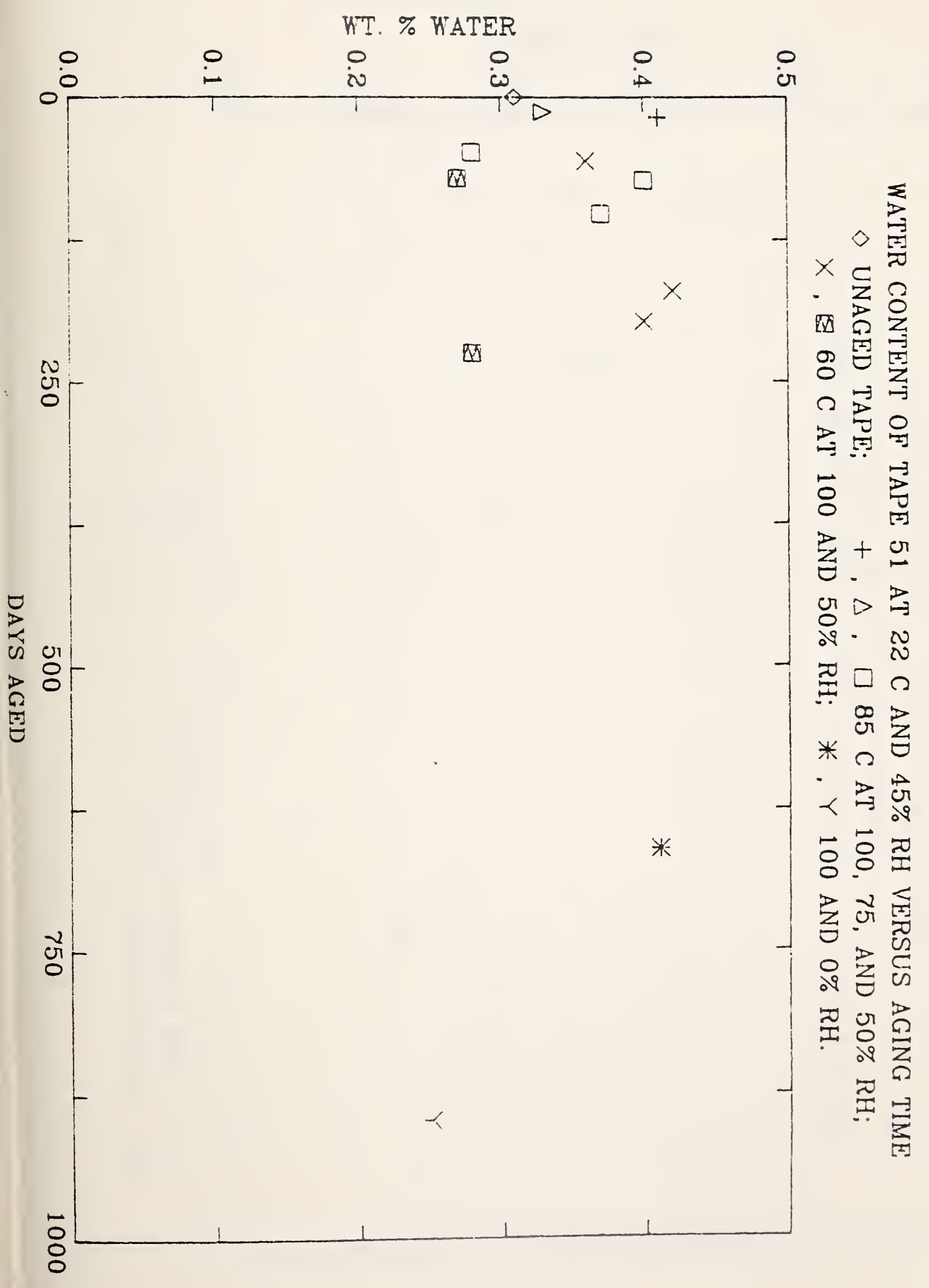




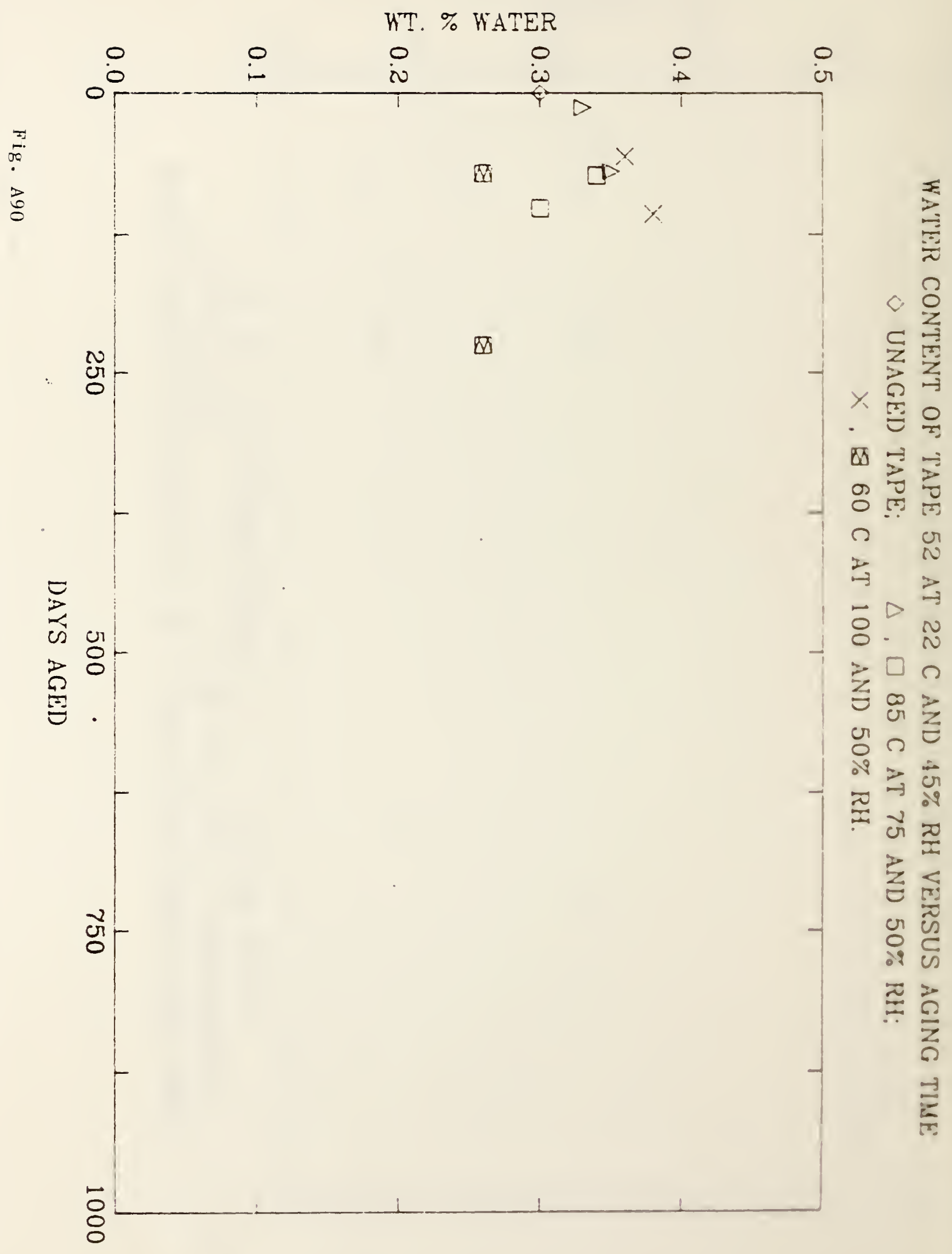




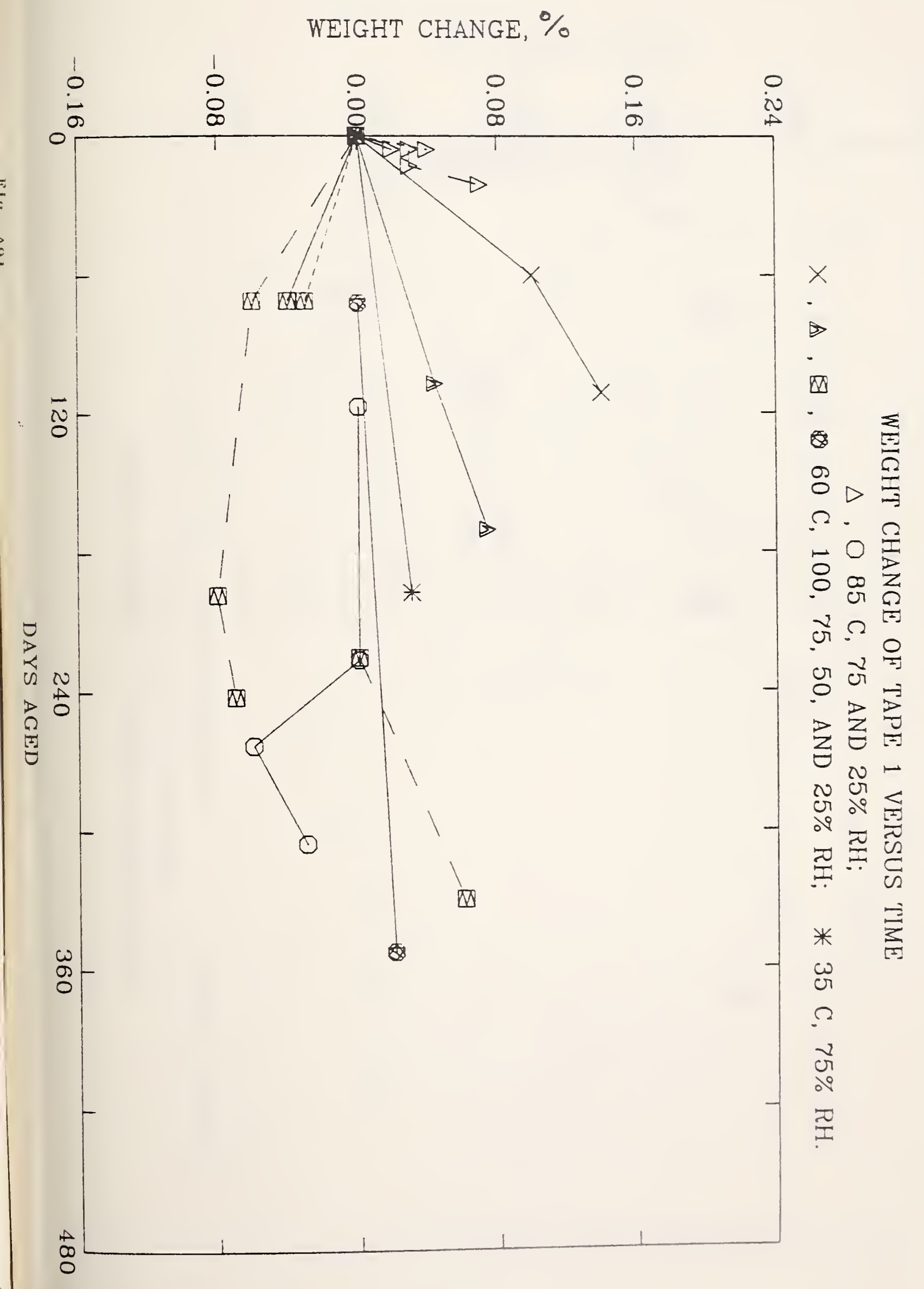




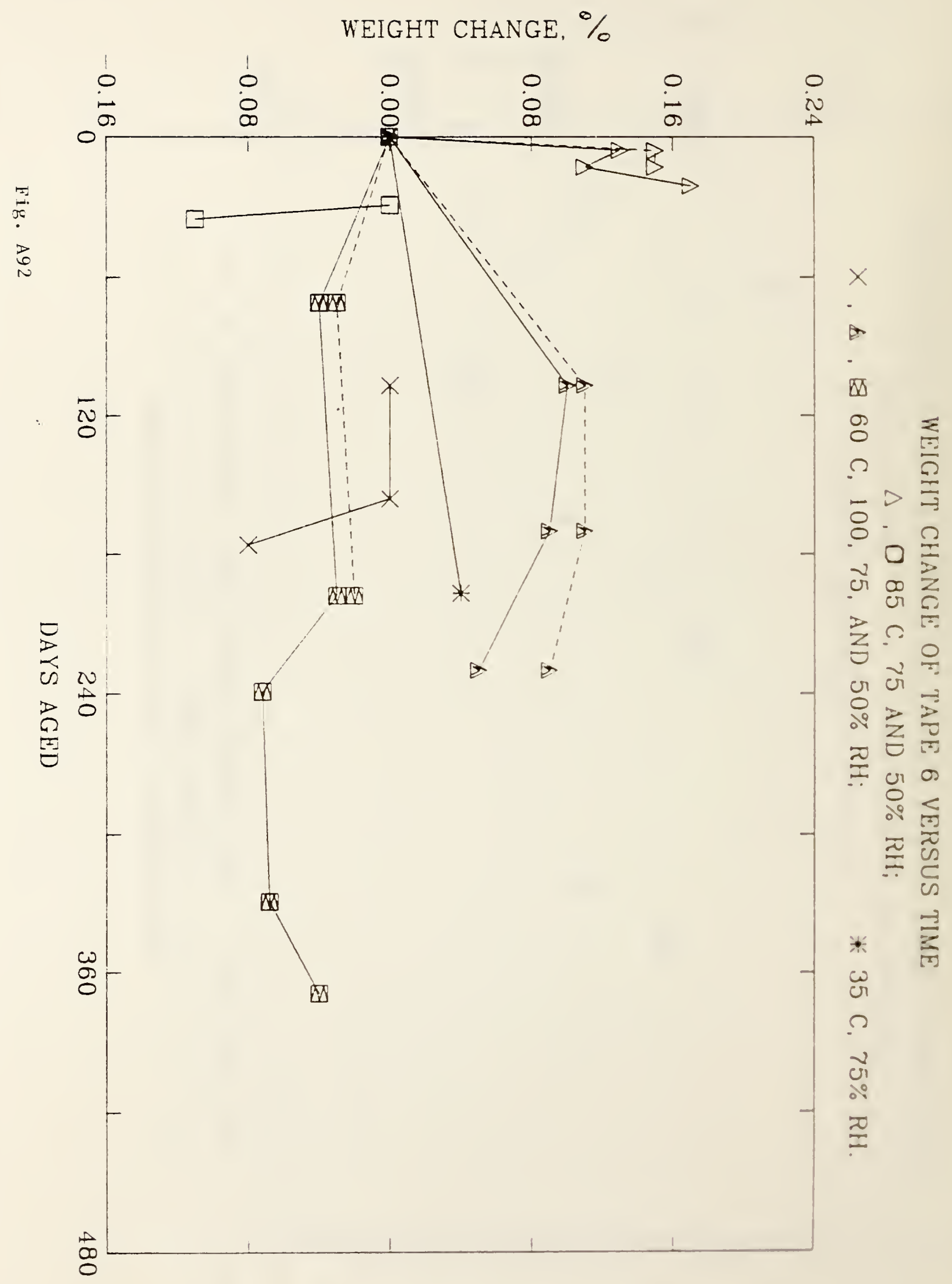




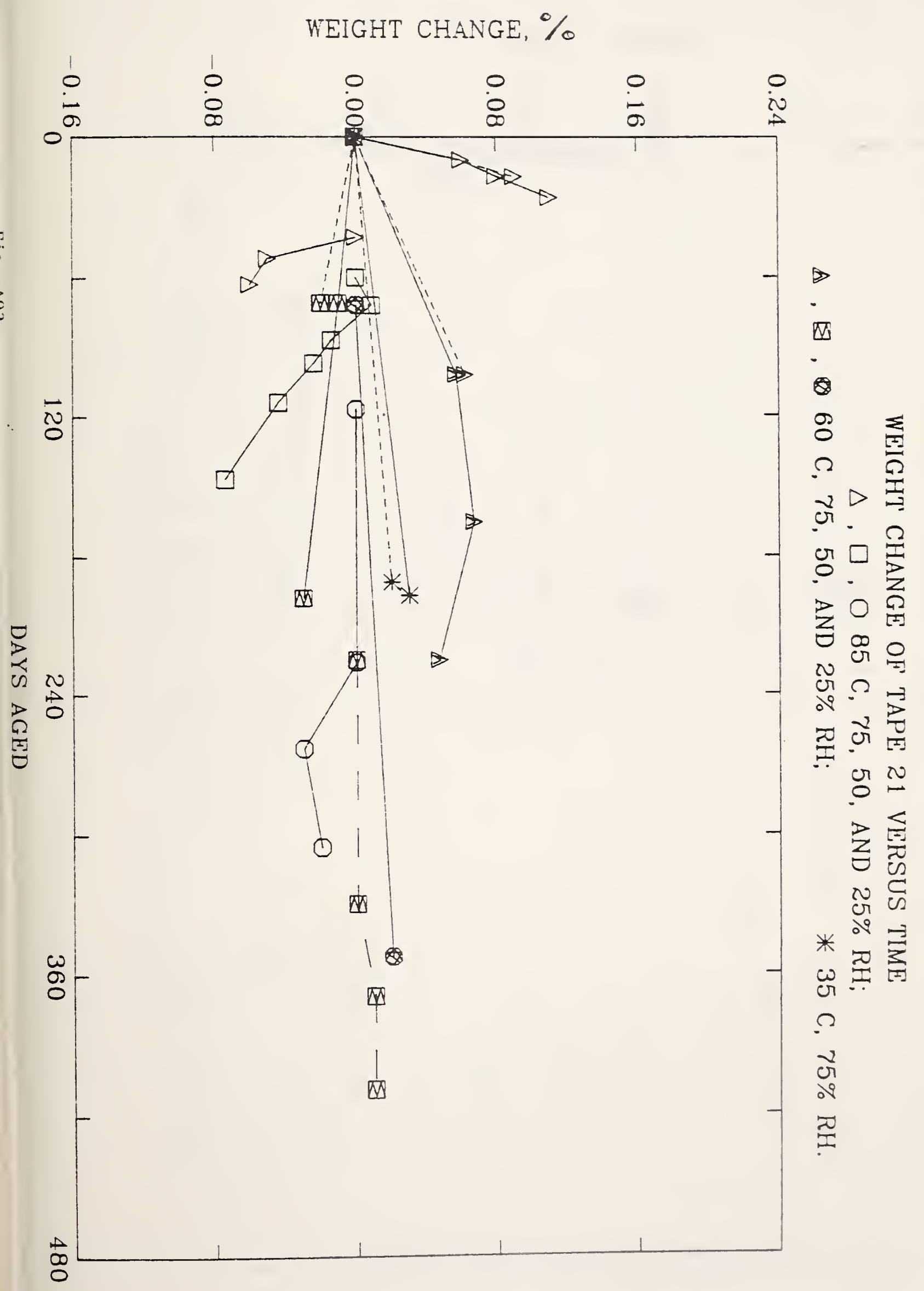




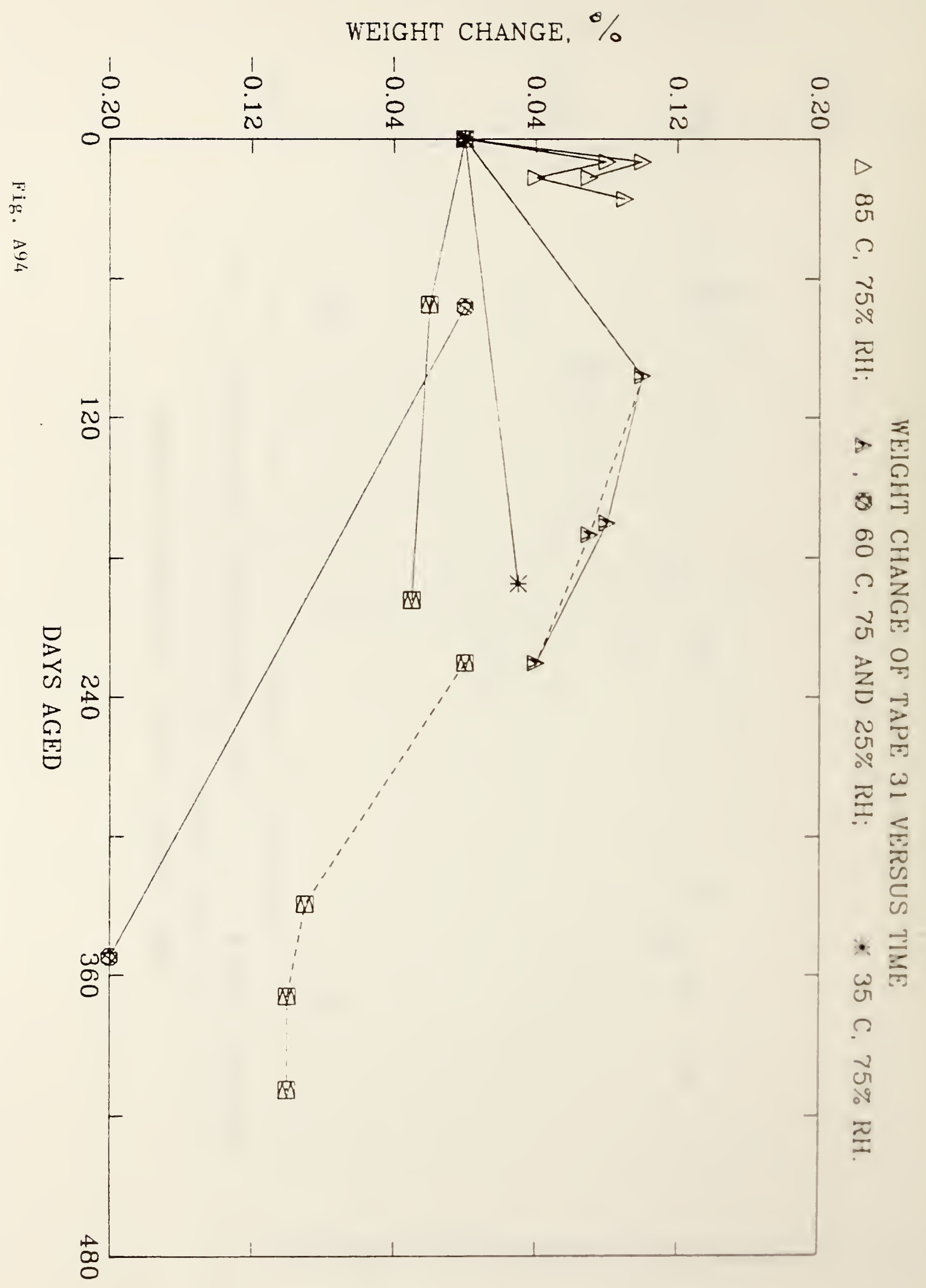




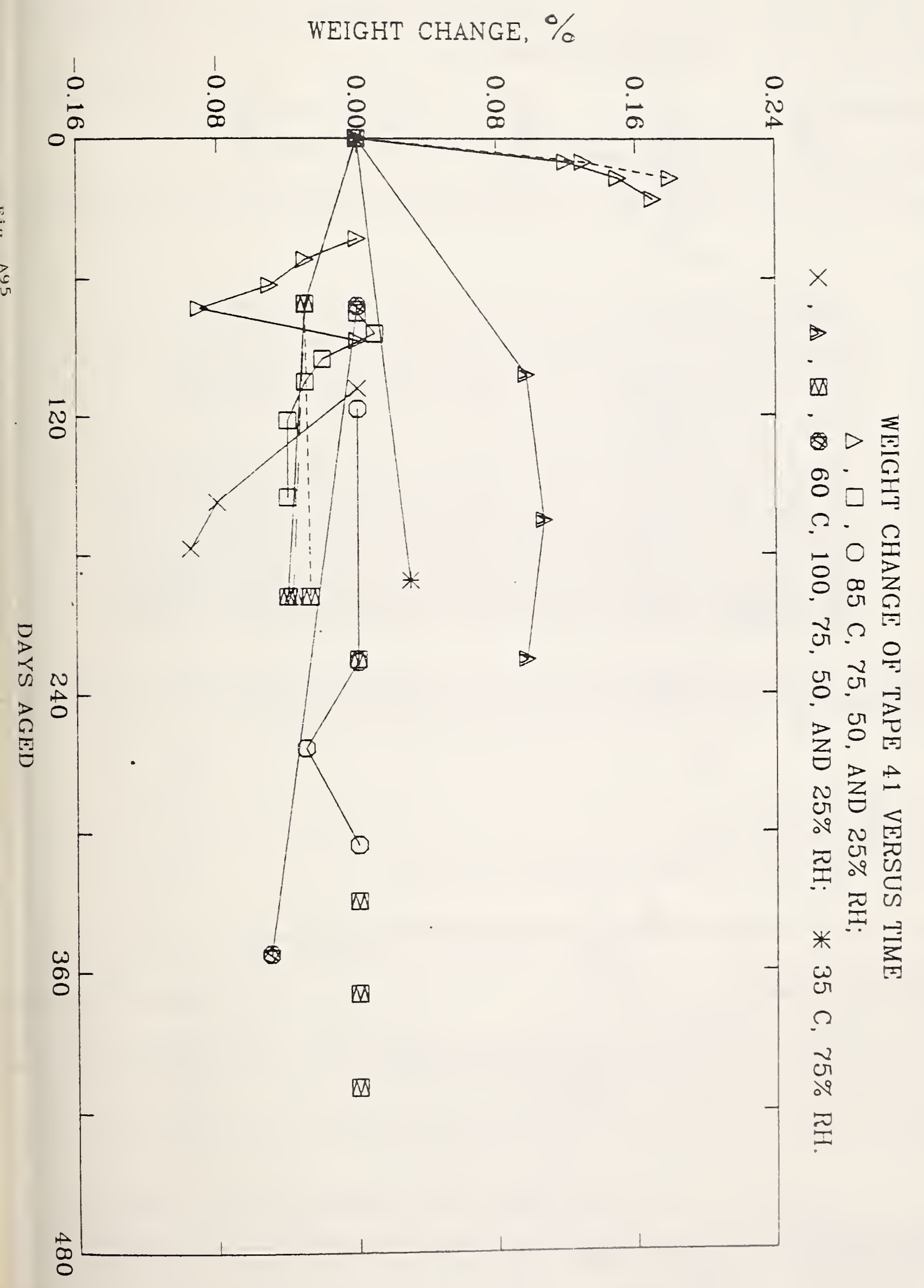




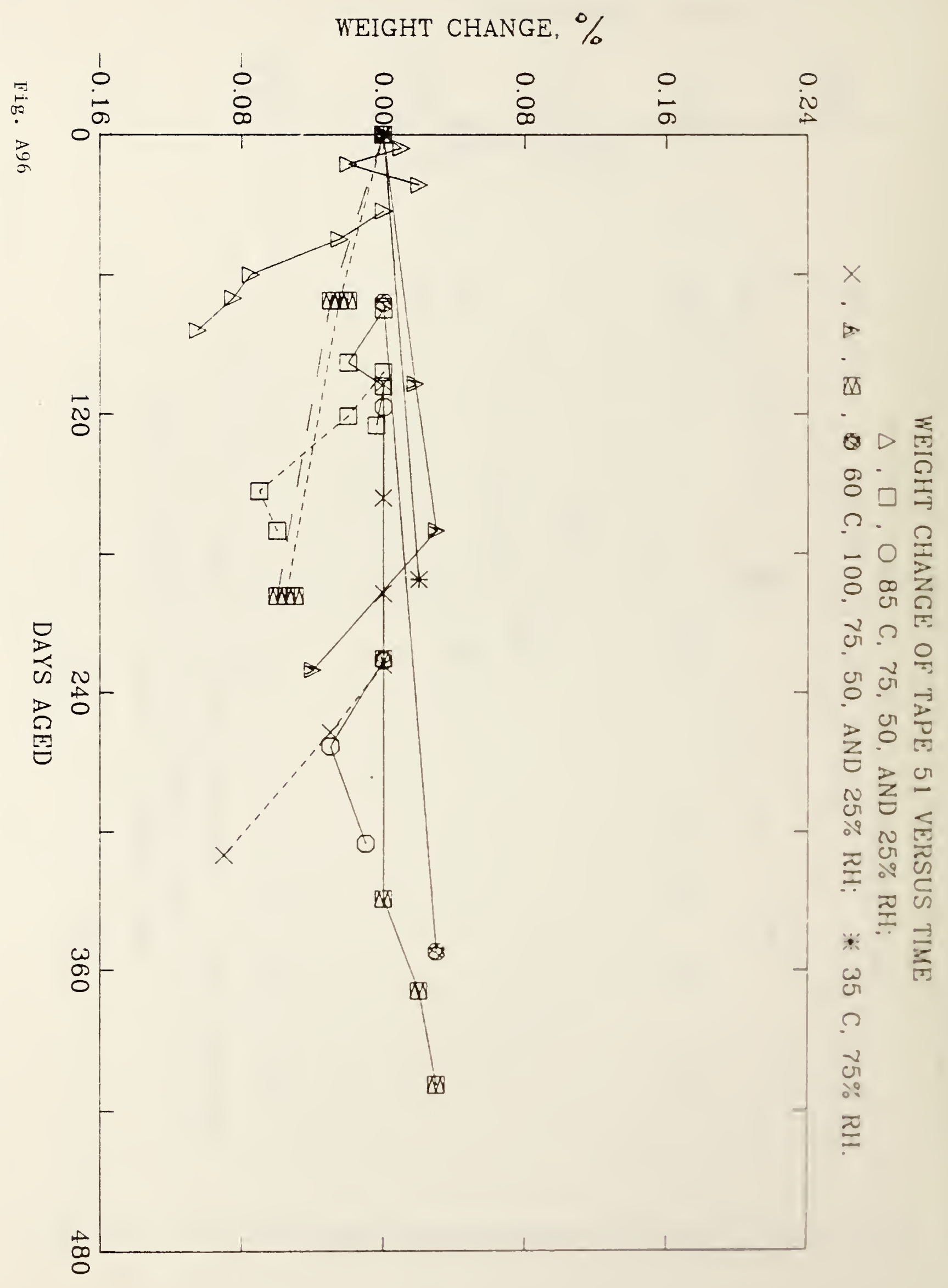




